


\section{Truwand H. Estill}
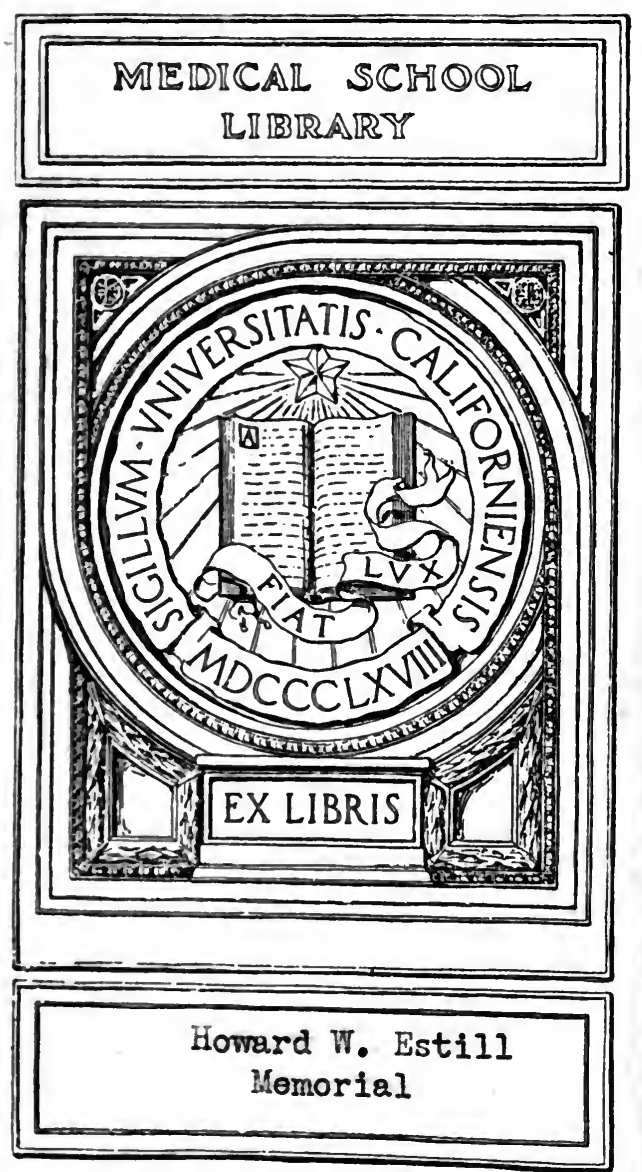

Digitized by the Internet Archive in 2007 with funding from Microsoft Corporation 


\section{ULTRAVIOLET RADIATION}




\section{OTHER BOOKS BY THE SAME AUTHOR}

1. Color and Its Applications, 1915, 1921.

2. Light and Shade and Their Applications, 1916.

3. The Lighting Art, 1917.

4. The Language of Color, 1918.

5. Artificial Light, Its Influence Upon Civilization, 1920

6. Lighting The Home, 1920.

7. Visual Illusions, 1921.

8. The Book of The Sky, 1922. 



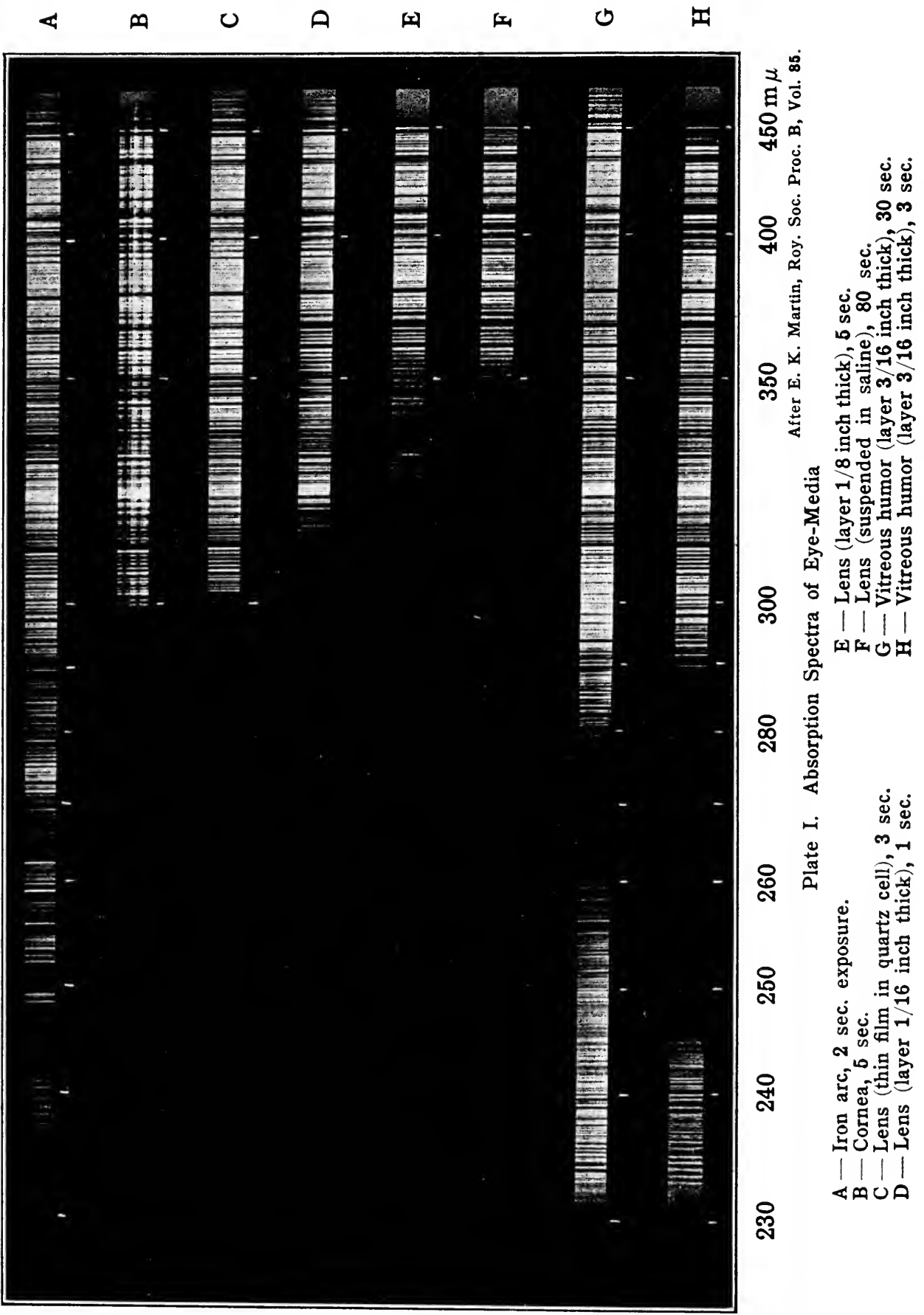




\title{
ULTRAVIOLET RADIATION
}

ITS PROPERTIES, PRODUCTION, MEASUREMENT, AND APPLICATIONS

\author{
BY \\ M. LUCKIESH
}

DIRECTOR OF APPLIED SCIENCE, NELA RESEARCH LABORATORIES NATIONAL LAMP WORKS OF GENERAL ELECTRIC CO.

Author of "Color and Its Applications," "Light and Shade and Their Applications," "The Lighting Art," "The Language of Color," "Artificial Light - Its Influence Upon Civilization," "Lighting The Home," "Visual Illusions," "The Book of The Sky," etc.

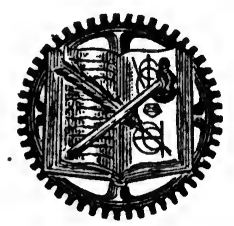

NEW YORK

D. VAN NOSTRAND COMPANY EIGHT WARREN STREET 
COPYRIGHT, 1922

BY D. VAN NOSTRAND COMPANY

Printed in the United States of America

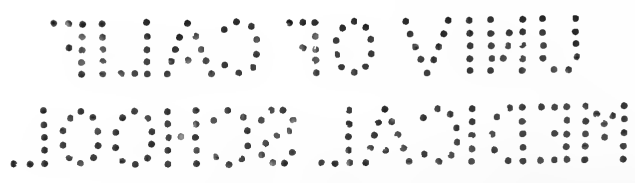


At Trinity College in Cambridge, stands a marble statue of Sir Isaac Newton holding a prism in his hand. This thoughtful silent face impressed Wordsworth as,

"The marble index of a mind forever Voyaging through strange seas of Thought, alone."

It is to the memory of this great man, who illuminated the pathway leading to the discovery of invisible radiation, that this book is dedicated. 



\section{PREFACE}

During the six score years which have elapsed since the discovery of ultraviolet radiation a great deal of attention has been given to its properties, production, and applications. As a consequence of this widening acquaintance with ultraviolet radiation, this form of energy is now of practical value to the chemist, the physicist, the engineer, the biologist, the ophthalmologist, the physician and others. Many sources of ultraviolet radiation are now available and the applications are rapidly increasing in number. Unfortunately much of the literature on the subject is confusing, owing to the lack of care in the choice of definitions, and limited in value, owing to carelessness in specifying important factors such as those pertaining to the spectral character of the radiation.

It is the primary aim of this book to present authentic data of such scope as to be useful to those who are interested in ultraviolet radiation. Theory has purposely been subordinated to experimental facts because the latter are not affected by the inevitable changes in theory. The author has drawn freely from the work of others although by no means is it claimed that all the best work has been included. In covering the scope in mind it has been necessary to choose among a large number of investigations. Many references have been presented and it is hoped that these will increase the usefulness of the book.

March 20, 1922.

M. LUCKIESH 



\section{CONTENTS}

Chapter Page

I. Introduction .................. 1

II. Solar Radiation.................... 15

III. Transparency of Gases................ $\quad 35$

IV. Transparency of Liquids.............. 46

V. Transparency of Solids.................. 72

VI. Transparency of Glasses................ $\quad 79$

VII. Reflection of Ultraviolet Radiation........... 93

VIII. Ultraviolet Radiation in Common Illuminants..... 107

IX. Experimental Sources.................. 133

X. Detection and Measurement............. 165

XI. Effects Upon Living Matter............... 204

XII. Various Photochemical Effects............... 223 



\section{LIST OF PLATES}

PLATE

PAGE

I. Absorption Spectra of Eye-Media .............. Frontispiece

II. The transmission of various media for ultraviolet radiation from the iron arc as obtained by a quartz prism spectrograph .........

III. Two ultraviolet spectra of the tungsten arc and two of the iron arc as obtained by a quartz prism spectrograph.............

IV. Ultraviolet spectra of the ordinary carbon arc, the iron arc, and the quartz mercury arc as obtained by various photographic ex-

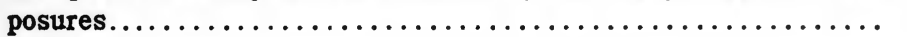

V. The white flame arc-a powerful source of "near" ultraviolet

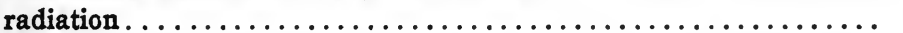

VI. The quartz mercury arc shown with the quartz arc exposed and also as used for exposing materials to its radiation............

VII. The ultraviolet spectra of the tungsten arc through quartz, at various

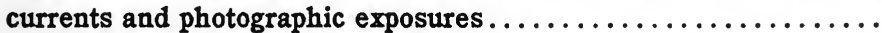

VIII. Ultraviolet transmission spectra of clear and cobalt glasses as obtained by a quartz prism spectrograph.................

IX. The radiation from the quartz mercury arc employed in a recirculating drinking-water system in a large factory . . . . . . . . 204

X. Radiant energy is finding many applications in therapeutics...... 211

XI. The white flame arc as used in dye-testing . . . . . . . . 223

XII. The carbon arc as used in blue-printing . . . . . . . . . . . 237 


\section{ULTRAVIOLET RADIATION}

\section{CHAPTER I \\ INTRODUCTION}

When Newton was an old man, acknowledged by civilization as the greatest of his race, he wondered what the world would think of his labors, adding, "It seems that I have been but as a child playing on the sea-shore, now finding some pebble rather more polished, and now some shell rather more agreeably variegated than another, while the immense ocean of truth extended itself unexplored before me."

This statement is characteristically modest. It is true that a great ocean of truth remained to be explored, but Newton ${ }^{1}$ discovered this ocean when, in the year 1666 , he found his way to the "sea-shore." Before that time something was known of the laws of reflection, refraction, and transmission of light, but Newton's epochmaking discovery of the spectrum revealed an unexplored region pertaining to the composition of light and of radiant energy in general. When he placed his glass prism near the hole which he had cut in a window shade, he expected to see the beam of light refracted and end on his vertical screen in beautiful colors. But this thinker was not content merely to perform an experiment with which he was familiar. He applied himself to inquiry pertaining to the "vivid and intense colours" as expressed in his own words. This led to the discovery of the variation of refrangibility with the wave-lengths of the radiant energy or radiation.

Newton saw only the visible radiation - light - and gave to the spectral colors, which he saw on the screen, 
the names, violet, indigo, blue, green, yellow, orange, and red. It is now known that with suitable apparatus more than one hundred distinctly different hues may be readily distinguished in the visible spectrum. ${ }^{2}$ Although Newton throughout the remainder of his life made numerous excursions into that unexplored "ocean of truth" and brought many facts to light he died without knowing that there was an extensive series of radiations, differing physically only in wave-lengths and frequency of vibration, of which visible light was only a very small part. When he saw the colored patch on the screen he had no means of learning that beyond the violet edge ultraviolet radiation was impinging upon the screen and beyond the red edge infra-red radiation was present. A silver compound would have detected the former; a delicate thermometer would have announced the latter. If his prism could have produced a normal spectrum of all the rays in the beam of solar energy and if his eyes could have seen it in its entirety from the extreme ultraviolet end to the farthest infra-red, he would have seen a spectrum along the entire length of the room. Now it is known that radiant energy of the same physical characteristics and differing only in wave-lengths and in frequency of vibration, includes not only visible light but ultraviolet and infra-red radiation, electric waves of a great range of wave-lengths and even $\mathrm{X}$-rays. If a normal spectrum of this entire range of wave-lengths of radiant energy could be produced and the portion of it due to visible radiation - light -were one foot long, the entire spectrum would be several million miles in length.

In the foregoing the terms "radiation" and "radiant energy" have been used. They will be used interchangeably throughout these chapters to express a certain form of energy. The term " light" appears to be best restricted to mean the sensation produced by visible radiation. Since Maxwell developed the electromagnetic theory, 
radiation or radiant energy is commonly termed electromagnetic energy. The velocity at which radiant energy is transmitted through a perfect vacuum or through interplanetary space is independent of the frequency or wave-length and is approximately 186,300 miles per second or $3 \times 10^{10}$ centimeters per second. By dividing the velocity by the wave-length, the frequency is obtained.

Three terms and symbols are in common use for designating wave-lengths. Their relations and magnitudes are as follows:

\begin{tabular}{|c|c|c|c|}
\hline Unit & Symbol & Millimeters & Relative length \\
\hline $\begin{array}{l}\text { Angström........ } \\
\text { Millimicron ...... } \\
\text { Micron......... }\end{array}$ & $\begin{array}{c}\mathbf{A}^{\circ} \\
\mathbf{m} \mu \text { or } \mu \mu \\
\mu\end{array}$ & $\begin{array}{l}\text { one ten-millionth } \\
\text { one millionth } \\
\text { one thousandth }\end{array}$ & $\begin{array}{l}1 \\
10 \\
10000\end{array}$ \\
\hline
\end{tabular}

For example the approximate boundary between the visible and the ultraviolet regions of the spectrum is expressed in the three units as follows: $4000 \mathrm{~A}^{\circ}, 400 \mathrm{~m} \mu$, $0.4 \mu$. This corresponds to a frequency of $75 \times 10^{13}$ per second. In the following chapters the millimicron will be used as the unit of wave-length because it appears to meet the requirements more satisfactorily than the other units. Its use obviates the inconvenience of the decimal point preceding the units. Instead of employing the symbol $\mu \mu$ as has been the general custom the symbol $m \mu$ has been chosen as being strictly correct.

The nature of radiation or radiant energy is still in doubt. The fact that it is transmitted through a vacuum calls for the creation by the imagination of a carrier. The "ether" was invented for this purpose and has served for many years. Many phenomena of light indicate that radiant energy is propagated in the form of 
wave motion and that the waves are transverse. However, these details, intensely interesting as they are scientifically, are not important from the viewpoint of this book. If the hypothetical "ether" must be discarded and the "waves" remodelled, the production, properties, and applications of ultraviolet energy will not be altered.

Before entering upon a discussion of ultraviolet energy the entire spectral range of radiant energy will be presented. The divisions are more or less arbitrary with the exception of visible radiation and even the limits of the visible spectrum are not well defined. The terms applied to the various regions have developed from certain properties or uses of radiations of the various ranges of wave-length. Sometimes this has caused confusion. For example, the terms, "chemical rays" and "actinic rays" are misleading. They have been applied to radiation including ultraviolet and that corresponding to the shortwave (blue and violet) end of the visible spectrum, notwithstanding the fact that radiant energy of many other wave-lengths produce chemical changes. This looseness in terminology has inhibited progress to some extent and has often cast uncertainty over work which has deserved a better fate.

Another case is the term "light." This is commonly used in three senses: (1) to express visual sensation; (2) to express radiant energy of wave-lengths included only in the visible spectrum; (3) to express the radiant energy throughout the entire (visible and invisible) spectrum. There appears to be no need for using the term in the third sense. The terms "ultraviolet radiation" and "infra-red radiation" are satisfactory for the invisible regions. If the use is confined to the first two, confusion would not be entirely eliminated but it would be greatly reduced. The author prefers to use the term "light" to express visual sensation; and the term "visible radiation" 
to express the radiant energy of only those wave-lengths capable of exciting visual sensation. These meanings will be adhered to throughout this book.

The approximate wave-length limits of the various spectral regions of radiant energy in the order of increasing wave-length are as follows:

Ultraviolet radiation

Wave-length $0-390 \mathrm{~m} \mu$

Extreme region 0-200

Gamma rays (arbitrary limits) 0 to $0.01 \mathrm{~m} \mu$

Robntgen rays (arbitrary limits) 0.01 to $50 \mathrm{~m} \mu$

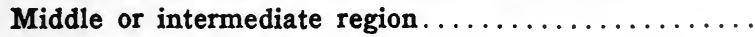
200-300

Near region. $300-390$

Visible radiation

$390-770 \mathrm{~m} \mu$

Violet.

$390-430$

Blue.

$430-470$

Blue-green

$470-500$

Green.

$500-530$

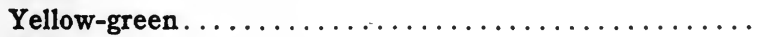

$530-560$

Yellow.

$560-590$

Orange

$590-620$

Red.

620-770

Infra-red radiation

$0.77-\infty \mu$

Near region.

$0.77-20$

Infra-red photography to $1 \mu$

Fluorite prism to $10 \mu$

Rock salt prism to $20 \mu$

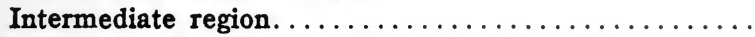

Selective reflection from rock salt to $50 \mu$

20-500

Selective reflection from potassium chloride to $61 \mu$

"Restrallen" method up to $354 \mu$

Electric oscillator method up to $500 \mu$

Extreme region.

Electric waves such as that radiant energy studied by Herz, that used in wireless electric circuits, that resulting from high frequency currents, and that due to ordinary alternating currents complete a long range of wave-lengths to beyond $12 \mathrm{~km}$. in wave-length.

For convenience in description the ultraviolet and infrared have been divided into three regions, namely, extreme, middle (or intermediate), and near (in reference to the 
visible region). This has been found to be convenient for descriptive purposes. The practical limits of the visible spectrum from the standpoint of the eye are $400 \mathrm{~m} \mu$ and $700 \mathrm{~m} \mu$. The approximate wave-length limits of the principal spectral hues are presented because of the convenience of such terms as "green," "blue," etc. However, when such terms are used for descriptive purposes the user should be certain that they actually represent approximately the spectral range. A spectroscope will determine this with certainty. It should be thoroughly realized that the eye is synthetic and not analytical. For example, a blue may appear blue but when examined by means of a spectroscope it may be seen to have a red band. Another striking case is yellow. It may appear yellow to the eye and still consist only of red and green. Yellow filters are commonly assumed to absorb ultraviolet radiation but many of them transmit some of the near ultraviolet. These are only three of many errors which can be easily made if the transmitted radiation is not analyzed by an analytical instrument. ${ }^{2}$

On considering the spectrum of radiant energy as a whole and the various properties of the radiation of various spectral ranges it is seen that visible radiation is merely that of a certain range of wave-lengths to which the visual sense responds. A wireless receiving station in an analogous manner is tuned to respond to radiant energy of a certain range of wave-lengths or frequencies. Silver chloride is affected by radiation of a certain range of frequences corresponding to ultraviolet and violet. Each of the various photographic emulsions "sees" a certain range of wave-lengths of radiation. This chemical process responds to certain waves and that to others and so on. Thus viewed as a whole, if we may stretch the analogy, there are a great many "eyes" varying in sensibility to radiant energy of various ranges of wavelength or frequency. 
It is unfortunate that more accurate data have not been given in many investigations especially pertaining to the wave-lengths of radiant energy employed. Too often such indefinite terms as "ultraviolet light," " actinic rays," "blue light," etc., have been used in describing results. In other words, the spectral limits and the spectral distributions of energy have not been determined. Many of the effects of radiation upon plant-life, in industrial chemistry, in therapeutics, and in other fields are still uncertain because of the lack of specifications as to spectral limits and energy-distribution.

Little definite progress can be made without a spectrograph and its optical system must be of quartz or of other material transparent to the near and middle ultraviolet regions. Even quartz fails for work in the extreme region. It should usually be possible to ascertain the spectral limits and energy-distribution of the illuminant used. Knowing these and especially the former, it is possible through characteristics of various substances, to define at least approximately, the radiation employed. Often there is no question regarding the spectral limits of the radiation of chief interest but there may be doubt as to the presence of other radiation. For example, effects are sometimes attributed to ultraviolet radiation when visible radiation is present. What effect may the latter have had? Another common example is the use of a blue glass with the assumption that blue light is the only radiation present. Most blue glasses transmit some of the near ultraviolet and the near infra-red. The commonest blue glass (cobalt) generally also transmits deep red and some infra-red radiation. Such looseness has caused a great deal of confusion and is responsible for the chaotic state of various phases of the use of radiant energy.

Although it was not until after Newton's discovery of the visible spectrum that analytical experiments were performed regarding the photo-chemical properties of 
light, the observations of the keen intellects of preceding centuries should not be overlooked. The part played by daylight in the production of the green coloring matter in plants was observed long before the Christian era. Aristotle noted this influence as early as the year 350 B.C. The bleaching of pigments and of other coloring media was also known in those early centuries. Even the alchemists hinted of knowledge of the existence of such photo-chemical effects. However, it was not until the latter half of the 17 th century that really scientific observations were made. Throughout the 18th century many facts were garnered from the unknown which paved the way for the rapid progress in the 19th century to which men like Bunsen and Roscoe contributed so much.

It is not the aim to present a detailed and chronological account of the development of the science of photochemistry, but rather to provide a hurried glimpse of the course of knowledge pertaining to effects of radiant energy in order that the reader may better appraise the status of our knowledge at the present time. Ten years after Newton described his decomposition of sunlight into its component colors by means of the prism, and discovered the variation of refrangibility with the hue, Römer, a Danish astronomer, discovered that light travelled at a finite velocity. It is remarkable that his determination of this velocity differed by only three per cent from the value accepted at the present time. Huygens enunciated the wave-theory of light in 1678. All these views must be modified to harmonize with present knowledge but this does not depreciate the value of the work of the pioneers. Science is ever in a state of flux and it is not expected that theories of today will still be unmodified tomorrow. While dealing with radiation in these chapters scientists are busy undermining prevalent ideas of continuous propagation of radiation, the wavetheory of the past, the hypothetical ether, and other 
"models" upon which scientific progress is built. But there is consolation in the thought that experimental facts are not altered. It is the interpretations and explanations that suffer.

Scheele in 1777 projected the visible spectrum upon silver chloride and noted the release of the chlorine and the production of metallic silver in the region of the violet rays. He was on the verge of discovering the ultraviolet region but it escaped his attention. However, he observed many photo-chemical reactions. The infra-red and ultraviolet regions were discovered almost simultaneously. W. Herschel announced the former in 1800 and Ritter in 1801 noted the effect on silver chloride of what proved to be ultraviolet radiation.

In the succeeding years several discoveries were made pertaining to the effect of visible and ultraviolet radiation upon silver salts, especially silver chloride. Gay Lussac and Thenard in 1809 noted various effects of light on chlorine and hydrogen. Already such chemical effects as the bleaching of chlorophyll and various dyes, and the decomposition of water by chlorine in bright sunlight had become known. In 1815 Planche noted the effects of light upon many metallic salts and a few years later Grotthus enunciated this photo-chemical absorption law, "Only the rays absorbed are effective in producing chemical change."

Discoveries of photo-chemical effects followed one after the other very rapidly in the early part of the nineteenth century. Chevreul, a pioneer in the science of color, described in 1837 the influence of air and moisture, in conjunction with sunlight, in the bleaching of vegetable colors. Although Scheele, Ritter and others paved the way for the development of photography, Niepce and Daguerre produced the first practicable process in about 1830 . E. Bequerel contributed much to photo-chemistry and many analytical researches in connection with the effect 
of radiation of various wave-lengths on silver salts. Gradually the science of photography developed until in 1873 Vogel increased the spectral range of sensitiveness of silver salts by introducing certain dyes. These are only a few of the highlights of the evolution of photography. Since Vogel's time thousands of researches have developed photography to a point where it is one of the best tools with which to invade the very realm whence it comes. Hurter and Driffield ${ }^{3}$ during the latter portion of the past century extensively investigated the photographic process.

Maxwell in about 1868 enunciated the electromagnetic theory of radiation which among other things predicted the existence of electric waves. Herz in 1888 verified this as to certain electric waves much greater in wave-length than the longest infra-red waves which had been measured. This left an unexplored gap in the long-wave region which has gradually been shortened in recent years until at the present time it may be said that this region has been almost completely explored.

In 1895 Röntgen discovered the marvelous X-rays which later were classified as radiations of extremely short wave-lengths thus leaving an unexplored gap between them and the shortest known ultraviolet radiations. This gap has been gradually shortened during the years which have elapsed since the discovery of $\mathrm{X}$-rays.

The limit of transparency of optical systems of glass is in general at about $340 \mathrm{~m} \mu$. As long as glass prisms were used for dispersing radiation into its spectrum the known spectrum could not be extended beyond the near ultraviolet. Quartz crystals were found to be transparent throughout the near and middle ultraviolet regions and in fact as far as $185 \mathrm{~m} \mu$. Iustruments employing quartz made it possible greatly to extend the known ultraviolet spectrum and the development of the art of fusing powdered quartz has further contributed to the accomplish- 
ments in this field. The transparency of fluorite extends much further into the ultraviolet than that of quartz and by using this substance Schumann ${ }^{4}$ during the period of 1890 to 1903 extended the explored region from 200 to $120 \mathrm{~m} \mu$.

The reflection-grating spectrograph which eliminates the necessity of employing transparent media in its construction now became a valuable accessory in the exploration of the extreme ultraviolet. It has been found that its reflection-factors for radiations of the extreme ultraviolet are sufficiently great for use in this work. However, gases absorb quite strongly the ultraviolet radiation in this region and therefore the grating spectrograph has been enclosed in a compartment which may be evacuated.

Gelatine is opaque to the extreme ultraviolet and inasmuch as photography has been the chief means of recording these short-wave spectra it was necessary for Schumann to develop a special photographic plate. This plate was flowed with an emulsion containing the least amount of gelatine which could be used in its preparation.

By eliminating the fluorite window it was possible to extend the explorations even to shorter wave-lengths. Lyman placed the light-source such as a spark in the spectrograph chamber and was soon able to extend the known spectrum to about $50 \mathrm{~m} \mu$. The disruptive discharge or high potential spark has been a popular source of radiation for investigating this region. Saunders, Merton, McLennan and others have investigated the extreme ultraviolet between the region where Schumann's labors ceased and about $50 \mathrm{~m} \mu$, but Lyman ${ }^{5}$ may be considered to be the pioneer. Thus it has been seen that the gap between the $\mathrm{X}$-ray and the ultraviolet spectra has been greatly shortened during the score of years succeeding Röntgen's discovery.

Recently it appears that Millikan ${ }^{\circ}$ has completely spanned the gap, for apparently he has produced X-rays by 
means of a very high potential spark which he has recorded by means of the photographic plate of the Schumann type. The remarkable success of Millikan and his colleagues in extending measurements to about $20 \mathrm{~m} \mu$ was due chiefly to improvements in various directions. Michelson made for them special concave gratings which gave relatively more intense first-order spectra than those employed previously by others. They employed very high potential sparks in their evacuated spectrograph and kept the pressure in the latter below $10^{-4} \mathrm{~mm}$. Millikan concluded that his spectrograms recorded certain lines belonging to the X-ray spectrum of carbon, thus completing the exploration of the gap between $X$-rays and known ultraviolet radiation of shortest wave-length.

Until the advent of the electric dynamo the only adequate source of ultraviolet radiation was the sun. This is unsteady, uncertain, and discontinuous as a source and limited in spectral range in the ultraviolet region. The carbon arc was the first artificial source of appreciable powerfulness, but in the earlier years of the electrical age the production of ultraviolet radiation in this manner was costly. As the sciences of electricity and of light-production advanced, richer and more powerful sources of ultraviolet radiation appeared. However, it may be said that the 20th century was the first to see the advent of artificial sources of this energy sufficiently efficient and adequate to draw marked attention to applications on a commercial scale.

Thus it is seen that the age of ultraviolet radiation of wide application has only recently dawned. It has found mankind in the possession of a great deal of general knowledge pertaining to the effects of radiant energy but somewhat lacking in specific details especially those pertaining to the spectrum. Technical literature contains thousands of references to effects of ultraviolet radiation but in many of them valuable specific data are lacking. 
Perhaps the most general weakness is the absence of information pertaining to the spectral limits and spectral distribution of energy. At least, if the source of the radiation is fully described and the spectral limits are specified there is much less doubt than in attributing a result merely to "ultraviolet energy."

It is difficult to measure the intensity of ultraviolet radiation but it may be accomplished in several ways. Another difficulty is the absence of a continuous-spectrum source but a small quartz spectrograph will accomplish much in clarifying some points such as spectral limits and approximate quantitative spectral distributions of energy. Until the spectral aspects are given closer attention, progress in our knowledge of the effects of radiation will be slow and uncertain.

The spectral transmission and reflection characteristic of many substances and the ultraviolet spectra of radiations from various sources are known to some extent. It is easy to obtain qualitative results of this nature by means of a quartz or reflection-grating spectrograph over a great range of the ultraviolet spectrum. Ordinary glass is opaque beyond the "near" region and is generally fairly opaque to energy of wave-lengths shorter than $340 \mathrm{~m} \mu$. Quartz is transparent to the "near" and "middle" regions, that is, down to the neighborhood of $185 \mathrm{~m} \mu$. The extreme ultraviolet is easily absorbed by most known substances but it can be studied by means of a vacuum spectrograph. The spectral limits of the transmission characteristics of various media are discussed in other chapters. It is the aim here to emphasize the increasing difficulty of dealing with ultraviolet radiation as the wave-length decreases. In other chapters practicable methods and useful data are presented. 


\section{References}

I. Phil. Trans. (Abridged), Roy. Soc. Vol. I.

2. M. Luckiesh, Color and Its Applications, I9I5, I92I.

3. Photographic Researches, Memorial Volume, Ig20.

4. Ber. Wien. Akad., I02, IIa, 625. Smithsonian Contributions, 29, No. I413, 1903.

5. Theodore Lyman, Spectroscopy of the Ultraviolet, I914: Astrophys. Jour., 23, I906, I8I; 25, I907, 45; 28, I908, 52 ; 33, I9II, 98; 35, I9I2, 34I; 38, I913, 282.

6. Astrophys. Jour. 52, I920, $47 ; 53$, I92I, I50. 


\section{CHAPTER II}

\section{SOLAR RADIATION}

Inasmuch as daylight is a very important factor in many chemical reactions and it is more or less a standard in many respects it appears necessary to discuss its characteristics in detail. For many years photography was almost solely dependent upon daylight but in recent years artificial illuminants have wrested supremacy in this respect from daylight. The testing of dyes and paints has been solely dependent upon sunlight until recently. Many other activities have been intimately associated with daylight but during the last score of years great strides have been made toward independence from daylight.

In most cases where ultraviolet radiation is useful, results are desired without regard to their similarity to those obtained under daylight, but there are some cases, such as the testing of paints and dyes for permanency, where results similar to those obtained under daylight are of interest. For example, under ordinary conditions the foe of paints and dyes is daylight, for artificial illumination is rarely sufficiently intense to have a marked effect upon their permanency. It is advantageous to test these materials under artificial radiation which is constant in intensity and controllable in every respect. However, the artificial radiation should yield results quite similar to that of daylight. This can be predicted if intensity and spectral character of the active radiation are approximately the same for the artificial and natural radiations.

Natural radiation, commonly called daylight, consists of (1) direct solar radiation, (2) diffuse radiation from the 
sky, and (3) radiation reflected from surroundings such as trees, buildings, etc. Radiation reflected from the surroundings is considerably modified owing to the selective reflection of the various surfaces. In general ultraviolet radiation is materially reduced in quantity and in spectral range by reflection. These three classes of natural radiation vary in proportions over wide ranges. On overcast days direct solar radiation is reduced to zero and the radiation from the sky is greatly modified by the clouds. At noon on very clear days, the total light reaching the upper side of a horizontal surface when the entire sky is unobstructed, consists of clear blue skylight and direct sunlight. In such cases the skylight is about 10 to 20 per cent of the total, the latter percentage being common on average clear days.

Noon sunlight is fairly constant in spectral character but its intensity varies with its altitude and with the condition of the atmosphere. ${ }^{1}$ Therefore solar radiation varies in photochemical action momentarily, daily, seasonally and geographically. On clear days in midsummer in the United States the intensity of illumination on a horizontal surface outdoors at noon reaches a value as high as 10,000 foot-candles. In midwinter on a clear day at noon the value is often only one-fourth or one-fifth as great for regions in the vicinity of 40 degrees latitude. On cloudy days, of course, the intensity of illumination may reach very low values but it is usually above 1000 foot-candles during midday. It may be stated that the intensity of daylight outdoors for several hours during midday is measured in thousands of foot-candles. Ordinary intensities of artificial illumination are a few footcandles. In other words unobstructed daylight during midday is commonly of the order of magnitude of a thousand times greater in intensity than that of ordinary artificial illumination. By using very powerful artificial sources at short distances the intensities of daylight may be approached or even exceeded in some cases. 
The sky is brightest when it is hazy or when a thin film of cloud is present but this brightness is obtained at the expense of direct solar radiation. It has been seen that the intensity of daylight outdoors can be measured in thousands of foot-candles. Indoors this is ordinarily reduced to less than a hundred foot-candles excepting near some unobstructed skylights. Furthermore the spectral character of natural radiation arriving indoors is altered by selective reflection, by surroundings and by selective absorption by the glass of skylights. This is easily shown by taking a photograph of the spectrum of the radiation from the sun or the sky through an open window by means of a quartz spectrograph. Then close the window and take another spectrogram. It will be seen that the latter does not extend quite as far into the ultraviolet as the former. Therefore where the greatest intensity of ultraviolet radiation is desired the unobstructed roof is the best place for operations. High altitudes offer advantages by escaping from much of the absorption of ultraviolet radiation by the lower atmosphere. At high altitudes such as attained by aircraft the relative clearness of the atmosphere is apparent by the extreme darkness of the sky and the relative greater brightness of the moon.

The intensity of daylight at midday on a clear day is about 1,000,000 times greater than that due to the full moon at zenith. At noon the moon, viewed from the earth's surface, is about as bright as an average clear sky. The moon's disk is about $\frac{1}{2}$ degree in diameter and therefore occupies about 0.00001 of the total visible sky. Of course the moon's brightness is augmented by the brightness of the sky and therefore the moon cannot appear darker than the sky; however, it is seen from the foregoing that the illumination due to average clear sky during midday is at least 100,000 times greater than that due solely to the full moon. Considering that the clear sky contributes only about one-fifth the total daylight at midday it is seen 
that the intensity of illumination at noon on a clear day is of the order of magnitude of 500,000 times greater than that due to the full moon. If the former is taken as $\mathbf{5 0 0 0}$ foot-candles the intensity of ilumination due to a full-moon at the zenith would be about 0.01 foot-candle. This is the order of magnitude. These magnitudes must be appreciated in many applications of ultraviolet radiation.

It may also be of interest to note the rate at which energy is delivered to the earth by the sun. The solar constant as determined by the Astrophysical Observatory of the Smithsonian Institution from 696 observations over a period of ten years is 1.932 calories per minute upon a projected area of one square centimeter, that is, for normal incidence on a square centimeter per minute. Over a great circle of the earth with a circumference of about 25,000 miles (the projected area presented to the sun) solar radiation is received at the rate of about $2.3 \times 10^{15}$ horse-power. This equals an average rate of about 7000 horse-power per acre; about 1.45 horse-power per square yard; about 0.16 horse-power per square foot. To utilize this tremendous quantity of radiant energy is one of the problems to be solved.

TABLE I

Duration of Sunshine

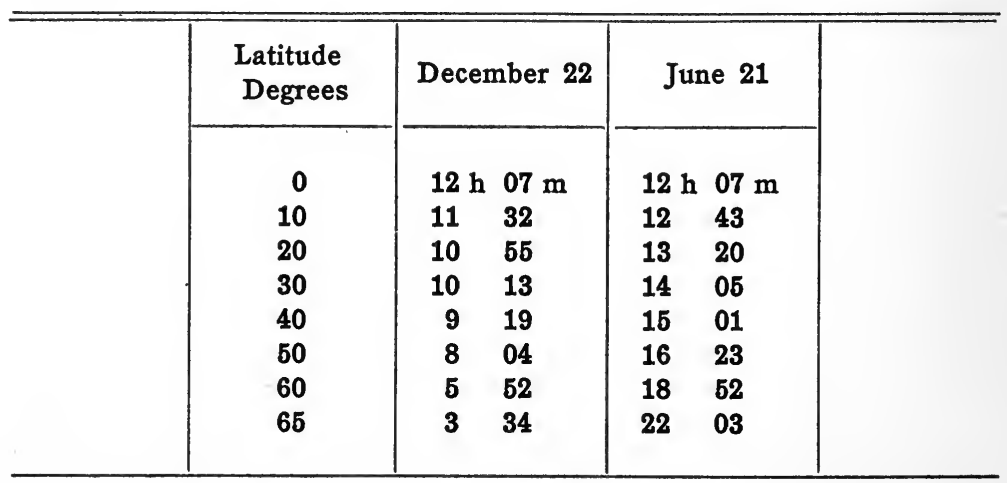


The duration of sunshine is of importance in many respects but for industrial processes solar radiation is not generally powerful enough throughout the entire period between sunrise and sunset. Table I gives some values of interest but more extensive data will be found elsewhere. ${ }^{2}$ The percentage of cloudiness varies considerably, depending upon the season and the geographical location so that it would be futile to attempt to present adequate data here.

In Table II the distributions of energy in the normal spectra of the radiation from the sun and from the sky are presented in arbitrary units as obtained by Abbott and his colleagues. The arbitrary unit is not of the same value for the last two columns.

TABLE II

Distributions of Energy in Radiation from Sun and Sky at Mt. Wilson

\begin{tabular}{c|c|c|c|}
\hline & \multicolumn{2}{|c|}{ Arbitrary units } \\
& Wave-length; $\mathrm{m} \mu$ & \multicolumn{2}{|c}{} \\
\cline { 2 - 4 } & Sun & Sky \\
\hline & & & \\
422 & 186 & 1194 & \\
457 & 232 & 986 & \\
491 & 227 & 701 & \\
566 & 211 & 395 & \\
614 & 191 & 231 & \\
660 & 166 & 174 & \\
\hline
\end{tabular}

The maximum for solar radiation in Table II is in the region of $470 \mathrm{~m} \mu$ but this is for relatively clear air at an altitude of 1730 meters or 5700 feet. At lower altitudes the sunlight is yellower, that is the maximum of the spectral energy-distribution shifts toward longer wavelengths. (See Table V.) The spectral distributions of energy in solar and in sky radiation may be found elsewhere ${ }^{3}$ compared with those of other illuminants. The 
solar spectrum extends to the neighborhood of $290 \mathrm{~m} \mu$ and although it diminishes in intensity in the ultraviolet region it really ends rather abruptly indicating a powerful absorption-band in the earth's or the sun's atmosphere. Dry atmosphere in general selectively scatters radiation of the shorter wave-lengths. The selectivity varies considerably with atmospheric conditions but for dry air (the layer vertically above Mt. Wilson, altitude 1730 meters and barometric pressure $620 \mathrm{~mm}$.) the spectral transmission-factors as obtained by Fowle ${ }^{4}$ are presented in Table III.

TABLE III

Spectral Transmission-Factors of Dry Atmosphere Above Mt. Wilson

\begin{tabular}{|c|c|c|c|c|c}
\hline $\mathrm{m} \mu$ & Per cent & $\mathrm{m} \mu$ & Per cent \\
\cline { 2 - 3 } & 360 & 66.0 & 574 & 90.5 & \\
\cline { 2 - 3 } 384 & 71.3 & 624 & 92.9 & \\
413 & 78.3 & 653 & 93.8 & \\
452 & 84.0 & 720 & 97.0 & \\
503 & 88.5 & 986 & 98.6 & \\
535 & 89.8 & 1740 & 99.0 & \\
\hline
\end{tabular}

The values in Table III agree very well with those expected from purely molecular scattering. When moisture and dust are present in the atmosphere the spectral transmission-factors are lower in value and are altered somewhat with respect to each other but there is still the same general increasing absorption with decreasing wavelength.

The transmission-coefficients of the atmosphere as computed from the equation

$$
e_{m}=e_{o} a^{m}
$$

are given in Table IV for several places of observation (Washington, Mt. Wilson, Mt. Whitney) according to 
the annals of the Astrophysical Observatory. In the foregoing equation $\mathrm{e}_{\mathrm{m}}$ is the intensity of the solar radiation after transmission through a mass of air, $\mathrm{m} ; \mathrm{m}$ is unity when the sun is at the zenith; $e_{o}$ is the energy which would have reached the point of observation if the atmosphere were perfectly transparent; $a$ is the fractional amount, $\mathbf{e}_{\mathrm{m}} / \mathbf{e}_{\mathrm{o}}$, actually reaching the point of observation when the sun is at the zenith.

TABLE IV

Transmission of Atmosphere. Transmission Coefficient, a

\begin{tabular}{r|c|c|c|c}
\hline $\mathrm{m} \mu$ & Washington & $\begin{array}{c}\text { Mount } \\
\text { Wilson }\end{array}$ & $\begin{array}{c}\text { Mount } \\
\text { Whitney }\end{array}$ & $\begin{array}{c}\text { One mile } \\
\text { nearer earth }\end{array}$ \\
300 & $\ldots \ldots$ & 0.460 & 0.550 & $\ldots \ldots$ \\
320 & $\ldots \ldots$ & 0.520 & 0.615 & $\ldots$. \\
340 & $\ldots \ldots$ & 0.580 & 0.692 & $\ldots$. \\
360 & $\ldots \ldots$ & 0.635 & 0.741 & $\ldots$. \\
380 & 0.380 & 0.676 & 0.784 & 0.562 \\
400 & 0.560 & 0.729 & 0.809 & 0.768 \\
460 & 0.690 & 0.832 & 0.887 & 0.829 \\
500 & 0.733 & 0.862 & 0.919 & 0.850 \\
600 & 0.779 & 0.900 & 0.940 & 0.866 \\
700 & 0.858 & 0.950 & 0.964 & 0.903 \\
800 & 0.886 & 0.970 & 0.976 & 0.915 \\
1000 & 0.922 & 0.980 & 0.975 & 0.941 \\
1500 & 0.938 & 0.976 & 0.965 & 0.961 \\
2000 & 0.912 & 0.970 & 0.932 & 0.940 \\
\hline
\end{tabular}

Nearer sea-level the values are smaller than those in Table IV. This is indicated in the data because the point of observation was lowest for Washington, next for Mt. Wilson, and highest for Mt. Whitney. Similarly the values computed for a point one mile lower than the observatory on Mt. Whitney indicates the rapid decrease in the intensity of radiation of the shorter wave-lengths.

The foregoing are for zenith depths of atmosphere. As the sun declines or decreases in altitude the air-mass 
increases approximately as the secant of the zenith distance. Thus if $m$ is unity for zenith sun, $m$ equals 2 when the sun is at 60 degrees. At 70 degrees $m$ equals about 2.9 ; at 80 degrees $m$ equals about 5.6 ; at 88 degrees $m$ equals probably about 20 .

The effect of air-mass upon the intensity and spectral distribution of solar radiation is shown in Table $V$. Any column may be plotted to obtain the spectral distribution curve of solar radiation.

TABLE V

Relative Spectral Values of Solar Radiation for Various Air-masses

\begin{tabular}{r|r|r|r|r|r|r}
\hline & & \multicolumn{2}{|c|}{ Washington } & \multicolumn{2}{|c|}{ Mt. Wilson } & Mt. Whitney \\
& & & & & \\
\cline { 5 - 6 } $\mathrm{m} \mu$ & $\mathrm{m}=0$ & $\mathrm{~m}=1$ & $\mathrm{~m}=2$ & $\mathrm{~m}=1$ & $\mathrm{~m}=4$ & $\mathrm{~m}=1$ \\
& & & & & & \\
\hline & & & & & & \\
300 & 54 & $\ldots \ldots$ & $\ldots \ldots$ & 25 & 2 & 30 \\
320 & 111 & $\ldots \ldots$ & $\ldots \ldots$ & 58 & 8 & 68 \\
340 & 232 & $\ldots \ldots$ & $\ldots \ldots$ & 135 & 26 & 160 \\
360 & 302 & $\ldots \ldots$ & $\ldots \ldots$ & 192 & 49 & 224 \\
380 & 354 & 134 & 51 & 239 & 74 & 278 \\
400 & 414 & 232 & 130 & 302 & 117 & 335 \\
460 & 618 & 426 & 294 & 514 & 296 & 548 \\
500 & 606 & 441 & 323 & 522 & 334 & 557 \\
600 & 504 & 393 & 306 & 454 & 331 & 474 \\
700 & 364 & 312 & 268 & 346 & 297 & 351 \\
800 & 266 & 236 & 209 & 258 & 235 & 260 \\
1000 & 166 & 153 & 141 & 163 & 154 & 162 \\
& & & & & & \\
\hline
\end{tabular}

The apparent black-body temperature of the sun as determined by the spectral distribution of solar radiation above the earth's atmosphere is between 6000 and 7000 degrees absolute (Centigrade +273 deg.). At sea-level the apparent black-body temperature is between 5000 and 6000 degrees absolute owing to the reddening influence of the atmosphere. 
The energy in the total solar spectrum may be considered to be about equally divided between the infra-red and the visible (plus ultraviolet). Langley ${ }^{5}$ obtained measurements indicating that about 60 per cent of the sun's radiation which reached the earth was in the infrared region, the remaining 40 per cent being visible and ultraviolet. It is seen from Table $\mathrm{V}$ that most of the $\mathbf{4 0}$ per cent is in the visible region although a very appreciable amount of solar energy is in the region between $300 \mathrm{~m} \mu$ and $400 \mathrm{~m} \mu$. For equal amounts of total energy there is a greater proportion of "near" ultraviolet energy in sky than in solar radiation.

The Fraunhofer lines in the solar spectrum are useful as comparison standards for spectroscopy although it is now usually more convenient to use the quartz mercury arc, a helium tube or some other source depending upon the region to be investigated. The principal Fraunhofer lines in the short-wave end of the solar spectrum are given in Table VI with the symbols sometimes used in designating them and the elements responsible for the lines.

\section{TABLE VI}

Wave-lengths (Angström units) of some Fraunhofer Lines in the Solar Spectrum

\begin{tabular}{|c|c|c|c|c|c|}
\hline Symbol & Element & Wave-length & Symbol & Element & Wave-length \\
\hline U & $\mathrm{Fe}$ & 2947.99 & $N$ & $\mathrm{Fe}$ & 3581.349 \\
\hline$t$ & $\mathrm{Fe}$ & 2994.53 & $\mathbf{M}$ & $\mathrm{Fe}$ & 3727.778 \\
\hline $\mathbf{T}$ & $\mathrm{Fe}$ & 3020.76 & $\mathbf{L}$ & $\mathrm{Fe}$ & 3820.586 \\
\hline $\mathbf{s}$ & $\mathrm{Fe}$ & 3047.725 & $\mathbf{K}$ & $\mathrm{Ca}$ & 3933.825 \\
\hline $\mathbf{S}_{1}$ & $\mathrm{Fe}$ & 3100.046 & $\mathbf{H}$ & $\mathrm{Ca}$ & 3968.625 \\
\hline $\mathbf{S}_{2}$ & $\mathrm{Fe}$ & 3100.430 & $\mathbf{h}$ & $\mathbf{H}$ & 4102.000 \\
\hline & $\mathrm{Fe}$ & 3100.787 & g & $\mathrm{Ca}$ & 4226.904 \\
\hline $\mathbf{R}$ & $\mathrm{Ca}$ & 3179.453 & G & $\mathrm{Ca}$ & 4307.907 \\
\hline & $\mathrm{Ca}$ & 3181.387 & & $\mathrm{Fe}$ & 4308.081 \\
\hline Q & $\mathrm{Fe}$ & 3286.898 & f & $\mathrm{Fe}$ & 4325.939 \\
\hline $\mathbf{P}$ & $\mathrm{Fe}$ & 3361.327 & $\mathrm{G}^{\prime}$ or $\mathrm{H} \gamma$ & $\mathbf{H}$ & 4340.634 \\
\hline 0 & $\mathrm{Fe}$ & 3441.155 & d & $\mathrm{Fe}$ & 4383.721 \\
\hline
\end{tabular}


The solar spectrum obtained by means of a quartz or reflection-grating spectrograph decreases very suddenly near $300 \mathrm{~m} \mu$ and ends abruptly near that wave-length. In this respect the radiation from electric incandescent lamps with glass bulbs approximates solar radiation because ordinary thin glass does not become totally opaque to ultraviolet radiation until the wave-length at which solar radiation disappears is approached. Of course, the spectral distributions are quite different but not to such an extent that many of the effects of solar radiation can be obtained with incandescent lamps when the intensity of illumination is of the same order of magnitude.

Cornu ${ }^{6}$ was one of the earliest to investigate the limit of the solar spectrum. $\mathrm{He}$ and his predecessors thought that the short-wave limit was due to selective absorption by the atmosphere. Therefore, in order to obtain the effect of variation in air-mass he photographed the sun's spectrum for various altitudes of the sun with the results indicated in Table VII.

\section{TABLE VII}

Limit of Solar Spectrum

\begin{tabular}{|c|c|}
\hline Time of day & Limit in $\mathrm{m} \mu$ \\
\hline & \\
\hline $10: 30$ & 295.5 \\
$0: 02$ & 295.0 \\
$1: 18$ & 295.5 \\
$1: 50$ & 297.0 \\
$3: 09$ & 299.0 \\
$3: 40$ & 304.5 \\
$4: 17$ & 304.5 \\
$4: 38$ & 307.0 \\
\hline
\end{tabular}

The shortening of the spectrum with increasing airmass naturally led him to think he had confirmed the assumption that the limit was due to ordinary atmos- 
pheric absorption. From such data he developed a theory relating depth of air and the limiting wave-length. ${ }^{7} \mathrm{His}$ conclusion was that the spectrum would be extended $1 \mathrm{~m} \mu$ if the photographs were made at an additional elevation of 663 meters. His first altitude was 170 meters. He tested the accuracy of his formula by obtaining spectrograms at altitudes of 660 meters and 2570 meters. His new results did not quite agree with his computations so he determined new constants, but his formulae will not be presented, for they were based upon the assumption that the limit of the solar spectrum was determined by the absorption of a homogeneous atmosphere whose density was distributed as indicated by the barometer. Cornu's formula certainly does not hold for the region from 180 to $240 \mathrm{~m} \mu$.

Among other conclusions Cornu concluded that the absorption of ultraviolet radiation by the atmosphere was due chiefly to nitrogen and to oxygen but the probable error of this conclusion will be seen later. $\mathrm{He}$ decided that solar radiation was a disinfectant chiefly upon the surface of bodies, apparently assuming that the active radiation was absorbed generally by thin layers of substances. He further decided that any medium which absorbs the blue, violet, and ultraviolet rays of solar radiation such as glass, dust, fog, and clouds, inhibits the disinfection desired from the standpoint of hygiene and sanitation. It is certain that consecutive days of rain and fog enhance the growth of pathogenic organisms but the active rays are not entirely absorbed by moderate depths of cloud and some clear glasses.

Miethe and Lehmann ${ }^{8}$ photographed the solar spectrum at various altitudes from 116 meters to 4560 meters and concluded that the last trace of photographic action was independent of the altitude. They discovered two lines $291.67 \mathrm{~m} \mu$ and $291.98 \mathrm{~m} \mu$ which had not been seen theretofore. 
The short-wave limits as determined by them for various altitudes at different places are shown in Table VIII.

TABLE VIII

Altitude
50 meters
116
1620
3136
4560

Limit of solar spectrum

$291.26 \mathrm{~m} \mu$

291.55

291.36

291.10

291.21

They concluded that the limit on their spectrograms, where photographic action ceased, was constant but that the distribution of density near this limit varied somewhat.

Dember ${ }^{9}$ investigated the limit of the solar spectrum by means of a quartz spectrophotometer and a photoelectric cell at an altitude of 4560 meters and found the limit at about $280 \mathrm{~m} \mu$. He concluded that he obtained a shorter limiting wave-length because his photo-electric cell was more sensitive than the photographic plate.

Wigand ${ }^{10}$ used the same spectrograph which Miethe and Lehmann employed but reached the high altitude of 9000 meters. He also concluded that the limit of the solar spectrum was independent of altitude for he found the same limit at the earth's surface as at the high altitude which he attained where only about one-third of the atmosphere was above him. He found the last indication of photographic action at $289.7 \mathrm{~m} \mu$. He attributed his lower value to the fact that he greatly reduced the fog on his plates by using a filter and thereby facilitated accuracy of measurement. This result further indicates a steep absorption curve due to the upper layers of the earth's atmosphere or to the sun's atmosphere.

Fabry and Buisson ${ }^{11}$ found the limit of the solar spectrum slightly less than $300 \mathrm{~m} \mu$ and concluded that its abrupt ending was due to the absorption-band of ozone. 
The maximum of the absorption-band of ozone is at $255 \mathrm{~m} \mu$ and it is quite marked between $200 \mathrm{~m} \mu$ and $290 \mathrm{~m} \mu$. A depth of ozone of $25 \mu$ at atmospheric pressure transmits only about one-half the radiation of a wave-length $255 \mathrm{~m} \mu$. They recently ${ }^{27}$ studied the solar spectrum between 290 and $315 \mathrm{~m} \mu$ in great detail and found the intensity of the radiation at $290 \mathrm{~m} \mu$ to be only one-millionth as great as at $315 \mathrm{~m} \mu$. Their work points conclusively to ozone as being responsible for the abrupt ending of the solar spectrum after passing through the atmosphere. The ozone in the atmosphere was determined to be equivalent to a thickness of $3 \mathrm{~mm}$. at atmospheric pressure. They also showed that the location of this ozone was in the upper layers of the atmosphere, above $40 \mathrm{~km}$. They conclude that the ozone is produced by solar radiation shorter than $200 \mathrm{~m} \mu$ and that ozone is dissociated by radiation of longer wave-length, thus accounting for an equilibrium state.

Kron ${ }^{12}$ also studied the extinction of light in the terrestrial atmosphere in the ultraviolet region. Strutt ${ }^{13}$ has discussed the transparency of the lower atmosphere for ultraviolet radiation and the relative poverty in ozone. $\mathrm{He}$ reviewed the work of Hartley ${ }^{14}$ who suggested that the ultraviolet limit of the solar spectrum was due to ozone and also the work of Fowler and himself ${ }^{15}$ which strengthened this view. He photographed the spectrum of the cadmium spark at a distance as great as 3600 feet and the spectrum of the quartz mercury arc at a distance as great as four miles. He used a quartz spectrograph and a small telescope containing cross-wires upon which the distant source could be focussed. The spectrum of the cadmium spark photographed through a horizontal distance of air 3600 feet in length extended to $231.3 \mathrm{~m} \mu$ and apparently was not diminished at $255 \mathrm{~m} \mu$ where the absorption of ozone is a maximum. This indicates the absence of ozone or at least that it was not present in 
appreciable amount. The spectrum of the quartz mercury lamp obtained by a two-hour exposure, extended to $253.6 \mathrm{~m} \mu$.

The extent of this spectrum cannot be compared directly with that of the solar spectrum at sea-level because the equivalent thickness of air traversed in that case (zenith sun) would be more than five miles, whereas the distance Strutt used was four miles, but he compared it with data described by Cornu obtained from the peak of Teneriffe. A brief summary is given in Table IX for equivalent thicknesses of homogeneous atmosphere.

\section{TABLE IX}

\begin{tabular}{l|c|c}
\hline \hline & $\begin{array}{c}\text { Thickness of air } \\
(\text { feet })\end{array}$ & $\begin{array}{c}\text { Limit } \\
(\mathrm{m} \mu)\end{array}$ \\
\cline { 2 - 3 } & 29,000 & 294.8 \\
Solar spectrum from near sea-level..... & 17,900 & 292.2 \\
Solar spectrum from Teneriffe......... & 20,100 & 253.6 \\
Mercury arc spectrum............... & & \\
\hline \hline
\end{tabular}

It will be noted that the corrections being made for barometric pressure, temperature, etc., in order to obtain equivalent thicknesses of homogeneous atmosphere, Table IX, afford a comparison of the transparency of the upper and lower layers of the atmosphere provided the limit of the solar spectrum is due to an absorbing medium in the upper air. Strutt's conclusion is that the lower air is far more transparent than the upper air for ultraviolet rays shorter than $300 \mathrm{~m} \mu$ if equal masses are considered, but this assumes the presence of an absorbing medium in the upper part of the earth's atmosphere which is still awaiting definite proof. However, the evidence is very strongly in favor of ozone as the medium which limits the solar spectrum. 
According to Strutt's experiments there was no evidence that the limit of the mercury spectrum through four miles of lower air was necessarily at $253.6 \mathrm{~m} \mu$. Longer exposures would probably reveal even shorter lines but this is not true of the solar spectrum. It ends so completely that long exposures do not appear to extend it.

Strutt made experiments on the absorption of radiation of wave-length $253.6 \mathrm{~m} \mu$ by ozone and concluded that $0.27 \mathrm{~m} \mu$ of pure ozone in four miles of air would suffice to produce the slight enfeeblement of this mercury line. Scattering of radiation by small particles acts in the same way as ozone to absorb ultraviolet radiation from a distant source so that this complicates the quantitative estimations.

Schuster ${ }^{16}$ by using the Rayleigh ${ }^{17}$ formula came to the conclusion that the selective absorption by the atmosphere may be accounted for by the selective scattering due to molecules of air and the computed results agree favorably with the data obtained by Abbott at Mt. Wilson. King ${ }^{18}$ modified this formula and found excellent agreement between computed and observed results. Fowle ${ }^{4}$ corrected King's formula and obtained excellent agreement as far as $370 \mathrm{~m} \mu$ for observations made at mountain observatories where the atmosphere is fairly free from dust. However, this does not settle the matter of the ultraviolet radiation of shorter wave-lengths.

Liveing and Dewar ${ }^{19}$ determined the absorption of oxygen in a tube $165 \mathrm{~cm}$. long under pressures of 85 and 140 atmospheres, obtaining the respective short-wave spectral limits, $266.4 \mathrm{~m} \mu$ and $270.4 \mathrm{~m} \mu$. This is the region in which ozone strongly absorbs, for its band is marked between $230 \mathrm{~m} \mu$ and $280 \mathrm{~m} \mu$. They also used a tube of oxygen 18 meters long and a pressure of 90 atmospheres which provides about the same mass of the gas as is contained by the atmosphere and found the shortest wavelength transmitted was $366 \mathrm{~m} \mu$. It has been suggested 
that perhaps their oxygen was not pure or that Beer's law does not hold for this region of the spectrum.

The results obtained by various investigators upon the absorption by ozone indicate that much more ozone is required to account for the limit of the solar spectrum than is present in the atmosphere near the earth. However, Pring ${ }^{20}$ found a much greater concentration of ozone at an altitude of 3.5 kilometers than at the earth's surface. This indicates a possibility of sufficient ozone in the entire atmosphere to account for the limit of the solar spectrum.

Abbott and Fowle ${ }^{21}$ using a quartz prism, two magnalium mirrors, and a spectro-bolometer at an altitude of 14,502 feet above sea-level observed no appreciable energy of shorter wave-length than $290 \mathrm{~m} \mu$.

In the high levels of the atmosphere there is very little moisture and the extreme ultraviolet radiation on passing through the dry oxygen may convert some or much of it into ozone. Where there is water-vapor present at ordinary temperatures the ozone would likely revert to oxygen. It appears certain that the presence of ozone in the upper atmosphere has been shown spectroscopically by several investigators.

Water-vapor possesses an absorption-band in the ultraviolet region the maximum of which is in the neighborhood of $175 \mathrm{~m} \mu$.

Air at atmosphere pressure and of a depth of $0.91 \mathrm{~cm}$., transmits no appreciable amount of radiation shorter than $170 \mathrm{~m} \mu$ in wave-length. Under the same conditions oxygen transmits to about $185 \mathrm{~m} \mu$.

Columns of nitric and nitrous oxides about $20 \mathrm{~cm}$. long transmits only about 12 per cent of radiation, $200 \mathrm{~m} \mu$ in wave-length.

Oxygen absorbs to about $186 \mathrm{~m} \mu$ at $0^{\circ} \mathrm{C}$. and when heated to $1800^{\circ} \mathrm{C}$. the absorption-band extends to beyond $300 \mathrm{~m} \mu$. 
Carbon-dioxide and nitrogen are practically transparent in the middle ultraviolet.

This leaves oxygen as possibly responsible for the limiting of the solar spectrum but ozone appears to be the probable agency.

Pure water is quite transparent to the near and middle regions and is fairly opaque to infra-red. According to one observer 80 per cent of the solar energy is absorbed in the first meter of lake water and only about one per. cent reaches a depth of four meters.

Kowalski ${ }^{22}$ obtained spectrograms of solar radiation reflected by snow at an angle of 45 degrees. His exposures were made during four hours at midday at an altitude of 630 meters. The spectral limit was at about $295 \mathrm{~m} \mu$ thus showing that there was no appreciable selective absorption. The reflection-factor of clean snow is more than 80 per cent.

Ultraviolet radiation of short wave-lengths transforms oxygen into ozone and it is thought by some that the ozone formed in the upper regions of the atmosphere by solar radiation sinks toward the earth and oxidizes various impurities. An electroscope is quickly discharged by the influence of ultraviolet radiation of short wave-length but the effect is greatly reduced by interposing a quartz plate. This indicates the region of wave-lengths of the effective radiation.

Various investigators have studied the photo-electric activities of solar radiation.

Many years ago Bunsen and Roscoe conducted extensive photo-chemical researches which did much in supplying a foundation for photo-chemistry. They expressed the chemical effects of radiation in terms of chemical photo-units, each unit being determined by the chemical action upon a normal explosive mixture of hydrogen and chlorine contained in an isolation vessel of such small dimensions that the variability of the extinction appearing 
in large vessels may be neglected when the explosive mixture is illuminated at a distance of one meter from a socalled normal flame. The normal flame burned carbonic oxide at a certain pressure at a platinum burner of certain dimensions. One "chemical light-unit" equalled 10000 of these photo-units. According to their formula, as presented by Sebelien, ${ }^{23}$ solar radiation reaching a horizontal area of the surface of the earth at an angle with the vertical will produce in one minute on each square unit of area a photo-chemical effect that may be expressed in "chemical light-units" by

$$
\mathrm{W}=318.3(\operatorname{Cos} \varnothing) 10^{-\frac{0.4758 P}{\operatorname{Cos} \phi}}
$$

where $\mathrm{P}$ denotes atmospheric pressure, the constant 318.3 corresponds to photo-chemical intensity of solar radiation outside the earth's atmosphere, the constant 0.4758 denotes the atmospheric extinction of direct solar radiation. ${ }^{24}$

Sebelien ${ }^{23}$ employing the formulae of Bunsen and Roscoe, calculated the quantity of " actinic light which on the midsummer day falls upon a horizontal element of surface from sunrise to sunset" for various degrees of north latitude. His data for direct solar radiation, for diffused. radiation from the sky, and for the sum of the two are presented in Table X using his terminology.

Recently Karrer and Tyndall ${ }^{25}$ have made an extensive investigation of the spectral transmission of the atmosphere in the visible region. Their results indicate a gradual decrease in transparency toward the short-wave end of the spectrum. They made their measurements. under various atmospheric conditions which may be characterized more or less approximately as follows: (1) clear sky and of low humidity; (2) overcast sky and of high humidity; (3) rainy. The average curve for the first general condition shows a gradual decrease in transparency with decrease in wave-length. That of the second 


\section{TABLE $X$}

Chemical "Light-units" per Unit Horizontal Area on Midsummer-day Chemical Light-units

\begin{tabular}{c|c|c|r}
\hline \hline $\begin{array}{c}\text { Degrees } \\
\text { N. Lat. }\end{array}$ & $\begin{array}{c}\text { Direct } \\
\text { Insolation }\end{array}$ & $\begin{array}{c}\text { Diffused } \\
\text { Sky Radiation }\end{array}$ & Total \\
\cline { 3 - 4 } & & & \\
\cline { 3 - 3 } 10 & 60656 & 22060 & 82716 \\
20 & 70891 & 23388 & 94479 \\
30 & $\mathbf{7 7 7 0 3}$ & 24539 & 102242 \\
40 & $\mathbf{7 9 0 6 0}$ & 25775 & 114835 \\
45 & 76178 & 27059 & 106701 \\
50 & 72584 & 27757 & 103935 \\
55 & 62704 & 28521 & 101105 \\
60 & 62064 & 28589 & 91293 \\
65 & 57089 & 30484 & 92548 \\
70 & 50267 & 32168 & 89257 \\
75 & 44587 & 35012 & 85279 \\
80 & 40080 & 37099 & 81686 \\
90 & 36211 & 38612 & 78700 \\
& & 39839 & 76048 \\
\hline \hline
\end{tabular}

condition shows two maxima, one at $580 \mathrm{~m} \mu$ and the other at $610 \mathrm{~m} \mu$. The average curve for the rainy condition exhibits a maximum at $640 \mathrm{~m} \mu$.

Recently Bigelow ${ }^{26}$ has published a treatise on solar radiation.

\section{References}

I. M. Luckiesh, Light and Shade and Their Applications, IgI6, Chap. VII.

2. Smithsonian Meteorological Tables.

3. M. Luckiesh, Color and Its Applications, Igr5 and I92I, 20.

4. Astrophys. Jour. 38, 1913, 392.

5. Astrophys. Jour. 17, 1903, 89.

6. Comp. Rend. 88, I878, I IOI and I285;89, I879, 808; 90 , I880, 940 ; III, I890, 94 I. 
7. Kayser's Handbuch III, 337 .

8. Ber. Berlin Akad. 8, I909, 268.

9. Abhand. Nat. Wiss. Gesell. Isis, Dresden, 2, I9I2, I.

I0. Phys. Zeit. I4, I9I3, II44.

II. Comp. Rend. I56, I913, 782 ; Jour. d. Phys. 3, I913, I96.

I2. W. Schmidt, Mon. Weather Rev. (U.S.) Dec. I9I4, 653.

I3. Proc. Roy. Soc. I918, 260.

I4. J. Chem. Soc. 39, I88I, III.

I5. Proc. Roy. Soc. A, 93, I9I 7, 577 .

I6. Theory of Optics, I909, 329.

I7. Collected Works, Vol. I, 87 and Vol. IV, 397.

I8. Phil. Trans. Roy. Soc. Lond. A, 212, I913, 375 .

I9. Kayser's Handbuch III, 36r.

20. Proc. Roy. Soc. A, 90, 204.

2I. Astrophys. Jour. I9II, I92.

22. Nature, March 30, I9II, I44.

23. Phil. Mag. 9, I905, 352.

24. Pogg. Ann. 108, 257.

25. Bur. Stds. Sci. Pap. No. 389.

26. The Sun's Radiation.

27. Astrophys Jour. 54, I921, 297. 


\section{CHAPTER III}

\section{TRANSPARENCY OF GASES}

In general most substances are increasingly opaque to ultraviolet radiation as the wave-length of the radiation decreases. This is one of the reasons for the difficulties encountered in the study of the extreme ultraviolet. In order to work with a degree of certainty with ultraviolet radiation, at least a small quartz spectrograph is indispensable. With such an instrument it is easy to determine the transmission characteristic of any substance as far as $200 \mathrm{~m} \mu$. However, some progress can be made without such an instrument if the general characteristics of reflecting and transmitting media are known. At least the spectral limits are usually made fairly certain in this manner. Sources of ultraviolet and methods of measurement are discussed in other chapters. In this chapter there will be presented certain spectral characteristics of common media which are easily described or recognized. A vast amount of data is available to the author through the examination of material such as eye-protective glasses, dyes, and paints, but it does not appear worth while to include data of this sort because of the uncertainty in the description of the substance due to the use of trade-names, etc.

In the preceding chapter the spectral transmission characteristics of several gases were touched upon briefly in connection with the limit of the solar spectrum. For the sake of completeness they will be briefly discussed again, but the references will not be repeated. In general, the most extensive work in the extreme ultraviolet has been done by Schumann ${ }^{4}$ and by Lyman. In the other regions there have been many investigators. 
Oxygen at atmospheric pressure possesses an absorption-band, according to Lyman, extending from $127 \mathrm{~m} \mu$ to $176 \mathrm{~m} \mu$. This band widens as the pressure increases. At a pressure of $40 \mathrm{~mm}$. it extends from $133 \mathrm{~m} \mu$ to $160 \mathrm{~m} \mu$ and at $15 \mathrm{~mm}$. it has diminished to a range from $135 \mathrm{~m} \mu$ to $150 \mathrm{~m} \mu$. One investigator found an increase in the extent of the absorption-band with increase in temperature. At $0^{\circ} \mathrm{C}$ the absorption-band ended at $186 \mathrm{~m} \mu$ but when the temperature was increased to $1800^{\circ} \mathrm{C}$ it extended into the near ultraviolet, that is, beyond $300 \mathrm{~m} \mu$. Liveing and Dewar employed oxygen in a tube $165 \mathrm{~cm}$. long and found the short-wave limit of its transmission to be $266.4 \mathrm{~m} \mu$ at a pressure of 85 atmospheres and $270.4 \mathrm{~m} \mu$ at a pressure of 140 atmospheres. They also found ${ }^{1}$ that a depth of 18 meters of oxygen at a pressure of 90 atmospheres, did not transmit radiation shorter than $336 \mathrm{~m} \mu$ in wave-length. According to Kreusler ${ }^{2}$ a column of oxygen $20.45 \mathrm{~cm}$. long, at a pressure of $759 \mathrm{~mm}$. and a temperature of $18.5^{\circ} \mathrm{C}$ absorbs 32.5 per cent at $186 \mathrm{~m} \mu$, 6.2 per cent at $193 \mathrm{~m} \mu$ and practically none at $200 \mathrm{~m} \mu$. This indicates a sharp absorption band. Apparently it is oxygen that makes air opaque to radiations shorter in wave-length than $185 \mathrm{~m} \mu$. Lyman ${ }^{3}$ has studied the absorption bands in detail. Kreusler's absorption-factors A (in per cent) including the absorption coefficients $a$ in the usual equation in which the transmission-factor equals $e^{-a d}$ where $d$ is the thickness (in his case $20.45 \mathrm{~cm}$.) are summarized herewith.

$\begin{array}{ccc}\mathrm{m} \mu & \mathrm{A} & \mathrm{a} \\ 186 & 32.5 & 0.02057 \\ 193 & 6.2 & 0.00336\end{array}$

Nitrogen is quite transparent to ultraviolet radiation, its slight absorption increasing gradually as the wave-length decreases. It is quite transparent even for radiation of wave-length $125 \mathrm{~m} \mu$. Schumann found it to be quite trans- 
parent at $160 \mathrm{~m} \mu$ and $\mathrm{Kreusler}{ }^{2}$ determined its absorption to be only 2.2 per cent at $186 \mathrm{~m} \mu$ for a depth of $20.45 \mathrm{~cm}$. at atmospheric pressure and room temperature. Lyman ${ }^{8}$ used a column $9.14 \mathrm{~mm}$. long at atmospheric pressure and observed only a slight absorption from $180 \mathrm{~m} \mu$ to $125 \mathrm{~m} \mu$.

Hydrogen is quite transparent but it is difficult to study great depths of it in a pure state because of the impurities arising from the container. Lyman by filling his "vacuum" grating spectroscope with hydrogen was able to obtain spectrograms for a depth of gas equal to about $200 \mathrm{~cm}$. at pressures from 1 to $5 \mathrm{~cm}$. An absorption-band was indicated at $170 \mathrm{~m} \mu$ but this disappeared as the gas was renewed several times so it is likely that it was due to an impurity. A slight absorption was also observed between 130 and $133 \mathrm{~m} \mu$. At atmospheric pressure the transparency of hydrogen ceased at about $160 \mathrm{~m} \mu$ but Lyman was not certain of the purity of the gas after contact with the walls of the vessel. Later Lyman ${ }^{6}$ reduced the possibility of contamination to a minimum by using a depth of gas equal to $65 \mathrm{~mm}$. He then observed that the hydrogen transmitted radiation of wave-lengths almost to the short-wave limit of transparency of very transparent fluorite. It may be said that hydrogen is very transparent to ultraviolet radiation.

Ozone was discussed at considerable length in Chapter II because of its possible relation to the abrupt ending of the solar spectrum. In the extreme ultraviolet the presence of ozone does not appear to alter the absorption of oxygen. Apparently ozone is not particularly absorbing in the extreme ultraviolet. It possesses a powerful absorption-band with a maximum at $258 \mathrm{~m} \mu$, a minimum at $205 \mathrm{~m} \mu$, and extending markedly between $230 \mathrm{~m} \mu$ and $280 \mathrm{~m} \mu$. This band has been studied by several investigators and its presence and form is fairly well established. Meyer ${ }^{7}$ using a photo-electric method obtained the values 
given in Table XI of the absorption coefficient, $a$, in the equation $\mathrm{E}=\mathrm{E}_{0} 10^{-\mathrm{ad}}$. According to the curve in his original paper the absorption rapidly increases for radiation shorter than $190 \mathrm{~m} \mu$ in wave-length.

\section{TABLE XI}

Absorption coefficients of ozone

\begin{tabular}{|r|r|r|r|}
\hline $\mathrm{m} \mu$ & \multicolumn{1}{|c|}{$\mathrm{a}$} & $\mathrm{m} \mu$ & $\mathrm{a}$ \\
193 & & & \\
\cline { 3 - 3 } 200 & 7.7 & 250 & 123.0 \\
210 & 11.5 & 260 & 126.0 \\
220 & 19.2 & 270 & 116.0 \\
230 & 48.6 & 280 & 73.4 \\
240 & 105.0 & 300 & 38.6 \\
& & & 30.3 \\
\hline
\end{tabular}

Ledanburg and Lehmann ${ }^{8}$ evaporated liquid ozone and obtained a high percentage of gaseous ozone. In low. concentrations they found that absorption extended to $316 \mathrm{~m} \mu$ but at higher concentrations bands appeared in the region of longer wave-lengths. The liquid ozone did not exhibit the ultraviolet bands.

Helium exhibits about the same degree of transparency as hydrogen between $125 \mathrm{~m} \mu$ and $190 \mathrm{~m} \mu$. According to Lyman no absorption in this region was observable.

Argon is of the same order of transparency as helium and hydrogen.

Carbon monoxide, according to Lyman, ${ }^{5}$ exhibits eight narrow absorption-bands between $125 \mathrm{~m} \mu$ and $160 \mathrm{~m} \mu$. It is more transparent to the extreme ultraviolet than carbon dioxide. The bands are shorter for shorter wavelengths and they decrease in width with a decrease in pressure of the gas. Its spectral transmission characteristic is quite complicated and apparently differs from any other gas which has been examined for transparency in the extreme ultraviolet. 
Carbon dioxide exhibits some absorption-bands in the extreme ultraviolet. Shumann states that its transparency extends considerably further into the ultraviolet than that of oxygen. According to Kreusler ${ }^{2}$ a column $20.45 \mathrm{~cm}$. long at a pressure of $750 \mathrm{~mm}$. and a temperature of $15^{\circ} \mathrm{C}$ absorbs 13.6 per cent at $190 \mathrm{~m} \mu, 4$ per cent at $193 \mathrm{~m} \mu$, and 1.8 per cent at $200 \mathrm{~m} \mu$. Kreusler's absorptionfactors A (in per cent) and absorption coefficients, a, are as follows :

\begin{tabular}{crc}
$\mathrm{m} \mu$ & \multicolumn{1}{c}{$\mathrm{A}$} & $\mathrm{a}$ \\
186 & 13.6 & 0.00574 \\
193 & 4.0 & 0.00213 \\
200 & 1.8 & 0.00079
\end{tabular}

Water vapor appears to have an absorption-band with a maximum between $160 \mathrm{~m} \mu$ and $170 \mathrm{~m} \mu$ but apparently there are no very satisfactory results available.

The transparency of air in the extreme ultraviolet is determined chiefly by its content of oxygen and in the middle ultraviolet and near the limit of the solar spectrum by its content of ozone. It is more transparent than oxygen at the same pressure. According to Lyman a depth of oxygen equal to $0.91 \mathrm{~cm}$. is opaque to radiations shorter in wave-length than $176 \mathrm{~m} \mu$ while the same depth of air transmits some radiation of wave-length $171 \mathrm{~m} \mu$. The absorption of ultraviolet by air is one of the factors which makes it necessary to employ vacuum spectroscopes in studying the extreme ultraviolet.

Kreusler ${ }^{2}$ found that a column of air $20.45 \mathrm{~cm}$. long at a pressure of $747 \mathrm{~mm}$. and a temperature of $14^{\circ} \mathrm{C}$ absorbed 8.8 per cent at $186 \mathrm{~m} \mu$ and no absorption was observable for radiation longer than $193 \mathrm{~m} \mu$ in wave-length. In other words air is quite transparent at $193 \mathrm{~m} \mu$ but almost opaque at $185 \mathrm{~m} \mu$.

Nitric and nitrous oxides were found by $\mathrm{Kreusler}^{2}$ to absorb the extreme ultraviolet very strongly. His results 
for a depth of $20.45 \mathrm{~cm}$. of nitric oxide at a pressure of $600 \mathrm{~mm}$. and a temperature of $18^{\circ} \mathrm{C}$ are as presented in Table XII.

Table XII

Absorption by Nitric Oxide

\begin{tabular}{|c|c|c|}
\hline $\begin{array}{l}\text { Wave-length } \\
\qquad \mathrm{m} \mu\end{array}$ & $\begin{array}{c}\text { Absorption-factor } \\
\text { A }\end{array}$ & $\begin{array}{c}\text { Absorption-coefficient } \\
\text { a }\end{array}$ \\
\hline 200 & 88.4 per cent & 0.14932 \\
\hline 210 & 76.3 & 0.09526 \\
\hline 220 & 72.0 & 0.08424 \\
\hline 230 & 54.6 & 0.05223 \\
\hline 240 & 30.5 & 0.02406 \\
\hline 250 & 4.7 & 0.00318 \\
\hline 300 & 1.2 & 0.00083 \\
\hline
\end{tabular}

Palmer ${ }^{9}$ studied the "volume ionization" effect observed by Lenard ${ }^{10}$ as produced by ultraviolet radiation of extremely short wave-length. It has been shown by Lyman $^{11}$ that when the secondary of a transformer is connected with additional capacity to the electrodes of a hydrogen-filled discharge containing traces of hydrocarbons, the excitation of the tube gives rise to carbon bands extending as far as $170 \mathrm{~m} \mu$ into the ultraviolet region and to strong hydrogen lines from $125 \mathrm{~m} \mu$ to $165 \mathrm{~m} \mu$. Palmer used such an arrangement with fluorite windows and a screen-cell containing oxygen. Lyman ${ }^{5}$ has found that the absorption of radiation in the extreme ultraviolet is in the form of a band and that as the pressure increases the absorption spreads much more rapidly toward the less refrangible side than in the other direction. For a column of gas $1 \mathrm{~cm}$. thick at atmospheric pressure the band extends from $126.8 \mathrm{~m} \mu$ to $177 \mathrm{~m} \mu$ and at a pressure of 0.02 atmosphere from $135 \mathrm{~m} \mu$ to $150 \mathrm{~m} \mu$. Palmer admitted oxygen into the screen-cell at various pressures thus controlling the effective rays from the discharge tube. This 
provides a "variable screen" for this particular part of the extreme ultraviolet region.

Palmer found that the ionization of air, oxygen, and nitrogen is considerable but exceedingly small with hydrogen. The power of ionization was found to increase greatly with decrease in the wave-length of radiation; at least this is true in the region of wave-lengths shorter than $185 \mathrm{~m} \mu$. The very large effect found with nitrogen may be due to a strong absorption of this gas for radiation between $130 \mathrm{~m} \mu$ and $150 \mathrm{~m} \mu$.

In experiments of this kind the Hallwach effect - the ionization produced at an electrically charged surface when illuminated by ultraviolet radiation - is confusing. Palmer eliminated this by covering the surfaces exposed to radiation with a film of soap solution. He also freed the gases from dust by admitting them through a long plug of cotton wool.

Peskov ${ }^{12}$ studied the spectral absorptions of chlorine and bromine and found that by varying a mixture of these two gases he could isolate regions of the spectrum as narrow as $240 \mathrm{~m} \mu$ to $250 \mathrm{~m} \mu$. These mixtures were found to obey Beer's law and therefore, after having obtained the requisite quantitative data, the mixture for filtering a certain spectral region could be calculated. According to Peskov, chlorine has a marked absorption between $300 \mathrm{~m} \mu$ and $400 \mathrm{~m} \mu$ as well as for the region of longer wave-lengths than $540 \mathrm{~m} \mu$. The absorption of bromine extends from $380 \mathrm{~m} \mu$ to $540 \mathrm{~m} \mu$ therefore a mixture of the two gases provides a screen for isolating the radiation of shorter wavelengths than $300 \mathrm{~m} \mu$.

The very fine absorption-bands or lines exhibited by the vapors of some liquids were first noticed by Pauer. ${ }^{13}$ Hartley ${ }^{14}$ thoroughly studied those of benzene vapor and came to the conclusion that the ordinary broad bands were due to fusion of the fine bands. He recorded about 300 ultraviolet absorption lines. 
Baly ${ }^{15}$ in applying the quantum theory concluded that the frequencies of the absorption-bands of a substance might be simple integral multiples of a fundamental frequency. According to this theory it would be possible by computation to predict unknown bands from known ones of different wave-lengths. $\mathrm{He}^{16}$ found that in the case of benzene and p-xylene, the frequencies of the centers of the groups of absorption, fluorescence, phosphorescence, and cathodo-luminescence bands are represented by integral multiples of the frequency of an infra-red band. Baly calculated the wave-lengths of the absorption lines of benzene vapor and found that there should be about 600 lines between the limits where Hartley found 300 provided the theory was correct. His computations agree well with the lines actually measured. He lays considerable stress upon the constant frequency difference which he has observed for so many substances. ${ }^{17}$

Stark ${ }^{18}$ and his colleagues photographed the absorption spectra of a large number of hydrocarbons in the form of vapor as far as $185 \mathrm{~m} \mu$ and arrived at interesting conclusions concerning the relation of linkings to absorptionbands. They examined the absorption spectra of hexane, cyclohexane, camphane, isobutylene, methyl butylene, hexylene, acetylene, diallyl, isobutylene, ethylene, methyl butadiene, dimethyl butadiene, methyl pentadiene, hexadiene, bornylene, camphene, pinene, limonene, sylvesterene, and a few other compounds.

Strasser ${ }^{19}$ investigated the ultraviolet absorption spectra of the vapors of several mono-substituted derivatives of benzene and found the absorption-bands to be similar for benzaldehyde, benzonitrile, benzyl alcohol, benzyl ethyl ether, and benzoic acid.

Witte ${ }^{20}$ determined the wave-lengths of the absorptionbands in the spectra of the vapors of benzene toluene, chlorobenzene, bromobenzene, aniline, phenol, and anisole, and estimated the relative intensities of the bands. 
The spectra appear to be more or less similar. They possess series of bands which exhibit a constant difference in frequency.

Ribaud ${ }^{21}$ determined the absorption coefficients of bromine vapor in the ultraviolet region.

The vapor of carbon bisulphide exhibits an absorptionband in the ultraviolet which Paurer has resolved into lines.

The vapor of ethyl benzene exhibits a number of absorption-bands between 230 and $275 \mathrm{~m} \mu$.

Schulz ${ }^{22}$ has discussed the work done on the ultraviolet absorption spectrum of benzene vapor and has presented the results of his own investigation. Using a concave grating and an iron arc he determined the positions of 75 bands. Between the members of a long series the mean difference in wave-length was found to be $9.21 \mathrm{~m} \mu$.

The absorption of radiation by the vapors of selenium, tellurium, mercury, zinc, cadmium, phosphorus, arsenic, and bismuth has been studied by Dobbie and Fox. ${ }^{23}$ Their investigation was confined chiefly to the visible region but extended into the near ultraviolet. A table of absorption bands is presented. Mercury vapor showed little absorption at any temperature. Cadmium exhibited no general absorption but a few sharply defined bands occur in the ultraviolet such as: a very fine sharp band at $379.3 \mathrm{~m} \mu$; a fine band at $326 \mathrm{~m} \mu$ which appeared first at about $600^{\circ} \mathrm{C}$. and widened with increase in temperature; a diffuse band at $318.6 \mathrm{~m} \mu$ which appeared at $900^{\circ} \mathrm{C}$; two sharp bands at about 365 and $370 \mathrm{~m} \mu$ appearing at $1200^{\circ} \mathrm{C}$; a band at $306.1 \mathrm{~m} \mu$ appearing at $1000^{\circ} \mathrm{C}$; and one at $338.2 \mathrm{~m} \mu$ which appeared at $1100^{\circ} \mathrm{C}$. Zinc behaved in general like mercury but at $110^{\circ} \mathrm{C}$ four very sharp bands appeared at $369.9,365.4,338.4$, and $328.4 \mathrm{~m} \mu$ respectively. No absorption bands were observed for phosphorus, arsenic, and antimony although the general absorption increased with increase of temperature. 
The ultraviolet band of ammonia and its occurrence in the solar spectrum has been discussed at length by Fowler and Gregory. ${ }^{24}$

Ribaud ${ }^{25}$ has presented a discussion of the absorption of radiation in different regions of the spectrum dealing chiefly with the broad continuous regions of absorption shown by gases, liquids and solids. He refers to experiments which lead to the conclusion that for the same substance in different physical states or for the same chemical group in different compounds, the maximum of the continuous region of absorption is more displaced toward the long wave-lengths the greater the value of the maximum absorption. Other experiments have shown that at a given temperature the damping in an absorption band only depends on the position of this band in the spectrum. In other words if two bodies have an absorption band in the same region of the spectrum the dampings or the widths of their bands are the same. According to Ribaud the width of an absorption band, which is solely a function of its position in the spectrum increases continuously on going from the ultraviolet towards the infra-red very nearly proportionally to the wave-length maximum. It is interesting to note that for all the ultraviolet and visible bands studied the observed widths of the absorption bands furnish a damping coefficient very approximately equal to the frequency.

\section{References}

I. Phil. Mag. 26, I888, 286.

2. Ann. d. Phys. 6, I901, 4I8.

3. Astrophys. Jour. 38, 1913, 284.

4. Smithsonian Contribution, No. I4I3, 29.

5. Astrophys. Jour. 27, 1908, 89.

6. Astrophys. Jour. 35, I9I2, 344.

7. Ann. d. Phys. 12, 1903, 849.

8. Chem. Centr. I906, I727. 
9. Phys. Rev. 32, I9II, I.

Io. Ann. d. Phys. I, I900, 486; 3, I900, 298.

II. Astrophys. Jour. 23, I906, I8I.

I2. J. Phys. Chem. 21, I9I7, 386.

I3. Wied. Ann. 61, 1897, 363 .

I4. Phil. Trans. 208, I908, 520.

I5. Phil. Mag. 27, I9I4, 632.

I6. Phil. Mag. 29, I9I5, 223.

I7. Phil. Mag. 3I, I9I6, 425.

I8. J. Chem. Soc. I913, abs. I04, 363.

Ig. Z. Wiss. Photochem. I4, I9I5, 28I.

20. Z. Wiss. Photochem. I4, I9I5, 347 .

21. Comp. Rend. I57, I913, 1065.

22. Zeit. Wiss. Phot. 20, I920, I.

23. Roy. Soc. Proc. 98, I920, 147.

24. Roy. Soc. Phil. Trans. 218, I9I9, 35I.

25. Comp. Rend. I7I, I920, II34. 


\section{CHAPTER IV}

\section{TRANSPARENCY OF IIQUIDS}

Absorption-bands may be defined by their wave-length limits, the character of the edges, and the position of the center, but for any single, solution, a curve showing the absorption-factors for various wave-lengths is most representative. Extinction-coefficients are also valuable because it is then possible to compute absorption curves for other concentrations and thicknesses, provided Beer's law is valid as it is very generally. Hartley devised a method of representing by a single curve certain essential facts concerning the absorption spectrum of a liquid or of a substance in solution. The positions of the edges of the absorption-bands were determined for layers of different thicknesses and a curve was plotted which related wavelength (or frequency) and the thickness of the layer. These curves show the positions of the centers of the absorption-bands and of the edges for layers of any thickness. They show whether the bands are symmetrical or not and indicate the thickness of liquid necessary for absorption to be evident.

In order to show the absorption or transmission characteristics of a liquid or a substance dissolved in a solvent quite completely it is necessary to consider wave-lengths (or frequencies) of radiation, concentration (or depth) of the liquid, and absorption (or transmission) factors. This involves a figure of three dimensions. The author ${ }^{1}$ has considered this figure graphically and has discussed various uses for spectral data.

Hartley's method of plotting absorption data has been widely used although to make the curves more convenient 
in size the logarithms of thicknesses instead of the thicknesses of the layers are usually plotted.

The law relating thickness and absorption or transmission, for radiation of a certain wave-length, may be expressed thus:

$$
\mathrm{J}=\mathrm{J}_{0} \mathrm{~A}^{-\mathrm{cd}} \text { or } \frac{\mathrm{J}}{\mathrm{J}_{0}}=\mathrm{A}^{\text {-cd }}=-\mathrm{cd} \log \mathrm{A}=\log \mathrm{T}
$$

where $\mathrm{J}_{0}$ is the intensity of radiation entering the liquid or other substance, $\mathrm{J}$ is the intensity on leaving, $\mathrm{A}$ is the transmission coefficient, $\mathrm{c}$ is the concentration of the dissolved substance, $d$ is the depth of the layer, and $T$ is the transmission-factor. The absorption-factor is found by subtracting the transmission-factor from unity unless there is loss by reflection or otherwise than by absorption. The author ${ }^{2}$ has utilized this law in many practical ways to greatly reduce spectrophotometric and other spectral measurements.

The absorption of ultraviolet radiation by dilute aqueous solutions of various salts was studied by Pidduck ${ }^{3}$ by means of a photo-electric method. He employed a spark between zinc electrodes in a Leyden-jar discharge circuit. The radiation passed through a wire grating which formed the positive plate of a condenser, the negative plate being of zinc connected to a pair of insulated quadrants of an electrometer. This is an application of the effect discovered by Hertz when he noted that the breakdown voltage of a gap was less when the metal terminals were illuminated by ultraviolet radiation. Of course, there is much uncertainty as to the spectral character of the radiation although a fair estimate of the spectral lines and the limits of the spectrum may be made.

There is a great decrease of the electrical action of ultraviolet radiation caused by transmission through ordinary clear tap-water as compared with the effect after passage through the same thickness of distilled water 
Pidduck used not only distilled and tap-water but an artificial tap-water consisting of small amounts of sodium chloride, magnesium sulphate, calcium sulphate, and calcium carbonate in distilled water. His control in each case was distilled water. The reduction in the electrical effect of ultraviolet radiation after passing through one of the solutions as compared to the effect after passing through distilled water depends upon the solution and the concentration of the impurity. For example, a thickness of $15 \mathrm{~mm}$. of a solution of sodium whose concentration was $2.5 \times 10^{-4}$ normal, showed a reduction in electrical effect to 0.946 of the effect obtained when distilled water was used. When the concentration was increased to $200 \mathrm{x}$ $10^{-4}$ the electrical effect was reduced to 0.35 of the distilled-water value. For $15 \mathrm{~mm}$. of ordinary clear tap-water the electrical effect as compared with that through distilled water ranged from 0.114 to 0.173 .

Pidduck concluded that the absorption of ultraviolet radiation (the photo-electrically active rays) might be a sufficiently delicate test to distinguish between different kinds of distilled water but he was unable to detect any difference in various specimens of distilled water tested by him. However, the method may have some applications.

Kreusler ${ }^{4}$ investigated the spectral transmission of distilled and ordinary tap-water. He found that water increased in absorption for the extreme ultraviolet on standing in a glass vessel and ascribed this increase to the dissolving of material from the vessel. For a thickness of $16.97 \mathrm{~mm}$. of distilled water he obtained the values given in Table XIII where $A$ is the actual absorption-factor for this thickness of water and $a$ is the absorption coefficient in the familiar equation.

In the foregoing the absorption coefficient is a in the equation $I=I_{0} e^{\text {ad }}$, where $I_{0}$ is the intensity of the radiation before transmission, I the intensity after transmission, 
TABLE XIII

Absorption of ultraviolet radiation by water

\begin{tabular}{c|c|c}
\hline $\begin{array}{c}\text { Wave-length } \\
\mathrm{m} \mu\end{array}$ & $\begin{array}{c}\text { Absorption-factor } \\
\mathrm{A}\end{array}$ & $\begin{array}{c}\text { Absorption coefficient } \\
\mathrm{a}\end{array}$ \\
\cline { 2 - 2 } 186 & 68.9 per cent & 0.06884 \\
193 & 24.5 & 0.01653 \\
200 & 14.2 & 0.00899 \\
210 & 9.8 & 0.00610 \\
220 & 9.2 & 0.00567 \\
230 & 5.6 & 0.00334 \\
240 & 5.2 & 0.00316 \\
260 & 4.2 & 0.00254 \\
300 & 2.5 & 0.00151 \\
\hline
\end{tabular}

and $d$ is the depth or thickness of the layer of water in centimeters. Values of the absorption coefficient for radiation of longer wave-lengths obtained by Ewan, Aschkinass, ${ }^{6}$ and Nichols ${ }^{7}$ are given in Table XIV.

TABLE XIV

Absorption of visible and near infra-red radiation by water

\begin{tabular}{c|c}
\hline $\begin{array}{c}\text { Wave-length } \\
\mathrm{m} \mu\end{array}$ & $\begin{array}{c}\text { Absorption coefficient } \\
\mathrm{a}\end{array}$ \\
\hline 415 & 0.00035 \\
430 & 0.00023 \\
460 & 0.0002 \\
487 & 0.0001 \\
500 & 0.0002 \\
550 & 0.0003 \\
600 & 0.0016 \\
650 & 0.0025 \\
779 & 0.272 \\
865 & 0.296 \\
945 & 0.538 \\
\hline
\end{tabular}


The general increase of the absorption coefficient with increase in wave-length is noticeable throughout the visible spectrum. The sudden rise in the absorption coefficient for the region of the near infra-red emphasizes the opacity of water for infra-red rays. Rubens ${ }^{8}$ gives reflection-factors, refractive-indices, and absorption coefficients for water from $1 \mu$ to $18 \mu$. It is interesting to note the minimum at $487 \mathrm{~m} \mu$. This accounts for the bluegreen color of deep clear water.

Hughes found $1 \mathrm{~cm}$. of water to be opaque to radiation shorter than $220 \mathrm{~m} \mu$ in wave-length. Lyman ${ }^{\circ}$ found that a prolonged exposure of a photographic plate to radiation passing through a fluorite cell containing a thickness of $0.5 \mathrm{~mm}$. of water showed a transparency for this depth of water as far into the extreme ultraviolet as $173 \mathrm{~m} \mu$.

Sodium, potassium, lithium, rubidium, caesium, barium, strontium, and magnesium react with liquid ammonia and produce excellent blue solutions. It is believed that the metal dissolves in the metal, forming a blue colloidal solution but these colored solutions are not permanent. Absalom ${ }^{10}$ dissolved these metals in ammonia and obtained blue solutions possessing valuable properties as ultra-violet filters. These solutions were quite fugitive but with dry ammonia and freshly scraped metal, Cottrell ${ }^{11}$ obtained blue solutions lasting as long as several years.

One general conclusion by Absalom was that transparency far into the ultraviolet region is much more commonly met with in the case of color due to colloidal metals than it has been found to be in ordinary colored salts or aniline dyes.. Liquid ammonia is opaque to radiation shorter in wave-length than $240 \mathrm{~m} \mu$. In all cases Absalom's blue solutions were opaque to radiation shorter than $244 \mathrm{~m} \mu$. A freshly prepared solution of colloidal gold was opaque to radiation shorter than $249 \mathrm{~m} \mu$ in wave-length but after it had stood for about a day the limit of transmission was at $277 \mathrm{~m} \mu$. 
Argo and Gibson ${ }^{12}$ studied the absorption of the blue ammonia solutions of sodium and magnesium for visible radiation and found that for the same intensity of color their absorption spectra are quite similar. They conclude that this is strong evidence in favor of the assumption that the coloring principle is the same in both cases. The blue color of these and other metallic solutions appears to be independent of the metal and the solvent used.

Glycerine is nearly opaque to radiation beyond $230 \mathrm{~m} \mu$. Pfiüger ${ }^{13}$ found a thickness of $1 \mathrm{~cm}$. to be opaque beyond $210 \mathrm{~m} \mu$ and absorption-factors as follows for radiation of other wave-lengths :

$\begin{array}{lrrrrr}\text { Wave-length } & 227 & 257 & 275 & 293 & 330 \mathrm{~m} \mu \\ \text { Absorption } & 81 & 50 & 57 & 46 & 24 \text { per cent. }\end{array}$

A depth of $1 \mathrm{~cm}$. of chemically pure ethyl-alcohol was found by Pflüger to absorb the following percentages of radiation of different wave-lengths:

Wave-length $203206214219227240280 \mathrm{~m} \mu$

$\begin{array}{lllllllll}\text { Absorption } & 96 & 86 & 72 & 63 & 42 & 28 & 20 & \text { per cent }\end{array}$

Glatzel ${ }^{14}$ has determined the absorption coefficients throughout the ultraviolet region for acetone, calcium nitrate, benzol, anthracene, and retene.

Acetone is transparent to about $310 \mathrm{~m} \mu$ and appears to have a maximum at $265 \mathrm{~m} \mu$ in the absorption-band which extends from 310 to $230 \mathrm{~m} \mu$.

Calcium nitrate is transparent to $250 \mathrm{~m} \mu$ but it absorbs more or less between 250 and $230 \mathrm{~m} \mu$. Apparently it is quite transparent to radiation longer than $310 \mathrm{~m} \mu$ in wavelength.

Benzol is transparent to radiation of longer wavelengths than $270 \mathrm{~m} \mu$. Several sharp absorption-bands lie between 235 and $270 \mathrm{~m} \mu$.

Anthracene exhibits several sharp absorption-bands between 320 and $390 \mathrm{~m} \mu$. 
Retene begins to absorb at $300 \mathrm{~m} \mu$, the absorption increasing rapidly with decreasing wave-length.

Canada balsam transmits ultraviolet radiation in a manner similar to ordinary glass. A thin film of the yellowish balsam may be said to be opaque to the middle and extreme regions; that is, to radiation shorter in wave-length than about $330 \mathrm{~m} \mu$.

Glacial acetic acid is quite transparent to the near and middle regions. A layer $3 \mathrm{~mm}$. thick transmits to the neighborhood of $200 \mathrm{~m} \mu$.

Acetone, xylene, and turpentine differ somewhat in spectral transmission, but in general layers $3 \mathrm{~mm}$. thick transmit only the near ultraviolet. Their spectral transmission characteristics are somewhat similar to those of ordinary glasses.

Ether in a layer $3 \mathrm{~mm}$. thick is quite transparent to about $300 \mathrm{~m} \mu$ and this layer is slightly transparent to the middle ultraviolet.

Collodion in thin films is transparent to about $220 \mathrm{~m} \mu$.

Liquid ammonia is transparent to $240 \mathrm{~m} \mu$.

Liquid ethylene absorbs radiation shorter than $235 \mathrm{~m} \mu$ in wave-length.

Nitroso-dimethyl-aniline dissolved in water is fairly transparent between $280 \mathrm{~m} \mu$ and $400 \mathrm{~m} \mu$. The best strength of this filter for isolating the near ultraviolet is one which just eliminates the blue and violet light. Inasmuch as this filter transmits other visible rays it is necessary to use such a filter as blue uviol (Jena) glass or a dye such as methyl violet contained preferably in a quartz cell or in a gelatine film on a quartz plate. If a red band is still transmitted this may be eliminated by a solution of copper sulphate or other filter transparent to the near ultraviolet.

Many combinations of aniline-dye solutions or dyed gelatine filters may be used for isolating portions of the near ultraviolet and visible regions. In general, gases and a few other media must be depended upon for isolating portions of the middle and extreme ultraviolet regions. 
Yellow dyes are often used as photographic filters and for other purposes but they can not be assumed from their appearance to be opaque to the near ultraviolet radiation. For example, gelatine films on glass plates dyed with aurantia, tartrazine, fluorescein, aniline yellow, orange G and uranin, which appear approximately alike to the unaided eye, differ markedly in spectral transmission in the near ultraviolet as shown by the author elsewhere. ${ }^{13}$ These filters each consisted of $6.5 \mathrm{~mm}$. of ordinary plate glass and a thin layer of dyed gelatine and each transmitted about 50 per cent of the (visible) light from a vacuum tungsten lamp. Three of them, aurantia, tartrazine, and fluorescein, were opaque to the blue, violet, and ultraviolet; that is, to radiation shorter in wave-length than about $470 \mathrm{~m} \mu$. The other three, orange $\mathrm{G}$, uranin, and aniline yellow transmitted the radiation from the mercury arc in the near ultraviolet to a wave-length about $350 \mathrm{~m} \mu$. The orange $\mathrm{G}$ filter transmitted the blue and violet lines but the uranin and aniline yellow filters absorbed these lines but transmitted the near ultraviolet to $350 \mathrm{~m} \mu$ fairly well.

The radiation from the quartz mercury arc in the region of $366 \mathrm{~m} \mu$ can be isolated for photographic purposes when the ordinary plate is used by various combinations of solutions or gelatine filters of aniline dyes in which clear glass elements are used. A combination of aniline green and resorcine blue isolates $366 \mathrm{~m} \mu$ fairly well but acid green and ethyl violet appear to be better for the purpose. For photographic plates sensitive only to the blue, violet, and ultraviolet, or for other photo-chemical reactions involving only these radiations, dense filters of methyl violet and other deep purple dyes are quite satisfactory for isolating the region from $350 \mathrm{~m} \mu$ to $400 \mathrm{~m} \mu$. Dense cobalt glass answers the same purpose. In these cases the visible red radiation is not effective and therefore need not be eliminated excepting in special cases. 
A solution of esculine is practically colorless (fluorescing a pale blue) and is quite opaque to the ultraviolet region when contained in a glass cell or in a gelatine film on glass.

In general, fluorescent solutions and solids are opaque to ultraviolet radiations although there are exceptions, especially some of the feebly fluorescent solutions.

Data pertaining to the spectral transmission-factors of many representative dyes have been published by the author elsewhere. ${ }^{1}$ Spectrograms of radiation transmitted by many dyes and other substances, have been published by Uhler and Wood, ${ }^{16}$ Mees, ${ }^{17}$ and others. Watson's recent treatise ${ }^{18}$ on the relation of color to chemical constitution contains a great deal of valuable material. Although most of the data pertains to visible and infrared radiation, there are valuable glimpses of the ultraviolet region.

For sharpening absorption-bands such absorption characteristics as that shown by neodymium ammonium nitrate are very useful. For example, it is easy to obtain filters that will eliminate all radiation excepting the green and yellow lines of the mercury spectrum. By the use of a solution of the salt of neodymium or by employing a glass containing this element, the yellow lines of mercury may be completely eliminated leaving the green line. This is an excellent monochromatic radiation and it is of special interest because it is almost identical in wave-length to that of the most luminous radiation.

Other mercury lines can be readily isolated as shown in Chapter VIII.

A dilute solution of Auramine $O$ in a quartz cell transmits as far into the ultraviolet as $250 \mathrm{~m} \mu$ but still absorbs the violet radiation between $400 \mathrm{~m} \mu$ and $450 \mathrm{~m} \mu$.

Dilute solutions of copper sulphate transmit the near ultraviolet and somewhat beyond $300 \mathrm{~m} \mu$.

A 1.5 per cent solution of cupric chloride in a quartz cell 
$5 \mathrm{~cm}$. in depth transmits as far into the ultraviolet as $320 \mathrm{~m} \mu$.

Plotinkoff ${ }^{10}$ investigated the absorption spectra of bromine and of cinnamic acid in benzene and determined the absorption coefficients of bromine in water, benzene, chloroform, and carbon tetrachloride. He used four lines of the mercury spectrum and concluded that bromine obeys Beer's law. He suggested that the bromine visible spectrum consists of two superposed absorption-bands. $\mathrm{He}$ also determined the absorption coefficients of aqueous solutions, erythrosine, acid-green, guina-green, potassium dichromate, and certain mixtures of dyes. He discussed the preparation of filters for isolating various spectral regions.

Drossbach ${ }^{20}$ obtained the ultraviolet absorption spectra of salts of rare earths, of alcohols, and of aromatic hydrocarbons. The spectra of the salts of erbium differ characteristically from those of didymium. The long-wave limit of absorption in the ultraviolet for various liquids are as follows : benzene, $290 \mathrm{~m} \mu$; toluene, $288 \mathrm{~m} \mu$; xylene, $310 \mathrm{~m} \mu$; $\mathrm{m}$-xylene, $307 \mathrm{~m} \mu$; mesitylene, $336 \mathrm{~m} \mu$; propyl alcohol, $290 \mathrm{~m} \mu$; isobutyl alcohol, $335 \mathrm{~m} \mu$; amyl alcohol, $332 \mathrm{~m} \mu$; allyl alcohol, $310 \mathrm{~m} \mu$. Methyl and ethyl alcohol are transparent throughout the near and middle ultraviolet regions. The results show that the presence of traces of the higher alcohols in methyl and ethyl alcohol can be detected by spectroscopy.

Massol and Faucon ${ }^{23}$ studied the absorption of certain alcohols for ultraviolet radiation. They found that the normal primary, secondary, and tertiary alcohols and three abnormal primary alcohols which they examined, exhibited a general progressive absorption for ultraviolet radiation. The tertiary alcohols were more transparent in the ultraviolet than the secondary and these, in turn, were more transparent than the primary. The three abnormal primary alcohols exhibited, in addition to the general ab- 
sorption characteristic of the normals, two absorptionbands in the region of $260 \mathrm{~m} \mu$ and $310 \mathrm{~m} \mu$, respectively. According to these investigators, these bands are exceptional, for they are not exhibited by the fundamental hydrocarbon, by the other alcohols, or the corresponding alkyl haloids. The corresponding aldehydes possess only one broad band which lies between the two bands noted above. They also studied the absorption of radiation by the chlorides of ethane, acetylene, ethylene. None of these exhibited the characteristic band of chlorine. Tetrachlorethylene absorbs more ultraviolet radiation than hexachlorethane or acetylene tetrachloride and this difference appears to depend upon the saturation of the molecule.

Massol and Faucon ${ }^{21}$ have investigated the transparency of saturated aliphatic alcohols to ultraviolet radiation of the near and middle regions. They used as a source of radiation an arc between an iron electrode and one of brass coated with an alloy of tin, lead, and cadmium. They obtained spectrograms over the range from 210 to $500 \mathrm{~m} \mu$. According to their results, ethyl and methyl alcohols are exceptionally transparent even to a depth of $10 \mathrm{~cm}$. Propyl alcohol is of lesser transparency but the absorption increases slowly with depth. Butyl, amyl, hexyl, heptyl, octyl, cetyl, and melissyl alcohols exhibit a rapidly increasing absorption as the depth of the layer increases in thickness up to about $1 \mathrm{~cm}$. but as the depth is still increased beyond this, the transparency diminishes much more slowly. According to these investigators the transmission-factors decrease in general as the molecular weight increases. The limit of the spectrum for thicknesses greater than one $\mathrm{cm}$. is approximately $310 \mathrm{~m} \mu$ for the primary alcohols with branched chains. They show two absorption-bands at about $260 \mathrm{~m} \mu$ and $310 \mathrm{~m} \mu$ respectively for layers less than one $\mathrm{cm}$. thick. In general, the order of transparency beginning with the least transparent 
is as follows: primary alcohols with branched chains, normal primary alcohols, normal secondary alcohols, tertiary alcohols.

The same investigators studied the absorption spectra of the eosins ${ }^{22}$ of certain confectionery colors ${ }^{23}$ and of various dyes. The ultraviolet range was 220 to $405 \mathrm{~m} \mu$. They ${ }^{67}$ have also shown that liquids and solutions which show absorption bands are the same which have been observed to exhibit magnetic birefraction. In some cases electric birefraction (Kerr-effect) goes together with absorption.

Malachite-green, acid-green $\mathrm{J}$, and Patent-blue exhibit a band in the visible, one near the boundary between the ultraviolet and visible, and one in the ultraviolet region. Water-blue $6 \mathrm{~B}$ and acid-magenta each show a large band between $275 \mathrm{~m} \mu$ and $320 \mathrm{~m} \mu$. Paris-violet and acid-violet $6 \mathrm{~B}$ possess only the absorption-band in the visible region.

The absorption spectra of the dyes derived from naphthaleneazonaphthol were also studied. These included Bordeaux B, Crystal ponceau, Bordeaux S, Coccine, Fast red. The two dyes Ponceau $R R$ and Scarlet $R$ which are derived from xyleneazonaphthol were also included in the investigation. The spectra of these dyes are similar, consisting, in general, of a broad band from the yellow to the violet. The ultraviolet is strongly absorbed and in the greater concentrations all radiations shorter than the longwave end of the visible spectrum are absorbed.

Acid magenta is quite transparent to the violet and near ultraviolet of wave-lengths longer than $320 \mathrm{~m} \mu$. For certain concentrations a sharp absorption-band is present in the region between 270 and $300 \mathrm{~m} \mu$.

Solutions of Orange I, Chrysoine, Naphthol yellow S, and Auramine $O$ were examined in concentrations $1: 10000$. Auramine $O$ is transparent more or less throughout the visible but has three bands in the ultraviolet located approximately at 265,310 , and $350 \mathrm{~m} \mu$. Naphthol-yellow S 
transmits some green and the remainder of the visible of longer wave-lengths and it has an absorption-band in the ultraviolet at about $385 \mathrm{~m} \mu$. Orange I transmits radiation of wave-lengths longer than the sodium yellow lines, $589.3 \mathrm{~m} \mu$, and has an absorption-band in the ultraviolet near $260 \mathrm{~m} \mu$. The transmission characteristic of chrysoine for the visible spectrum lies between that of Orange I and Naphthol yellow $\mathrm{S}$.

According to Massol and Faucon a solution of fluorescein exhibits three absorption-bands between 260 and $335 \mathrm{~m} \mu$ when of certain concentration and thickness; eosin, one band in the region of $335 \mathrm{~m} \mu$; and erythrosin and dichloroletraiodofluorescein (Rose bengal) each display an increasing absorption without bands. The concentration of these solutions was 1 in 10000 .

Doubtless the fastness of dyes is related more or less to their absorption of ultraviolet radiation, but the relation is perhaps more simple and dependent for dyes of similar constitution. Certainly there are dyes of considerably greater permanency which absorb more ultraviolet energy than others which bleach rapidly.

Meyer and Fischer ${ }^{24}$ have investigated the absorption in the ultraviolet region of solutions of fuchsone, benzaurin, Dobner's violet, salts of hydroxyphlenyl phthalide, dithiofluorane, the alkali salts of quinizarin and purpurin, and several triphenylmethanes.

Kruss ${ }^{25}$ investigated the ultraviolet absorption spectra of the azo-compounds, the components of the azo dyes, and the derivatives of triphenylmethane. The solvents were ethyl alcohol, water, and in some cases sulphuric acid. The colorless bases and components of the dyes exhibit marked absorption-bands in the ultraviolet but these bands differ considerably for the various groups of dyes although for a given group the bands are quite similar, differing chiefly, though slightly, in position. Apparently it is possible to determine the group to which a dye belongs 
by means of a spectrogram of its absorption spectrum. Kruss strengthened the belief that the absorption of ultraviolet radiation increases with the number of double bonds in the molecule. He also reviewed previous work pertaining to absorption spectra of organic dyes. Dhere and Rhyncki ${ }^{26}$ examined the spectra of the colorings, carotine and xanthophyll, and found that they are relatively transparent to ultraviolet radiation of longer wave-lengths than $225 \mathrm{~m} \mu$.

Bielecki and Henri ${ }^{27}$ compared the absorption spectra of three fatty acids and the esters isomeric with them. The absorption of the number of groups of isomeric esters was determined in aqueous and alcoholic solutions for various radiations. They concluded that the absorption spectra of the various acids differ from those of the esters isomeric with them and that the difference is independent of the solvent. They also concluded that the absorption of ultraviolet radiation is controlled by the molecular complexity and increases with the complexity. A study of the four isomeric esters, butyl acetate, propyl proprionate, ethyl n-butyrate, and methyl valerate indicated that their absorption spectra vary considerably and are dependent on the molecular arrangement. They also studied the absorption by fatty acids and their esters in alcoholic solutions and by sodium formate and acetate in aqueous solutions and from the results they computed the molecular absorption coefficients. Their tabulated figures show that the absorption of ultraviolet radiation is almost the same for the esters as for the acids, the absorption of a compound of this type being determined by the acid group, the alcohol radical exerting small effect. Alcoholic solutions should show greater absorption than aqueous solutions. The acids in their order of increasing absorption are acetic, propionic, formic, butyric, and valeric. It is seen that the absorption increases with the addition of $\mathrm{CH}_{2}$ to the molecule. The sodium salts which they studied exhibited less absorption than the acids themselves. 
Bielecki and Henri ${ }^{28}$ have also extended their studies from monobasic fatty acids to polybasic saturated and unsaturated acids and their corresponding hydroxy acids. They conclude as a general result of their work that the effect of different chromophores in a molecule is not additive but that the "absorption constant" is equal to the product of the "absorptive factors" corresponding to the chromophores and the " exaltation factors" which depend upon the relative position of the chromophores in the molecule. These values vary with the wave-length of radiation.

The same investigators ${ }^{29}$ determined the absolute values of the absorption of ultraviolet radiation for a number of acids containing an ethylene and from a comparison of saturated acids determined the effect of such a linking. The ethylene linking in acids increases the absorption and the effect appears to increase as the linking approaches the carboxyl group.

Bielecki and Henri ${ }^{30}$ made a quantitative investigation of the ultraviolet absorption spectra of ethyl and methyl acetoacetates, ethyl ethylacetoacetate and diethylacetoacetate, ethyl crotonate, mesityl oxide, pyruvic acid, ethyl puruvate, and ethyl laevulate. They have arrived at several conclusions from their studies of the influence of constitution on the absorption of ultraviolet radiation, especially pertaining to the effect of various groups upon the increase in absorption and the displacement of the bands.

The same investigators ${ }^{31}$ studied the absorption of acetone and of aqueous and alcoholic solutions of acetone throughout the region between $215 \mathrm{~m} \mu$ and $370 \mathrm{~m} \mu$ and determined the absorption coefficients for radiations of various wave-lengths. A single absorption-band was found in each case, the maximum being at $270.6 \mathrm{~m} \mu$ for alcoholic solutions and at $264.8 \mathrm{~m} \mu$ for aqueous solutions.

Stark ${ }^{32}$ investigated the conditions under which an inflexion occurs in a spectral absorption curve and concluded 
from the point of inflexion of the curve for acetone that it has a less intense absorption-band at about $330 \mathrm{~m} \mu$.

Bielecki and Henri ${ }^{33}$ investigated the effect of the various groups containing nitrogen in aliphatic monamines, diamines, nitriles, carbylamines, oximes, and amides on the absorption of ultraviolet radiation. The absorption constant increases with decreasing wave-length as far as $214 \mathrm{~m} \mu$.

Ley and Fisher ${ }^{34}$ studied the absorption spectra and fluorescence of the various imides. Succinimide exhibits absorption at about $400 \mathrm{~m} \mu$ and magnesium succinimide is still more transparent. The introduction of bromine into the molecule of maleinimide shifts the absorptionband toward longer wave-lengths. The presence of an amino group shifts the absorption-band toward longer wave-lengths and the addition of acid to solutions of amino-imides shifts the band toward shorter wave-lengths.

Strobble ${ }^{35}$ has shown that the red and the yellow modifications of fluorenone (diphenyleneketone) differ both in solid form and in solution. The absorption spectra of alcoholic solutions of these appear to be the same in the ultraviolet region.

According to Bielecki and Henri ${ }^{33}$ the aliphatic ketones and aldehydes possess absorption-bands at about $275 \mathrm{~m} \mu$, the position depending upon the alkyl group. It shifts toward longer wave-lengths with increase in the number of $\mathrm{CH}_{2}$ groups.

Gelbke ${ }^{36}$ studied the absorption spectra of several ketones in ethyl alcohol and water. The band of acetone whose maximum is at $268 \mathrm{~m} \mu$ shifts toward longer wavelengths when one or more hydrogen atoms is displaced by alkyl, phenol, halogen, nitroso, or carbonyl groups. Alkyl groups cause a displacement of 5 to $10 \mathrm{~m} \mu$ and the effects of the other groups are greater. The shifting of the band is attended by a broadening of the band and an increase in absorption. 
Magini ${ }^{37}$ has studied the absorption spectra of maleic and fumoric acids, asparagine, and the tartaric acids. $\mathrm{He}$ also investigated a number of aromatic compounds which exhibit strong absorption. These compounds in almost every case show distinct bands which were displaced toward longer wave-lengths when a hydroxyl group is replaced by a carboxyl or an amino group. The introduction of a second carboxyl group into the chain appears to annul the increase in absorption and displacement of the bands resulting from the first. The isomerides rank in respect to increasing absorption in the order, meta, ortho, and para, respectively.

Magini ${ }^{38}$ has compared the absorption spectra of solutions of catechol, resorcinol, and quinol. They possess sharp absorption-bands in the region between 250 and $290 \mathrm{~m} \mu$. Of the three, resorcinol exhibits the least absorption and quinol the greatest. The absorption spectra of ortho and meta compounds possess the same maxima and minima but quinol differs from its isomerides in a peculiar absorption-band beginning at $250 \mathrm{~m} \mu$.

Henri and Wurmser ${ }^{39}$ have reached an interesting conclusion regarding the correctness of the Grotthus' photochemical law of absorption, which holds that "only the rays absorbed are effective in producing chemical change." They found that the maximum decomposition of acetone and ethyl acetate corresponds spectrally to the region of maximum absorption. The absorption curve of acetaldehyde exhibits a maximum at $277.5 \mathrm{~m} \mu$, then decreases to a minimum toward shorter wave-lengths and finally increases gradually in the region of still shorter wavelengths. However, the decomposition is a maximum at $277.5 \mathrm{~m} \mu$ but it gradually decreases toward shorter wavelengths, it is slight in the extreme region, and no perceptible minimum of action is found between the maximum and the extreme region.

Gompel and Henri ${ }^{40}$ have made a quantitative investi- 
gation of the absorption of ultraviolet radiation by the three alkaloids, atropine, cocaine, and apoatropine, in alcoholic solutions. They determined the molecular constants of absorption for the maxima and the minima of the absorption spectrum. The spectrum of cocaine is quite different than that of the others. It exhibits a band at $231 \mathrm{~m} \mu$ which makes it possible to detect one part of cocaine in 200,000 of solution. One part of atropine can be detected in 2000 parts of solution and one part of apoatropine in 5000 parts of solution.

Dhere ${ }^{41}$ examined the near and middle ultraviolet spectra of various depths of solutions of some of the purine series. The spectrograms show that the extent of the absorption spectra of the purines toward the longer wavelengths increases with the amount of oxygen in the molecule. $\mathrm{He}^{42}$ also examined the absorption spectrum of adreaniline in the ultraviolet region and found it to be similar to that for cathechol but its band is located at a slightly greater wave-length than the latter. Oxidation widens the band and displaces it toward the visible region.

The absorption spectra of the purplish solutions of santonin and dihydrosantonin in alcoholic potassium hydroxide, and of hydroxysantonins in alcoholic sodium ethoxide have been shown by Mayer ${ }^{43}$ to be similar in the visible, the principal band being between 440 and $540 \mathrm{~m} \mu$. However, the slight differences are accentuated in the ultraviolet region where the spectrum of santonin differs from the other two which resemble each other.

Gibbs and Pratt ${ }^{44}$ investigated the ultraviolet absorption spectra of phenol, o-cresol, o-hydroxybenzyl alcohol, salicylic acid, and of methyl ether, of salicylic acid and methyl salicylate. They also noted the influence upon the absorption spectra of the addition of alkali. The absorption spectra of benzyl alcohol, benzyl acetate, benzyl methyl ether, benzyl chloride, and methyl benzoate were also studied and it was found that the first four exhibit the same band, lying in the same region as that of benzene. 
The same investigators also photographed the absorption spectra of o- and p-nitrophenols, and p-nitrosophenol, containing various amounts of sodium ethoxide.

Purvis ${ }^{45}$ studied the absorption spectra of alcoholic solutions of derivatives of benzoic acid to ascertain the influence of substitution in the nucleus upon the absorption, and also the effect when the nucleus and acid radical are separated by saturated and unsaturated aliphatic groups as in phenylacetic, cinnamic, mandelic, and phenylpropionic acids. He studied the following derivatives substituted in the nucleus: ortho-, meta-, and para-isomerides of toluic acid, chlorobenzoic acid, bromo benzoic acid, iodobenzoic acid, and nitro-benzoic acid. The nitro group in benzoic acid is responsible for an extended though feeble band far out in the ultraviolet region.

Purvis ${ }^{45}$ also investigated the influence upon the absorption spectra of halogen and nitrile derivatives of benzene and toluene of (1) the introduction in the benzene nucleus of the two dissimilar atoms of chlorine and bromine as in the o-, $\mathrm{m}$-, and $\mathrm{p}$-chlorobromo benzenes, as compared with the dichlor- and dibromo-benzene and with benzyl chloride; (2) the introduction of the nitrile group as in benzonitrile and the o-, m-, and p-toluonitriles, as compared wih phenylacetonitrile; and (3) by the total replacement of the hydrogen atoms in the nucleus, as in hexachlorbenzene and hexamethylbenzene or by the addition of six atoms of chlorine as in hexachlorocyclohexane.

Kober ${ }^{46}$ has found that the absorption of aliphatic amino-acids in acid or alkaline solutions is only general in the ultraviolet. The aromatic amino-acids possess absorption-bands which may aid in detecting them in peptide chains. An excess of alkali increases the absorption and shifts the bands toward longer wave-lengths. The spectra of di- and tri-peptides exhibit no peculiar absorption.

Baly and Hampson ${ }^{47}$ have determined the absorption spectra of azobenzene, aminoazobenzene, dimethylamino- 
azobenzene, and benzeneazophenyltrimethylammonium iodide.

Baly ${ }^{48}$ claims that the wave-lengths of the ultraviolet absorption-bands of phenol and aniline may be computed by using the constants which are characteristic of the infra-red spectra of benzene and water, and of benzene and ammonia, respectively. The agreement is quite satisfactory.

Baly and Tryhorn ${ }^{49}$ studied the absorption spectra of ethyl alcohol solutions of salicylaldehyde and aqueous solutions of pyridine of various concentrations. They found on increasing the quantity of solvent at first there results a shift of the absorption-band toward the visible region until a maximum wave-length is reached which depends upon the affinity between solvent and solute. Further dilution results in a shift of the band in the opposite direction until a minimum wave-length is reached.

Cain ${ }^{50}$ has shown that there is a similarity between the absorption spectra of p-benzoquinonediazide and of a-naphthalenediazonium chloride.

Ley and Hegge ${ }^{51}$ have examined the visible and ultraviolet absorption spectra of the cupric salts of the aminoacids, glycine, A- and B-alanines, piperidinacetic acid, anilonoacetic acid, aceturic acid, and a B-diaminopropionic acid.

Hantzsch and Voigt ${ }^{52}$ examined the ultraviolet absorption spectra of the nitro compounds. They concluded that the true nitro-group exhibits feeble absorption at high concentrations, 0.1 to 0.01 normal; that the simple acigroup possesses a weak general absorption; and that the introduction of further unsaturated negative groups scarcely influences the absorption of true nitro-compounds but very greatly increases the absorption of aci-nitro-compounds and makes it quite selective in character.

Garrett ${ }^{53}$ employing a quartz spectrograph and a nickel spark examined the absorption spectra of solutions of sul- 
phurous acids, sodium sulphite, ammonium sulphite, sodium metabisulphite, potassium metabisulphate, rubidium hydrogen sulphite, potassium hydrogen sulphite, acetone sodium hydrogen sulphite, and potassium sodium sulphite.

According to Stark and Levey ${ }^{54}$ the absorption spectrum of benzene displays a group of bands between 230 and $270 \mathrm{~m} \mu$ and a group of stronger bands between 190 and $210 \mathrm{~m} \mu$. Napthalene displays similar groups, the more intense one lying between 190 and $220 \mathrm{~m} \mu$ and the less intense one between 230 and $310 \mathrm{~m} \mu$. It will be noted that those of napthalene are of greater wave-lengths than those of benzene.

Wiemer ${ }^{55}$ examined the absorption spectrum of ethyl benzene between 230 and $275 \mathrm{~m} \mu$ for the vapor and for solutions in ethyl alcohol. In both cases there were series of bands diminishing with increasing wave-length. An increase in temperature broadened the bands toward longer wave-lengths without affecting the short-wave edges. The absorption spectrum of toluene appeared simliar to that of theyl benzene but the bands were slightly displaced toward the shorter wave-lengths.

Pflüger ${ }^{56}$ determined the absorption-factors of several ethereal oils and synthetic organic substances for various lines of the mercury spectrum. The substances were placed in a quartz cell and the energy was measured by means of a thermopile.

Bielecki and Henri ${ }^{57}$ determined the absorption spectra of aliphatic alcohols, acids, ketones, aldehydes, and esters. The alcohols exhibited a progressively increasing absorption from 300 to $214 \mathrm{~m} \mu$ which was augmented by the addition of $\mathrm{CH}_{2}$ groups in the molecule. Oxalic acid was found to be 30,000 times and the monobasic acids about 2000 times, more absorbing than methyl alcohol.

Rosanoff ${ }^{58}$ examined the ultraviolet absorption spectra of hydrogen peroxide and concluded that it was quite 
probable that the absorption of radiation of short wavelengths by radioactive substances is partially due to the hydrogen peroxide formed by the emanation.

Shaefer, Higgemann, and Köhler ${ }^{58}$ studied the absorption spectra of sulphurous acid and its salts and esters, sulphur dioxide, chlorous acid, and the chlorites, nitric acid, nitrates, and alkyl nitrates, and hypochlorous acids and its salts and esters. They employed a large range of concentrations.

The absorption of the halogens and their acids for ultraviolet radiation has been studied by Cohen and Stuckhardt ${ }^{60}$ using quartz, uviol glass, and ordinary glass.

Vallet ${ }^{61}$ in studying the effect of ultraviolet radiation from a quartz mercury arc on bacillus coli communis in various solutions found that ethyl alcohol, glycerol, and certain saline solutions are quite transparent to the effective radiation. However, peptone, albumen, and oil were among those liquids which were found to be quite opaque to the effective radiation which is, in general, of shorter wave-length than $300 \mathrm{~m} \mu$.

The transparency of various coloring matters in different concentrations has been studied by Miethe and Stenger ${ }^{62}$ by means of a quartz spectrograph. The region of maximum transparency of tartrazine solutions increases from $300-308 \mathrm{~m} \mu$ in the strongest solution to $280-391 \mathrm{~m} \mu$ in the weakest solution. The concentrations were varied from $1: 1000$ to $1: 20000$. For similar concentrations of filter yellow the corresponding regions are $296-308 \mathrm{~m} \mu$ and $270-500 \mathrm{~m} \mu$ respectively, and for Martius yellow 321$330 \mathrm{~m} \mu$ and $296-374 \mathrm{~m} \mu$. For a concentration of $1: 9000$ of nitrosodimethylaniline the maximum transparency is at $299-365 \mathrm{~m} \mu$ and increases only slightly with dilution. For a concentration of 1:1000 of eosin the maximum transparency is $368-390 \mathrm{~m} \mu$ and for $1: 10000$ this region increases to $271-470 \mathrm{~m} \mu$. With increasing dilution fluorescein increases in transparency down to $260 \mathrm{~m} \mu$. They also in- 
vestigated the well-known transmission-band of a silvered quartz mirror and found for exposures increasing from 5 to 640 seconds the region of transparency increased from $308-330 \mathrm{~m} \mu$ to $302-388 \mathrm{~m} \mu$. They concluded that the mirror is decidedly less suitable as a filter than the dyestuff filters.

Stumpf ${ }^{63}$ in a search for filters which transmit ultraviolet radiation examined a number of yellow dyes and found that flavazin $L$ gave the best result. It is fairly transparent between 290 and $320 \mathrm{~m} \mu$.

The absorption of ultraviolet radiation by unsaturated compounds recently has been further treated by Ley. ${ }^{64}$ This work was especially concerned with the anomalous hypochromous effects of the alkyles in the case of derivatives of styrene, stilbene, and cinnamic acid. With the introduction of alkyles into alpha-compounds one absorption band of styrene vanishes and the other is displaced toward shorter wave-lengths contrary to expectation. In beta-compounds the displacement is in the opposite direction. The work was done by the method of Hartley-Baly and iron arcs and alcoholic solutions were employed.

The effect on the ultraviolet absorption of acetone and its homologues in a solvent has been investigated by Rice. ${ }^{65}$ The results show that all the aliphatic ketones except acetone and methyl ethyl ketone follow Beer's law, the molecular extinction being independent of the concentration and of the solvent. With these exceptions there are deviations when ionizing solvents are used owing to partial disruption of the associated molecules. Kundt's rule, according to which the absorption band is displaced toward the red as the solvent increases in refractivity, holds good as a rough generalization. When a pure substance is dissolved in a solvent of ionizing type, the absorption center moves toward the ultraviolet, whereas if the substance is dissolved in a solvent of neutral, nonionizing character the absorption center either remains un- 
affected or is displaced toward the red end of the spectrum. The conclusion is drawn that this is probably a general rule valid for absorbing substances of all classes.

Orndorff, Gibbs and Scott ${ }^{66}$ found the transmission of one $\mathrm{cm}$. of absolute ethyl alcohol in the region from 240 to $370 \mathrm{~m} \mu$ to be less after boiling than before being heated. It is possible that the change in transmission is not due to any real change in absorption but to scattering produced by colloidal particles of the material of the flask or to oxidation of the alcohol.

\section{References}

I. Color and Its Applications, I92I ; J. Frank. Inst. 184, 1917, 73 and 227.

3. Trans. I. E. S., 9, 1914, 839 .

3. Phil. Mag., I7, I909, 7 I0.

4. Ann. D. Phys., 6, Igor, 4I8.

5. Proc. Roy. Soc., 57, 1894 .

6. Wied. Ann., 55, 1895 .

7. Phys. Rev., I, I893, I.

8. Ladenburg, Verh. d. Phys. Ges., I909, I9.

9. Nature, 8, July, Igro.

Io. Phil. Mag., 33, I9I 7, 450.

Ir. J. Phys. Chem., I9r4.

12. Phys. Rev., 7, I9I6, 33.

I3. Phys. Zeit., 5, 215.

14. Phys. Zeit., I, I900, I73 and 285.

I5. Trans. I. E. S., 9, I9I4, 472.

16. Atlas of Absorption Spectra.

17. Atlas of Absorption Spectra.

18. Color in Relation to Chemical Constitution, rgr8.

I9. Z. Phys. Chem., 79, I912, 357 .

20. Ber., 35, 1902, I 486 .

2I. Bul. Soc. Chem., II, I9I2, 93 I.

22. Bul. Soc. Chem., I3, I9r3, 217 .

23. Comp. Rend., I57, I913, 206, 386, 513, 700.

24. Ber. 46, 1913, 46, 70, 92. 
25. Z. Phys. Chem. 5I, 1905, 257.

26. Comp. Rend. 157, I9r3, 501.

27. Comp. Rend. I55, I9I2, I6I7; I56, I9I3, 550.

28. Ber. 46, I9I3, 2596.

29. Comp. Rend. I57, I9r $3,372$.

30. Comp. Rend. I58, I9r4, 866 and 567.

3I. Comp. Rend., I56, I9I3, 884.

32. Phys. Zeit. I4, I9r $3,845$.

33. Comp. Rend. I56, I913, I860.

34. Ber. 46, rgr 3,327 and 3627 .

35. Ber. 44, I9II, I48I.

36. J. Chem. Soc. I9r3, abs. ro4, 87.

37. J. Chem. Soc., I904, abs. 86, ro7.

38. J. Chem. Soc. I903, abs. 84, 706.

39. Comp. Rend. I56, I913, 230.

40. Comp. Rend. I56, I9I3, I 54I.

4I. Comp. Rend. I4I, I905, 7 I9.

42. Bul. Soc. Chem. I, I907, 834 .

43. Atti. Accad. Lincei, I9I4, 23, I, 422.

44. J. Chem. Soc. I9I 5, abs. I08, 500.

45. J. Chem. Soc. I07, I91 5, 966 and 496.

46. J. Biol. Chem. 22, I9I5, 433.

47. J. Chem. Soc. I07, I9r 5, 248.

48. Phil. Mag. 30, I9r 5, 510.

49. J. Chem. Soc. I07, I9I5, Ir2I.

50. Ber. 46 , rgr 3 , ror.

5I. Ber. 48, I9r $5,70$.

52. Z. Phys. Chem. 79, rgr2, 592.

53. J. Chem. Soc. 107, I915, I324.

54. J. Chem. Soc. I9r 3 , abs. 104, 366.

55. Z. Wiss. Photochem. II, I9I3, 33.

56. Phys. Zeit. I0, I909, 406.

57. Comp. Rend. I55, I912, 456.

58. J. Chem. Soc. 1912, abs. 102, 875.

59. Z. Elecktrochem. 2I, I9I5, 8I.

6o. Z. Phys. Chem. 9I, IgI6, 722.

6r. Comp. Rend. I50, Igro, 632 .

62. Zeits. Wiss. Phot. I9, I9r9, 57. 
63. Zeit. Wiss. Phot. 20, I921, I83.

64. Zeits. Wiss. Photochem. I8, I9I9, I77.

65. Am. Chem. Soc. J. 42, I920, 727.

66. Phys. Rev. I9, I922, 393.

67. Soc. Chemie Bul. 25 and 26, 1919, 585. 


\section{CHAPTER V}

\section{TRANSPARENCY OF SOLIDS}

The transparency limits and spectral transmission characteristics of various solids are important in studies and applications of ultraviolet radiation. In case a quartz or reflection-grating spectograph is unavailable, data pertaining to the media employed are useful in indicating the spectral limits of the radiation involved. Furthermore, various media provide a means of eliminating different spectral regions and thus provide a means of systematic investigation. Owing to the extensive use of glasses these are discussed separately in Chapter VI. The present chapter deals with other solids.

Although the transparency of quartz extends sufficiently into the ultraviolet region to be suitable for optical systems in the study of the near and middle regions of the ultraviolet, it was clear colorless fluorite that aided Schumann in invading the extreme region. Lyman ${ }^{1}$ found clear colorless fluorite, 1 to $2 \mathrm{~mm}$. thick, to transmit radiation of wave-lengths as short as $125 \mathrm{~m} \mu$. Specimens of fluorite vary considerably in their spectral range of transparency. Hughes ${ }^{2}$ examined thirty specimens and found only five which transmitted further into the ultraviolet than crystalline quartz. Two specimens of clear colorless fluorite showed limits at $133 \mathrm{~m} \mu$ and $170 \mathrm{~m} \mu$ respectively. This emphasizes the necessity of testing each specimen regardless of its appearance. Lyman examined specimens, 1 to $2 \mathrm{~mm}$. thick, cut from pink, green, purple, and yellow fluorite and found their transparencies to vary considerably. Of fifty-seven specimens, forty-two showed limits of transparency to be at 


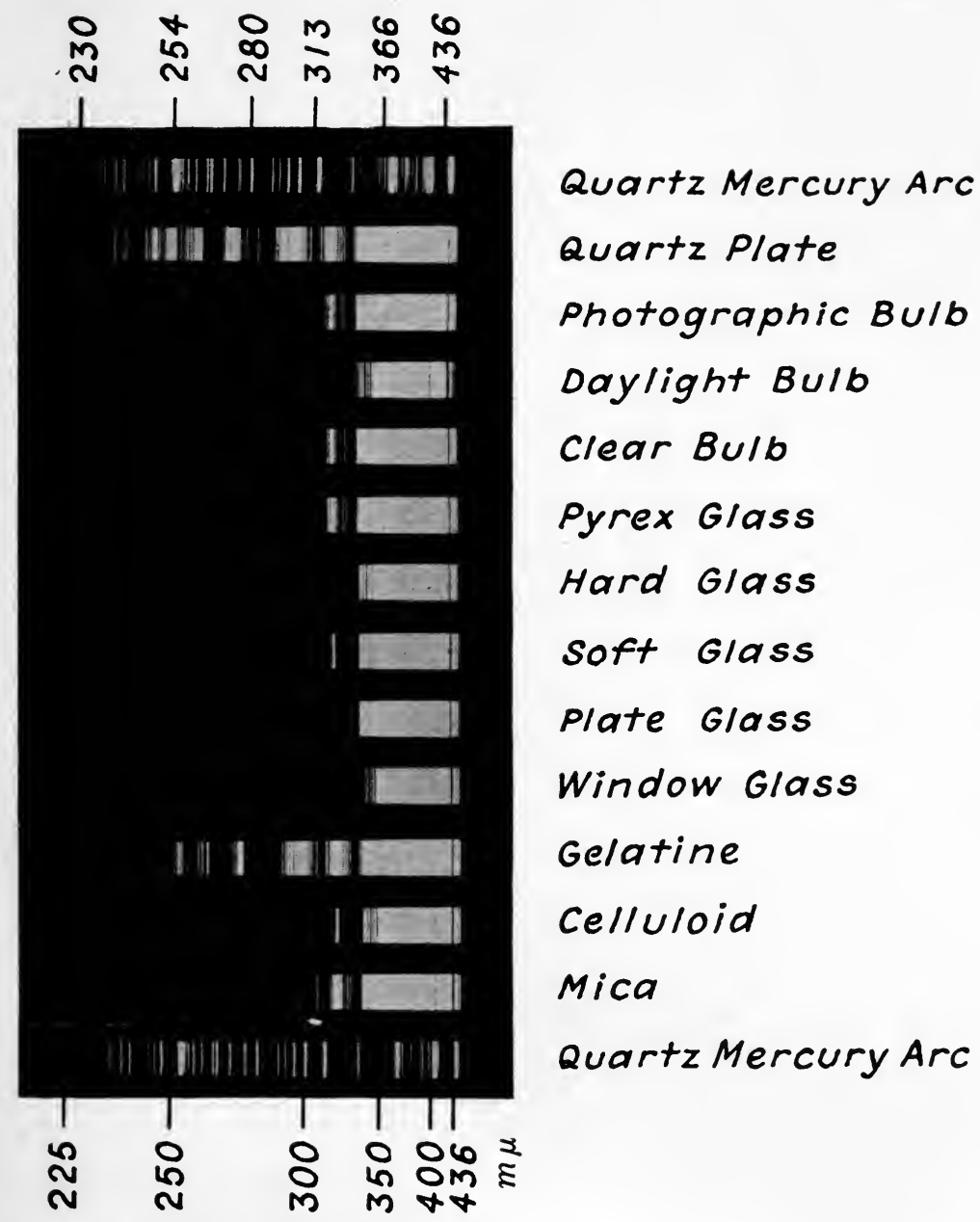

Plate II. The Transmission of various media for ultraviolet radiation from the iron arc as obtained by a quartz prism spectrograph. Spectra of the quartz mercury arc shown for comparison. 

longer wave-lengths than $170 \mathrm{~m} \mu$; ten were about equal in transparency to quartz $1 \mathrm{~mm}$. thick; and five were nearly as good as his best specimen noted above. He concluded that deep coloration was a fair indication of limited transparency but certain greenish specimens were exceptions, they being as nearly transparent as the specimen which transmitted to $125 \mathrm{~m} \mu$. By heating, the color of fluorite can be made to disappear and there is usually a consequent gain in transparency. At the present time the best specimens of fluorite are the most transparent known solids for the extreme ultraviolet.

Quartz ranks next to fluorite as a solid transparent to ultraviolet radiation. There is considerable difference between crystalline and fused quartz, the former usually being transparent further into the ultraviolet than the fused silica. The crystals vary considerably in transparency, the best specimens being transparent to radiation as short as $145 \mathrm{~m} \mu$ in wave-length. Lyman $^{3}$ found a piece of crystalline quartz $0.2 \mathrm{~mm}$. thick to transmit radiation of wave-lengths as short as $145 \mathrm{~m} \mu$. For a thickness of $2 \mathrm{~mm}$. the transparency had shrunk to $150 \mathrm{~m} \mu$ and a specimen $20 \mathrm{~mm}$. thick was opaque to radiation shorter than $160 \mathrm{~m} \mu$ in wave-length and was almost opaque to radiation between $160 \mathrm{~m} \mu$ and $200 \mathrm{~m} \mu$ in wave-length. It may be that $200 \mathrm{~m} \mu$ is the limit of transparency of quartz spectroscopes owing to the great depth of quartz through which the radiation must travel. Pflüger ${ }^{4}$ found variations in the transparency of quartz crystals and a generally lower transparency when the path of radiation was parallel to the axis than when perpendicular. For a specimen $1 \mathrm{~cm}$. thick he obtained the following values of absorption:

$$
\begin{array}{lrrr}
\text { Wave-length......186 } & 203 & 214 & 222 \mathrm{~m} \mu \\
\text { Absorption....... } 33 & 16 & 8 & 6 \text { per cent }
\end{array}
$$

Fused quartz varies widely in transparency as does the natural crystal. Hughes ${ }^{2}$ found fused quartz 0.3 to $0.4 \mathrm{~mm}$. 
thick, to transmit 24 per cent of the radiation of wavelength $185 \mathrm{~m} \mu$; 36 per cent of $197 \mathrm{~m} \mu$; and 40 per cent of $200 \mathrm{~m} \mu$. This rapid decrease in transparency indicates the reason for $185 \mathrm{~m} \mu$ being about the short-wave limit of radiation emitted by the mercury arc enclosed by a fused silica tube. The mercury line $184.9 \mathrm{~m} \mu$ can be obtained from a quartz mercury arc whose tube consists of fused silica nearly $1 \mathrm{~mm}$. thick. Pflüger ${ }^{4}$ examined specimens of fused quartz and for example, found a specimen $2.8 \mathrm{~mm}$. thick to be opaque to radiation shorter than $200 \mathrm{~m} \mu$ in wave-length.

Lyman $^{3}$ in search of material which would be transparent enough for extreme ultraviolet radiation in order that it might be used for the construction of windows for vacuum tubes, etc., examined many substances. He found borax, adularia, calcite, chrysoberyl, sanidin, arragonite, apophyllite, silver chloride (horn silver), diamond, and kunzite quite opaque to radiation of shorter wave-length than $200 \mathrm{~m} \mu$ and some of them opaque to even longer wavelengths.

Gypsum, $1 \mathrm{~mm}$. thick and bounded by cleavage surfaces transmitted radiation of wave-lengths slightly beyond $170 \mathrm{~m} \mu$.

Colemanite was opaque to radiation shorter than $175 \mathrm{~m} \mu$ in wave-length.

Sugar, $1 \mathrm{~mm}$. thick cut from "rock candy" was less transparent than colemanite.

Barite, 1 to $2 \mathrm{~mm}$. thick was opaque to radiation of wave-lengths shorter than $175 \mathrm{~m} \mu$.

Alum, $1 \mathrm{~mm}$. thick, appeared to be more transparent than barite but its spectrum also ended at about $175 \mathrm{~m} \mu$.

Celestite was transparent down to about $170 \mathrm{~m} \mu$.

Lyman found a specimen of topaz from Ceylon to possess great transparency for the extreme ultraviolet, its transparency extending to about $157 \mathrm{~m} \mu$ for a specimen $1.5 \mathrm{~mm}$. thick. He found topaz from Japan, Siberia and 
Utah much less transparent than the specimen from Ceylon but this may be due to a peculiarity of the individual specimen.

Pflüger ${ }^{4}$ found calcspar $6.1 \mathrm{~mm}$. thick to absorb as follows :

$\begin{array}{lrrrr}\text { Wave-length ...214 } & 231 & 240 & 258 & 280 \mathrm{~m} \mu \\ \text { Absorption..... } 97 & 69 & 44 & 26 & 15 \text { per cent }\end{array}$

Rock-salt possesses much higher dispersion than quartz or fluorite, therefore Pflüger recommended rock-salt prisms protected from disintegration by air by thin quartz plates cemented with glycerine. However, Lyman found rock-salt to be less transparent to the extreme ultraviolet radiation than quartz and the absorption to increase rapidly beyond $180 \mathrm{~m} \mu$. A specimen $2 \mathrm{~mm}$. thick became opaque at $177 \mathrm{~m} \mu$. Pflüger obtained the following values of absorption-factor for a thickness of $5.65 \mathrm{~mm}$. of rock salt:

$\begin{array}{lrrr}\text { Wave-length.....186 } & 210 & 231 & 280 \mathrm{~m} \mu \\ \text { Absorption...... } 30 & 23 & 14 & 4.5 \text { per cent }\end{array}$

Absalom ${ }^{5}$ determined the short-wave limit of transmission for various gems and minerals. He employed an arc between copper poles and a small quartz spectrograph. His results which apply, of course, to his particular specimens, are presented in Table XV. The wave-length values represent the wave-length in each case at which complete absorption begins; that is, they represent the short-wave limits of transparency. The natural-blue rock-salt was said to be mined at the boundary of the salt with some of the potash minerals. A piece of ordinary colorless rocksalt was colored a deep blue by cathode rays. It appeared to have about the same transparency for ultraviolet radiation as the natural-blue specimen. The color induced by cathode rays was present only at the surface. The violet specimen of Chili saltpetre, occurring naturally, can be decolorized by heat. The author ${ }^{6}$ has shown this to be 
true of the purplish tinge brought out in clear glass (containing small amounts of manganese) by the influence of ultraviolet radiation. After decolorization by heat the violet tinge can be restored to the saltpetre by exposure to cathode rays. Likewise the purplish tint can be brought out in clear glass, containing manganese in small quantities, by X-rays. ${ }^{6} \quad$ Absalom concluded that there is a strong likelihood of the coloring in many of the substances which he examined being due to colloidal metals.

\section{TABLE XV}

Short-wave Limits of Transparency of Various Substances

\begin{tabular}{|c|c|}
\hline Natural blue rock-salt. & 225 \\
\hline Rock-salt colored blue by cathode rays......... Beyond & 225 \\
\hline Sylvite, white (native potassium chloride)....... Beyond & 225 \\
\hline Sylvite, colored blue by cathode rays......... Beyond & 225 \\
\hline Fluorspar, colored violet by cathode rays........ Beyond & 225 \\
\hline 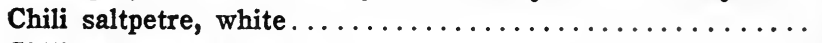 & 351 \\
\hline 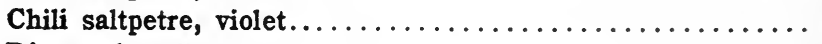 & 325 \\
\hline 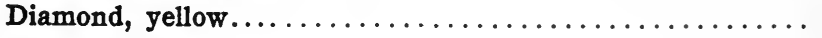 & 320 \\
\hline 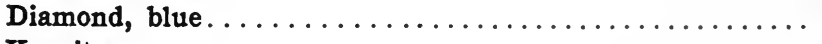 & 315 \\
\hline 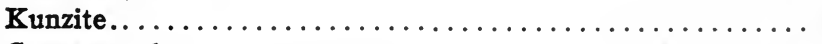 & 305 \\
\hline 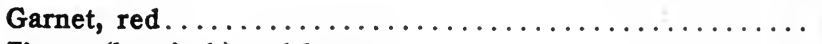 & 402 \\
\hline Zircon (hyacinth) red-brown............. & 262 \\
\hline 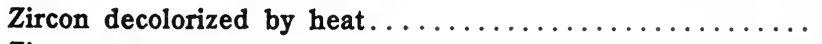 & 244 \\
\hline 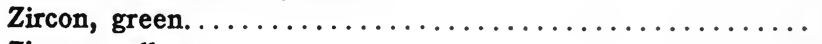 & 402 \\
\hline Zircon, yellow.................. & 402 \\
\hline 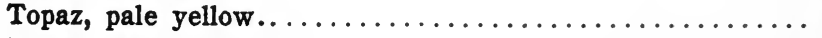 & 262 \\
\hline 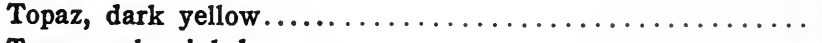 & 229 \\
\hline Topaz, pale pink-brown............... & 262 \\
\hline 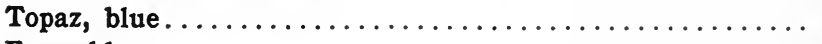 & 296 \\
\hline 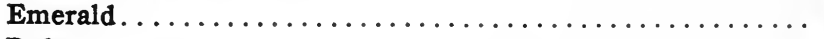 & 320 \\
\hline 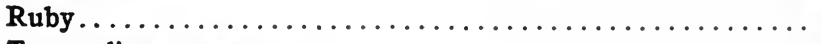 & 300 \\
\hline 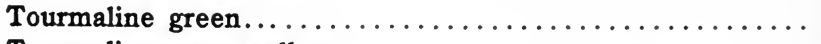 & 351 \\
\hline 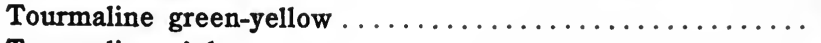 & 300 \\
\hline 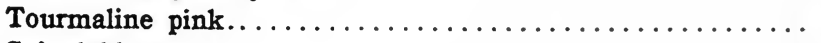 & 306 \\
\hline 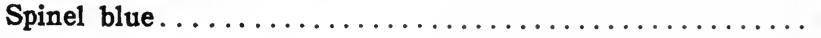 & 402 \\
\hline Spinel purple... & 325 \\
\hline$\ldots \ldots \ldots \ldots \ldots \ldots$ & 300 \\
\hline 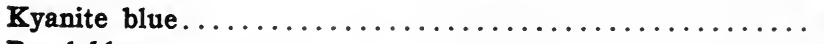 & 320 \\
\hline 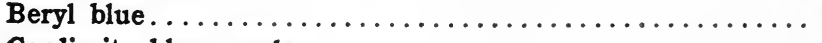 & 327 \\
\hline Cordierite blue-purple. . & 325 \\
\hline girngorm & \\
\hline
\end{tabular}


Gelatine in thin layers is quite transparent to the near and middle ultraviolet but it is quite opaque to radiation of shorter wave-lengths than $200 \mathrm{~m} \mu$. For this reason non-gelatine photographic plates must be used for photographic investigations in the extreme ultraviolet region. Gelatine filters may be made by incorporating the dye in a solution of 6 grams of gelatine to 100 grams of water heated to about $50^{\circ} \mathrm{C}$. This is flowed upon a level plate of quartz, glass, or other material, and allowed to dry. A fixed photographic plate may be dyed successfully by allowing it to soak in a dye-solution. In fact, this is usually the best way for those lacking in experience with gelatine solutions, provided the filter is to be used only in the region where glass is transparent.

A film of silver may be deposited of such thickness that it will transmit a narrow band between 310 and $330 \mathrm{~m} \mu$ and still be fairly opaque to the remainder of the ultraviolet region. Miethe and Stenger ${ }^{9}$ found for exposures increasing from 5 to 640 seconds the region of transparency increased from $308-330 \mathrm{~m} \mu$ to $302-388 \mathrm{~m} \mu$.

Dense cobalt-blue glass isolates the near ultraviolet for many photo-chemical processes such as ordinary photography. There is usually a deep red band transmitted but this can be absorbed by a solution of copper sulphate. The latter also absorbs much of the infra-red radiation. Cobalt oxide is one of the few coloring materials which does not decrease the transparency to ultraviolet radiation. In fact the author ${ }^{7}$ has shown positive evidence of its extending the limit of transparency of glass farther into the ultraviolet.

Thin sheets of "celluloid" and photographic film are transparent to the near ultraviolet but are fairly opaque beyond $300 \mathrm{~m} \mu$.

Mica varies considerably in transparency but in general it strongly absorbs ultraviolet radiation of short wavelengths. Specimens examined are similar to ordinary 
glass in spectral transmission, being quite opaque beyond $300 \mathrm{~m} \mu$. Specimens of mica can be obtained in various colors and these are in general more opaque to ultraviolet radiation than the colorless specimens.

Doelter ${ }^{8}$ has discussed the coloring matter of various minerals including precious stones.

The cornea of the human eye is opaque to radiation shorter than $295 \mathrm{~m} \mu$ in wave-length; slightly absorbing for radiation between 295 and $315 \mathrm{~m} \mu$ in wave-length; and quite transparent to radiation of longer wave-lengths between 315 and $750 \mathrm{~m} \mu$. The lens of the adult human eye is opaque to radiation shorter than $376 \mathrm{~m} \mu$ in wave-length and usually to all ultraviolet radiations. Apparently the lens of the eye of a child transmits slightly between 315 and $330 \mathrm{~m} \mu$.

\section{References}

I. Spectroscopy of the Extreme Ultraviolet, I914, 58.

2. Photo-electricity, I914, I37.

3. Astrophys. Jour. 25, 1907, 47 .

4. Phys. Zeit. 5, I904, 215.

5. Phil. Mag. 33, I9I $7,450$.

6. Luckiesh, Gen. Elec. Rev. 20, I9I7, 67r.

7. J. Frank. Inst. I86, IgI8, III.

8. Monatsh. 30, I909, I79.

9. Zeits. Wiss. Phot. I9, I9I9, 57. 


\section{CHAPTER VI}

\section{TRANSPARENCY OF GLASSES}

The many kinds of glass are so widely used that it appears of interest to discuss them in a separate chapter. In general, it may be said that what is termed "clear" glass is opaque to the middle and extreme ultraviolet. Most of them are quite transparent to the near ultraviolet to the neighborhood of about $350 \mathrm{~m} \mu$ but from this point their transparency rapidly falls off to practically zero at $300 \mathrm{~m} \mu$. A spectrogram of skylight or of sunlight taken with ordinary window glass intervening will show a shortening at the short-wave end as compared to the spectrogram taken through the open window. As has been seen in Chapter II, the short-wave limit of solar radiation is in the neighborhood of $295 \mathrm{~m} \mu$ for a point near sea-level. Ordinary window glass cannot be considered to transmit radiation of this wave-length; however, there are plenty of glasses of appreciable thicknesses whose transparency to visible radiation persists undiminished to the region of $350 \mathrm{~m} \mu$. The spectral transmission curves of "clear" glass show rather sudden changes; that is, when appreciable absorption begins it increases rapidly with wave-length. Naturally, the manufacturers of glass are reluctant to liberate data pertaining to the chemical constitution of their products. The transmission characteristics can be determined readily by means of a quartz spectrograph and other apparatus, but there usually remains an indefiniteness due to the use of trade names and other terms which do not even approximately specify the contents of the glass.

The transparency of so-called flint glasses ordinarily does not extend quite as far into the ultraviolet as that 
of crown glasses. In other words, glasses of high refractive-index are likely to be less transparent in the region of $310 \mathrm{~m} \mu$ as those of lower refractive-index. In Table XVI are found the short-wave limits of transparency (or of absorption) of certain representative clear colorless glasses $2 \mathrm{~mm}$. in thickness.

TABLE XVI

\begin{tabular}{|c|c|c|}
\hline & Refractive-index & Absorption limit \\
\hline Common glass... & $\ldots$ & $295 \mathrm{~m} \mu$ \\
\hline Light crown ........... & 1.51 & 295 \\
\hline Extra light flint. . & 1.54 & 298 \\
\hline Medium crown. . & 1.52 & 300 \\
\hline Light flint. . . . . . . . . . & 1.57 & 305 \\
\hline Medium flint............. & 1.62 & 315 \\
\hline Extra dense flint.......... & 1.69 & 335 \\
\hline Schott's heavy flint......... & $\ldots$ & 340 \\
\hline
\end{tabular}

The variation in the short-wave limit of transparency of glasses can be utilized to great advantage in controlling the spectral range of radiation in the near ultraviolet region. By means of a series of glasses such as those represented in Table XVI it is possible to explore the properties of the near ultraviolet even when the total radiation is used, that is, when no spectroscope is employed. For example, if a high intensity of the near ultraviolet radiation is desired, a quartz mercury arc, iron arc, or other source may be used with a screen of light crown glass. After noting the effect on the phenomenon under investigation, a thicker specimen or a medium crown glass may be used. Thus gradually the near ultraviolet spectrum may be shortened at the short-wave end with obvious possibilities in systematic investigation. In a manner similar to this it is possible to determine the amount of total ultraviolet energy radiated by various sources. One of 
the essentials is a screen which cuts off only the ultraviolet radiation. By comparing the energy with and without the screen the difference will yield the desired values. For this latter purpose Euphos glass has been used, and as will be seen in Table XVIII, other glasses of the proper thickness answer the purpose. The practical limit of transparency depends upon the thickness as well as upon the particular kind of glass, so that a given specimen may be ground to the thickness which suits the purpose best.

The loss by reflection of perpendicularly incident radiation at a polished surface of glass can be computed by means of Fresnel's formula

$$
R=\left[\frac{\mathrm{n}-1}{\mathrm{n}+1}\right]^{2}
$$

provided the refractive-index $\mathrm{n}$ is known. This loss is about four per cent for each surface of light crown glass and nearly seven per cent in the case of heavy flint glass. This statement pertains only to the region of normal dispersion and to yellow light. The amount of reflected radiation being dependent upon the refractive-index and the latter varying with the wave-length of radiation, it is obvious that the amount of reflected radiation depends upon the wave-length. For determining the loss by reflection for smaller angles of incidence than 90 degrees the more general formula involving the angle of incidence is used. This can be found in treatises on optics. The percentage of reflected light increases slowly with increasing angle of incidence up to 60 degrees. It then increases rapidly, becoming, of course, very great at angles of incidence near 90 degrees.

It is customary to consider that values of refractiveindex are for the $D$ lines of sodium unless otherwise stated. As an example of the variation of refractive-index with wave-length, an ordinary silicate crown glass had a refractive-index of 1.504 for $770 \mathrm{~m} \mu$ and this steadily increased to 1.56 for $276 \mathrm{~m} \mu$. 
Clear colorless glasses will transmit usually approximately 90 per cent of the perpendicularly incident visible radiation but this depends upon the refractive-index. However, it is not uncommon for glasses to show a gradual decrease in transparency from one end of the spectrum to the other. This slight selective absorption may usually be predicted by observing the color of a considerable thickness of the glass. It is not uncommon to note a decrease in transparency toward the ultraviolet. Inasmuch as these characteristics are so dependent upon the constituents of glasses and the purity of the sand, etc., it is not profitable to give much data pertaining to specific glasses. Hovestadt ${ }^{1}$ has presented many details concerning Jena glasses and Grebe ${ }^{2}$ has described the Jena " lightfilters." In recent years certain glass manufacturers of this country have given increasing attention to "optical" glasses and special glass filters.

The lead glass of which many incandescent-lamp bulbs are made is highly transparent to about $350 \mathrm{~m} \mu$ but the absorption rapidly increases from this point, becoming practically total at $300 \mathrm{~m} \mu$. A spectrogram of the near ultraviolet after passing through the "hard" glass of which some bulbs are now being made, extends slightly further into the short-wave region than the spectrogram through lead glass. The transparency of "pyrex" extends slightly further than the so-called "hard" glass, ending at a wave-length about $290 \mathrm{~m} \mu$ for a specimen a few mm. thick.

Borosilicate crown glass $2 \mathrm{~mm}$. thick is opaque beyond $297 \mathrm{~m} \mu$. A specimen of this kind of glass one $\mathrm{cm}$. thick transmitted 8 per cent at $309 \mathrm{~m} \mu$.

Common soda glass 2 to $3 \mathrm{~mm}$. thick is practically opaque beyond $330 \mathrm{~m} \mu$ but a thin layer, about $0.2 \mathrm{~mm}$. thick, sometimes transmits feebly nearly to $250 \mathrm{~m} \mu$.

$Z_{\text {schimmer }}{ }^{3}$ has published various papers pertaining to the transparency of glass for ultraviolet radiation in 
relation to chemical composition. According to him, a specimen of "uviol" glass developed by Schott (Jena) transmits 50 per cent of radiation of wave-length $305 \mathrm{~m} \mu$ when the thickness of the glass in $1 \mathrm{~cm}$. For a thickness of $1 \mathrm{~mm} .50$ per cent of radiation of wave-length $280 \mathrm{~m} \mu$ is transmitted. A specimen of " uviol " crown $2 \mathrm{~mm}$. thick transmitted as far into the ultraviolet as $280 \mathrm{~m} \mu$ and the same thickness of "uviol" flint was transparent as far as $285 \mathrm{~m} \mu$. A sheet of "uviol" glass as thin as a microscope cover-glass was transparent as far as $248 \mathrm{~m} \mu$ whereas an ordinary cover glass is opaque beyond $280 \mathrm{~m} \mu$. This glass is extremely useful and has been used considerably for cells and other parts of optical systems. It is said that photographs of stars through this glass reveal many more than through ordinary glass.

Zschimmer ${ }^{4}$ has also studied the influence of chemical constitution upon the transparency of glass to ultraviolet radiation. He states that boric oxide and silica when quite pure are transparent to radiation even shorter than $200 \mathrm{~m} \mu$ in wave-length. The addition of metallic oxides increases the absorption and decreases the spectral range of transparency. He says that sodium oxide decreases the transparency more than potassium oxide and lead oxide even more so. Lyman ${ }^{5}$ has shown that boric oxide is not as transparent as quartz in the ultraviolet for equal thicknesses.

Fritsch ${ }^{6}$ has published a recipe for a durable glass which he claims is transparent to ultraviolet radiation as far as $185 \mathrm{~m} \mu$. It specifies 6 grams of commercial calcium fluoride mixed with 14 grams of boric oxide, both in powdered form. This is melted in a platinum crucible and the liquid is poured out on an unheated sheet of platinum, taking care to avoid too rapid cooling.

Pflüger ${ }^{7}$ measured by means of a thermocouple the transparency of various glasses as far as $357 \mathrm{~m} \mu$. Kruss ${ }^{8}$ determined the spectral transmission-factors of glasses to 
about $300 \mathrm{~m} \mu$ by means of a fluorescent-screen photometer. Pfliger determined the absorption-factors of various clear glasses, $1 \mathrm{~cm}$. in thickness for the near ultraviolet. His results, presented in Table XVII, show the spectral transmission characteristics of various kinds of clear glasses. He used a thermopile in making his determinations and his original article may be of interest to some in this connection. It is apparent from these data that the heavier glasses are less transparent in the near ultraviolet region than the lighter crown glasses. A similar result is indicated in Table XVI.

\section{TABLE XVII}

Absorption-factors (in per cent) of Various Clear Glasses of $1 \mathrm{~cm}$. Thickness

\begin{tabular}{|c|c|c|c|c|c|c|}
\hline Wave-length, $\mathrm{m} \mu$ & 357 & 388 & 415 & 442 & 500 & 640 \\
\hline Borosilicate crown.... & 4.7 & 2.5 & 1.2 & & 0.7 & 0.5 \\
\hline Calcium-silicate crown.... & 3.4 & 2.5 & 1.8 & 1.4 & 0.5 & 0.3 \\
\hline Heaviest baryta crown. & 35.0 & 9.8 & 5.2 & 3.4 & 2.5 & 1.6 \\
\hline Telescope flint........ & 49.0 & 30.0 & 12.0 & 3.6 & 0.7 & 0.7 \\
\hline Baryta light flint.... & 9.0 & 6.0 & 2.7 & $\ldots$ & 1.6 & \\
\hline Baryta light flint.... & 18.0 & 8.6 & 2.5 & 2.1 & 0.9 & 0.5 \\
\hline Silicate flint....... & 28.0 & 9.6 & 4.1 & . & 0 & 0 \\
\hline Heavy silicate flint....... & 41.0 & 28.0 & 6.9 & $\ldots . .$. & 0.9 & 0.5 \\
\hline
\end{tabular}

The spectral transmission characteristics, the transmission factors and the colors of glasses are affected by temperature. A number of colored glasses have been studied by the author ${ }^{10}$ and the transmission-factors determined for the heterogeneous light from a tungsten lamp. The temperature range was $0^{\circ} \mathrm{C}$ to $350^{\circ} \mathrm{C}$. In general, the transmission-factors decreased with increase in temperature, the decrease being as great in one case (a copper red glass) as 58 per cent for the whole range in temperature. In one case the transparency increased with the 
temperature. The coloring ingredients in the glasses were copper, gold, manganese, cobalt, chromium, and others. In some cases the color-change with increasing temperature indicated a decrease in transparency to the radiation of shorter wave-lengths. In other cases the reverse was indicated. Apparently there is a shift in the absorption-band accompanying a change in temperature. Cobalt blue glasses showed little change in transparency. There is an excellent field of research open in this connection. What the influence is upon the transparency to ultraviolet radiation is unknown.

Gibson ${ }^{11}$ studied the effect of temperature upon the coefficient of absorption of certain glasses of known composition. The coloring elements in the glasses were cadmium, selenium, and uranium and the temperature range was from -180 to $430^{\circ} \mathrm{C}$. They found an enormous increase in the absorption-factor in certain parts of the spectrum as the temperature increased. In the case of selenium red glass, for example, the absorption-factor for certain wave-lengths was about 50 times greater at $430^{\circ} \mathrm{C}$ than at $-180^{\circ} \mathrm{C}$. The absorption-bands shifted toward longer wave-lengths with increasing temperature but inasmuch as the colors of their glasses ranged only from canary to red, no general conclusion can be drawn for glasses of all colors. A systematic investigation of greater extent should yield much of interest.

Apparently no studies have been made upon the effect of temperature upon the spectral transmission in the ultraviolet region. In some cases the results for the visible region encourage one to conjecture concerning the ultraviolet region but this is seldom a safe procedure, especially without a broad acquaintance with spectral characteristics.

It has been observed for years that arc-lamp globes gradually acquire a purplish tinge. This has been studied spectrally and there is no doubt that the purplish tint is 
due to manganese. ${ }^{12}$ The color is readily driven out by the application of moderate heat and inasmuch as this temperature is below that of the softening point of glass, the author has suggested that glassware which has assumed this purplish tint can be cleared up by heating in a suitable oven. The practice of introducing manganese into clear glass which is to be used outdoors merely to counteract the blue-green tint common to iron impurity in the silica is open to criticism where a slight blue-green tinge is not objectionable. The manganese increases the absorption of the glass and by counteracting the tinge due to iron, really makes a light shade of "smoke" glass.

For lighting glassware outdoors and for many skylights the almost unavoidable slight tinge of blue-green is not objectionable especially when the transparency is not only initially reduced by manganese but is decreased more and more on exposure to radiation. Some arc-lamp globes which were examined showed a reduction in transparency to 55 per cent of their initial value. ${ }^{12}$ There is strong evidence that the "bringing out" of the purplish manganese color is due to the short-wave radiation near the spectral limit of transmission of glass. For example, glass globes in which tungsten lamps have burned for years show no purplish tint but the same globes exposed to sunlight will develop the color.

Ultraviolet radiation, cathode rays, and $\mathrm{X}$-rays bring out various colors in glasses and various crystals. $F$. Giesel ${ }^{13}$ used a quartz mercury arc on various glasses. Out of eight glasses, four showed a change in color within 15 minutes which developed to deep violet in 12 hours. Giesel states that the coloring is due to manganous silicate.

Gortner ${ }^{14}$ studied the action of solar radiation on several pieces of glass and found that glass containing as much as 0.2 per cent of manganese assumed the purplish tinge of manganese in a few weeks. The depth of color- 
ing increased with the time of exposure but some pieces containing manganese did not discolor.

It appears that the development of the purplish tinge is not solely a matter of the presence of manganese but it is likely to be dependent more or less on chemical state, conditions of manufacture, or the ingredients associated in the glass. Röntgen radiation is said to cause a reducing action in some cases and ultraviolet produces its effect by oxidation. Oxides of iron, manganese, and chromium are the most common coloring elements of minerals.

Blue uviol (Jena) glass $2 \mathrm{~mm}$. thick transmits radiation as far into the ultraviolet as $285 \mathrm{~m} \mu$.

The author ${ }^{15}$ noted the interesting fact that, by the incorporation of a slight amount of cobalt into a certain glass (the constitution otherwise remaining the same), the limit of transparency was extended slightly further toward the shorter wave-lengths. Perhaps this partially accounts for the transparency of blue uviol beyond $300 \mathrm{~m} \mu$.

Didymium imparts a very complex spectral transmission curve to glass. When dense enough a didymium glass will absorb the mercury yellow lines $(578 \mathrm{~m} \mu)$ without seriously diminishing the intensity of the green line $(546 \mathrm{~m} \mu)$. Its spectral transmission curve shows many maxima and minima but the chief one is at about $580 \mathrm{~m} \mu$ and extends very markedly between 570 and $590 \mathrm{~m} \mu$.

Neodymium colors glass a purple and praseodymium imparts a greenish yellow color.

Filters for isolating the other mercury lines and for other purposes are discussed elsewhere. ${ }^{16}$

Most of the elements which impart a yellow, orange, or red color to glass effectively reduce the transparency for the near ultraviolet. An exception is gold red which in its lighter densities is a rose-purple, fairly transparent to the near ultraviolet.

Cerium in glass is of value in absorbing the ultraviolet. It imparts only a slight color. 
Chromium in glass strongly absorbs the ultraviolet. Quantities of less than 1 per cent are opaque to ultraviolet when the glass is 1 or $2 \mathrm{~mm}$. thick.

Cobalt (blue) and nickel (blue) and manganese (purple) have little or no effect in the near ultraviolet region.

Copper (blue-green) and iron (blue-green) have only a slight effect in this region.

Lead reduces the extent of the transparency of glass in the ultraviolet.

Uranium in glass in amounts of 1 to 4 per cent effectively absorbs ultraviolet radiation.

Crookes ${ }^{17}$ made and examined spectroscopically over 300 tinted glasses of known composition with the aim of producing a glass which effectively absorbed the invisible radiation at both ends of the visible spectrum. By superposing on the radiation from a Nernst lamp, the radiation from a high-tension electric discharge between poles of pure metallic uranium he claimed to have a practically continuous spectrum from $200 \mathrm{~m} \mu$ to $800 \mathrm{~m} \mu$. His specimens of glass were of the form of flat plates $2 \mathrm{~mm}$. thick. For measuring the amount of infra-red obstructed by the glass specimen he used a thermopile and a plate of biotite (black mica) which transmits nearly all the infra-red while absorbing 80 to 90 per cent of the light. A plate of dark smoky quartz accomplishes the same result as biotite but Crookes found it less easy to work with than the latter. $\mathrm{He}$ also employed a radiometer balance. A standard flux was used in all his mixtures.

He obtained glasses whose short-wave limit of transparency varied from the ordinary limit for glass to the short-wave region of the visible spectrum. Several of them absorbed nearly all the infra-red radiation from his source. They varied in transparency to light over wide limits. The commercial Crookes glass is one of the best specimens. 
The author ${ }^{16}$ has published the spectral transmission curves of many coloring media in glass. These refer only to the visible spectrum but they are often of value in considering the ultraviolet region.

There are so many commercial glasses of indefinite composition that it appears futile to present spectral data. Some data of this character is to be found in the references already given. Recently Coblentz and Emerson ${ }^{18}$ have presented spectral transmission curves for many commercial glasses, particularly for the visible and infrared regions. Gibson and McNicholas ${ }^{19}$ and also with Tyndall ${ }^{20}$ have also presented spectral data pertaining to commercial glasses. The compositions of the glasses are not given but the form of the spectral transmission curve in the case of colored glasses containing one chief coloring metal, is sufficient for one familiar with the relation of color to composition of glasses. By comparing the curves given in the papers mentioned above with the spectral curves presented elsewhere by the author, ${ }^{16}$ the principal coloring ingredients may be determined in many cases.

The spectral transmission curves of cobalt blue glasses have a sharp maximum in the violet and also a sharp rise in the deep red. Those for moderate and light densities also exhibit a characteristic secondary maximum at $560 \mathrm{~m} \mu$.

Smoke glasses contain a variety of coloring ingredients, the aim being that the combined effect is one of complete neutralization of color. This is seldom achieved because "smoke" glasses are usually bluish, reddish, or purplish. The presence of cobalt in these glasses is often distinguishable by the presence of the secondary maximum at $560 \mathrm{~m} \mu$ in the spectral transmission curve.

Uranium (fluorescent) glass often exhibits an irregular spectral transmission curve, the location and character of the maxima and minima indicating the presence of uranium in glasses of unknown composition. It com- 
monly shows an absorption-band at about $410 \mathrm{~m} \mu$ and a transmission-band at about $370 \mathrm{~m} \mu$.

The spectral transmission curves of amber glasses differ considerably in form depending upon the ingredients.

The presence of a sharp absorption-band at $580 \mathrm{~m} \mu$ and the shape of this band in the spectral transmission curves of Crookes glass indicates the presence of didymium or a near relative.

The approximate short-wave limits of transmission for a number of commercial glasses which are sufficiently standardized or described to be of value, are given in Table XVIII. The data have been obtained from various references already given.

TABLE XVIII

Approximate Short-wave Limit of Transparency of Various Glasses

\begin{tabular}{|c|c|c|}
\hline Trade Name & Thickness & Limit \\
\hline & $\mathrm{mm}$. & $\mathrm{m} \mu$ \\
\hline 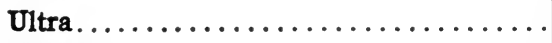 & 0.39 & 280 \\
\hline Pyrex.................... & 0.77 & 300 \\
\hline 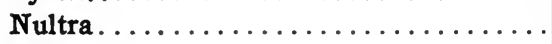 & 4.84 & 360 \\
\hline Noviol A.... & 2.00 & 410 \\
\hline Noviol B.......... & 3.22 & 440 \\
\hline Noviol $c \ldots \ldots \ldots \ldots \ldots \ldots$ & 4.23 & 460 \\
\hline 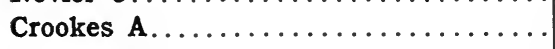 & 1.79 & 345 \\
\hline 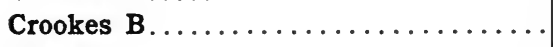 & 1.93 & 350 \\
\hline Luxfel $\ldots \ldots \ldots \ldots \ldots \ldots \ldots$ & 2.00 & 340 \\
\hline Rifleite. . . . . . . . . . & 3.14 & 475 \\
\hline 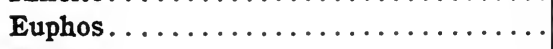 & 1.95 & 400 \\
\hline Fieuzal $\ldots \ldots \ldots \ldots \ldots \ldots \ldots \ldots$ & 2.13 & 350 \\
\hline Akopos $\ldots \ldots \ldots \ldots \ldots \ldots \ldots$ & 2.17 & 410 \\
\hline Hallauer . . . . . . . . . . . . . . & 1.90 & 410 \\
\hline 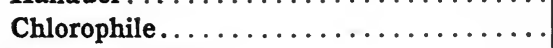 & 1.98 & 350 \\
\hline Saniweld (light) $\ldots \ldots \ldots \ldots \ldots \ldots$ & 1.82 & 500 \\
\hline
\end{tabular}


"Ultra" (Corning) glass is not appreciably colored and is fairly transparent to $300 \mathrm{~m} \mu$. A thin specimen transmits to about $260 \mathrm{~m} \mu$ but one $0.4 \mathrm{~mm}$. thick becomes opaque at $280 \mathrm{~m} \mu$. This glass transmits further into the ultraviolet than most glasses.

"Nultra" (Corning) glass is yellowish and absorbs to some extent between 500 and $400 \mathrm{~m} \mu$ but a specimen a few $\mathrm{mm}$. thick is practically opaque at the short-wave limit of the visible region; that is, at about 390 or $400 \mathrm{~m} \mu$. "Noviol" (Corning) glass is a yellowish glass which has a high transparency for the visible spectrum but absorbs the ultraviolet completely when $2 \mathrm{~mm}$. thick. It selectively absorbs blue and violet light.

Euphos glass ${ }^{21}$ quite effectively absorbs the ultraviolet radiation although in thin layers it still transmits slightly throughout the near ultraviolet.

Coblentz and Emerson ${ }^{18}$ have presented the transmission-factors of a large number of commercial glasses for the total radiation from four sources, namely, a gasfilled tungsten lamp, a quartz mercury arc, a magnetite arc, and the sun. (See Chapter VIII).

\section{References}

I. Jena glass, I902.

2. Zeit. f. Inst., 2I, I9or, Ior.

3. Zeit. f. Inst. 23, 1903, 360.

4. Zeit. f. Electrochem. II, I905, 629.

5. Astrophys. Jour. 28, 1908.

6. Phys. Zeit. 8, I907, 5 I8.

7. Phys. Zeit. 4, I903, 429.

8. Zeit. f. Inst. 23, I903, 197 and 229.

9. Ann. d. Phys. II, I903, 56r.

ro. J. Frank. Inst. 187, I919, 225; J. Amer. Cer. Soc. 2, I9I9, 743; Color and Its Applications, I92I, 396.

II. Phys. Rev. 7. I9I6, I94.

I2. Gen. Elec. Rev. 20, I9I7, 671. 
I3. Elec. I905, 1053.

I4. Amer. Chem. J. 39, I908, I57.

I5. J. Frank Inst. I86, I9I8, III; Color and Its Applications, I92I, 399.

I6. Color and Its Applications, I92I.

I7. Phil. Trans. Roy. Soc. London, 214, I9I4, I.

18. Bur. Stds. Tech. Pap. No. 93.

I9. Bur. Stds. Tech. Pap. No. Irg.

20. Bur. Stds. Tech. Pap. No. I48.

2I. Trans. I. E. S. 9, I9I4, 472. 


\section{.}




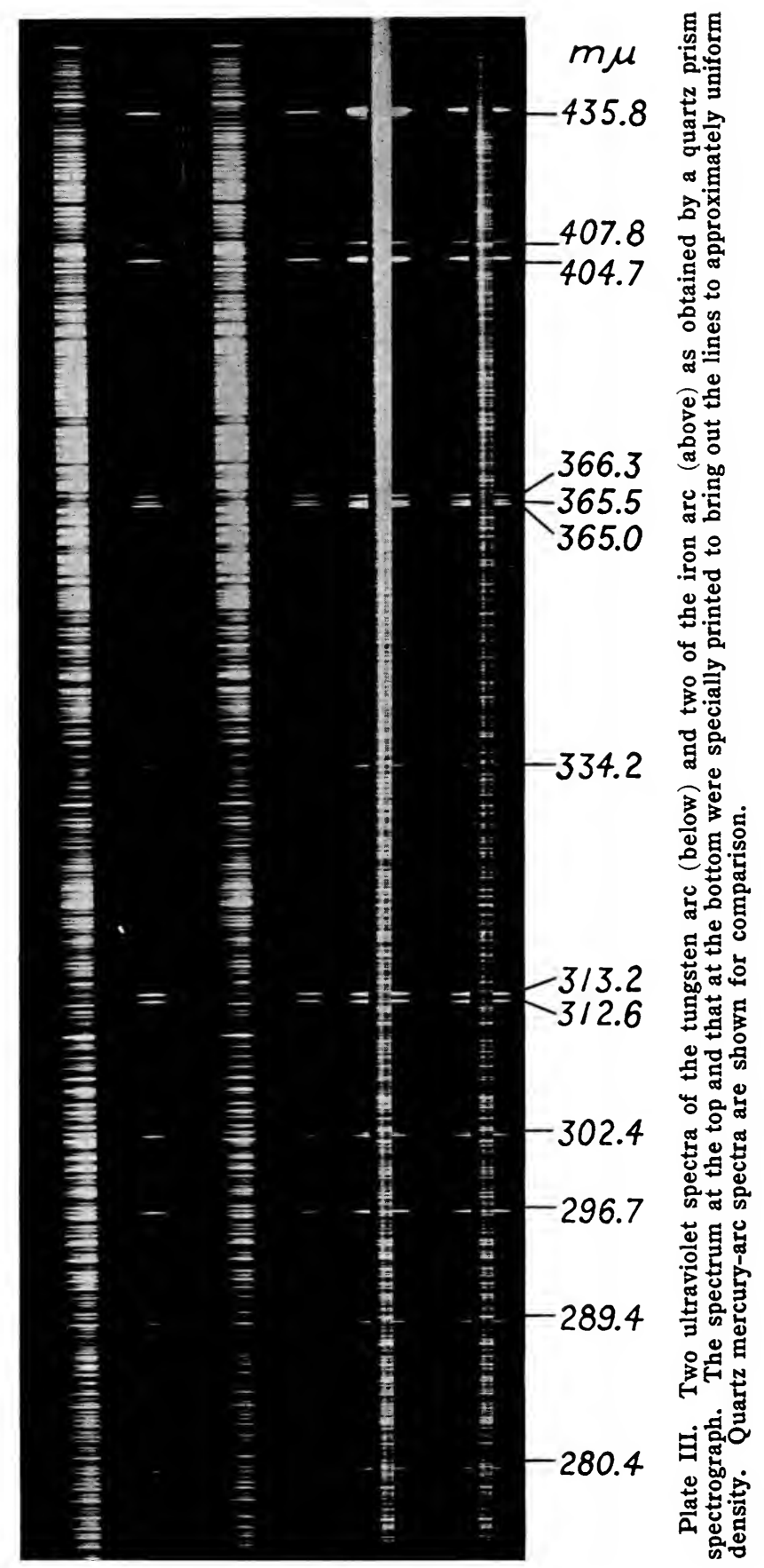




\section{CHAPTER VII}

\section{REFLECTION OF ULTRAVIOLET RADIATION}

In general, it may be said that ultraviolet radiation undergoes considerable absorption by reflection. Of course, this is to some extent true of any radiation, but substances which possess reflection-factors of high values for ultraviolet radiation do not appear to be as common as the so-called "white" substances from the viewpoint of visible radiation. Many substances reflect the near ultraviolet fairly well but the middle and extreme ultraviolet are generally absorbed to a considerable degree. Much of the ultraviolet energy is absorbed by some substances in the excitation of fluorescence.

Snow is an excellent reflector of the ultraviolet energy in solar radiation. Photographs of the spectrum of solar radiation reflected from snow show that the spectrum extends practically undiminished to $295 \mathrm{~m} \mu$ which is approximately the limit of the solar spectrum. These spectrograms indicated that the ultraviolet radiation is almost totally reflected as is the case for visible radiation. The reflection-factor of snow for visible radiation is commonly between 80 and 90 per cent. The high reflection-factor of snow for ultraviolet radiation is one factor contributing toward the development of snowblindness. The tremendous quantity of energy reflected into the eyes from an unusual angle and the relatively greater transparency of the lower eyelids are very important factors.

There are many occasions where the reflection-factors of substances should be investigated. In photography and in other photo-chemical activities at least the near 
ultraviolet must be reflected. It is common to use merely a so-called "white" pigment or other substance, however, there is a great difference in the reflectionfactors of "white" substances for ultraviolet radiation. For example, zinc white, sometimes called Chinese white, will photograph darker than some equally white substances upon which some of it has been placed. This indicates a lower reflection-factor for the radiation affecting ordinary photographic emulsions than the other white surface.

This is only one example of many, but there are so many kinds of surfaces, substances, and combinations, that it does not appear worth while to attempt to present data. It is a simple matter to determine qualitatively the spectral reflection characteristic of any surface by means of a quartz spectrograph or even two quartz lenses and a quartz prism. If the ordinary spectrograph is used it will be found advantageous to cut a hole in the side of the instrument near the point at which it makes an acute angle with the plate-holder. The surface to be investigated should be placed in the position usually occupied by the photographic plate or the fluorescent focussing screen. On looking through the hole which has been provided one sees the visible portion of the spectrum of the source and will often see the ultraviolet spectrum faintly fluorescent because most substances fluoresce at least slightly. Now if the eye is replaced by a camera at the hole, the spectrum of the source, reflected by the substance under investigation, can be photographed. By such a procedure it is almost as easy to determine qualitatively spectral reflection characteristics as it is to ascertain spectral transmission.

Hagen and Rubens ${ }^{1}$ studied the absorption of ultraviolet, visible and infra-red radiation by thin layers of metals. They ${ }^{2}$ also investigated the reflection-factors of metals. They employed a direct photometric method 
using an arc as a source and worked as far into the ultraviolet as $250 \mathrm{~m} \mu$. Some of their results are condensed in the paragraphs which follow.

Gold possesses high reflection-factors for the long-wave visible radiation but there is a minimum in the near ultraviolet between 350 and $400 \mathrm{~m} \mu$. It reflects 39 per cent of radiation of wave-length $250 \mathrm{~m} \mu$.

The reflection characteristic of copper is similar to that of gold. Its reflection-factor is about 26 per cent in the region of $250 \mathrm{~m} \mu$.

The reflection-factor of platinum is fairly high in the visible region, sloping downward toward the ultraviolet and is about 34 per cent at $250 \mathrm{~m} \mu$.

Iron and nickel appear to resemble platinum in reflection characteristics. Iron reflects 33 per cent and nickel 38 per cent of radiation of wave-length $250 \mathrm{~m} \mu$.

A new silver mirror, of course, reflects very well in the visible. Its reflection-factor was found to drop to 4 per cent at $316 \mathrm{~m} \mu$ and then to rise to about 34 per cent at $250 \mathrm{~m} \mu$.

Mach's magnalium consisting of 69 parts of aluminum and 31 parts of magnesium reflected more than 80 per cent throughout the visible and dropped only to 67 per cent at $250 \mathrm{~m} \mu$. This is an unually high reflection-factor for the middle ultraviolet. The permanence of its surface is said to be excellent.

Various alloys exhibit high reflection-factors in the visible region which generally decrease with decrease in wave-length in the ultraviolet.

Ross's alloy, consisting of 68.2 parts copper and 31.8 parts tin, reflects about 56 per cent at $400 \mathrm{~m} \mu$ and about 30 per cent at $250 \mathrm{~m} \mu$.

Brandes-Schünemann's alloy, consisting of 41 parts copper, 26 nickel, 25 tin, 8 iron, 1 antimony, reflects about 50 per cent at $400 \mathrm{~m} \mu$ and about 36 per cent at $250 \mathrm{~m} \mu$.

Schröder's alloy, 66 copper, 22 tin, and 12 zinc, reflects 
about 60 per cent at $400 \mathrm{~m} \mu$ and 40 per cent at $250 \mathrm{~m} \mu$. Another Schröder alloy, 60 copper, 30 tin, and 10 silver, has reflecting characteristics similar to the preceding one.

According to Lyman ${ }^{3}$ the Brashear alloy of which his grating was constituted and with which he did such excellent work in the extreme ultraviolet, resembles the Ross alloy in spectral reflection characteristic. He states that it appears likely that the reflection curve for Ross alloy suffers a minimum in the middle ultraviolet and then rises again in the region of extremely short wave-lengths. He sounds a caution to the effect that it is not safe to predict the behavior of metals in the Schumann region from data obtained on the less refrangible side of wavelength $250 \mathrm{~m} \mu$.

Voigt ${ }^{4}$ measured the relative phase retardation and the ratio of amplitudes of the two components vibrating at right angles to each other, involved in the polarization of radiation reflected from metallic surfaces. From these data the refractive-index, the absorption-coefficient, and the reflection-factor for normal incidence may be computed. Minor ${ }^{5}$ used such a method in studying the characteristics of metals in respect to ultraviolet radiation and obtained values of reflection-factors for radiation of various wave-lengths. For details, the reader should refer to the original paper. His computed values of reflection-factors (in per cent) for perpendicular incidence are given in Table XIX for various polished metals.

Minor's results for steel are in fair agreement with those of Hagen and Rubens. ${ }^{\circ}$ In fact, his values for the various metals agree as well as might be expected with the other data available. In general, the differences are greatest for radiation of the shorter wave-lengths. Silver shows a sharp band between $300 \mathrm{~m} \mu$ and $330 \mathrm{~m} \mu$, the minimum being at about $315 \mathrm{~m} \mu$. Minor presents in his original paper more detailed results for silver than is 
TABLE XIX

Reflection-factors of Metals (in per cent)

\begin{tabular}{|c|c|c|c|c|}
\hline $\mathbf{m} \mu$ & Steel & Cobalt & Copper & Silver \\
\hline 226.5 & 34.8 & $\ldots$ & $\ldots$ & 18.4 \\
\hline 231.3 & 35.7 & 31.8 & 29.0 & 19.9 \\
\hline 257.3 & 39.6 & 39.7 & 27.9 & 24.1 \\
\hline 298.1 & 42.6 & 46.7 & 26.4 & 15.4 \\
\hline 316.0 & $\ldots$ & $\ldots$ & $\ldots$ & 4.2 \\
\hline 325.5 & 44.8 & $\cdots$ & $\cdots$ & 8.5 \\
\hline 346.7 & $\ldots$ & 51.1 & 31.5 & 68.0 \\
\hline 361.1 & 51.2 & $\ldots$ & $\ldots$ & 77.4 \\
\hline 395.0 & 53.5 & 57.7 & 40.1 & 87.1 \\
\hline 450.0 & 55.4 & 63.3 & 50.5 & 91.7 \\
\hline 500.0 & 56.9 & 65.5 & 55.5 & 93.2 \\
\hline 550.0 & 57.7 & 66.6 & 58.4 & 94.2 \\
\hline 589.3 & 58.4 & 67.5 & 74.1 & 95.0 \\
\hline 630.0 & 59.0 & $\ldots$ & 80.5 & $\ldots$ \\
\hline
\end{tabular}

given in Table XIX. He also measured the optical constants of steel, cobalt, copper, and silver. Steel and cobalt exhibit anomalous dispersion, their dispersion curves being very similar to each other, but the refractive-index curve of steel has a weak minimum at $326 \mathrm{~m} \mu$. Copper exhibits normal dispersion but the refractiveindex changes more or less abruptly at $300 \mathrm{~m} \mu$ and at $550 \mathrm{~m} \mu$. For shorter wave-lengths than $250 \mathrm{~m} \mu$ the dispersion of copper again becomes anomalous. The dispersion of silver is anomalous between $225 \mathrm{~m} \mu$ and $280 \mathrm{~m} \mu$, normal between $280 \mathrm{~m} \mu$ and $395 \mathrm{~m} \mu$, and in the visible spectrum it becomes anomalous. According to Minor the maximum refractive-index of silver is 1.57 . (at $295 \mathrm{~m} \mu$ ) and the minimum is 0.155 (at $395 \mathrm{~m} \mu$ ). The refractiveindex of steel steadily increased from 1.3 (at $226 \mathrm{~m} \mu$ ) to 2.65 (at $630 \mathrm{~m} \mu)$. That of cobalt steadily increased from 1.1 (at $231 \mathrm{~m} \mu$ ) to 2.15 (at $590 \mathrm{~m} \mu$ ) and that of copper decreased from about 1.4 (at $235 \mathrm{~m} \mu$ ) to 0.562 (at $630 \mathrm{~m} \mu$ ). 
Meier, ${ }^{7}$ employing the same method as Voigt and Minor, investigated the optical constants of bismuth, gold, iodine, iron, mercury, nickel, platinum, selenium, zinc, and two alloys. His results compare favorably with the results of others but close agreement cannot be expected because of the very probable differences in the surfaces as to polish, etc. A summary of Meier's computations of the spectral reflection-factors for various metals is presented in Table XX. In his paper Meier compares his results with those of Rubens and Hagen, Pfliger, Shea, Kundt, and others. His values for gold are in general somewhat greater than those of Rubens and Hagen but they compare favorably in the case of nickel. The coppersilver alloy consisted of equal parts of the two constituents. The composition of Wood's alloy is not given but it will be noted that the reflection-factors for the ultraviolet are quite great. Wood's alloy is easily made of bismuth, lead, tin, and cadmium. An alloy of these metals consisting respectively of $15,8,4$ and 3 parts, melts in the neighborhood of $75^{\circ} \mathrm{C}$. Possessing as it does high reflection-factors for ultraviolet radiation, this alloy or modifications of it may be useful. The mercury as used by Meier was contained in a glass cell but corrections were applied so that the results presented are for a mercuryair surface.

Frehafer ${ }^{8}$ investigated the reflection and transmission of ultraviolet radiation by sodium and potassium for a spectral range from $250 \mathrm{~m} \mu$ to $550 \mathrm{~m} \mu$. She used the quartz mercury arc as a source and a sodium photo-electric cell as the recording apparatus. For almost normal incidence (10 deg.) the reflection-factor of sodium was high through the range studied. It was about 80 per cent from $250 \mathrm{~m} \mu$ to $400 \mathrm{~m} \mu$, then it rose to 88 per cent at $450 \mathrm{~m} \mu$, and it remained at about 92 per cent from this point to $550 \mathrm{~m} \mu$. On the other hand, the reflection-factor of potassium was about 96 per cent at $550 \mathrm{~m} \mu$ and rapidly decreased 
TABLE XX

Reflection-factors (in per cent) of Various Metals

\begin{tabular}{l|c|c|c|c|c|c|c|c|c|c}
\hline $\mathrm{m} \mu$ & Gold & Nickel & $\begin{array}{c}\text { Plati- } \\
\text { num }\end{array}$ & $\begin{array}{c}\text { Bis- } \\
\text { muth }\end{array}$ & Zinc & Iodine & $\begin{array}{c}\text { Alloy } \\
\text { cu+ag }\end{array}$ & $\begin{array}{c}\text { Wood's } \\
\text { alloy }\end{array}$ & $\begin{array}{l}\text { Mer- } \\
\text { cury }\end{array}$ & $\begin{array}{c}\text { Sele- } \\
\text { nium }\end{array}$ \\
\hline & & & & & & & & & & \\
257.3 & 27.6 & 30.7 & 37.1 & 20.1 & 20.5 & $\ldots$ & 16.2 & 52.7 & $\ldots$ & 23.3 \\
274.9 & 27.5 & 37.6 & 43.1 & 24.8 & 47.6 & $\ldots$ & 15.0 & 56.6 & $\ldots$ & 25.3 \\
298.1 & 30.4 & 39.4 & 47.6 & 31.2 & 60.2 & $\ldots$ & 19.3 & 61.1 & $\ldots . .3$ & 31.8 \\
325.5 & 35.1 & 40.4 & 48.9 & 36.0 & 68.2 & 15.0 & 27.6 & 64.9 & 65.7 & 32.5 \\
361.1 & 37.7 & 41.2 & 52.4 & 42.5 & 70.5 & 26.0 & 36.6 & 65.2 & 70.6 & 30.3 \\
398.2 & 39.4 & 50.6 & 57.5 & 46.7 & 71.6 & 30.0 & 44.0 & 68.8 & 73.1 & 30.5 \\
441.3 & 42.3 & 56.1 & 58.4 & 48.9 & 73.2 & 33.3 & 62.5 & 67.6 & 74.2 & 29.2 \\
467.8 & 43.2 & 59.6 & 58.9 & 50.8 & 74.3 & 34.2 & 68.6 & 66.1 & 74.7 & 28.4 \\
508.0 & 57.4 & 62.1 & 58.9 & 52.2 & 75.1 & 34.0 & 66.6 & 68.6 & 74.6 & 27.2 \\
589.3 & 81.5 & 65.5 & 59.0 & 54.3 & 74.5 & 30.3 & 81.3 & 70.1 & 75.3 & 25.1 \\
668.0 & 88.3 & 68.3 & 59.4 & 57.2 & 73.1 & $\ldots$ & 88.1 & 70.5 & $\ldots$ & 23.4 \\
& & & & & & & & & & \\
\hline
\end{tabular}

to about 12 per cent at $250 \mathrm{~m} \mu$. These two metals represent respectively perhaps the highest and lowest reflection-factors of any metals for ultraviolet radiation. They were studied in the form of opaque mirrors in contact with fused quartz plates. The transmission-factors of thin films of these two metals decreased steadily from $250 \mathrm{~m} \mu$ to $550 \mathrm{~m} \mu$. Frehafer also investigated the ratio of the reflection-factors (at $45 \mathrm{deg}$. incidence) for light polarized with the electric vector respectively parallel and perpendicular to the plane of incidence. This ratio was found to possess a maximum value near $334 \mathrm{~m} \mu$ for both sodium and potassium but was greater for the former.

Nutting ${ }^{9}$ determined the reflection-factors of steel, cyanine, selenium, and glass. He employed a photographic polarization photometer and sparks of aluminum, zinc, and cadmium for the ultraviolet region. Some of his results are presented in Table XXI for radiation of various wave-lengths. 
TABLE XXI

Reflection-factors (in per cent) of Various Substances

\begin{tabular}{|c|c|c|c|c|c|c|}
\hline \multirow{2}{*}{$\mathrm{m} \mu$} & \multirow{2}{*}{ Steel } & \multirow{2}{*}{ Selenium } & \multirow{2}{*}{ Cyanine } & \multicolumn{3}{|c|}{ Glass } \\
\hline & & & & A & B & C \\
\hline 257 & 33.3 & & & & 7.83 & \\
\hline 274 & 35.3 & 10.0 & 6.8 & 4.67 & 7.48 & 9.55 \\
\hline 309 & 43.0 & & 6.8 & 4.52 & 6.94 & \\
\hline 334 & 43.7 & 12.7 & 6.9 & 4.48 & 6.58 & 9.48 \\
\hline 361 & 48.8 & & 6.6 & & & \\
\hline 395 & & 15.1 & 6.7 & 4.31 & 5.86 & 9.4 \\
\hline 410 & 52.0 & & & $\ldots$ & $\ldots$ & $\ldots$ \\
\hline 430 & & 15.8 & 4.0 & $\ldots$ & $\ldots$ & $\ldots$ \\
\hline 470 & 54.0 & 16.7 & 2.0 & 4.2 & 5.6 & \\
\hline 510 & & 16.9 & 1.7 & $\ldots$ & $\ldots$ & 9.0 \\
\hline 534 & 55.4 & & & $\ldots$ & $\ldots$ & \\
\hline 550 & & 18.0 & 9.2 & & & 9.3 \\
\hline 589 & 55.9 & 18.4 & 13.3 & 4.16 & 5.37 & 9.39 \\
\hline 620 & $\ldots$ & 14.3 & 13.8 & $\ldots$ & $\ldots$ & $\ldots$ \\
\hline
\end{tabular}

The results obtained by Nutting for the steel mirror show a rapid decrease in reflection-factor for radiation of shorter wave-length than $400 \mathrm{~m} \mu$; that is, the reflectionfactor is fairly high (above 50 per cent) throughout the visible spectrum but it decreases rapidly in the ultraviolet region.

Selenium mirrors were made by fusing the element on glass and covering it with plate glass, removing the latter when cool. The data show an increase in reflectionfactor from the red to the yellow-green and a gradual drop toward the ultraviolet region.

Cyanine exhibits a strong narrow absorption-band in the yellow and therefore is an interesting substance for the study of anomalous dispersion of solids. Mirrors of it were made by casting. The data presented in Table XXI are Nutting's values for a fresh surface. The reflec- 
tion-factor rises in the red region to a maximum in the yellow. It falls to the low value of 1.26 per cent in the green $(500 \mathrm{~m} \mu)$ and then gradually increases to a nearly constant value in the ultraviolet region.

Nutting noted that exposure to radiation produces great changes in the reflection-factor and other optical constants of cyanine. Among other changes, the anomalous dispersion disappeared after the surface had been exposed for some time to radiation. This exposure did not affect the reflection-factors for ultraviolet radiation.

The glasses whose reflection-factors were determined by Nutting were "telescope crown" designated in Table $\mathrm{XXI}$ as $\mathrm{A}$; baryt-flint, $\mathrm{B}$; and $\mathrm{C}$, a glass of high refractiveindex (1.9) and low dispersion. The reflection-factors are for a single polished surface in each case.

E. O. Hulburt ${ }^{10}$ has presented data pertaining to the reflection-factors of various metals and alloys for ultraviolet radiation. He used a concave reflecting grating of speculum metal and was able to record wave-lengths from 380 to $100 \mathrm{~m} \mu$. For a source of ultraviolet radiation he employed an end-on hydrogen tube as devised by Lyman. ${ }^{3}$ The tube was of the internal capillary type equipped with a fluorite window and filled with hydrogen at about $1.5 \mathrm{~mm}$. pressure of mercury. This was excited by a 1100 -volt transformer. For measuring the radiation he used a sodium photo-electric cell connected to an electrometer.

Most of the data obtained by Hulburt are presented by him in the form of curves from which the values in the following descriptions were taken. He found that the reflection-factors for radiation of shorter wavelengths than $300 \mathrm{~m} \mu$ are rarely above 50 per cent although silicon was a noteworthy exception for it showed a reflection-factor of 76 per cent in the region from 200 to $300 \mathrm{~m} \mu$. He obtained brilliant opaque films of silicon by cathodic sputtering. In most cases he polished the 
metals with rouge and chamois. Some data pertaining to the metals studied by Hulburt are as follows:

Aluminum. - Films were made by cathodic sputtering on glass from a freshly scraped aluminum cathode in mercury vapor. The reflection-factor varied from about 70 per cent at $380 \mathrm{~m} \mu$ to about 23 per cent at $180 \mathrm{~m} \mu$.

Antimony. - A polished cathodic film showed reflection-factors varying from about 32 per cent at $380 \mathrm{~m} \mu$ to about 14 per cent at $180 \mathrm{~m} \mu$.

Bismuth. - A polished cathodic film steadily decreased in reflection-factor from about 37 per cent at $380 \mathrm{~m} \mu$ to 15 per cent at $180 \mathrm{~m} \mu$.

Cadmium. - A polished cathodic film varied in reflection-factor from about 60 per cent at $380 \mathrm{~m} \mu$ to about 20 per cent at $180 \mathrm{~m} \mu$.

Carbon. - A cathodic film showed very low reflectionfactors compared with silicon, which is its neighbor in the periodic system and which has similar electrical properties. Its reflection-factor remained practically constant at about 16 per cent down to about $210 \mathrm{~m} \mu$ and then gradually decreased to 10 per cent at $180 \mathrm{~m} \mu$.

Carborundum. - A perfect surface of a crystal showed reflection-factors increasing from about 11 per cent at $380 \mathrm{~m} \mu$ to about 20 per cent at $180 \mathrm{~m} \mu$. The curve is of the same character as that for any dielectric, such as quartz. The value of the reflection-factor indicates a very high value of refractive index.

Chromium. - Both a solid polished plate and polished cathodic films were used. The polished plate showed reflection-factors decreasing from 30 per cent at $380 \mathrm{~m} \mu$ to about 18 per cent at $320 \mathrm{~m} \mu$ then remaining at this value to about $250 \mathrm{~m} \mu$. A defined minimum of about 16 per cent was found at $240 \mathrm{~m} \mu$ and a maximum of about 23 per cent at $215 \mathrm{~m} \mu$. The reflection-factor then steadily decreased to 18 per cent at $180 \mathrm{~m} \mu$. 
Cobalt. - A polished sheet of rolled metal showed a steady decrease in reflection-factor from 55 per cent at $380 \mathrm{~m} \mu$ to about 33 per cent at $180 \mathrm{~m} \mu$. The values throughout the region studied were comparatively high.

Copper. - Both electrolytic and cathodic films were used. The former showed reflection-factors decreasing from 35 per cent at $380 \mathrm{~m} \mu$ to 25 per cent at $250 \mathrm{~m} \mu$ with a rise to 32 per cent at $210 \mathrm{~m} \mu$ and a decrease to about 20 per cent at $180 \mathrm{~m} \mu$. The cathodic film showed generally higher values throughout. The mean value was about 32 per cent from 380 to $200 \mathrm{~m} \mu$.

Gold. - Cathodic films showed a decided maximum of 35 per cent at about $300 \mathrm{~m} \mu$, the reflection-factor decreasing to 15 per cent at $180 \mathrm{~m} \mu$. A polished plate gave practically the same results as old cathodic films. Between 300 and $380 \mathrm{~m} \mu$ the reflection-factor was about 30 per cent.

Lead. - A cathodic film decreased in reflection-factor from about 42 per cent at $380 \mathrm{~m} \mu$ to about 21 per cent at $180 \mathrm{~m} \mu$.

Magnalium. - A good mirror of this alloy of aluminum (69 parts) and magnesium (31 parts) was not produced by Hulburt, but such as it was it showed a decrease from about 47 per cent at $380 \mathrm{~m} \mu$ to 9 per cent at $180 \mathrm{~m} \mu$. Hagen and Rubens obtained values from 81 to 67 per cent between 357 and $251 \mathrm{~m} \mu$ respectively.

Magnesium. - A polished mirror showed a steady decrease from 48 to 25 per cent from 380 to $220 \mathrm{~m} \mu$ respectively thence a more rapid decrease to 11 per cent at $180 \mathrm{~m} \mu$.

Molybdenum. - A polished specimen showed reflectionfactors of about 40 per cent from 380 to $300 \mathrm{~m} \mu$; thence a rapid decrease to a marked minimum of 24 per cent at $250 \mathrm{~m} \mu$. The value was about 30 per cent between 230 and $200 \mathrm{~m} \mu$ after which it again decreased.

Nickel. - A polished electrolytic film plated upon a 
cathodic film showed a decrease from 50 per cent at $380 \mathrm{~m} \mu$ to 37 per cent at $250 \mathrm{~m} \mu$, thence to a defined maximum of 46 per cent at $211 \mathrm{~m} \mu$. The reflection-factor then decreased rapidly to 30 per cent at $180 \mathrm{~m} \mu$.

Palladium. - A cathodic film showed a very gradual decrease from 30 per cent at $380 \mathrm{~m} \mu$ to about 15 per cent at $180 \mathrm{~m} \mu$.

Selenium. - A mirror was made by pouring melted selenium upon glass and removing it after it became cold. The reflection-factor decreased from 30 per cent at $380 \mathrm{~m} \mu$ to 10 per cent at $180 \mathrm{~m} \mu$.

Silicon. - A piece of silicon was ground with emery and then polished with rouge. It and other specimens showed very high values of reflection-factors, namely 60 per cent or greater throughout the whole range from 380 to $180 \mathrm{~m} \mu$.

Silver. - Two specimens showed decided minimums at about $310 \mathrm{~m} \mu$. The reflection-factor decreased rapidly from about 70 per cent at $380 \mathrm{~m} \mu$ to about 5 per cent at $310 \mathrm{~m} \mu$. The values then increased to about 33 per cent at $230 \mathrm{~m} \mu$ and then decreased to about 16 per cent at $180 \mathrm{~m} \mu$.

Speculum. - This alloy of copper (68 parts) and tin (32 parts) is used for making reflection gratings. All of Hulburt's curves showed a gradual decrease in reflection-factor with decreasing wave-length. The mirror giving the highest values varied in reflection-factor from more than 60 per cent at $380 \mathrm{~m} \mu$ to 21 per cent at $180 \mathrm{~m} \mu$. This was a freshly polished surface. Exposure to air gradually reduced the reflection-factor for all wavelengths.

Steel. - A polished piece of hardened steel showed a decrease in reflection-factor from 55 per cent at $380 \mathrm{~m} \mu$ to 17 per cent at $180 \mathrm{~m} \mu$.

Stellite. - A polished specimen of this alloy of chromium and cobalt exhibited a maximum (42 per cent) at 
$215 \mathrm{~m} \mu$ and a minimum (36 per cent) at $240 \mathrm{~m} \mu$. Chromium exhibits a similar maximum and minimum. The reflection-factors for the stellite mirror decreased from about 60 per cent at $380 \mathrm{~m} \mu$ to 30 per cent at $180 \mathrm{~m} \mu$.

Tantalum. - A polished specimen showed a gradual decrease in reflection-factor from 28 per cent at $380 \mathrm{~m} \mu$ to 12 per cent at $180 \mathrm{~m} \mu$.

Tellurium. - A polished cathodic film decreased in reflection-factor from 40 per cent at $380 \mathrm{~m} \mu$ to 23 per cent at $250 \mathrm{~m} \mu$ thence the decrease was very gradual to 20 per cent at $180 \mathrm{~m} \mu$.

Tin.-A cathodic film three days after polishing showed reflection-factors decreasing from 31 per cent at $380 \mathrm{~m} \mu$ to 7 per cent at $180 \mathrm{~m} \mu$.

Tungsten. - A polished specimen showed a reflectionfactor of about 30 per cent from 380 to $310 \mathrm{~m} \mu$. It then gradually decreased to a value of about 15 per cent at $260 \mathrm{~m} \mu$. The value then remained practically constant to $180 \mathrm{~m} \mu$.

Zinc. - A polished cathodic film showed a reflectionfactor of about 51 per cent from 380 to $300 \mathrm{~m} \mu$. It then gradually decreased to 15 per cent at $180 \mathrm{~m} \mu$.

The data obtained by Hulburt shows that throughout the region from 380 to $180 \mathrm{~m} \mu$ the reflection-factor decreased in general with decreasing wave-length and was never zero. The high reflection-factors of silicon indicate that this metal would have advantages for mirrors and gratings in ultraviolet investigations and should have other practical applications. Platinum and nickel also appear to be especially serviceable in the ultraviolet. 


\section{References}

I. Ann. d. Phys. 8, I902, I.

2. Ann. d. Phys. II, I903, 873 .

3. Astrophys. Jour. 23, I906, I8I.

4. Phys. Zeit. 2, I901, 303.

5. Ann. d. Phys. ro, 1903, 58r.

6. Zeit. f. Inst. I9, I899, 293; 22, I902, 52.

7. Ann. d. Phys. 3I, I9Io, Ior7.

8. Phys. Rev. I5, I920, Iro.

9. Phys. Rev. I6, I903, I29.

Io. Astrophys. Jour. 42, I9I 5, 205. 


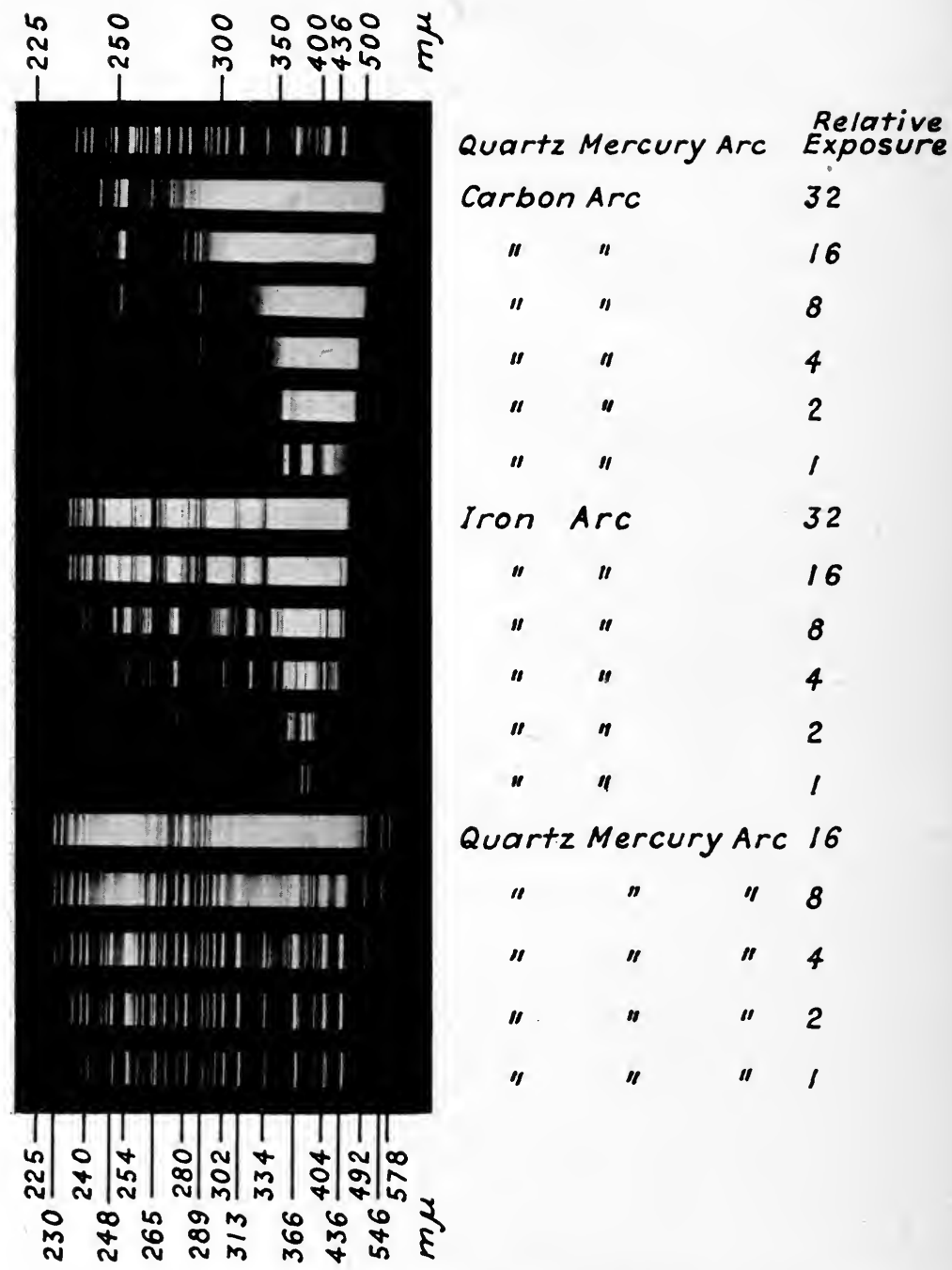

Plate IV. Ultraviolet spectra of the ordinary carbon arc, the iron arc, and the quartz mercury arc as obtained by various photographic exposures. The exposures for one radiant are not directly comparable with those of the other radiants. 


\section{CHAPTER VIII}

\section{ULTRAVIOLET RADIATION IN COMMON ILLUMINANTS}

There are many sources of ultraviolet radiation among which to choose in meeting any particular conditions; however, there are few which are powerful enough to be widely applicable to industrial arts or even to replace solar radiation in photo-chemistry. The ideal source for many purposes, especially in scientific investigation, is one emitting a continuous spectrum of high and uniform intensity but this does not exist for any large range in the ultraviolet regions. It is a common practice to use a spark which emits many spectral lines in combination with a continuous-spectrum source when absorption spectra are to be determined.

The principal sources available are discharge tubes, sparks, arcs, incandescent solids, and combinations of these. If the source must be surrounded by a container, as in the case of the discharge tube and the mercury vapor lamp, the spectral character of the radiation is immediately limited by the spectral transmission characteristic of the container. Thus glass limits the spectral range of radiation from the common mercury (glasstube) lamp and quartz does in the case of the quartz mercury lamp. The transmission- and reflection-factors of materials used in connection with sources of ultraviolet is of primary importance. Discharge tubes equipped with fluorite windows of the best quality have enabled investigators to explore the ultraviolet spectrum beyond the transparency limits of quartz and other media but fluorite becomes opaque at about $120 \mathrm{~m} \mu$. At this point it must be abandoned and the source must be placed in 
the same vessel as the photographic plate or other recording device. Even the vessel must be evacuated owing to the absorption by air.

The sun is still a much-used source of radiation when only the near ultraviolet is required. Notwithstanding its unreliability, it is depended upon for various purposes owing to the high intensity and to the relatively low cost of its radiation compared with artificial radiation for photo-chemical activities.

However its supremacy in photo-chemical arts is being seriously menaced in various quarters. In Tables XXIV and $\mathrm{XXV}$ it is seen that solar radiation is not extremely rich in ultraviolet energy as compared with artificial sources. It is its overwhelming intensity which makes sunlight relatively so effective.

Incidentally solar radiation ranks higher than any other illuminant in luminous efficiency, that is, in lumens per watt. From radiation and illumination measurements luminous efficiency may be computed. Ives, using data obtained by Kimball, ${ }^{2}$ computed the luminous efficiency of solar radiation at the earth's surface. His results are given in Table XXII.

TABLE XXII

Luminous Efficiency of Solar Radiation

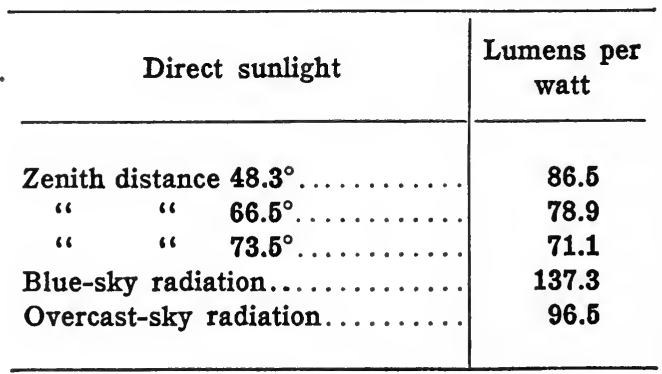

On comparing the values in Table XXII with the luminous efficiencies of artificial illuminants in Table 
$\mathrm{XXIV}$, it is seen that the latter are much smaller. The excessively high luminous efficiency of solar radiation is due primarily to the high temperature of the sun but also to the absorption of infra-red radiation by the atmosphere. This means that a great portion of solar radiation reaching the earth's surface is in the visible region.

The limelight which was produced by Drummond about a century ago was one of the earliest artificial sources of radiation which emitted an appreciable quantity of near ultraviolet energy. This consists essentially of a piece of rare-earth oxide (zirconia, etc.) in a hot flame such as oxyhydrogen. This has the advantage of burning in the air without a container and therefore has some uses in experimental work. However the Nernst glower is more convenient and usually more satisfactory.

The Nernst glower, now practically obsolete as a commercial illuminant, owes its efficiency to rare-earths and high melting-point. It has the advantage of operating in air without an enclosure. Allen ${ }^{3}$ states that its spectrum extends to $210 \mathrm{~m} \mu$ but is very faint between that wavelength and $250 \mathrm{~m} \mu$. Its greatest photographic effect (ordinary emulsions) is in the violet and blue regions.

Many of the early experiments on photo-chemistry were done with burning magnesium usually in the form of ribbon. This source finds uses even at the present time despite its inconvenience and unsteadiness. It has the advantage of requiring no equipment except a match to ignite it.

The gas-mantle, which was a great improvement in the production of artificial light, emits little ultraviolet radiation except that close to the visible spectrum. It owes its efficiency to rare-earths.

Eder ${ }^{4}$ investigated the photo-chemical intensity of some of the earlier sources. Of course, the term "chemical intensity" is very indefinite and the results depend upon the particular reaction used. In this case the action on 
silver bromide was employed as a mode of comparing the various sources. His results are presented in Table XXIII. The results with the hefner lamp, burning amyl acetate, are taken as a standard and the "relative actinism" is the ratio of the chemical effect upon silver bromide of the radiation from one source upon silver bromide to that of the hefner lamp. These data serve only to show very approximately the relative amounts of violet and ultraviolet radiation emitted in each case. In each case the source of radiation was at a distance of one meter from the silver bromide.

TABLE XXIII

Relative Effects Upon Silver Bromide

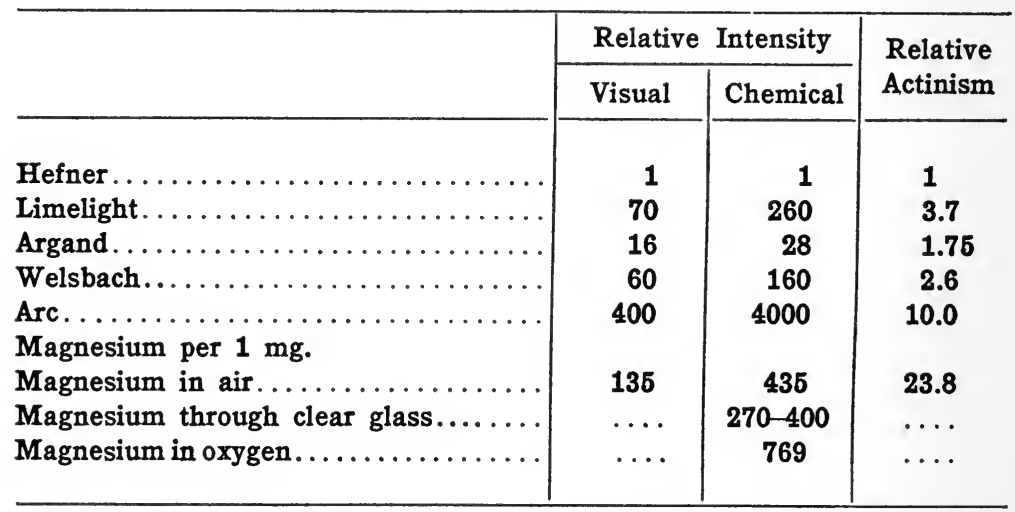

Jones, Hodgson, and Huse ${ }^{5}$ made an extensive study of the photographic efficiencies of various common illuminants. They employed the three classes of photographic emulsions, namely, ordinary, orthochromatic, and panchromatic. Some of their data are presented in Table XXIV. In the second column are the values of luminous efficiency which aids in specifying the conditions of operation of the sources. The values in the last three columns pertain to the relative photographic action per watt, the sun's action on the three emulsions being taken as 100 in 
each case. These values are based upon energy-consumption. There are many cases where it is of interest to have values upon a visual basis; that is, to know the photographic (or other action) per unit to brightness or per foot-candle. A table of these values is found in the original work but they may be obtained in any case from Table XXIV by dividing the photographic efficiency by the lumens per watt and multiplying the quotient by 150 in order to obtain values in terms of those for the sun. This procedure gives what may be termed relative actinic value per lumen.

TABLE XXIV

Relative Photographic Action Per Watt for Three Classes of Emulsions

\begin{tabular}{|c|c|c|c|c|}
\hline \multirow{2}{*}{ Source } & \multirow{2}{*}{$\begin{array}{l}\text { Lumens } \\
\text { per watt }\end{array}$} & \multicolumn{2}{|c|}{ Relative Photographic } & Efficiency \\
\hline & & Ordinary & Orthochromatic & Panchromatic \\
\hline 1. Sun........... & 150 & 100.00 & 100.00 & 100.00 \\
\hline 2. Acetylene........ & 0.7 & 0.14 & 0.21 & 0.24 \\
\hline 3. Acetylene screened & 0.07 & 0.04 & 0.04 & 0.04 \\
\hline $\begin{array}{c}\text { 4. Pentane.......... } \\
\text { Mercury arc }\end{array}$ & 0.45 & 0.05 & 0.9 & 0.13 \\
\hline 5. Fused quartz...... & 40 & 158.0 & 130.0 & 99.0 \\
\hline 6. "Nultra" glass... & 35 & 50.0 & 47.0 & 39.0 \\
\hline $\begin{array}{c}\text { 7. Crown glass........ } \\
\text { Carbon arc }\end{array}$ & 37 & 79.0 & 68.0 & 62.0 \\
\hline 8. Ordinary glass.... . & 12 & 10.0 & 9.0 & 8.5 \\
\hline 9. White flame..... & 29 & 52.0 & 45.0 & 42.0 \\
\hline 10. Enclosed........ & 9 & 11.0 & 11.0 & 10.0 \\
\hline 11. "Aristo" ....... & 12 & 62.0 & 86.0 & 60.0 \\
\hline $\begin{array}{l}\text { 12. Magnetite arc..... } \\
\text { Incandescent filament }\end{array}$ & 18 & 12.0 & 14.0 & 10.0 \\
\hline 13. Carbon. ......... & 2.44 & 0.37 & 0.52 & 0.68 \\
\hline 14. Carbon.......... & 3.16 & 0.51 & 0.74 & 0.95 \\
\hline 15. Tungsten, vacuum & 8.0 & 1.7 & 2.2 & 2.7 \\
\hline 16. Tungsten, vacuum & 9.9 & 2.4 & 3.0 & 3.5 \\
\hline 17. Tungsten, gas-filled & 16.6 & 6.1 & 6.8 & 7.7 \\
\hline 18. Tungsten, gas-filled & 21.6 & 8.9 & 9.8 & 11.0 \\
\hline 19. Mercury vapor tube & 23.0 & 47.0 & 54.0 & 42.0 \\
\hline
\end{tabular}


The plates used in obtaining the data in Table XXIV were as follows:

Ordinary. Seed 23 , chiefly sensitive from about $360 \mathrm{~m} \mu$ to about $500 \mathrm{~m} \mu$.

Orthochromatic. A special experimental plate, chiefly sensitive from about $400 \mathrm{~m} \mu$ to about $610 \mathrm{~m} \mu$.

Panchromatic. Wratten, chiefly from about $400 \mathrm{~m} \mu$ to about $720 \mathrm{~m} \mu$. The data thus gives an idea of the relative quantities of radiation of these spectral ranges emitted by these various sources.

The data in Table XXIV is very useful in judging common illuminants as to "actinic" value but the descriptive notes which follow must be considered in connection with them. In some cases it will be noted that a glass lens was interposed between the source and the photographic plates.

A few notes pertaining to the sources included in Table $\mathrm{XXIV}$ are as follows:

1. The sunlight exposures were made on a clear day between $1: 30$ and $2: 30$ p. $\mathrm{m}$.

2. The acetylene burner was standard, the flame being cylindrical.

3. The acetylene source was also screened with a blue filter that transmitted light closely approximating average daylight.

4. The pentane source was a standard Harcourt lamp adjusted according to standard specifications.

5. The quartz mercury arc operated at 220 volts and 3.4 amperes. A reflector consisting of a polished plate of black glass $2 \mathrm{~cm}$. thick was employed, it being assumed that the reflection from the surface was non-selective. The intensity was reduced by a pair of quartz lenses.

6. This source was also screened with a piece of heavy lead glass $4 \mathrm{~mm}$. thick, known as "Nultra"; 
It was quite colorless and had a transmissionfactor of about 90 per cent for the visible rays.

7. Conditions were the same as in 6 except that one of the quartz lenses was replaced by one of clear crown glass.

8. The carbon arc was an automatic-feed type with carbons at right-angles. It operated at 110 volts d. c. and 6 amperes with a 60-volt drop across the arc. The positive carbon was $6 \mathrm{~mm}$. in diameter and cored. The intensity was reduced by glass lenses.

9. The white flame arc operated at 115 volts d. c. and 24 to 26 amperes with an 85-volt drop across the arc. The lower white flame carbon was $10 \mathrm{~mm}$. and positive; the upper carbon was $13 \mathrm{~mm}$. and cored. The flame was 2.5 to $3 \mathrm{~cm}$. long. The intensity was reduced by means of one quartz and one crown glass lens.

10. The enclosed arc was enclosed by a glass cylinder with close-fitting metal ends. The carbons were of ordinary cored type, at right angles, and the positive crater was fully exposed to the photographic plate. It operated at 110 volts d. c. and 8 amperes with a 65-volt drop across the arc.

11. The "Aristo" was an enclosed arc with vertical carbons the positive being above. It operated at 220 volts and 16 amperes. The length of the arc was about $2.5 \mathrm{~cm}$.

12. The magnetite arc was of the commercial type. It operated at 110 volts d. c. and 4 amperes. Its intensity was reduced by glass lenses.

19. The mercury vapor arc was in a glass tube $45 \mathrm{~cm}$. long and $2.8 \mathrm{~cm}$. in diameter. It operated at 115 volts d. c. and 3.5 amperes, the actual drop across the tube being 3.5 amperes. Radiation from a section of the tube $2 \mathrm{~cm}$. long in the middle of the length was tested. 
The values in the table for tungsten lamps are applicable only to those particular lamps. The operating efficiencies of incandescent lamps are gradually increasing and they are determined by lighting considerations. The economic factors of photo-chemical arts are quite different. For example, in ordinary photography the exposure is usually short and the operating temperature of the filament of a tungsten lamp used for this purpose can be considerably above the normal for ordinary lighting without introducing a prohibitive expense due to the short life of the lamps. A blue-glass bulb was developed by the author several years ago in order to have a photographic incandescent lamp of high actinic value per lumen for such fields as portraiture. For the same filament-temperature its actinic value per watt is about the same as a clearglass lamp of the same size and its actinic value per lumen is about three times as great. These values are based upon the ordinary photographic plate. However, this tungsten photographic lamp is designed to operate at a higher filament-temperature than a clear-glass lamp of the same size and therefore is more powerful photographically. The values for the blue-bulb photographic tungsten lamp presented by Jones, Hodgson, and Huse are very obviously not for the standardized blue-bulb photographic lamp and not for the proper operating conditions. This lamp is useful in many cases where only a moderate amount of near ultraviolet radiation is required.

The radiation of short wave-lengths from a tungsten filament increases in quantity much more rapidly with increase in filament-temperature than the radiation of long wave-lengths. For this reason it is sometimes well to operate the tungsten lamp at voltages considerably above normal. It has been found ${ }^{6}$ that, for an ordinary photographic plate (Seed 23) and a 1000-watt gas-filled tungsten lamp operating at 18 lumens per watt, an increase of 17 per cent in voltage above normal doubles the photo- 
graphic action. In other words, for the ordinary plate an increase in voltage from 115 to 135 volts reduced the wattage to one-half in order to obtain the same photographic action. For an increase of 17 per cent in voltage the photographic action on an orthochromatic plate increased 67 per cent.

The extent of the spectra of some common illuminants and a brief discussion of them has been presented elsewhere by the author. ${ }^{7}$ Spectral transmission-curves are also given for lead and for "Euphos" glasses. The spectra presented are for a mercury arc (glass tube) skylight, a tungsten (vacuum) lamp, a quartz mercury arc, a yellow flame arc (opal glass), a carbon arc (bare) and a carbon arc (clear glass).

The magnetite arc exhibits a spectrum of titanium and iron which is extremely rich in lines throughout the near ultraviolet region and down to $230 \mathrm{~m} \mu$. It is especially rich between 330 and $290 \mathrm{~m} \mu$, a region of particular interest owing to the fact that this is the region where the solar spectrum ends.

Bell ${ }^{8}$ has presented data pertaining to the ultraviolet energy in artificial light-sources. He used a Rubens thermopile to receive the radiation from the source. This was connected with a sensitive galvanometer and the radiation from a standard carbon incandescent lamp was used as a standard. It was found that $1 \mathrm{~mm}$. on the galvanometer-scale equalled 35.3 ergs per second per square centimeter at the thermopile. He used a quartz cell containing a thickness of $1 \mathrm{~cm}$. of distilled water. The quartz and distilled water are transparent to ultraviolet, visible, and infra-red radiation from about 120 to $1300 \mathrm{~m} \mu$. The ultraviolet radiation was separated from the remainder by using a piece of "Euphos" glass of proper thickness and quality. The procedure was to measure the quantities of radiation reaching the thermopile through the cell, with and without the Euphos in the path. Bell's 


\section{TABLE XXV}

Ultraviolet Radiation from Various Sources

\begin{tabular}{|c|c|c|c|}
\hline & $\begin{array}{l}\text { Deflections } \\
\text { due to ultra- } \\
\text { violet (cm.) }\end{array}$ & $\begin{array}{l}\text { Total ultra- } \\
\text { violet ergs } \\
\text { per sec. per } \\
\text { sq. cm. }\end{array}$ & $\begin{array}{l}\text { Ultraviolet } \\
\text { ergs per sec. } \\
\text { per sq. cm. } \\
\text { per ft-cand. }\end{array}$ \\
\hline- & & & , \\
\hline Quartz Hg. arc, opal glass. & 3.70 & 1305 & 4.3 \\
\hline 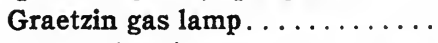 & 0.92 & $\ldots$ & 11.7 \\
\hline Carbon (gem) filament, 100-watt & 0.61 & 215 & 14.8 \\
\hline Cooper Hewitt Hg. tube, glass... & 1.64 & 577 & 15.5 \\
\hline Sunlight direct............ & 2.28 & $\ldots$ & 16.1 \\
\hline Acetylene flame........... & 0.52 & $\ldots$ & 18.4 \\
\hline Tungsten, vacuum, 100-watt.... & 1.90 & 670 & 22.7 \\
\hline Nernst lamp, glass globe..... & 1.81 & 640 & 25.5 \\
\hline Magnetite arc, glass......... & 22.40 & 7900 & 30.3 \\
\hline Magnetite arc, quartz......... & 29.00 & 10240 & 36.3 \\
\hline Quartz Hg. Arc, bare, old.... & 16.77 & 5920 & 38.3 \\
\hline Quartz Hg. arc, bare, new.... . & 32.10 & 11350 & 87.6 \\
\hline Carbon arc, quartz.......... & 74.00 & 26200 & 91.0 \\
\hline
\end{tabular}

results are presented in Table XXV. In the second column are given the galvanometer deflections due to the ultraviolet radiations. These are given in centimeters so that these values must be multiplied by 353 to give the actual ergs per second per square centimeter due to ultraviolet radiation from the various sources. The energy values are found in the third column and afford a direct comparison of the relative amounts of ultraviolet energy supplied by the various sources. They represent the absolute amounts of energy received per second per square centimeter at a distance of $50 \mathrm{~cm}$. from the sources. In the last column are the amounts of ultraviolet energy accompanying the energy necessary to be appraised visually as one foot-candle.

It is interesting to note the decrease in output of ultraviolet radiation as the age of a quartz mercury arc increases. This perhaps has been noted by those who 


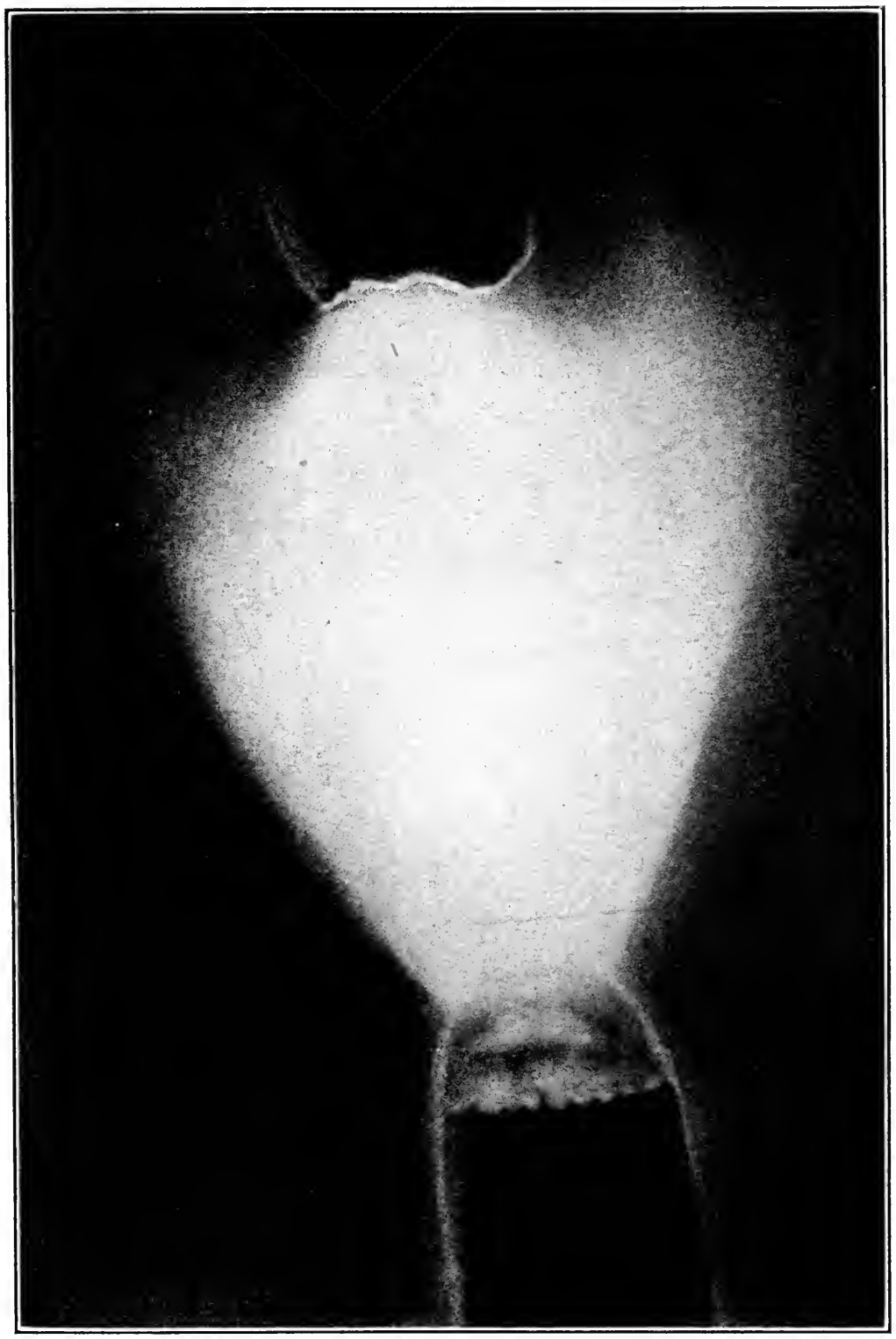

Plate V. The white flame arc - a powerful source of "near" ultraviolet radiation approximating solar radiation in many of its effects. 


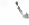

1
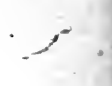

. 18 
have employed the quartz arc for its ultraviolet energy. Bell's data indicate a very great difference between the old and the new quartz mercury arcs which he examined. The new one emitted more than twice the amount of ultraviolet emitted by the old one notwithstanding they were rated equally in watts. The magnetite arc was of commercial type and it emitted as much ultraviolet radiation as the new quartz mercury arc. The electrical input was perhaps about the same in the two cases. The carbon arc was of the enclosed type operating at 6.6 amperes d. c. A quartz window was placed in the globe and it was found that 30 per cent of the energy emitted through the quartz window was cut off by the Euphos glass. There are powerful bands in its spectrum between 350 and $360 \mathrm{~m} \mu$ and between 380 and $390 \mathrm{~m} \mu$. A comparatively small change in the output is effected by interposing clear glass.

Verhoeff and $\mathrm{Bell}^{\circ}$ have made an extensive investigation of the pathological effects of radiant energy and the eye. This will be discussed in a later chapter. The data in Table XXVI is taken from this work and it may help to convey an idea of the absorption of various media. The transmission-factors of the various media are for radiation from a commercial magnetite arc. They found that this arc operating at 9 amperes and 750 watts provided at a distance of $50 \mathrm{~cm}$. an intensity of ultraviolet energy shorter than $390 \mathrm{~m} \mu$ in wave-length, equal to 15000 ergs per second per sq. $\mathrm{cm}$. of which about 3500 ergs was of shorter wave-length than $300 \mathrm{~m} \mu$ as against 57.00 ergs per second per sq. $\mathrm{cm}$. for the quartz mercury arc at the same distance in the same spectral region.

The transmission-factors for the total radiation from four common light-sources have been determined by Coblentz and Emerson ${ }^{10}$ for a large number of commercial glasses. A few of these are presented in Table XXVII. Presumably the three artificial light-sources were operated 


\section{TABLE XXVI}

Transmission-factors for Radiation from a Magnetite Arc

Filter

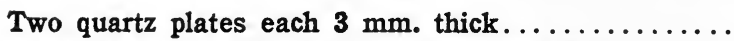

Same plus $5 \mathrm{~cm}$. distilled water (water-cell).........

Water-cell and dense flint glass (limit $335 \mathrm{~m} \mu$ )......

Water-cell and medium flint glass (limit $315 \mathrm{~m} \mu$ )....

Water-cell and light flint glass (limit $305 \mathrm{~m} \mu$ ).......

Water-cell and crown glass (limit $295 \mathrm{~m} \mu) . \ldots \ldots \ldots$

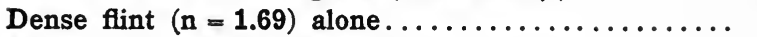

Medium flint $(n=1.63)$ alone.............. 45

Light flint $(n=1.57)$ alone $\ldots \ldots \ldots \ldots \ldots \ldots \ldots, 40$

Crown $(n=1.51)$ alone.................. 43

at their commercial ratings. The quartz mercury arcs were new. The tungsten lamp was a 500-watt gas-filled stereopticon lamp.

There are various types of mercury arcs available but they may be divided into two chief classes - those with glass-tubes and those with quartz-tubes. The glass-tube mercury arc or a quartz mercury arc equipped with a glass globe, emits ultraviolet radiation in the near region, that is, of wave-lengths longer than about $300 \mathrm{~m} \mu$. The quartz arcs emit in general the near and middle ultraviolet. They are made in large sizes and also in various "concentrated" forms but their radiation does not differ materially.

The spectrum of the quartz mercury arc has many powerful lines but also a number of gaps. Between the powerful group of lines at $365 \mathrm{~m} \mu$ and the double line at $313 \mathrm{~m} \mu$ there is only one strong group and that is at $334 \mathrm{~m} \mu$. A gap exists between $313 \mathrm{~m} \mu$ and a group at $302.5 \mathrm{~m} \mu$ and another between the latter and $297 \mathrm{~m} \mu$.

The output of mercury arcs operating at high temperatures as is the case of the quartz arc diminishes considerably as the lamps age. It has been found that the ultraviolet spectrum of the quartz mercury arc diminishes in intensity as the lamp ages, especially for radia- 
TABLE XXVII

Transmission-factors of Various Media for Radiation from Four Different Sources

\begin{tabular}{|c|c|c|c|c|c|}
\hline \multirow[b]{2}{*}{ Medium } & \multirow{2}{*}{$\begin{array}{l}\text { Thickness } \\
\text { in } \mathrm{mm} \text {. }\end{array}$} & \multicolumn{4}{|c|}{ Transmission-Factor } \\
\hline & & $\begin{array}{c}\text { Tungsten } \\
\text { lamp }\end{array}$ & $\begin{array}{l}\text { Quartz } \\
\text { Hg. Arc }\end{array}$ & $\begin{array}{c}\text { Magnetite } \\
\text { Arc }\end{array}$ & Sun \\
\hline Freuzal B, green-yellow... & 2.04 & 71.6 & 26.9 & 46.0 & 63 \\
\hline Euphos B, green-yellow.. . & 3.12 & 78.8 & 24.7 & 53.0 & 64 \\
\hline Akopos, green-yellow..... & 1.58 & 84.6 & 29.5 & 59.0 & 74 \\
\hline Noviweld 6, green-yellow & 2.17 & 0.9 & 0.4 & 0.2 & 0.9 \\
\hline Saniweld, dark, amber... & 1.32 & 78.1 & 10.6 & 43 & 60 \\
\hline Noviol B, yellow........ & 2.88 & 74.1 & 32.2 & 56 & 75 \\
\hline Crookes A, neutral...... & 1.97 & 85.3 & 46.1 & $\ldots$ & 89 \\
\hline Crookes B, neutral...... & 2.00 & 75.7 & 32.0 & 64 & 69 \\
\hline Gold plate, film......... & $\ldots$ & 2.6 & 7.2 & 1.2 & 12 \\
\hline Selenium, red,........ & 2.90 & 67.8 & 7.9 & 48 & 48 \\
\hline Window glass, clear. ..... & 1.85 & $\ldots \ldots$ & 59.6 & $\cdots$ & 82 \\
\hline Crown glass........... & 1.56 & & 64.9 & $\cdots$ & 92 \\
\hline Mica, brown . ......... & 1.30 & $\ldots \ldots$ & 35.4 & $\ldots$ & ... \\
\hline Mica, colorless ......... & 0.09 & $\ldots \ldots$ & 43.1 & $\cdots$ & $\ldots$ \\
\hline Water, clear........... & 10.00 & 34.2 & $\cdots$ & $\cdots$ & $\cdots$ \\
\hline Clear water (glass cell)... & 10.00 & & 56.0 & & $\ldots$ \\
\hline Clear water (quartz cell).. & 10.00 & $\ldots \ldots$ & 83.0 & $\ldots$ & 76 \\
\hline
\end{tabular}

tion shorter than $254 \mathrm{~m} \mu$. It has been suggested that this decrease may be due to the greyish deposit on the walls of the tube or that the composition of the gas undergoes change. It may be well to try cooling the quartz tube in an attempt to preserve the constancy of the output of ultraviolet radiation. This decrease in ultraviolet intensity with age has been verified by physical, chemical, and biological tests.

It has been stated that the average life of the 220-volt quartz mercury arc is between 2500 and 3000 hours and that the tubes can be re-exhausted about three times.

A great deal of work has been done in investigating 
the spectrum of mercury. Huff ${ }^{11}$ has discussed the spectra of mercury as obtained from mercury arcs in air and in tubes and also in the spark. He found that by increasing the capacity in the secondary of a coil giving an alternating current discharge, the spectrum changed from that of the arc to one containing the characteristic lines of the spark. The introduction of self-induction in the secondary of such a coil tends to reduce the spectrum of the spark to that of the arc. The arc in this case consisted chiefly of a hollow carbon rod filled with mercury. He found the arc-spectrum obtained in this manner to extend into the short-wave region as far as $187 \mathrm{~m} \mu$ when photographed for one hour by means of a large grating spectrograph.

Arons ${ }^{12}$ gives a list of the more intense lines of the quartz mercury arc. There are a large number of lines emitted from the arc in a quartz tube, extending from $230 \mathrm{~m} \mu$ to $579 \mathrm{~m} \mu$. Line $254 \mathrm{~m} \mu$ is very intense and, according to Hughes, is well situated so as to be very effective in producing photo-electrons from most metals. There are a number of weak lines between $185 \mathrm{~m} \mu$ and $200 \mathrm{~m} \mu$. These do not appear strong on a photographic plate but they are quite active photo-electrically. The quartz mercury arc emits lines of still shorter wave-length which are absorbed by the fused quartz tube.

Hughes ${ }^{13}$ placed a mercury arc and a metal plate in the same vacuum. By assuming Ladenburg's law - the velocity of emitted photo-electrons increases with decreasing wave-length and is proportional to the frequency of the exciting radiation - Hughes concluded that the mercury spectrum extends to $123 \mathrm{~m} \mu$ but the radiation is weak between $145 \mathrm{~m} \mu$ and $178 \mathrm{~m} \mu$. He showed that the mercury arc in a fused-quartz tube whose walls were 0.5 to $1 \mathrm{~mm}$. thick, emitted radiation as short as $184.9 \mathrm{~m} \mu$ in wavelength. Lyman observed line $177.5 \mathrm{~m} \mu$ from a fused quartz arc. 
Anthracene is photo-electrically active under the radiation from a quartz mercury arc but it is not photo-electric to radiation greater than $220 \mathrm{~m} \mu$ in wave-length. Therefore radiation of shorter wave-length than $220 \mathrm{~m} \mu$ is transmitted by the fused-quartz tube. The transparency of air must be reckoned with in this region of the spectrum. For example, the mercury line, $184.96 \mathrm{~m} \mu$, will be quite effective when the air-path is short but will be feeble or may be completely absorbed if the air-path is long. Thus the transparency of fused quartz, and finally of air, limits the extent of the spectrum of the quartz mercury arc under ordinary conditions. Inasmuch as there is a gap in the spectrum of the mercury arc between $190 \mathrm{~m} \mu$ and a point near $185 \mathrm{~m} \mu$, the former wave-length is likely to be the limit of the spectrum under most conditions. Considering the diminution of the ultraviolet spectrum due to aging of the quartz mercury arc it seems reasonable to set $200 \mathrm{~m} \mu$ as the usual limit of the spectrum of the quartz mercury arc. Of course the limit of the glass-tube mercury arc is determined by the glass and, therefore, the limit of the spectrum of the glass mercury tube is near $300 \mathrm{~m} \mu$.

Hallwach ${ }^{14}$ measured the energy of the various mercury lines by a thermo-electric method and obtained the relative values in Table XXVIII. For the sake of future reference his values of relative photo-electric activity of these lines for potassium are also included.

The relative values in Table XXVIII are referred to those for $436 \mathrm{~m} \mu$ in each case. Of course, the relative intensities of the various lines vary considerably depending upon various factors, but those in this table give an

TABLE XXVIII

$\begin{array}{lrrrrrrrr}\text { Wave-length, m } \mu \ldots . . . & 578 & 546 & 436 & 406 & 365 & 313 & 254 & 217 \\ \text { Relative energy....... } & 116 & 169 & 100 & 67 & 119 & 90 & 38 & 55 \\ \text { Photo-electric activity } & \text { (potassium) } & & & & & & \\ \text { Relative actual..... } & 3.2 & 8.3 & 100 & 79 & 218 & 301 & 198 & 390 \\ \text { Relative specific.... } & \mathbf{2 . 7} & 4.9 & 100 & 118 & 183 & 334 & 520 & \mathbf{7 1 0}\end{array}$


idea of what may be expected. The photo-electric effects of the various lines upon potassium are referred to as "relative actual." By correcting these values to a uniform energy (dividing values in third line by those in the second line) the relative specific photo-electric activities of radiations of various wave-lengths are obtained for potassium.

Lyman ${ }^{15}$ studied the spark-spectrum of mercury as far into the extreme ultraviolet as $126 \mathrm{~m} \mu$. He gives a table of about 100 lines between this wave-length and $205 \mathrm{~m} \mu$ for the spark spectrum. For the arc-spectrum the shortest wave-length in his table is about $140 \mathrm{~m} \mu$ and he presents only 5 lines between this and $185 \mathrm{~m} \mu$.

An indication of the emission of short-wave radiation of high intensity by the quartz mercury arc is the ozone with which the air is charged in the vicinity of one of these sources. Incidentally it is well to wear glasses when working with this lamp and various bare arcs to prevent the painful irritation in the outer eye-media which is a common result of middle ultraviolet radiation.

The lines in the spectrum of the mercury arc are often quite readily isolated by means of filters so that they afford intense sources of monochromatic or homogeneous radiation.

The two yellow lines 577 and $579 \mathrm{~m} \mu$ (represented approximately by $578 \mathrm{~m} \mu$ ) can be isolated by a yellow filter having a steep absorption-band on the short-wave side so that line $546 \mathrm{~m} \mu$ is absorbed. Chrysoidine and eosine are fairly satisfactory if the former is diluted and the eosine is added until the green line disappears.

An aqueous solution of neodymium ammonium nitrate or neodymium chloride (or a neodymium or didymium glass) of sufficient density, possesses a very sharp absorption-band in the vicinity $578 \mathrm{~m} \mu$ sufficiently strong to absorb the yellow lines and to transmit the green line, $546 \mathrm{~m} \mu$, quite freely. 
Solutions of Neptune green $\mathbf{S}$ and chrysoidin isolate line $546 \mathrm{~m} \mu$ fairly well but not as satisfactorily as the preceding filter.

Many yellow filters will eliminate the lines of shorterwave-length and the infra-red will be almost completely absorbed by several centimeters of water. One centimeter of water is opaque to radiation longer than $1400 \mathrm{~m} \mu$. The opacity of water for infra-red can be increased by the addition of copper chloride. Coblent ${ }^{16}$ has discussed filters for the infra-red.

A solution of potassium bi-chromate is satisfactory for eliminating the blue, violet, and ultraviolet lines.

The line $436 \mathrm{~m} \mu$ can be eliminated by using a solution of potassium permanganate and one of nickel nitrate of just sufficient strength to eliminate the other lines. The two solutions should be kept separate. Another fairly satisfactory combination for isolating this line is dense cobalt (blue) glass and a solution of quinine.

A solution of aesculine absorbs the ultraviolet lines quite completely and if dense enough it may be used in the foregoing to replace the quinine for eliminating line $405 \mathrm{~m} \mu$.

Line $405 \mathrm{~m} \mu$ is fairly well isolated by methyl violet and quinine sulphate in separate cells. It also transmits lines $408 \mathrm{~m} \mu$ and $398 \mathrm{~m} \mu$, the latter rather faintly.

Lines 365 and $334 \mathrm{~m} \mu$ are transmitted by methyl violet and nitrosodimethylaniline. Line $334 \mathrm{~m} \mu$ may be eliminated by thick glass.

R. W. Wood has recommended for isolating line $313 \mathrm{~m} \mu$, a silver film deposited upon a quartz plate, but according to Hughes, if the film is thick enough to absorb the adjacent lines it very greatly diminishes the intensity of $313 \mathrm{~m} \mu$. He found a certain sheet of mica transmitted $313 \mathrm{~m} \mu$ almost entirely but still was quite opaque to $303 \mathrm{~m} \mu$. This provides at least a sharp cut-off on the short-wave side. 
A great variety of arcs may be devised by the investigator but there are only a few commercial arc-lamps available. These are the common carbon arc, open or enclosed, the various flame arcs which utilize carbons impregnated with various chemical salts and the magnetite arc consisting of a positive electrode of copper and a negative one of magnetite (iron oxide). The carbon and especially the white flame arcs are in use extensively for photo-engraving, dye-testing, etc. They can be arranged for a wide variety of wattages. The magnetite arc is in use largely for street-lighting but it can be adapted to many other purposes owing to its fairly intense ultraviolet radiation. Most commercial arcs are designed to consume less than 1000 watts but by increasing the size of the electrodes much more powerful sources can be devised.

The ultraviolet spectrum of the ordinary carbon lamp is confined chiefly to the near ultraviolet, although there are some strong lines and many weak ones in the middle region. Relatively more ultraviolet radiation is emitted by the faint flame of the arc than by the crater from which most of the light comes. By impregnating the carbons with various elements and salts a wide variety of spectra can be obtained; for example, by using iron compounds a rich iron spectrum may be obtained extending throughout the near and middle regions to $200 \mathrm{~m} \mu$. It is the iron oxide which makes the magnetite arc rich in ultraviolet radiation. Spectra of the mercury, iron and carbon arcs will be found elsewhere. ${ }^{17}$

Lindemann ${ }^{18}$ studied the radiation from the carbon arc by observing the photo-electric effect of a copper-oxide sensitive plate. He found the greatest effect due to the radiation from the violet tufts at the extremities of the electrodes which consist of unburnt carbon vapor. $\mathrm{He}$ also concluded that impregnated carbons produce smaller photo-electric effects than ordinary carbons. 
The impregnation of carbons with various elements and compounds has been a fruitful field of research. It has resulted in the development of carbons for so-called "flame arcs." In these more light, as a rule, is emitted by the arc (flame) than by the craters. The introduction of various materials into carbons results in quite a variety of colors, and Mott ${ }^{19}$ has done a great deal of work in this field in recent years. Calcium fluoride produces yellow light which consists really of green and red lines superposed on a more or less white light. The yellow flame arc emits moderate amounts of violet and ultraviolet radiation. Strontium fluoride is chiefly responsible for the color of the red flame arc. Various other colors are produced by the following materials: copper, blue; silicon or iron, red-violet; titanium, blue; didymium oxide, violet; thorium oxide, reddish; ceric oxide, blue; lanthanum oxide, blue.

Of all the flame arcs the one in widest use at the present time, owing chiefly to its extreme richness in near ultraviolet radiation, is the white flame arc. It owes its spectral qualities largely to rare earths. According to Mott and Bedford" "the radiation of the snow-white flame arc is the closest approach to sunlight plus blue sky of any known illuminant, considering either the visible or the ultraviolet spectrum. The spectrum is a mass of lines crowded close together and is confined chiefly to wave-lengths longer than $300 \mathrm{~m} \mu$. The ultraviolet radiation of the snow-white flame arc does not produce ozone in quantities detectable by the odor as in the case of the quartz mercury arc, indicating the absence of the short wave-lengths which produce ozone." According to Mott there is a marked decrease in photographic effect in the region of $300 \mathrm{~m} \mu$ compared with other flame carbons or the open arc. Flame carbons have been made which emit much energy between 200 and $300 \mathrm{~m} \mu$. 
Mott and Bedford ${ }^{20}$ have presented comparative results obtained with the various flame arcs for several chemical reactions. These present better than a detailed description some of the relative merits. In Table XXIX are their results pertaining to the effect of different sources on a 10 per cent solution (by volume) of bromine in toluol contained in glass and in quartz. The sources were at a distance of two feet and the time required for the bromine color to disappear was measured in each case.

\section{TABLE XXIX}

Bromination Time for Different Sources

\begin{tabular}{|c|c|c|}
\hline & $\begin{array}{l}\text { Glass } \\
\text { Tube }\end{array}$ & $\begin{array}{l}\text { Quartz } \\
\text { Flask }\end{array}$ \\
\hline White flame arc, 25 amp. 90 arc volts. & 36 & 36 \\
\hline Yellow flame arc, 25 amp. 90 arc volts. & 25 & 24 \\
\hline Red flame arc, 25 amp. 90 arc volts ........... & 170 & 21 \\
\hline 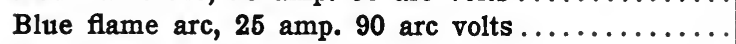 & 210 & 60 \\
\hline 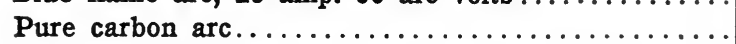 & 280 & 58 \\
\hline Tungsten lamp, 750-watt, gas-filled clear bulb.. & . & 274 \\
\hline Tungsten lamp, 1000 -watt, gas-filled blue bulb...... & $\ldots$ & 235 \\
\hline Mercury vapor lamp, 3.3 amp. 110-volt. .......... & & 610 \\
\hline
\end{tabular}

The last three sources in Table XXIX are enclosed with glass so that the results obtained with them are more directly comparable with those obtained with the arcs when the bromine was contained in the glass test tube.

The results of a test of the effect upon solio paper of the radiations from the flame arcs operated at 25 amperes and 90 arc-volts are presented in Table XXX. The reciprocals of the average time required in each case for equal coloration is the basis of the figures. The glass used in this case was ordinary window glass $2.3 \mathrm{~mm}$. thick.

Paraphenylenediamine and nitric acid provide a reaction which is a satisfactory test for ultraviolet radiation, and 


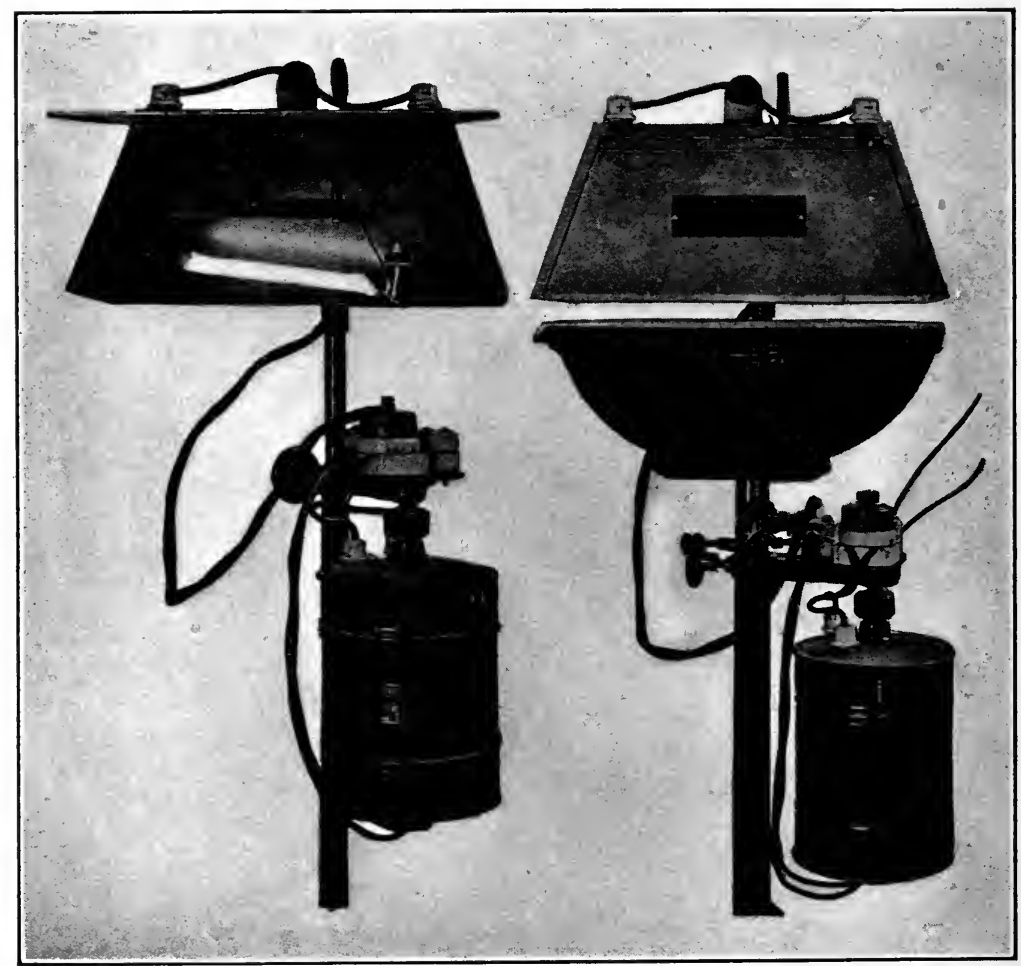

Plate VI. The quartz mercury arc shown with the quartz arc exposed and also as used for exposing materials to its radiation. 
TABLE XXX

Relative Photographic Effect on Solio Paper

\begin{tabular}{|c|c|c|}
\hline & No Glass & With Glass \\
\hline White flame.. & 100 & 80 \\
\hline Yellow flame..... & 35 & 17 \\
\hline Red flame........ & 30 & 22 \\
\hline Blue flame...$\ldots \ldots \ldots$ & 60 & 30 \\
\hline Pure carbon arc. & 40 & 24 \\
\hline
\end{tabular}

Mott and Bedford used it for comparing the various arcs. They impregnated white blotting paper with a solution, consisting of 1 gram of paraphenylenediamine, $3 \mathrm{cc}$. distilled water, 2 cc. nitric acid (sp. gr. 1.21). The blotting paper was then dried in a steam oven, for if it is dried slowly as by leaving it over night it blackens and is useless. This is not appreciably sensitive to the radiations from the gas mantle, electric incandescent filament lamps, and the Nernst glower. On exposure to ultraviolet the impregnated paper turns green and finally to a metallic brown color. Mott and Bedford found that best test results were obtained at a distance of two feet from the 25 ampere arc on exposing in increments of one-half minute without glass. Owing to the absorption of glass for the ultraviolet the exposures when it was used were increased to five minutes. Their results are presented in Table XXXI. This gives a rough estimate of the relative amounts of ultraviolet radiation referred to the blue flame arc. Without glass the blue flame arc was the most powerful but with glass the white flame arc was quite superior.

The same investigators compared the relative efficacies of the radiations from the white flame arc and the quartz mercury arc of approximately the same wattage, in producing chlorination. The radiation from the white flame 


\section{TABLE XXXI}

Relative Photographic Efiect on Paraphenylenediamine

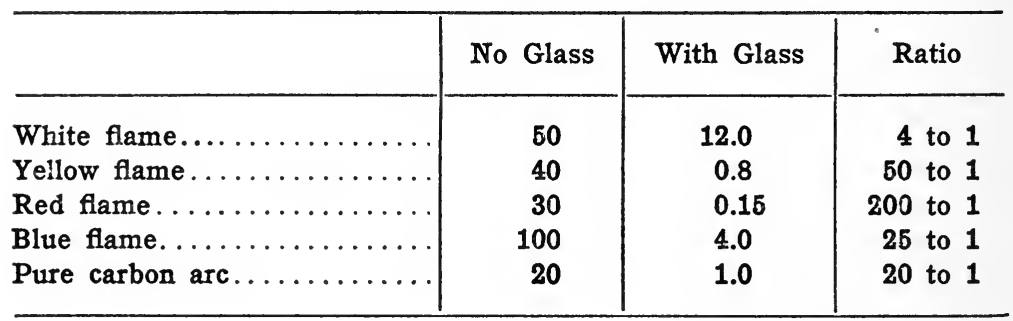

arc appeared to be superior from every viewpoint. A decided advantage possessed by the white flame arc is that it is very efficient even when glass vessels are used. Furthermore it can be made to emit enormous quantities of radiation if necessary.

Mott ${ }^{21}$ made elaborate tests of the flame arc in paint and dye-testing and concluded that at a distance of two feet it provided an intensity more intense than summer sunlight. Inasmuch as its spectrum is similar to daylight on a clear day and as it is reproducible and controllable it should find greater usefulness. Certainly where powerful sources of near ultraviolet and other radiations which are chemically active are needed, the white flame arc is perhaps the most promising commercial source available. Of course the quartz mercury arc possesses some advantages in steadiness and operation over long periods without any attention.

Various other photo-engraving arcs are available but they are usually ordinary carbon arcs of high currentdensity.

Henri ${ }^{22}$ concluded that the intensity of the ultraviolet radiation from a quartz mercury arc increases with increase in temperature of the tube. By cooling the tube with running water he found the intensity of the ultraviolet to be only one-fourteenth as powerful as when the tube was surrounded by air. 
The commercial gas-filled tungsten lamps emit a continuous spectrum of appreciable intensity in the near ultraviolet. By operating them at excessive voltages the intensity of the ultraviolet can be greatly increased. For some work it is advantageous to cement a quartz window to such a lamp.

Gehlhoff ${ }^{23}$ has presented some data pertaining to the distribution of energy from tungsten and tantalum spirals immersed in nitrogen or argon. He equipped the lamp with a quartz window. Although the ultraviolet spectrum is weak and is confined to the near region, this source has the advantage of being continuous. It is useful in some investigations.

As has already been stated the output of ultraviolet radiation from an incandescent filament lamp increases very rapidly with increase of the temperature of the filament. Furthermore the operating conditions of incandescent filament lamps used for photochemical reactions should not be the same as those which have been standardized from an economic viewpoint for such lamps when used for ordinary lighting purposes. Additional photographic results as obtained by $\mathrm{L}$. L. Holladay, A. H. Taylor and the author are shown in Table XXXII for four representative photographic plates. The Mazda C lamp consumed 1000 watts and operated at its normal voltage at an efficiency of 16.8 lumens per watt. The latter is a direct indication of the temperature of the filament. The Mazda C photographic blue-bulb lamp which consumed 1000 watts is designed for photographic work and therefore operates at a higher filament temperature. This increase in temperature over that of the normally operating filament corresponds to an increase in voltage of approximately 10 per cent. The luminous efficiency owing to the absorption of light by the blue bulb was 10.8 lumens per watt in these experiments. The Cooper-Hewitt (glass tube) and quartz 


\section{TABLE XXXII}

Relative Photographic Power Per Lumen of Total Radiation of Various Illuminants

\begin{tabular}{|c|c|c|c|}
\hline \multirow{2}{*}{ Source } & \multirow{2}{*}{ Plate } & \multicolumn{2}{|c|}{ Relative Photographic Value } \\
\hline & & Direct & Once reflected \\
\hline Mazda $\mathbf{C}$ (clear) $\ldots \ldots \ldots \ldots$ & Seed 23 & 1.00 & 1.00 \\
\hline Mazda C (blue-bulb)....... & “ & $\ldots$ & 1.36 \\
\hline Tungsten-mercury arc. . . . . & “ & 3.24 & 2.88 \\
\hline Cooper-Hewitt.......... & “ & 8.19 & 5.50 \\
\hline Quartz mercury arc....... & “ & 12.93 & $\ldots$ \\
\hline Solar radiation. ............ & “ & $\ldots$ & 1.97 \\
\hline Mazda $\mathbf{C}$ (clear) .......... & Orthonon & 1.00 & 1.00 \\
\hline Mazda C (blue-bulb)... & " & $\ldots$ & 1.62 \\
\hline Tungsten-mercury arc..... & “ & 2.54 & 3.36 \\
\hline Cooper-Hewitt.......... & “ & 6.58 & 6.94 \\
\hline Quartz mercury arc...... & “ & 9.29 & $\ldots$ \\
\hline Solar radiation. .......... & “6 & $\ldots$ & 1.79 \\
\hline Mazda C (clear) ........... & $\begin{array}{l}\text { Panchromatic } \\
\text { Type } \mathbf{M}\end{array}$ & 1.00 & 1.00 \\
\hline Mazda C (blue-bulb). & " & $\ldots$ & 1.33 \\
\hline Tungsten-mercury arc..... & “ & 3.13 & 2.75 \\
\hline Cooper-Hewitt. . ......... & “ & 6.37 & 4.42 \\
\hline Quartz mercury arc....... & “ & 10.82 & $\ldots$ \\
\hline Solar radiation. ........ & “ & $\ldots$ & 1.99 \\
\hline Mazda C (clear)....... & $\begin{array}{l}\text { Panchromatic } \\
W \text { and } W\end{array}$ & 1.00 & $\ldots$ \\
\hline Tungsten-mercury arc. & " & 2.96 & \\
\hline Cooper-Hewitt. . . . . . & “ & 6.31 & $\ldots$ \\
\hline Quartz mercury arc.. & "6 & 7.71 & $\ldots$ \\
\hline
\end{tabular}

mercury arcs were commercial lamps operating at their commercial ratings. The sunlight was the direct rays of the sun on a clear day with the sun at an altitude of about 45 degrees. In the table the results are given for direct radiation which did not pass through any media except air and also for radiation reflected from the first surface of black glass. The tungsten-mercury arc was an experimental lamp with a glass bulb. The radiation was 
emitted by an incandescent filament and also by mercury vapor. Owing to the fact that it involves a mercury arc as well as an incandescent filament it appears possible to greatly increase its photographic value. The panchromatic plate was a type $M$. The results for the mercury arcs were considerably lower in value for a Wratten and Wainright (W and $W$ ) panchromatic plate than those shown for the type $M$. The illumination intensity at the plate was determined by photometering the visible light. An energy relation of these data can be obtained by considering the lumens per watt.

The author and his colleagues, Holladay and Taylor, are conducting an investigation of the photographic action of the radiation from tungsten filaments operating at various temperatures from $2050^{\circ} \mathrm{K}$ to $3400^{\circ} \mathrm{K}$. At the present time only preliminary results are available. The approximate sensitivities of various commercial plates at these two extreme temperatures and an intermediate one are respectively as follows:

$\begin{array}{lccc} & 2050^{\circ} \mathrm{K} & 2500^{\circ} \mathrm{K} & 3400^{\circ} \mathrm{K} \\ \text { Seed 26 } & 4 & 9 & 21 \\ \text { Seed 23 } & 1.5 & 4 & 10 \\ \text { Orthochromatic } & 5 & 9 & 20 \\ \text { Panchromatic } & 3 & 4.5 & 9\end{array}$

These approximate preliminary values of sensitivity are the reciprocals of the inertia in meter-candle-seconds and are intercomparable. The orthochromatic plate was an Orthonon and the panchromatic was a Wratten and Wainright.

\section{References}

I. Trans. I. E. S. II, I9I6, 888.

2. Trans. I. E. S. II, I9I6, 399.

3. Photo-electricity, I913, I06.

4. Sitz. Ber. Wien. Akad. Apr. I9r3; Beitr. Photochemie, II, I49. 


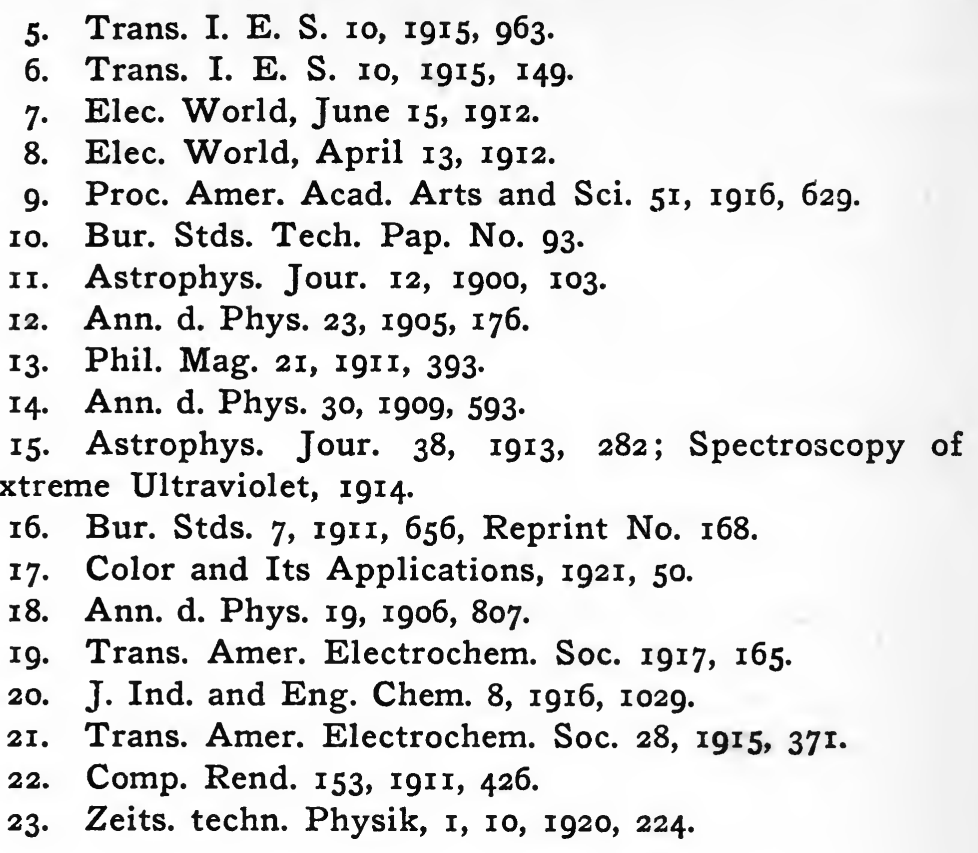



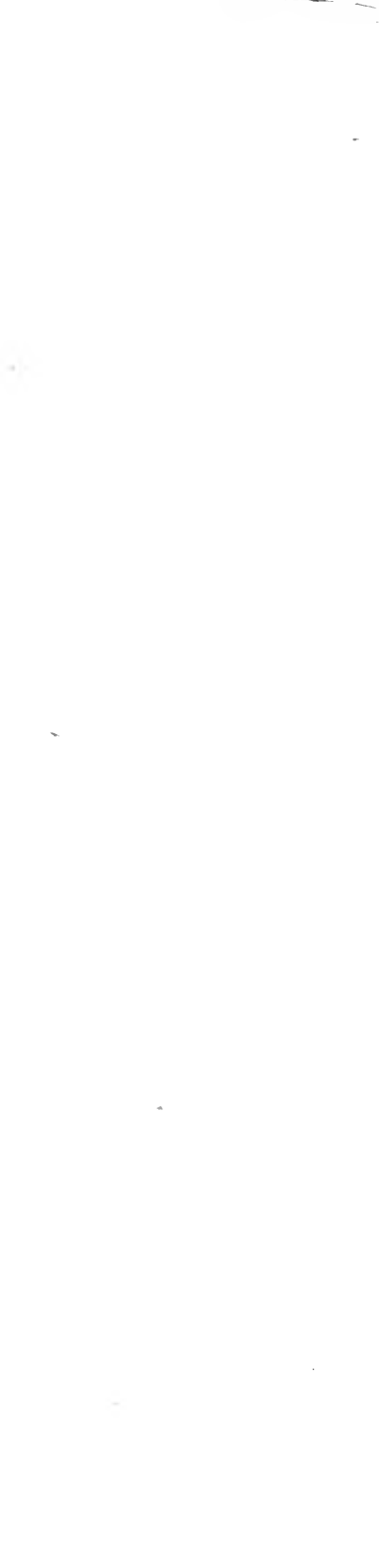


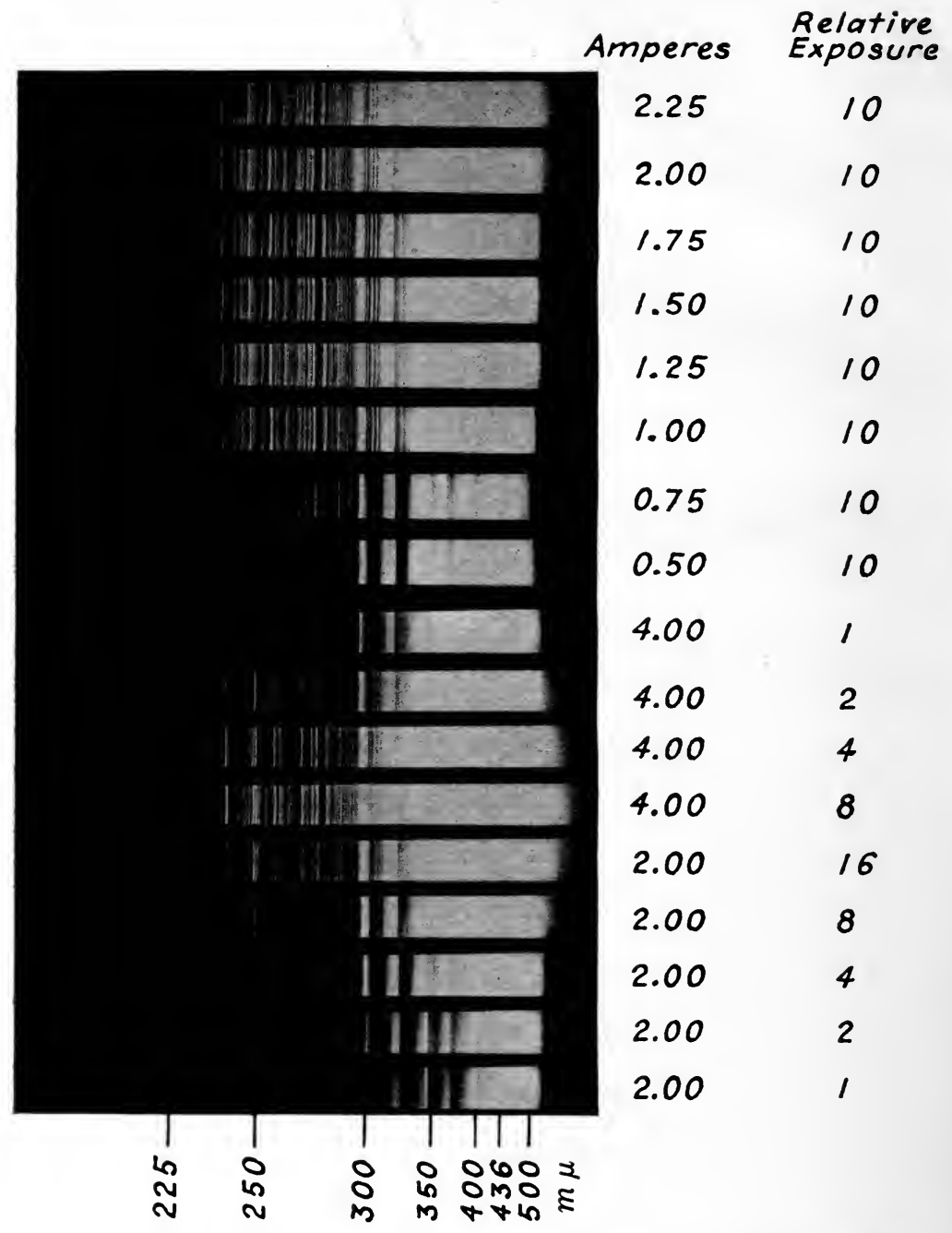

Plate VII. The ultraviolet spectra of the tungsten arc through quartz, at various currents and photographic exposures, as obtained by a quartz prism spectrograph. 


\section{CHAPTER IX \\ EXPERIMENTAL SOURCES}

In the preceding chapter the common illuminants which are useful from the standpoint of ultraviolet radiation have been discussed. Besides these there are many sources available to the investigator. The radiations from gases in discharge tubes have been widely used in studying the properties of the middle and extreme ultraviolet and in mapping other spectra in these regions. A large variety of metals are available for producing spectra by sparks operated under various conditions. These metals and their compounds are also available for use as electrodes or for impregnating carbon electrodes of arcs. All these provide such a variety of spectra that the investigator should seldom be unable to find a fairly suitable source of radiation. The ideal source for many purposes, having a uniform and continuous spectrum, is not available.

The intensity of ultraviolet radiation may be increased manifold in some cases by focusing the image of the source by means of lenses of quartz or other suitable media. For example, blackening of lithopone was produced in less than a minute by focusing upon it the image of a quartz mercury arc by means of a quartz lens. Under solar radiation on a clear day in summer, the time required for blackening was considerably greater. If reflection is resorted to for the purpose of intensifying the ultraviolet radiation it is well to be certain of the reflection-factors of the substance for the ultraviolet.

The spectra of various sources of ultraviolet radiation are touched upon more or less in other chapters. Kayser ${ }^{1}$ 
has assembled a great deal of data of this character. An atlas of emission spectra has been published by Hagenbach and Konen, ${ }^{2}$ a translation by King also being available. This contains emission spectra of the sparks, arcs, and flames of many elements. Lyman ${ }^{3}$ has published much data pertaining especially to emission spectra in the extreme ultraviolet. The Smithsonian Institution has published tables prepared by Fowle ${ }^{4}$ which are a source of much information pertaining to spectra. Spectra and spectral energy-distribution curves of lightsources and spectral transmission curves of many media may be found elsewhere. ${ }^{5}$ These and various other references will supply the data necessary for many purposes.

Discharge tubes can be made of various forms but a constriction is usually desirable in order to increase the radiation per unit of projected area. Tubes made of glass are useful only in the visible and near ultraviolet regions but if these are fitted with quartz or fluorite windows their usefulness can be extended far into the ultraviolet region, the spectral range depending upon the emission of the gas but usually upon the transparency of the window. At best a window if fastened with cement is liable to be a source of trouble. If the spectrum need not extend much beyond $200 \mathrm{~m} \mu$ it is best to make the tubes of fused quartz. However in order to extend it to $125 \mathrm{~m} \mu$ a fluorite window is necessary. When it is necessary to extend the investigation beyond this, there being no media sufficiently transparent, the source and the receiver are placed in the same vacuum.

A plate-glass window may be fused to glass vessels by maintaining the glass at a temperature sufficiently high to avoid cracking while applying heat locally. Fairchild ${ }^{B}$ has described the details of such a process. Different kinds of glass can be joined together by successive steps using glasses of the proper range of expansion coefficients. It should be possible to join a plate of fused quartz to glass if necessary. 
The emission spectra of gases have been quite extensively studied. Hydrogen emits a large number of lines of considerable strength in the extreme ultraviolet extending to wave-length at least as short as $90 \mathrm{~m} \mu$. Schumann extended the map of the hydrogen spectrum to the limit of transparency of fluorite, that is to about $125 \mathrm{~m} \mu$.

According to Lyman, hydrogen possesses two distinct spectra in the visible and ultraviolet regions. The primary spectrum consists of relatively few lines and it is augmented by a disruptive discharge. The secondary spectrum is made up of a large number of lines and is best produced for observation by using a continuous current. There is a gap between the two spectra from $248 \mathrm{~m} \mu$ to $168 \mathrm{~m} \mu$ but this gap appears as a faint continuous spectrum. Lyman ${ }^{3}$ has presented a table of more than 300 hydrogen lines extending from about $123 \mathrm{~m} \mu$ to $167 \mathrm{~m} \mu$.

A pressure in the hydrogen discharge tube of from 1 to $5 \mathrm{~mm}$. will yield a rich spectrum. Hall and St. John ${ }^{7}$ found that the radiation from a hydrogen discharge tube which passed through a fluorite window was about 250 times more powerful in producing a photo-electric effect on a zinc plate than the radiation from the mercury arc.

The spectrum of oxygen in a discharge tube extends only through the near and middle regions of the ultraviolet. Lyman ${ }^{8}$ found no lines between $123 \mathrm{~m} \mu$ and $200 \mathrm{~m} \mu$.

Argon in a discharge tube yields no lines of shorter wave-length than $190 \mathrm{~m} \mu$ but by using a disruptive discharge Lyman succeeded in bringing out quite a number of lines in this region. $\mathrm{He}^{3}$ has presented a table of 39 lines between $133 \mathrm{~m} \mu$ and $189 \mathrm{~m} \mu$ obtained by means of a disruptive discharge through a tube containing argon at 1 to $2 \mathrm{~mm}$. pressure. At pressures of 1 to $2 \mathrm{~cm}$. very few lines appear.

Lyman was unable to obtain any lines from a helium 
discharge tube, at pressures from 1 to $17 \mathrm{~mm}$., between $125 \mathrm{~m} \mu$ and $200 \mathrm{~m} \mu$. Recently Fricke and Lyman ${ }^{9}$ studied the spectrum of helium extensively between $50 \mathrm{~m} \mu$ and $130 \mathrm{~m} \mu$ and discovered a strong line at $58.5 \mathrm{~m} \mu$.

Of all the spectra of gases which have been examined in the extreme ultraviolet, carbon monoxide is the only one which yields a spectrum comparable in richness of lines with the hydrogen spectrum. Carbon dioxide emits a similar spectrum but weaker than that of carbon monoxide. Lyman ${ }^{3}$ has presented a table of about 100 lines due to carbon monoxide between $133 \mathrm{~m} \mu$ and $207 \mathrm{~m} \mu$.

Mercury vapor in a vacuum tube equipped with a fluorite window yields a strong spectrum between $103 \mathrm{~m} \mu$ and $168 \mathrm{~m} \mu$. Lyman has presented a table of about 200 mercury lines between 126 and $205 \mathrm{~m} \mu$.

Nitrogen in a discharge tube emits a banded spectrum throughout the ultraviolet regions. Lyman ${ }^{8}$ has studied the spectrum in the extreme ultraviolet as far as $138 \mathrm{~m} \mu$. The shortest wave-length, outside this region, presented by Kayser is at about $205 \mathrm{~m} \mu$.

Billon-Daguerre ${ }^{10}$ has constructed Geissler tubes of silica containing rarefield gases for the production of ultraviolet radiations of short wave-length. $\mathrm{He}$ describes several forms with and without quartz jackets.

There are various electrical arrangements for operating a spark-gap but two essentials usually are high voltage and a condenser in parallel. When the spark-gap breaks down there are oscillations set up which provide a "fat" spark. High-frequency apparatus can be employed. There are various small transformers available for use with spark-gaps. The condensers may be Leyden jars or they can be readily constructed from sheets of glass and thin metal plates such as brass or tin-foil. Transformers are obtainable which will step-up the voltage from an ordinary lighting circuit to 25000 volts. Some of these have a means for controlling the secondary volt- 
age. The spark-gap is placed in series with the secondary and a condenser in parallel with it. The transformer charges the condenser and the latter is discharged at the spark-gap. This produces a high-frequency oscillation.

Kowalski ${ }^{11}$ has shown that the wave-length of maximum radiation is shifted toward longer wave-lengths as the oscillatory current is increased. However, an increase in the amount of energy consumed at the spark-gap causes a shift toward shorter wave-lengths but the displacement depends to some extent upon the nature of the electrodes. $\mathrm{He}$ claims that the intensity of the mean wave-lengths varies inversely with the frequency. There is a definite relation between the frequency of the primary current, the capacity and the number of sparks per second if a resonance transformer is used. Thus it is possible to determine the best conditions.

There is available on the market an apparatus for producing ultraviolet radiation which employs a small transformer which steps the voltage from $110-220$ to 4000 volts, a suitable condenser, and an adjustable spark-gap consisting of iron terminals. The iron electrodes are enclosed in a small cylindrical chamber of insulating material open at one end and having insulating heads of adjusting screws projecting outside, by means of which the frequency can be increased from 60 cycles per second, for example, to ten or twenty times that value.

Schunck ${ }^{12}$ has described a spectroscopic investigation of sources of ultraviolet radiation in which he used a quartz spectrograph. He studied the sparks and arcs of tungsten, iron, and molybdenum; cored carbons filled with haematite, wolframite, pitchblende, pure tungsten and molybdenum; small carbons boiled in solutions of sodium tungstate, uranium nitrate, ammonium molybdate, and titanous chloride. Tungsten electrodes yielded the richest ultraviolet spectrum extending to about $200 \mathrm{~m} \mu$. The molybdenum spectrum is similar but it is weak- 
ened from $230 \mathrm{~m} \mu$ to shorter wave-lengths. The iron spectrum contains groups of intense lines to about $225 \mathrm{~m} \mu$ but the lines are not as numerous as in the tungsten spectrum. The carbons impregnated with uranium nitrate and ammonium yielded an intense spectrum to about $230 \mathrm{~m} \mu$. The impregnated carbons yielded more powerful spark spectra than arc spectra. Cored carbons containing powdered tungsten and haematite exhibited a less powerful spectrum than the tungsten electrodes.

Millikan and Sawyer ${ }^{13}$ used hot sparks requiring as much as 150,000 volts per millimeter. They published a table of the zinc lines in the extreme ultraviolet from 214 to $92.8 \mathrm{~m} \mu$. According to them the line of shortest wavelength published previously for any metal was $97.79 \mathrm{~m} \mu$. They found indications of lines even shorter than this in wave-length. The spark was maintained in a vacuum so high that residual gases played no rôle in the discharge. The source of energy was a condenser charged by a static machine. Millikan has since discovered radiations of still shorter wave-length. ${ }^{45}$

Lenard ${ }^{14}$ produced a spark consuming about 1000 watts. He used a large induction coil and passed 90 amperes through the primary. A spark-gap with aluminum terminals was connected to the secondary with a condenser of 0.11 microfarads in parallel. This spark emitted ultraviolet radiation very rich in energy of short wave-lengths.

The high-tension electric discharge between terminals of pure metallic uranium has been used as a source of ultraviolet radiation. Crookes ${ }^{15}$ superposed upon this radiation that from a Nernst glower and claimed to obtain from the combination a practically continuous spectrum from 200 to $800 \mathrm{~m} \mu$.

The high-tension discharge between aluminum terminals under water has been used by Howe ${ }^{16}$ and later by others as a source of ultraviolet radiation. The spectrum is practically continuous from $230 \mathrm{~m} \mu$ to the long-wave 
region of the visible spectrum. The gap under water may be from 1 to $15 \mathrm{~mm}$. long. Under proper conditions no lines are superposed on the continuous spectrum. This usually necessitates photographing an "index" line-spectrum upon the plate or otherwise establishing the wavelength scale. Brass terminals have been successfully substituted for aluminum ones. It appears that the nature of the water has an influence upon the results. It is best to use distilled water circulated through the apparatus.

Extensive tables of spark spectra of metals are available for the near and middle ultraviolet regions but much less work has been done in the region of shorter wavelengths than $200 \mathrm{~m} \mu$. Schumann ${ }^{17}$ studied the spark spectra of many metals. Handke, ${ }^{18}$ Lyman $^{18}$ and a few others have contributed much of the spectral data for this region.

It should be noted that if one merely desires to expose something to the radiations of the smallest wave-lengths emitted by sparks between metal electrodes the difficulty is not nearly as great as if the wave-lengths of the lines are to be measured. In the former case it is only necessary to produce the spark in a gas, such as hydrogen, which is transparent to the radiations, and to place the material in the same chamber. In the latter case it is necessary to have the measuring apparatus in the chamber which entails greater difficulties.

Kowalski ${ }^{20}$ has proposed electrodes of nickel, tungsten and their alloys, either alone or in combination with rare earths, for the terminals of a spark-gap which emits powerful ultraviolet radiation. By arranging the circuit conditions carefully, a great amplitude of current density is obtained. He suggests that in sterilizing liquids the terminals be plunged into the liquid using a protecting tube of quartz if necessary. He claims that greater efficiency in producing ultraviolet radiation is obtained by employing different materials for the two electrodes. 
Lyman ${ }^{3}$ has presented tables of the spectra of various elements for the extreme ultraviolet. The tables contain for the silver spark, 95 lines between 167 and $197 \mathrm{~m} \mu$; for the gold spark, 118 lines between 162 and $198 \mathrm{~m} \mu$; for the copper spark, 91 lines between 159 and $189 \mathrm{~m} \mu$; for the calcium spark, 30 lines between 125 and $188 \mathrm{~m} \mu$; for the strontium spark, 9 lines between 153 and $185 \mathrm{~m} \mu$; for the barium spark, 17 lines between 133 and $187 \mathrm{~m} \mu$; for the zinc spark, 52 lines between 163 and $199 \mathrm{~m} \mu$; for the tin spark, 29 lines between 170 and $199 \mathrm{~m} \mu$; for the cadmium arc, 13 lines between 140 and $200 \mathrm{~m} \mu$; and for the zinc arc, 11 lines between 137 and $165 \mathrm{~m} \mu$.

The foregoing discussion has been confined to the extreme ultraviolet region in order to indicate the shortwave limits of spectra which are available for experimental purposes. There is a much greater amount of data pertaining to spectra available for the middle and near regions. Besides the various references Kayser's Handbuch d. Spectroscopie contains a great deal of data.

There is little quantitative data available pertaining to the spectral energy distribution in the ultraviolet radiation from various light-sources. Owing to the nature of the sources and the variation in the spectra due to a number of causes, quantitative data would not be of much value unless obtained for the particular source and conditions of immediate interest. It is more difficult at present to measure ultraviolet energy, for example, than visible radiation, although it can be done directly and indirectly in various ways as will be shown in a later chapter.

The spark offers many spectra more or less rich in intense lines depending upon the composition of the electrodes. Pfluiger ${ }^{21}$ has made absolute measurements of the energy of various lines in the ultraviolet region, by means of the thermopile, and the results indicate that the ultraviolet energy radiated by the sparks passing between electrodes of a number of the metals is greater than indi- 
cated by spectrophotography. He found that the maxima of the spectral energy-distributions of aluminum, zinc, cadmium, nickel, cobalt, iron and magnesium are in the ultraviolet regions.

Pflïger ${ }^{22}$ has presented a table of the relative intensities of the principal lines in the spark spectra of fifteen metals throughout a spectral range from $180 \mathrm{~m} \mu$ to $225 \mathrm{~m} \mu$. A summary of some of the results which he obtained under his conditions are presented herewith. Under different experimental conditions others have found lines of shorter wave-length in most cases.

Aluminum gave several groups of lines between 180 and $200 \mathrm{~m} \mu$ with some especially strong lines in the region of $185 \mathrm{~m} \mu$. A few weak lines showed between 200 and $260 \mathrm{~m} \mu$. Quite a number of moderately intense lines are present from $300 \mathrm{~m} \mu$ throughout the visible spectrum. Lyman $^{3}$ recorded many lines between 124 and $186 \mathrm{~m} \mu$.

Cadmium showed a group of moderately intense lines in the region of $186 \mathrm{~m} \mu$ and a few weak ones between this wave-length and $210 \mathrm{~m} \mu$. At this point the lines began to strengthen and many appeared throughout the remainder of the ultraviolet and visible region. A group of strong lines was found between 210 and $235 \mathrm{~m} \mu$. Those from $250 \mathrm{~m} \mu$ throughout the visible spectrum were of moderate intensity.

Zinc yielded no lines shorter than $200 \mathrm{~m} \mu$ but there were groups of strong ones between this point and $210 \mathrm{~m} \mu$. From $215 \mathrm{~m} \mu$ to $240 \mathrm{~m} \mu$ the lines were scarce and weak but from $240 \mathrm{~m} \mu$ throughout the remainder of the ultraviolet region and the entire visible spectrum, lines of moderate intensity were plentiful. Handke ${ }^{18}$ recorded about 52 lines between 163 and $200 \mathrm{~m} \mu$.

Iron yielded lines of moderate intensity from $190 \mathrm{~m} \mu$ throughout the ultraviolet and visible regions, the most intense group being between 240 and $255 \mathrm{~m} \mu$. Lyman ${ }^{23}$ found various lines throughout the extreme ultraviolet region and particularly strong ones near $180 \mathrm{~m} \mu$. 
Cobalt appeared to possess rather weak lines from 190 to $215 \mathrm{~m} \mu$ and lines of moderate intensity from $215 \mathrm{~m} \mu$ throughout the ultraviolet and visible regions. The strongest group was between 230 and $240 \mathrm{~m} \mu$.

Nickel yielded no lines of shorter wave-length than $197 \mathrm{~m} \mu$. From this point they were weak until $210 \mathrm{~m} \mu$ was reached then there were lines of moderate intensity up to $215 \mathrm{~m} \mu$. A group of strong ones were found between 215 and $240 \mathrm{~m} \mu$; lines of moderate intensity extended from 240 to $270 \mathrm{~m} \mu$ but from $270 \mathrm{~m} \mu$ to the longwave end of the visible region the lines were rather scarce and weak.

Silver emitted a few weak lines between 185 and $200 \mathrm{~m} \mu$ and quite a number of moderate ones from $210 \mathrm{~m} \mu$ to $250 \mathrm{~m} \mu$. A gap existed from 250 to $310 \mathrm{~m} \mu$ but a few moderately intense lines appeared in the near ultraviolet and visible regions. Handke recorded nearly 100 lines between 165 and $200 \mathrm{~m} \mu$.

Copper did not furnish any lines shorter than $195 \mathrm{~m} \mu$ but many of moderate intensity appeared between this point and $230 \mathrm{~m} \mu$. They were weak up to $250 \mathrm{~m} \mu$ and a gap existed between this point and $395 \mathrm{~m} \mu$. A few of moderate intensity were recorded in the visible region. Handke ${ }^{18}$ recorded nearly 100 lines between 160 and $190 \mathrm{~m} \mu$.

Gold did not emit any strong lines. The line of shortest wave-length recorded was at about $190 \mathrm{~m} \mu$ and quite a few moderately weak lines appeared between 190 and $230 \mathrm{~m} \mu$. The table shows a gap between 230 and $395 \mathrm{~m} \mu$ with a few moderately intense lines in the visible. Handke found more than 100 lines between 160 and $200 \mathrm{~m} \mu$.

Tin did not yield any strong lines. Pflüger found a group near $190 \mathrm{~m} \mu$, a gap from that point to $210 \mathrm{~m} \mu$, and weak lines between 210 and $313 \mathrm{~m} \mu$. Moderately intense lines appeared throughout the near ultraviolet and visible regions. Handke recorded about 30 lines between 170 and $200 \mathrm{~m} \mu$. 
Antimony emitted scarcely any lines excepting a few of moderate intensity in the visible.

Platinum yielded lines of moderate intensity from $190 \mathrm{~m} \mu$ to the end of the visible spectrum but not as many as in the case of iron or cadmium.

Palladium emitted rather weak lines between 190 and $225 \mathrm{~m} \mu$, moderately intense ones up to $260 \mathrm{~m} \mu$, but only a few weak ones between this point and the long-wave end of the visible.

Magnesium yielded strong lines between $275 \mathrm{~m} \mu$ and the visible spectrum. Lyman and also Handke have recorded a few lines between 170 and $200 \mathrm{~m} \mu$.

Pflüger recorded a few weak lines for mercury between 185 and $200 \mathrm{~m} \mu$ with the strongest of the group at about $190 \mathrm{~m} \mu$. He found a gap between 200 and $220 \mathrm{~m} \mu$; a group of moderately intense ones between 220 and $230 \mathrm{~m} \mu$; a gap between 230 and $250 \mathrm{~m} \mu$; and moderately intense ones between 260 and the red end of the visible region. The fact that Pflüger recorded only a few mercury lines compared with Lyman and others who examined the spectra only qualitatively indicates that these relatively few were the strongest ones, for he used a thermopile and determined relative energy. The thermopile is enormously less sensitive than the photo-electric cell or photographic plate for detecting the presence of spectral lines. However, this makes Pflüger's results especially valuable for some purposes for they represent presumably the strongest lines in the various spectra. Of course, it should be noted that the distribution of energy may vary with conditions in the electrical circuit. Pflüger used a spark $2 \mathrm{~mm}$. long and two small Leyden jars across it.

Pflüger also presented a condensed table of strongest lines and groups of lines emitted by the metals which he examined. This is reproduced in Table XXXIII, the values of galvanometer-deflections indicating the relative intensities. It should be noted in connection with the 


\section{TABLE XXXIII}

Strongest Lines and Groups of Lines in the Spark

Spectra of Metals

\begin{tabular}{|c|c|c|c|c|c|}
\hline $\mathrm{m} \mu$ & Metal & Deflection & $\mathrm{m} \mu$ & Metal & Deflection \\
\hline 186 & $\mathrm{Al}^{*}$ & 173 & 240 & Co & 140 \\
\hline$\ldots$ & $\mathrm{Cd}^{*}$ & 27 & 241 & $\mathrm{Fe}$ & 125 \\
\hline 190 & $\mathrm{Sn} *$ & 62 & 249 & $\mathrm{Fe}$ & 126 \\
\hline 193.5 & $\mathrm{Al}^{*}$ & 58 & 250.2 & $\mathrm{Zn}^{*}$ & 80 \\
\hline 195 & $\mathrm{Hg}$ & 40 & 255.8 & $\mathrm{Zn}^{*}$ & 85 \\
\hline 199 & $\mathrm{Al}^{*}$ & 50 & 257.3 & $C d^{*}$ & 41 \\
\hline 202.5 & $\mathrm{Zn}_{\mathrm{n}} *$ & 225 & 258 & Co & 80 \\
\hline 206 & $\mathrm{Zn}^{*}$ & 280 & 261.4 & $\mathrm{~Pb}^{*}$ & 12 \\
\hline 208.7 & $\mathrm{Zn}^{*}$ & 160 & 274.7 & $\mathrm{Fe}$ & 125 \\
\hline 210 & $\mathrm{Zn}^{*}$ & 220 & 274.8 & $\mathrm{Cd}^{*}$ & 49 \\
\hline 213.8 & $\mathrm{Zn}^{*}$ & 60 & 277.1 & $\mathrm{Zn}^{*}$ & 25 \\
\hline 214.4 & $\mathrm{Cd}^{*}$ & 185 & 280 & Mg* & 950 \\
\hline 219 & $\mathrm{Ni}$ & 107 & 285 & Mg* & 153 \\
\hline 219.4 & Cd* & 120 & 293 & Mg* & 189 \\
\hline 220.3 & $\mathrm{~Pb}^{*}$ & 32 & 309 & $\mathrm{Mg}$ & 35 \\
\hline 221 & $\mathrm{Ni}$ & 140 & 326 & $\mathrm{Sn}$ & 19 \\
\hline$\ldots$ & Co & 53 & $328-334$ & $\mathrm{Zn}$ & 60 \\
\hline 226.5 & $\mathrm{Cd}^{*}$ & 170 & $340-346$ & $\mathrm{Cd}$ & 25 \\
\hline 231.5 & $\mathrm{Cd}^{*}$ & 190 & 361 & $\mathrm{Cd}$ & 45 \\
\hline 232 & $\mathrm{Ni}$ & 175 & 365 & $\mathrm{Hg}$ & 52 \\
\hline 233 & $\mathrm{Ag}$ & 36 & $\ldots \ldots$ & $\ldots$ & $\ldots$ \\
\hline
\end{tabular}

An $*$ indicates that there were lines so close together that their combined energy was measured.

preceding paragraphs pertaining to Pflüger's work on spark spectra that he only considered spark spectra for regions of longer wave-length than $180 \mathrm{~m} \mu$. Furthermore he was unable to record weak lines by his method. This accounts for the absence of data pertaining to lines in the extreme ultraviolet region.

Ross ${ }^{24}$ has described a powerful aluminum spark which he used in photo-chemical investigations. He connected the spark-gap to the secondary of a large induction coil with a large Leyden jar in parallel. The primary circuit 
operated at 3.4 amperes and 110 volts. By placing variable resistors and an ammeter in the primary circuit he was able to obtain a fairly constant source of radiation. The aluminum terminals were sharpened after each observation. They were of large cross-section and arranged so that they would be cooled by conduction by dishes of ice and iron plates in contact with them. He found that the rate of decomposition of the iodides was at least twice as great in the case of the aluminum spark as in the case of any other common metals which he used.

The arc is another useful source of ultraviolet radiation. It is usually easier to devise than the spark or vacuum tube but on the other hand it is generally less satisfactory owing to its unsteadiness. The commercial arc lamps have been discussed in Chapter VIII but for many experimental purposes an arc can be constructed very simply which is more satisfactory. The ordinary carbons can be bored and filled with metals and compounds, or material may be placed on the tips of the electrodes or in a cup drilled in the end of one of them. Arc spectra differ in general from line spectra but those elements which produce spark-spectra rich in ultraviolet radiation, usually emit powerful ultraviolet radiation in the arc.

Electric arc carbons impregnated with iron salts emit powerful ultraviolet radiation. In fact iron is one of the best materials for electrodes. It is a simple matter to construct an arc which will emit ultraviolet energy, provided hand-control is satisfactory. An iron rod and a carbon rod may be employed successfully for the two electrodes, however, two iron rods serve the purpose very well. These terminals can be kept cool effectively by means of heavy brass or copper sleeves which may be moved along the iron rods as the latter are consumed.

A particularly successful arc of this type can be made 
in an hour or so. ${ }^{25}$ The upper pole, which is negative, may be an iron rod about $\frac{1}{4}$ inch in diameter. This is surrounded by a movable but well-fitted solid sleeve of copper or brass about one inch in diameter. The sleeve should be turned down to a conical shape at the arc end in order not to obstruct unduly the radiation from the arc. It is set so that about $\frac{1}{8}$ inch of the iron electrode protrudes from the conical end. The lower electrode, which is positive, may be an iron rod about $\frac{1}{2}$ inch in diameter with the end of the form of a shallow cup. One electrode should be adjustable vertically. In preparing the arc a bead of molten metal is developed in the dished end of the lower electrode by striking the arc repeatedly. This bead and the dished end of the lower electrode become oxidized, which apparently diminishes deterioration as the arc plays between the bead and the upper electrode. The latter is well cooled by the massive copper sleeve and the arc is steadily maintained between it and the molten bead. Such an arc will operate at a fairly high current density for thirty minutes without adjustment.

Arcs between copper electrodes have been successfully used and an arc between silicon terminals emits intense ultraviolet radiation accompanied by little light.

Zinc, cadmium, and aluminum have been used successfully in the crater of the positive electrode of a carbon arc. The inner vapors of a carbon arc are carbon, cyanogen, and carbon monoxide. These alone radiate ultraviolet energy but it is neither intense nor rich in spectral lines or bands. Metals can be easily introduced into the arc in the form of wire, thin rod, or powder embedded in the carbon.

Mott ${ }^{56}$ has published interesting data pertaining to the appearance of the arc when various chemicals are melted in it.

The arc can be operated in an atmosphere of hydrogen, nitrogen, etc., in order to prevent oxidation. In the study 
of the arc spectra of metals this is sometimes very satisfactory. Deposit is diminished which is essential to the success of some work. There is the danger of explosion in the use of hydrogen which must be guarded against. This danger is not present when nitrogen is used and it appears more satisfactory than hydrogen in some cases in other respects.

Sometimes it has proved undesirable to operate sparks in air and in these cases other gases have been employed.

Varly ${ }^{27}$ has recommended an arc between iron terminals in an atmosphere of hydrogen as a constant source of ultraviolet radiation. He connected the electrodes to the secondary of an induction coil with three large Leyden jars in parallel. An alternating current of 4 amperes passed through the primary coil. He claimed that the ultraviolet radiation remained practically constant in intensity for days if employed for ten-second periods, allowing rest-periods of a few minutes between each short run.

The enormous beam intensities obtained by some of the modern search-lights are due to small electrodes, the hot ends of which are cooled in a blast of air or alcohol-vapor. The electrodes are rotated in some cases. Rotation has often been applied in experimental work in effort to obtain uniformity.

It has been found that alloys of silver and cadmium work well in the arc. Such an alloy consisting of 60 per cent cadmium melts at $700^{\circ} \mathrm{C}$. The arc is steady and has been kept in one position by rotating the electrodes in opposite directions.

Cadmium in a quartz tube has been utilized as a source of ultraviolet radiation.

An arc between tungsten electrodes and operated in an atmosphere of hydrogen or nitrogen is a source of intense ultraviolet radiation. Its spectrum consists of several hundred measurable lines. The tungsten arc is best operated in a sealed bulb containing argon or a mix- 
ture of argon and nitrogen at atmospheric pressure. A heating coil placed near the arc can be used for starting the arc and the coil may serve as one electrode. However, the arc is perhaps more satisfactory if two small buttons of tungsten serve as electrodes with the heating coil as an auxiliary. A series of spectra of this tungsten arc for various currents has been published by the author. ${ }^{28}$ They were obtained for the radiation emitted through a crystalline quartz window cemented to the bulb by means of sodium silicate, the seal being further protected on the outside by means of Khotinsky cement. The window was cemented upon the open end of the glass tube about one inch in diameter which protruded sufficiently from the bulb to remain cool. The spectrum consists of many lines between 200 and $400 \mathrm{~m} \mu$.

Morphy and Mullard ${ }^{29}$ have described a tungsten arc similar to the foregoing. The lamp contains a tungsten filament which also forms one electrode. The hot filament ionizes the gas so that an arc is formed between it and another tungsten electrode. The bulb is made of quartz and the output of ultraviolet radiation therefore is large.

Tungsten arcs such as these in glass bulbs can be purchased at the present time.

Several attempts have been made to employ combinations of tungsten and mercury. The radiation from these tungsten-mercury arcs is that due to incandescent tungsten and the mercury vapor. The total radiation is quite actinic but is limited in usefulness for work requiring a continuous spectrum in the ultraviolet or one packed with spectral lines by the relative scarcity of mercury lines compared with iron lines, for example, obtained from the iron arc.

The mercury arcs of commercial type have been discussed in Chapter VIII. Small ones can be made of glass without much difficulty but there are few persons skilled 
in working quartz. Quartz lamps of various shapes for special purposes can be supplied by manufacturers. Double-walled quartz arcs have been made so that the arc can be cooled by circulating water over the inner tube. This maintains a low density of the mercury vapor which favors the production of ultraviolet radiation. The spectrum of mercury has been discussed in other chapters. Ellis and Wells ${ }^{30}$ have described various special mercury arcs used by investigators or supplied by manufacturers.

By way of improving the vacuum in quartz mercury arcs, von Recklinghausen ${ }^{31}$ has suggested the use of metals which absorb nitrogen at high temperatures. Magnesium, boron, and titanium are proposed for this purpose. $\mathrm{He}$ has also studied the proper distribution of the mercury and has employed a series of electrodes. ${ }^{32}$

For sealing molybdenum and its alloys into quartz a flux has been recommended consisting of ten parts silica, one part alumina and one part boric acid. The content of silica in the flux should be increased as the quartz is approached.

Knipp ${ }^{33}$ has described in detail the construction of a quartz mercury lamp for which he claims several advantages such as ease of starting and control of the mercury. It is portable and it can be taken apart for cleaning or for introducing various materials into the arc.

Helbronner and von Recklinghausen ${ }^{34}$ have devised a powerful source of ultraviolet radiation which consists of a quartz U-tube the legs of which nearly touch each other, the electrodes of mercury being therefore side by side. The tube is $14 \mathrm{~mm}$. in diameter and the legs are $160 \mathrm{~mm}$. long. The lamp operates on 500 volts and takes $3 \mathrm{am}$ peres with 375 volts actually across the electrodes. The candle-power perpendicular to the axis is said to be 8000.

Bovie $^{35}$ has described simple quartz mercury arcs for 
photochemical investigations. He also gives detailed instructions for making such a lamp in a variety of forms. Anyone interested in constructing a mercury arc of special form will find it helpful to consult Bovie's paper.

Henning ${ }^{38}$ determined the mean value of the expansion coefficient of quartz to be 0.00000054 per degree per unit of length for temperatures up to $1000^{\circ} \mathrm{C}$.

Sand ${ }^{37}$ has described a cadmium vapor lamp comparable to the mercury arc. The cadmium is placed in a quartz envelope and is melted by external heating before starting. The cadmium is prevented from adhering to the sides of the quartz container by the presence of powdered zirconia.

Cooper Hewitt ${ }^{36}$ has patented the use of metals such as thallium and caesium in the construction of quartz mercury arcs in order to increase the output of ultraviolet radiation. Mercury is used for the anode and the other metal serves as the cathode.

A manufacturer of mercury arcs has devised a type known as the "hot-cathode" lamp. In place of the mercury at the anode a spiral of tungsten wire is used. A reservoir of mercury forms the cathode. The tungsten wire is sealed into the quartz tube by a graduated mixture of glass and fused quartz so that at the wire the seal is of glass.

Kowalski ${ }^{39}$ found the oscillating spark to be more efficient as a source of ultraviolet radiation than the quartz mercury arc, particularly for sterilizing water. According to his experiments only 45 to 90 watt-hours of electrical energy were necessary for sterilizing 1000 gallons of water. Of course, the material of the electrodes, the frequency of the circuit, and other conditions affect the character of the ultraviolet radiation emitted by the spark. To increase the amplitude, the induction was reduced as much as possible and capacity was introduced. He found the relative intensities from a $22 \mathrm{~mm}$. gap between invar 
terminals were $1,1.3,1.6$, and 2 respectively for frequencies of 50, 40, 30, and 20 sparks per second. The percentages of radiation determined horizontally in the direction of the axis of a 110-volt Heraeus quartz mercury arc operating at 3.1 amperes and 90 arc-volts were: "heat" 24 per cent; visible radiation 41 per cent; ultraviolet radiation 35 per cent. From a $22 \mathrm{~mm}$. spark gap with invar electrodes at 30 sparks per second and 50.5 amperes in the oscillating circuit, the percentages were: " heat" 22 per cent; visible radiation 18.6 per cent; and ultraviolet radiation 59.4 per cent.

Verhoeff and Bell ${ }^{40}$ determined the amounts of energy radiated in various spectral regions by a 220 -volt 3.5 -ampere quartz mercury tube with a voltage drop of 90 volts across the tube. A water-cell was placed before the lamp so that the radiation passing through was practically all visible and ultraviolet. Under these conditions they found that 35 per cent was visible and 65 per cent was ultraviolet radiation between 200 and $400 \mathrm{~m} \mu$. This ultraviolet radiation was equally divided between the near and middle regions, one-half being between 200 and $300 \mathrm{~m} \mu$ and the other half between 300 and $400 \mathrm{~m} \mu$. Under these conditions the energy intensity at $50 \mathrm{~cm}$. from the tube was about 11000 ergs per second per sq. $\mathrm{cm}$. of radiation shorter than $400 \mathrm{~m} \mu$ in wave-length and about 5500 ergs per sec. per sq. $\mathrm{cm}$. of radiation shorter than $300 \mathrm{~m} \mu$ in wave-length.

According to Tian ${ }^{41}$ he noted in experiments on the effect of ultraviolet radiation on water that the endothermic combinations produced by radiations of $190 \mathrm{~m} \mu$ in wave-length are often destroyed by radiations of other wave-lengths. For example, in making ozone it is desirable to avoid those rays which restrict the reaction. Quartz mercury lamps must be operated at a low voltage as the total radiation increases greatly with voltage while the radiation of $190 \mathrm{~m} \mu$ in wave-length increases much more slowly. 
He devised a lamp having a quartz tube down the center of which an insulated iron wire is passed. This makes a contact with a mercury cathode at the bottom. The anode is a cylinder of iron. The advantage claimed for this lamp is that it operates on low voltage and also it can be immersed conveniently in liquids. If alternating current is to be applied to it, the anode is made double as usual, the two being separated by means of mica.

Allamand ${ }^{42}$ determined the relative amounts of energy in the principal lines of the spectrum of a mercury arc in a uviol-glass (Jena) tube. These were determined by means of a thermopile and are referred to the blue line as 100 units. The results are as follows:

$\begin{array}{lrrrrrr}\text { Wave-length, } \mathrm{m} \mu \ldots \ldots \ldots & 578 & 546 & 436 & 405 & 362 & 313 \\ \text { Relative energy } \ldots \ldots \ldots \ldots & 27 & 73 & 100 & 56 & 42 & 17\end{array}$

Lehmann ${ }^{43}$ has described a filter for ultraviolet rays consisting of blue uviol (Jena) glass filled with a solution of copper sulphate and coated outside with gelatine containing nitrosodimethylaniline. A quartz mercury arc or iron arc is used as the source of ultraviolet radiation and lenses of quartz concentrate the rays.

The spectrum of oxidizing phosphorus has been photographed in the ultraviolet region by Centnerszwer and Petrikaln. ${ }^{44}$ They used a solution of phosphorus in paraffin and passed a strong current of air over it. After an exposure of 95 hours they found sharply defined lines and a band near $325 \mathrm{~m} \mu$. The author attempted to photograph the ultraviolet spectrum of oxidizing phosphorus but was unable to obtain any photographic action in the ultraviolet with exposures of fast plates in a quartz spectrograph as long as 75 hours.

Among the most recent work in the extreme ultraviolet region is that of Millikan ${ }^{45}$ who extended the spectrum to about $20 \mathrm{~m} \mu$. He used high potential sparks in a vacuum and succeeded in extending the known spectrum of vari- 
ous elements to the following limits: carbon, $36.05 \mathrm{~m} \mu$; zinc, $31.73 \mathrm{~m} \mu$; iron, $27.16 \mathrm{~m} \mu$; silver, $26 \mathrm{~m} \mu$; nickel, $20.2 \mathrm{~m} \mu$. Evidence is presented in this work which indicates that the characteristic L series of X-rays of carbon have now actually been obtained by ordinary mechanical gratings and that the gap between X-rays and ordinary radiation appears to have been closed.

This actual linking of the extreme ultraviolet spectrum with the X-ray spectrum was accomplished by intermittent sparking between electrodes from $0.1 \mathrm{~mm}$. to $2 \mathrm{~mm}$. apart with a battery of Leyden jars charged to potentials of several hundred thousand volts by a powerful induction coil. A mercury diffusion-pump was attached to the vacuum spectrometer in order to reduce the pressure of the gases evolved by the sparking below $10^{-4} \mathrm{~mm}$. The production of this kind of spark was found impossible if the pressure of the evolved gases exceeded the foregoing value. Specially ruled gratings were used for producing the spectra. These gratings were such as to throw as much radiation of short wave-length as possible into the first-order spectrum. Millikan, Bowen, and Sawyer ${ }^{46}$ succeeded in producing specially ruled gratings which met the requirements of work in the extreme ultraviolet. They measured about 75 spectral lines of carbon between $36 \mathrm{~m} \mu$ and $193 \mathrm{~m} \mu$; about 200 lines due to iron between $27 \mathrm{~m} \mu$ and $215 \mathrm{~m} \mu$; and about 75 lines due to nickel between $73 \mathrm{~m} \mu$ and $186 \mathrm{~m} \mu$. They have presented these in their paper in the form of tables.

According to Millikan ${ }^{45}$ the substances of greatest interest for studies in this extreme region are those of small atomic number, for no X-ray spectra of the $L$ series have been recorded with crystal gratings in the case of elements of atomic number less than 30. Furthermore substances of atomic number much lower than this are beyond the range of the methods of X-ray spectrometry, because of the fact that the wave-lengths of the $L$ rays 
from such substances become so large in comparison with the grating space of crystal gratings that sharp images can not be formed.

The lowest limit thus far reached by Millikan was obtained with nickel and has a value of $20.2 \mathrm{~m} \mu$ which is between one and two octaves farther down than the lowest values previously obtained. The lowest limit found for carbon was $36.05 \mathrm{~m} \mu$ which was not at the limit of the grating. The evidence is quite convincing that Millikan's plates, obtained with the carbon spark, exhibited the whole spectrum which the carbon atom is able to emit up to and including its X-radiations of the so-called $\mathrm{L}$ type. Furthermore by examining through a quartz window the radiation of these high-potential carbon sparks with a fluoroscope strong $\mathrm{X}$-rays were found to be emitted.

Tables have been presented by Gramont ${ }^{47}$ which contain the ultimate lines in the dissociation spectra of 83 elements. One column contains lines determined visually; another shows those obtained by means of a "crown uviol " spectrograph between 317 and $480 \mathrm{~m} \mu$; and a third column records those below $317 \mathrm{~m} \mu$ photographed by means of a quartz spectrograph. In another paper ${ }^{48}$ he discusses arc-spectra of metals with low melting-point.

Pierucci ${ }^{49}$ has confirmed the conclusions of others that the spectral lines of highest excitation are confined to the center of the arc crater. He drilled an axial hole into the positive carbon and placed this carbon below and in line with the negative one. The crater was photographed through the hole by means of a reflecting prism thus eliminating the light of the outer regions of the arc. The successive elimination of low-excitation lines as the temperature rises was well shown by spectrograms of calcium and sodium.

McLennan ${ }^{50}$ has described a vacuum grating spectrograph which he employed for studying the arc spectra of several elements. He provided for removing exuded 
gases, for using gratings of various sizes, and for arranging its carrier and controls so that adjustments may be easily made. He made a study of a tungsten arc in helium at a pressure of 30 to $40 \mathrm{~cm}$. of mercury. A small heating coil was used to start the arc and the latter could be established and maintained constant for hours with distances of 5 to $6 \mathrm{~mm}$. between the electrodes.

The extreme ultraviolet arc-spectra of certain metals have been studied by McLennan, Ainslie, and Fuller. ${ }^{51}$ They employed a vacuum spectrograph with a fluorite optical system and a vacuum arc-lamp. They studied $\mathrm{Cd}, \mathrm{Cu}, \mathrm{Zn}, \mathrm{Al}, \mathrm{C}, \mathrm{Fe}, \mathrm{Sn}, \mathrm{Pb}, \mathrm{Tl}, \mathrm{Ni}$, and $\mathrm{Co}$ between 140 and $240 \mathrm{~m} \mu$. McLennan and colleagues ${ }^{52}$ employed a fluorite spectrograph in the study of short-wave arc spectra in vacuo and the spark-spectra in helium of various elements. They describe the details of their apparatus and present tables of the vacuum arc spectra of antimony, bismuth, calcium, magnesium, selenium, silver, and copper and of the spark-spectra in helium of antimony, bismuth, aluminum, cadmium, lead, magnesium, thallium, and tin. The spectral region was below $185 \mathrm{~m} \mu$. Their results with the vacuum grating spectrograph extend the known vacuum-arc spectrum of copper to $122 \mathrm{~m} \mu$. They also investigated the spark-spectra of silicon, tellurium, molybdenum, and zirconium and have presented ${ }^{53}$ a table of wave-lengths of the lines observed between 163 and $185 \mathrm{~m} \mu$. In previous work McLennan and Lang ${ }^{54}$ studied the spectrum of mercury down to $143.5 \mathrm{~m} \mu$, of iron to $142.7 \mathrm{~m} \mu$, and of carbon down to $58.4 \mathrm{~m} \mu$.

According to de la Roche ${ }^{55}$ the spark-spectra of various elements in reducing gases may be very different in air, oxygen, carbon dioxide, and sulphur dioxide. The spark-spectra in the latter gases are very similar. The change due to reducing gases was exhibited by spectra of electrodes of $\mathrm{Te}, \mathrm{Mo}, \mathrm{Ni}, \mathrm{W}, \mathrm{Sb}, \mathrm{Sn}$, less in those of 
$\mathrm{Ca}, \mathrm{Ag}, \mathrm{Au}$, and not at all with $\mathrm{Zn}$ and $\mathrm{Cl}$. Self induction appeared to weaken these spectra in reducing gases.

Carter and King ${ }^{56}$ have studied the production of spectra of metals in high vacua. They vaporized $\mathrm{Mn}$, $\mathrm{Ti}, \mathrm{Mg}$, and $\mathrm{Cd}$ by heating by means of a stream of cathode rays and excited the vapor by the bombardment of the cathode particles. In the ultraviolet region there is a relatively high intensity of lines as compared with the arc and furnace spectra.

L. and E. Bloch ${ }^{57}$ presented tables of spark-spectra containing 36 new mercury lines of rather low intensity in the region between 140 and $164 \mathrm{~m} \mu$. They employed a prism spectrograph and amalgams of cadmium and sodium as electrodes. They also present 18 new copper lines between 154 and $166 \mathrm{~m} \mu ; 12$ new zinc lines and 13 new thallium lines between 144 and $184 \mathrm{~m} \mu$; various lines of antimony, arsenic, bismuth and tin between 140 and $185 \mathrm{~m} \mu$.

L. and E. Bloch ${ }^{58}$ have presented tables containing 67 zinc lines, 99 cadmium lines, 10 lead lines, 115 iron lines, and 143 cobalt lines in the region between $140 \mathrm{~m} \mu$ and $185 \mathrm{~m} \mu$. Most of the lines were found to be rather weak, but two lead lines, $182.17 \mathrm{~m} \mu$ and $179.63 \mathrm{~m} \mu$, were quite intense.

Dhein ${ }^{59}$ has published the results of measurements on the arc spectrum of cobalt. His tables contain several hundred lines between 259 and $742 \mathrm{~m} \mu$ which are compared with the results of Krebs and Stüting. He used a concave grating and specially sensitized his plates when working in the region of greater wave-length than $500 \mathrm{~m} \mu$.

Schumacher ${ }^{60}$ has presented tables of wave-lengths of about 360 lines in the spectrum of the iron are in the region of 210 to $237 \mathrm{~m} \mu$.

Hicks ${ }^{61}$ in the course of his systematic investigations of spectra has discussed the copper spectrum as well as 
that of silver, of gold, and of other elements. The arcspectrum of copper is very rich in lines.

Eder ${ }^{62}$ has conducted a systematic investigation of the rare-earths. In this paper he presents a table of wave-lengths of about 4400 lines of the arc-spectrum of dysprosium between 228 and $700 \mathrm{~m} \mu$. In previous papers he presents data pertaining to other rare-earths. $\mathrm{He}$ studied ${ }^{63}$ a chloride or oxide of gandolium prepared from gandolium obtained by fractionation of samarin and europium. The fractions of the latter indicate spectral lines of an unknown element.

Ludwig ${ }^{64}$ has published a series of papers on spectral determinations. In this paper he discusses the arcspectrum of vanadium between 220 and $465 \mathrm{~m} \mu$. He obtained very steady arcs operating on 0.5 amperes and 220 volts by using copper electrodes containing vanadic acid. He also used carbon electrodes impregnated with divanadyl tetrachloride. In all of his extensive work on arc-spectra the electrodes are of the respective metal or of either copper or carbon. A hole is made in the lower (positive) electrode to take the substance to be studied or the carbon is impregnated. He compares his observations with those of other investigators.

Belke ${ }^{65}$ has published data pertaining to the arc-spectrum of tungsten from 225 to $698 \mathrm{~m} \mu$ and has included comparison data.

The arc-spectrum of tantalum and of molybdenum are reported on in the same volume by Josewski and by Puhlmann respectively.

The arc-spectrum of scandium has been investigated by Crookes. ${ }^{66}$ The material was prepared from wilkite and then mixed in a powdered state with finely divided silver. This mixture was compressed into small rods which were used as electrodes. This spectrum was photographed along with that of pure silver and that of iron. A table is presented consisting of wave-lengths of 101 scandium lines from 242 to $630 \mathrm{~m} \mu$. 
The arc-spectrum of cerium nitrate was investigated by Klein ${ }^{67}$ using a concave grating. The salt was placed in a hole in the lower (positive) carbon and an iron salt was added to obtain the iron spectrum for purposes of comparison. Tables of wave-lengths are presented for the region between 251 and $455 \mathrm{~m} \mu$ and the measurements are compared with the previous work of others.

Vahle ${ }^{68}$ using the same apparatus investigated the arc-spectrum of zirconium nitrate between 228 and $717 \mathrm{~m} \mu$.

Recently Hagenbach and Schumacher ${ }^{6 \theta}$ have presented tables of lines in the spectra of cadmium and of zinc observed in the electrodeless ring-discharge. The results indicate that this ring-discharge spectrum is more like the spark than the arc but that it contains more lines than the arc and spark together. The intensities in the ring-discharge spectrum are in some cases quite different from those in the arc and the spark spectra.

Series in the spectrum of Argon have been discussed by Nissen $^{70}$ and numerical data are included in the paper.

Burns, Meggers, and Merrill ${ }^{71}$ have measured 55 lines in the spectrum of neon, between 336.9 and $849.5 \mathrm{~m} \mu$, by means of the interferometer.

Paschen ${ }^{72}$ has recently presented tables containing about 850 lines of the neon spectrum from 255 to $984 \mathrm{~m} \mu$. The infra-red lines are taken chiefly from Meissner's ${ }^{73}$ work. The tables include intensities and frequencies and and also show to which series the various lines belong. These series are further discussed in another paper. ${ }^{74}$ Grotrian ${ }^{75}$ also discusses these series.

The intensity relations in the spectrum of helium have been discussed at length by Merton and Nicholson. ${ }^{78}$ They consider three factors which affect the distribution of intensity among the lines in the spectrum: (1) The electrical conditions of excitation; (2) the presence of impurities; (3) the pressure of gas in the discharge tube. They 
studied the effect of cathode distance, the regions of maximum emission, and the various series of lines.

Lyman ${ }^{77}$ has recently discussed the helium series in the extreme ultraviolet and Hicks ${ }^{78}$ has added some comments. Compton and Lilly ${ }^{79}$ have studied the excitation of the spectrum of helium by bombarding pure helium with electrons from a hot-filament cathode at various pressures up to $24 \mathrm{~mm}$. The fact that after striking the arc it could be maintained by a potential difference as small as eight volts by using large currents indicates that in an intense discharge a large proportion of the atoms are in an abnormal state and therefore require less energy for excitation. As the voltage was increased the sharp subordinate series became relatively weaker and as the pressure increased the band spectrum became stronger and the enhanced line weaker. The band spectrum was stronger near the cathode while the enhanced line was stronger near the anode.

The spectra of compound gases in vacuum tubes have been studied recently by Bair. ${ }^{80}$ The gases were ammonia, nitrous oxide, nitrogen peroxide, carbon dioxide, hydrogen sulphide, and sulphur dioxide. The ammonia band in the visible spectrum has two heads each degraded on both sides. The band at $337.1 \mathrm{~m} \mu$ is probably not due to ammonia for it was observed in tubes long after the characteristic color of ammonia disappeared. The discharge-tubes were operated both with gas flowing and at rest. The two oxides of nitrogen exhibited strongly the third positive group of nitrogen bands especially when the gas was flowing. This group of bands was observed from 190.2 to $345.8 \mathrm{~m} \mu$. Of the two negative groups of carbon bands the first appeared probably due to carbon monoxide and the second to carbon dioxide. Bair discovered several new bands in this second group and forty new bands in the spectrum of sulphur dioxide, extending this group to $212.4 \mathrm{~m} \mu$. 
Holst and Oosterhuis ${ }^{81}$ have described experiments which appear to show that the so-called cyanogen bands are not due to nitrogen but to one of its compounds which condenses at a much higher temperature, probably cyanogen. In some of the experiments the discharge tube was immersed in liquid oxygen and the spectrogram was obtained through the walls of the Dewar vessel. On one spectrogram the bands $385.5,388.3$, and $416.8 \mathrm{~m} \mu$ appeared but the others were absent. It thus appears possible that the bands are due to two different carriers.

The origin of the cyanogen bands has been investigated by Barratt ${ }^{82}$ by observing the flame spectra of a number of gases containing carbon, hydrogen, nitrogen and oxygen. The cyanogen bands are strongly developed in flames of coal-gas and nitrous oxide, of coal-gas and air, of carbon monoxide, air and ammonia, of $\mathrm{HCN}$ and air, of methylamine and air, and other nitrogenous organic substances. The bands are absent from the flame of hydrogen and nitrous oxide if all traces of carbon are excluded and are not found in hydrocarbon-oxygen flames in general or in ammonia-oxygen flame. Carbon is essential to the production of the bands and the appearance of the cyanogen bands is a delicate test for carbon and for compounds of nitrogen admitted in the form of a gas to hydrocarbon flames burning in air. The intensity of the cyanogen bands when carbon compounds are admitted to the hydrogen-nitrous oxide flame was not found to bear a simple relation to the amount of carbon added.

Anderson ${ }^{83}$ has described a method of obtaining high temperatures for laboratory purposes which may have some applications in the ultraviolet region. The method consists in electrically exploding a fine wire in a confined space. When the explosion occurs in air confined in a tube or slot the flash gives a brilliant continuous spectrum crossed by the absorption lines of the elements of which the wire is composed. Iron, copper, nickel, 
and manganin so far have been investigated. It is hoped that it may be possible by this means to imitate steliar absorption spectra of the solar type. By discharging a large condenser, charged to 26000 volts, through a fine wire $5 \mathrm{~cm}$. long, about 30 calories of energy were dissipated in about one hundred thousandth of a second. If all this energy had entered the two mgm. of wire it would have raised its temperature to $300000^{\circ} \mathrm{C}$. According to Anderson the brilliant flash possessed a brightness corresponding to a temperature of about $20000^{\circ} \mathrm{C}$. or about 100 times the brightness of the sun. A method of producing fine wires on a lathe is also described.

The spectrum of the iron arc has been recently investigated by $\mathrm{H}$. Schumacher ${ }^{84}$ who used a vertical arc $6 \mathrm{~mm}$. in length and a current of 4 amperes at 20 volts. He checked his results with the arc-lines of copper, silver, and nickel and compared his observations with those of Kayser and Runge. St. John and Babcock ${ }^{85}$ have determined the wave-lengths of the lines of the iron arc by means of grating and interferometer measurements between 337 and $675 \mathrm{~m} \mu$. They have presented a table of 1076 lines most of which were measured on many spectrograms.

Strutt ${ }^{86}$ used a sodium-vapor arc in quartz in studying the line-spectrum of sodium as excited by fluorescence. He found that the excitation of sodium vapor by the second line of the principal series leads to the emission of line, $330.3 \mathrm{~m} \mu$, and the $\mathrm{D}$ line. $\mathrm{He}$ also studied the absorption of the vapor. Polarization could not be detected in the ultraviolet resonance radiation, though it has been readily observed in $\mathrm{D}$ resonance radiation. Datta ${ }^{87}$ used a similar lamp in a study of the vacuum arc-spectra of sodium and potassium. 


\section{References}

r. Handbuch d. Spectroscopie.

2. Atlas of Emission Spectra, I905.

3. Spectroscopy of the Extreme Ultraviolet, I9I4.

4. Smithsonian Physical Tables.

5. Color and Its Applications, I921.

6. J. Opt. Soc. Amer. 4, I920, 496.

7. Phys. Rev. I, I9I3, 329.

8. Astrophys. Jour. 33, I9II, 98.

9. Phil. Mag. 4I, I92I, 8I4.

Io. French patent 4I9II7.

II. Comp. Rend. I58, I337.

I2. Lancet I9I 7, 996.

13. Phys. Rev. I2, I9I8, I67.

I4. Sitz. Heid. Akad. Wiss. Igro.

I5. Trans. Roy. Soc. London, 214, I9I4, I.

I6. Phys. Rev. 8, I9r6, 674.

17. Ber. Akad. Wis. Wien. I02, IIa, 438 and 694.

18. Inaug. Dis. Berlin, I909.

19. Astrophys. Jour. 35, I912, 34I.

20. French patent 468215 .

2I. Z. Wiss. Phot. 2, I904, 3 I.

22. Ann. d. Phys. 13, 1904, 901.

23. Astrophys. Jour. 38, I9I3, 282.

24. J. Amer. Chem. Soc. I906, 786.

25. Met. and Chem. Eng. I8, I9I8, 232.

26. Trans. Amer. Electrochem. Soc. Igr7.

27. Phil. Trans. 202, I904, 430.

28. J. Frank. Inst. I85, I9I8, 552 .

29. Chem. Abs. I9I 7, 235.

30. Chem. Engr. vol. 26.

3I. U. S. patent III0576.

32. U. S. patents Iogr 244 and III0574.

33. Phys. Rev. 30, I9I0, 64I.

34. Comp. Rend. I55, I9I2, 852.

35. J. Biol. Chem. 20, I9I5, 315.

36. Ann. d. Phys. Io, I903, 446. 
37. Elec. Rev. 67, 1916, 654 .

38. U. S. patent II97629.

39. Elec. Rev. 66, I9I5, I055.

40. Proc. Amer. Acad. Arts and Sci. 51, I9I6, 637.

4I. Comp. Rend. I56, ro63.

42. Trans. Chem. Soc. I07, I9I5, 682.

43. Phys. Zeit. I9ro, ro39.

44. Z. Phys. Chem. 80, 235.

45. Astrophys. Jour. 52, 1920, 47.

46. Astrophys. Jour. 53, I92I, 150.

47. Comp. Rend. I7I, I920, I I06.

48. Comp. Rend. I70, I920, 3 I.

49. N. Cimento, I8, IgIg, 82.

50. Roy. Soc. Proc. 98, I920, II4.

5I. Roy. Soc. Proc. 95, I9I9, 3 I6.

52. Roy. Soc. Proc. 98, I920, 95.

53. Proc. Roy. Soc. 98, 1920, I09.

54. Roy. Soc. Proc. 95, I919, 258.

55. Bull. Soc. Chem. 25, r9I9, 305.

56. Astrophys. Jour. 49, I9I9, 224.

57. Comp. Rend. I7I, I920, 320, 709 and 909.

58. Comp. Rend. I72, I92I, 803 and 851 .

59. Zeits. Wiss. Phot. I9, I920, 289.

6o. Zeits. Wiss. Phot. I9, I9I9, I49.

61. Phil. Mag. 39, I920, 457.

62. Akad. Wiss. Wien Ber. I27, IgI8, rogg.

63. Chem. Zentralbl. I9I7, 362 .

64. Zeits. Wiss. Photochem. 16, I9I7, 157 .

65. Zeits. Wiss. Photochem. I7, I9I7, I32 and I9I8, I45.

66. Roy. Soc. Proc. 95, I919, 438.

67. Zeits. Wiss. Photochem. 18, I9I8, 45.

68. Zeits. Wiss. Photochem. I8, I9I8, 84.

69. Zeits. Wiss. Phot. I9, IgIg, I29 and I42.

70. Phys. Zeits. 21, I920, 25.

7I. Bull. Bur. Stds. I4, I9I8, 765 .

72. Ann. d. Physik. 60, I9r9, 405.

73. Ann. d. Physik. 58, I9r9, 333.

74. Ann. d. Physik. 63, r920, 201.

75. Phys. Zeit. 21, I920, 638 . 
76. Roy. Soc. Phil. Trans. 220, I9I9, I37.

77. Nature, I04, I9I9, 3 I4.

78. Nature, I04, I919, 393.

79. Astrophys. Jour. 52, I920, I.

80. Astrophys. Jour. 52, I920, 301.

81. K. Akad. Amsterdam, Proc. 23, I921, 727.

82. Roy. Soc. Proc. 98, 1920, 40.

83. Astrophys. J. 51, I920, 37.

84. Zeits. Wiss. Phot. I9, I9I9, 149.

85. Astrophys. J. 53, I92 I, 260.

86. Roy. Soc. Proc. 96, I9I9, 272.

87. Roy. Soc. Proc. 99, I9I9, 69. 


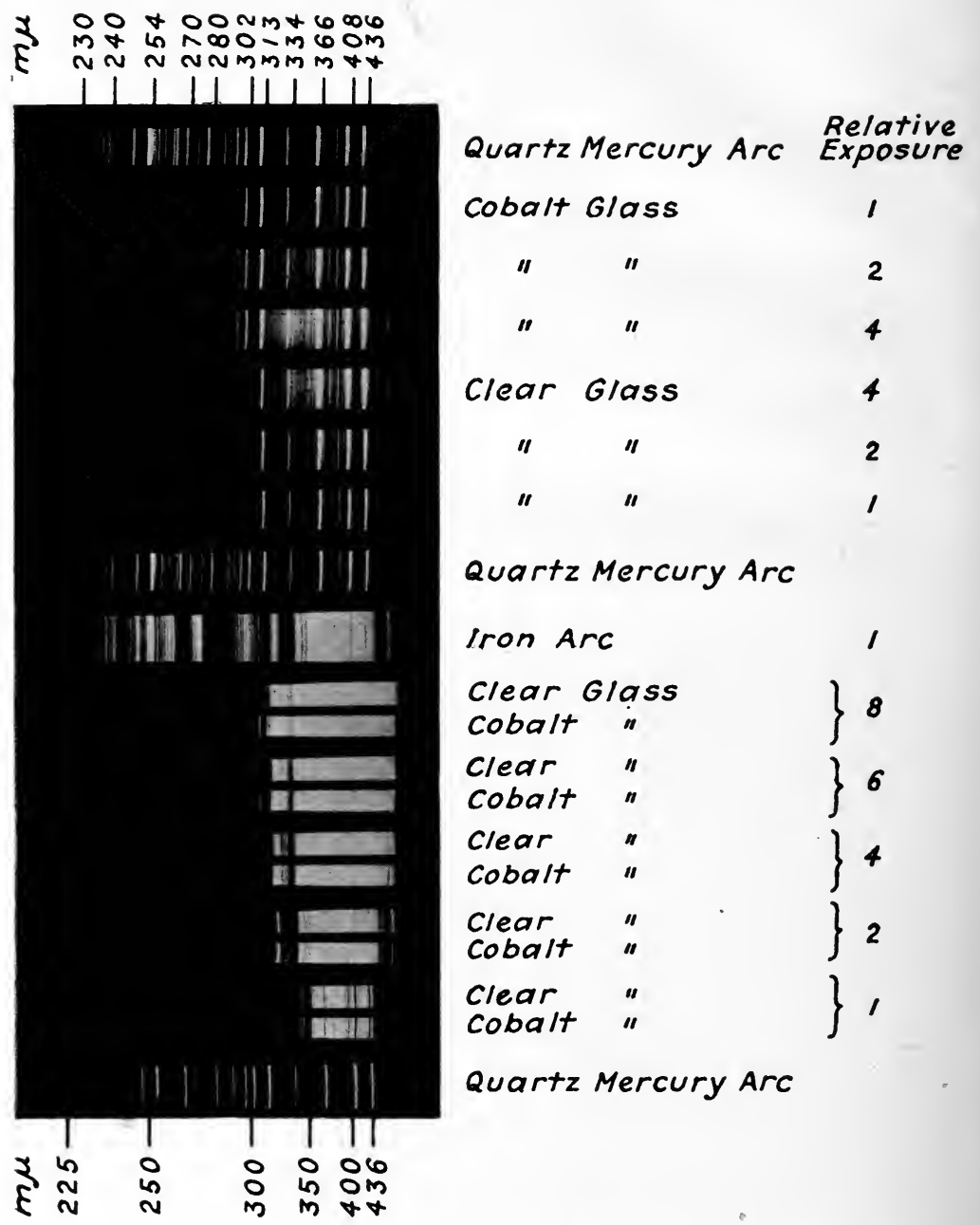

Plate VIII. Ultraviolet transmission spectra of clear and cobalt glasses as obtained by a quartz prism spectrograph. The sources of radiation were the quartz mercury arc and the iron arc. Both glasses were of the same composition with the exception of the addition of a slight amount of cobalt to one of them. 


\section{CHAPTER $\mathrm{X}$ \\ DETECTION AND MEASUREMENT}

A great variety of means is available for detecting ultraviolet radiation and many of these may be utilized for measurements. The absolute measurement of radiation can be directly achieved by means of instruments such as the bolometer, thermocouple, thermopile, and radiometer, which measure incident radiation. Absolute measurements can be obtained also by indirect comparison methods in which the photographic plate, the photoelectric cell, the phenomenon of phosphorescence, the selenium cell, and a large number of photo-chemical reactions may be utilized. The types of apparatus and the methods for measuring ultraviolet radiation are restricted by the characteristics of this radiation. One of the greatest restrictions is the relatively smaller quantities of energy usually encountered than in investigations of visible and infra-red radiations. On the other hand, there are many effects peculiar to ultraviolet radiation which do not attend infra-red radiation. The same comparison can be drawn between ultraviolet and visible radiation although these two spectral regions have much in common.

In general, any effect which is produced by ultraviolet radiation may be utilized in obtaining measurements pertaining to the latter. These effects may be photochemical, photogenic, physical, physiological, germicidal, photo-electrical, etc., although there is more or less overlapping of these in many phenomena. In fact, these divisions themselves are not strictly independent of each other. It is not the intention to discuss the methods of measurement in detail because previous chapters contain much pertinent data and detailed accounts of the 
various instruments may be found elsewhere. The data in other chapters pertaining to reflectivity and transparency of various media indicate the limitations and uses of these media in the measurement of ultraviolet radiation.

The determination of the spectral characteristics of ultraviolet radiation is one of the most essential kinds of data upon which to base conclusions and to depend for future progress, but by dispersing radiation into its spectrum, the ability of energy-measuring instruments to record the enfeebled radiation is very seriously taxed. In many cases it is quite sufficient to use filters such as quartz, glass, etc., and to measure total radiation, provided the source and its conditions of operation are accurately described. In such cases the thermopile, the bolometer, and the radiomicrometer, are usually sufficiently sensitive. Scientific literature abounds with references to the development and use of such instruments and their accessories but it is not a function of this book to discuss these works. Coblentz ${ }^{1}$ has presented an excellent discussion of these instruments which includes many details of construction and operation. Nutting ${ }^{2}$ has treated these, the photographic plate, and radiation laws.

Langley developed the bolometer which consists essentially of a blackened strip of metal. This strip absorbs the radiant energy and its temperature is therefore increased. The temperature-rise is determined by noting the change in electrical resistance. This strip has been placed in a vacuum with a consequent improvement in operation. Coblentz advises a vacuum of not more than $0.1 \mathrm{~mm}$. mercury pressure. Among the many contributions on vacuum bolometers are those by Paalzow and Rubens, ${ }^{3}$ Buchwald $^{4}$ and Warburg, Leithauser, and Johansen. ${ }^{5}$ Coblentz described the difficulties due to drift caused by unequal warming of the strips and to the variations caused by air-currents. He compared the bolometer with the thermopile. 
The name of Rubens is associated with the development of the thermopile perhaps more than any other. The thermopile consists of thermocouples arranged so that the effect of a single couple is augmented by that of others. It consists essentially of a number of thermoelements or thermocouples connected in such a manner that the proper ones are heated by the incident radiation. The difference in temperature between these junctions and the cooler ones causes a current to flow. A sensitive galvanometer records the current which is a measure of the incident radiant energy.

The thermopile is used either in a vacuum or in a screened chamber open to the air. Iron-constantin couples have been extensively used but copper-constantin, bismuth-silver and bismuth-iron are also employed. The thermoelectric power of copper-constantin is somewhat lower than that of iron-constantin but the copper possesses the advantage of not rusting. Coblentz ${ }^{1}$ has presented valuable details, pertaining to the various kinds of thermopiles, drawn from his extensive experience. He found that the Rubens thermopile was only about one-half as sensitive as a bolometer but that it could be improved by using thinner wires and by placing it in a vacuum.

The thermopile is more sluggish than the bolometer and therefore is less adapted to work requiring instantaneous registration. However, on account of its greater steadiness it is recommended for measuring feeble radiation such as in the ultraviolet regions of the spectrum. The two instruments are about equally efficient in measuring radiant energy; that is, they are about equally sensitive to radiant energy.

Pflüger ${ }^{6}$ employed the thermopile successfully in the measurement of ultraviolet radiation as far as $186 \mathrm{~m} \mu$.

The radiometer devised by Crookes ${ }^{7}$ is familiar to many as an interesting toy, but even in the original form of rotating vanes it can be used to measure radiation of 
sufficient intensity at least approximately. A relation between revolutions per second and intensity of radiation can be obtained. Crookes fastened pieces of pith, one black and the other white, at the ends of a long straw. This was suspended by a silk fiber in a glass tube. The later ones seen in optical shops consist of upright vanes of mica blackened on one side. This "paddle wheel" is suspended upon a pin by a small cup of glass so that friction is reduced to a minimum. The glass bulb is exhausted to a low pressure. The rotation is caused by the unequal bombardment of the two sides of the vane by the molecules of the rarefied gas. The blackened side becomes warmer than the other by the absorption of heat and the gas molecules in contact with the blackened side have imparted to them greater kinetic energy than those on the other side. The net pressure of the bombardments causes the wheel to rotate with the blackened sides of the vanes hindmost.

Although the radiometer described in the preceding paragraph has been used to measure radiant energy, Nichols ${ }^{8}$ was the first to make a sensitive instrument employing this principle. He employed two blackened vanes of mica or of thin platinum fastened to a horizontal arm. This was suspended by means of a very fine quartz fiber. Radiation is permitted to fall upon one of the vanes and this causes a tendency to rotate the arm. A mirror attached to the suspended system reflects the image of a scale and in this manner the deflection is measured. The sensitiveness of this instrument is a function of the pressure of the gas, of the kind of gas, and of the distance of the vanes from the window of the enclosure. The pressures employed are a few hundredths of a millimeter of mercury. Coblentz ${ }^{\circ}$ has discussed this instrument in detail. According to him, the instrument is not selective and is as efficient in the ultraviolet as is the bolometer. In this same paper Coblentz also presented many details pertaining to the bolometer. 
The radiomicrometer was developed by Boys ${ }^{10}$ and by d'Arsonval. ${ }^{11}$ The former used a loop of copper wire to which a junction of bismuth-antimony was soldered. The latter used a loop, one-half of which was silver and the other half was palladium. The instrument is essentially a moving-coil galvanometer having a single loop of wire with a thermojunction at one end.

Féry ${ }^{12}$ made what he termed a radiomicrometer which consisted of a loop of copper joined at the bottom by means of a piece of constantin wire. The two junctions were placed at the same height, side by side, and covered with thin strips of silver. The latter were polished on one side and blackened on the other. The deflection of this system, properly screened, is a measure of the incident radiation. Schmidt ${ }^{13}$ made such an instrument with a suspended system consisting of bismuth-antimony. Coblentz ${ }^{14}$ has devised various improvements. He found that by placing it in a vacuum its sensitiveness was almost double. He showed that the highest efficiency is obtained when the resistance of the thermocouple is equal to the combined resistance of the connecting wires and of the auxiliary galvanometer. According to Coblentz ${ }^{9}$ the sensitiveness of the galvanometer is very limited and is perhaps only one-fifth that of the best bolometers. It is not a promising energy-measuring instrument for the ultraviolet. This leaves the field chiefly to the bolometer and the thermopile.

The auxiliary galvanometer which is necessary in the use of the bolometer, the thermopile, and the radiomicrometer, is one of the difficult obstacles. Various investigators have given much attention to its development. Valuable discussions will be found in the works of Coblentz cited in the preceding paragraphs.

Of course, a thermometer with a blackened bulb can be used to measure radiation but it is not sensitive enough to be considered in the same company with the 
thermopile and the bolometer. However, Callender ${ }^{15}$ recently described a thermoelectric balance for the measurement of radiation. A thermojunction in the form of a disk is exposed to radiation and the rise in temperature is opposed by the well-known cooling (Peltier) effect produced by sending an electric current through the junction. Another thermocouple in contact with the disk indicates the amount of compensation. This instrument has been termed a radiobalance. For details pertaining to its construction the original paper should be consulted. Coblent ${ }^{1}$ has also discussed it at length.

Weber ${ }^{16}$ has described a micro-radiometer which forms two arms of a Wheatstone bridge. These arms consist of a narrow glass tube containing a drop of mercury at the center and solutions of zinc sulphate at the ends, into which platinum electrodes are immersed. The ends of glass tube are large bulbs containing air and having rock-salt windows. One of the bulbs is coated inside with lamp-black or platinum black, with the exception of the window, and outside with an opaque non-conducting material. When radiation is permitted to enter the window of the blackened bulb the air is expanded and the liquids are pushed toward the other bulb. This alters the relative lengths of the column of mercury and of the zinc sulphate solutions between the platinum terminals which unbalances the bridge owing to the change in the resistances of these two arms. The instrument does not appear to be sensitive enough for the measurement of ultraviolet radiation spectrally, but it may have some use in the measurement of total ultraviolet or other radiation of sufficient intensity.

It is well known that the resistance of selenium changes when exposed to radiation and this phenomenon has been utilized in the measurement of radiation. However, selenium is very selective in this respect, it being most sensitive to long-wave visible radiation and much 
less sensitive to ultraviolet radiation. A photoelectric cell, on the other hand, is usually more sensitive to the energy of shorter wave-lengths than to that of longwave visible radiation. ${ }^{17}$ The photoelectric cell is also selective in its action. In the case of the blackened parts of the energy-measuring instruments discussed in the preceding paragraphs, there is practically no selectivity. The black coat, which is commonly lamp-black or platinum-black, is non-selective, at least in the near ultraviolet, visible, and infra-red regions. Its chief fault is that it does not absorb all the incident radiation; that is, it is not perfectly black. This error is usually very small and the procedure can be such as to eliminate its effect.

Some of the various forms of energy-measuring instruments already described are quite sensitive enough to measure total ultraviolet radiation between certain spectral limits, but only the thermopile and bolometer appear to have wide applications in spectral energy measurements. Even these must be given every advantage of experience, skill in manipulation, and sensitiveness of galvanometer. Pfluger ${ }^{18}$ obtained spectral energy measurements of the radiations from arcs and sparks by means of a bolometer and a fluorspar prism. He was able to measure the relative energy of the strongest lines as far as $186 \mathrm{~m} \mu$ but he was unable to measure the fainter ones. $\mathrm{He}^{19}$ also used the thermocouple in determining the spectral absorption-factors of various substances.

The great advantage of measuring energy directly has led various investigators to push the energy-measurement instrument to the limit of its ability. Hagen and Rubens ${ }^{20}$ employed the thermopile as far as $250 \mathrm{~m} \mu$ in their studies of the spectral reflection-factors of metals. Other references to such applications are found in other chapters.

As previously stated, the effects of radiation between certain wave-lengths can be studied by means of filters 
and instruments which measure total radiant energy. This suffices in many cases and certainly is much better than making no attempt at isolation. The ideal in many other cases is to make refined spectral investigations by means of the spectroscope. The reflection grating possesses the advantage of producing a normal spectrum. For absolute measurements the selectivity of the substance upon which the grating is ruled must be known. The concave grating is readily applicable to the near and middle ultraviolet regions, that is, for radiation as short as $200 \mathrm{~m} \mu$ in wave-length. Air is opaque to the extreme ultraviolet so that Schumann, the pioneer investigator in this region, constructed a vacuum grating spectrocsope. ${ }^{21}$

Lyman ${ }^{22}$ constructed a vacuum grating spectroscope and was the first to make successful measurements of wave-lengths in the extreme ultraviolet region. His work has been very extensive in this region and much of the data available is due to his ingenuity and persistency.

The grating spectroscope has been a popular instrument for invading unexplored regions because of its normal spectrum. When a prism is used, its dispersion curve must be known. This involves much uncertainty in unexplored regions. Morris-Airey ${ }^{23}$ was one of the first to devise a transmission-grating for the ultraviolet. He ruled a plate of fluorite for this purpose but his investigation was not very successful. Others have tried the fluorite grating with mediocre success. The concave reflection grating in a vacuum has been the most successful apparatus for the extreme ultraviolet.

McLennan and Lang ${ }^{24}$ among others have investigated the extreme ultraviolet with a vacuum grating spectroscope.

Millikan ${ }^{78}$ and his colleagues ${ }^{79}$ were able to extend the study of the spectra of certain elements far into the 
extreme ultraviolet chiefly by the perfection of a vacuum spectrometer and of specially ruled gratings. A mercury diffusion-pump was connected with the spectrometer enclosure and was operated continuously notwithstanding the fact that the source of radiation, which was a very high potential spark, was operated intermittently. The spark-gap varied in length from $0.1 \mathrm{~mm}$. to $2 \mathrm{~mm}$. and the sparking was accomplished in the high vacuum by means of a battery of Leyden jars charged to a potential of several hundred thousand volts obtained from a powerful induction coil. The gratings were ruled with great precision and with a light touch so that about half the original surface was left between the rulings. It was not found practical to increase the number of lines to more than 1100 per millimeter. In the ordinary process of ruling gratings for work in the visible spectrum the surface of the grating is entirely cut away by the ruling-diamond with the result that most of the radiation is thrown into spectra of higher order than the first. For work in the extreme ultraviolet the overlapping of spectra renders all but the first order almost useless, so that it is very desirable to produce a first-order spectrum as intense as possible. Results obtained with this apparatus are presented in Chapter IX.

Merton ${ }^{80}$ has described a method of spectrophotometry applicable to any part of the spectrum which can be photographed through quartz lenses and prisms. This method consists in crossing the dispersing system with a very coarse grating and reducing the length of the slit to a very small value. The grating is placed between the prism and the camera lens of the spectrograph with the lines of the grating perpendicular to the refracting edge of the prism. As a result of this arrangement a continuous spectrum appears on the photographic plate as a dark central strip with a succession of other strips of different intensities on either side. The intensities of 
these orders are determined by the ruling of the grating, and the width of the strips by the length of the slit. In the case of a "line" spectrum the spectral lines are recorded on the plate as dots of different densities on both sides of the central dot. If the last dots which are just visible in the case of two lines are noted, a previous knowledge of the relative intensities of the different orders corresponding to these dots makes it possible to determine the relative intensities of the lines. Owing to the fact that the slit is very small (approaching a point in size), different regions of a light-source may be investigated and for the same reason the method may be applied to the study of stellar spectra.

Merton made and examined a number of gratings and found the most convenient ruling for use with the quartz spectrograph to be about 25 lines to the inch. Wirewound gratings are not feasible in this case because a very small rotation of the grating about an axis parallel to the rulings considerably alters the distribution of intensity in the different orders by changing the ratio of the transparent to the opaque parts of the grating.

Gratings employed for this purpose should not be made by cutting grooves in a transparent surface owing to the characteristics introduced by irregularities and another disturbing factor, not independent of wave-length, which is due to the form of the groove. Merton coated a quartz plate with a very thin layer of lamp-black by holding the plate over burning toluene and then flowed over the plate a thin mixture of alcohol and shellac. The ruling was done by means of a bone tool in a shaping machine possessing an automatic feed. Lord Rayleigh's formula ${ }^{81}$ can be applied to gratings consisting of alternate transparent and opaque bars for computing the brightness of any order. Merton calibrated his gratings by means of a neutral wedge for which the density-step as a function of wave-length had been determined as de- 
scribed in a previous investigation..$^{82}$ As a source of light for this calibration the mercury blue line, $435.9 \mathrm{~m} \mu$ was used.

L. and E. Bloch ${ }^{83}$ have investigated the spectra of many elements by means of a vacuum spectrograph with lenses and prism of fluorite. The apparatus is enclosed in a brass casting $2 \mathrm{~cm}$. thick and is closed by three thick brass plates disposed before the prism, slit, and photographic plate respectively. The plate opposite the slit contains a fluorite window so that the source of radiation can be located outside the chamber. The latter is exhausted to a pressure less than $0.001 \mathrm{~mm}$. With this apparatus spark-spectra of different metals have been investigated down to about $140 \mathrm{~m} \mu$. They employed a condensed spark in hydrogen at atmospheric pressure.

The quartz spectrograph is perhaps the most generally useful apparatus for work with the near and middle ultraviolet. Its transparency extends to about $185 \mathrm{~m} \mu$. Several types are available but it is easy to make one if the essential optical parts, a prism and two lenses, are available. In fact, sometimes it is advantageous to use two prisms. Hilger supplies a small spectrograph which is very useful and a large one which yields an ultraviolet spectrum about $18 \mathrm{~cm}$. long. In all these prism instruments the spectrum is brought to a focus in a plane considerably inclined to the optical axis owing to the chromatic aberration of the simple lenses. This obliquity can be utilized to advantage in some investigations by cutting a window in the side near the acute angle. Through this, fluorescent spectra of solids, for example, may be viewed and even photographed. By projecting the spectrum downward at the proper angle it may be brought to focus on the surface of fluorescent liquids and the latter may be studied in this manner. For this purpose one or two prisms and two lenses of quartz sometimes can be used more advantageously than a complete instrument. 
Houston $^{25}$ has described a spectroscope suitable for work in the ultraviolet, visible, and infra-red regions although no new fundamental principle is involved. Radiation from a slit is rendered parallel by a concave mirror of nickel. It then passes through a prism of quartz, glass, or rock-salt, depending upon the region to be studied, and the spectrum thus formed is brought to a focus by another concave nickel mirror which may be rotated. According to Houston, the nickel mirrors are only about one-half as efficient as quartz lenses, but owing to better collimation, larger apertures may be used than in the case of lenses. There are certain advantages in the focusing of the mirrors. A rhomb of quartz is used to divide the beam of radiation and surfaces of roughened silica diffusely reflect the energy. The two spectra are juxtaposed on the photographic plate or in the eyepiece.

Lankshear ${ }^{26}$ has described an instrument consisting of two identical quartz systems of reflecting prisms and lenses which focus two beams of radiation from the same source upon the slit of a quartz spectrograph. The medium to be studied for ultraviolet absorption is placed in the path of one of the beams and a novel sector is placed in the path of the other. The sector is designed to avoid intermittent illumination which sometimes casts doubt on photographic results.

Fluorescent substances are very convenient for focusing or for examining ultraviolet spectra. A fluorescent uranium plate glass is one of the best for this purpose. The phenomenon of fluorescence has been utilized considerably for visual observations in the ultraviolet. It performs a function similar to that of the photographic plate. It makes it possible to observe the ultraviolet visually which is quite desirable in many cases. In this manner approximate transparency limits of substances can be determined quickly if a powerful source of ultra- 
violet radiation is focused upon the slit of the spectrograph by means of a quartz lens. It does not possess the advantage of permanent record as the photographic plate does. Various applications of fluorescence have been made in instruments for the study of ultraviolet radiation.

The calibration of spectroscopes for the ultraviolet is now a comparatively simple matter because there are many well-determined spectral lines available for that purpose. The grating spectroscope presents no difficulty in this respect because of the normal spectrum. It is only necessary to photograph a pure spectrum of a spark, a discharge tube, or an arc whose spectral lines have been carefully determined by some one. The data pertaining to spectra are found in various references which have been given in preceding chapters.

When it is necessary to know the refractive-indices of various substances such as quartz and fluorite, these can be found in the various optical tables already cited. One of these ${ }^{27}$ which is quite accessible gives the refractiveindices of fluorite, Iceland spar, rock-salt, sylvine (potassium chloride), and quartz for various wave-lengths as far into the ultraviolet as $185 \mathrm{~m} \mu$.

Stark ${ }^{28}$ determined the refractive-indices of fluorite from 185 to $656 \mathrm{~m} \mu$. Martens ${ }^{29}$ obtained the refractiveindices of the ordinary and the extraordinary rays from 198 to $768 \mathrm{~m} \mu$, and the refractive-indices of rock-salt and of sylvine from 185 to $500 \mathrm{~m} \mu$. Handke ${ }^{30}$ determined the indices of refraction of fluorite as far as $131 \mathrm{~m} \mu$.

Owing to the importance of quartz and the prevalence of quartz prisms in ultraviolet investigations the refractive-indices as determined by various investigators are presented in Table XXXIV. These are mean values ${ }^{27}$ in air at a temperature of $18^{\circ} \mathrm{C}$. for the ordinary and the extraordinary rays. In the table $n_{o}$ and $n_{e}$ are the refractive indices for the ordinary and the extraordinary rays respectively. 
TABLE XXXIV

Index of Refraction of Quartz

\begin{tabular}{l|r|r}
\hline $\mathrm{m} \mu$ & \multicolumn{1}{|c|}{$\mathrm{n}_{\mathrm{o}}$} & \multicolumn{1}{c}{$\mathrm{n}_{\mathrm{e}}$} \\
\hline 185 & 1.67582 & 1.68999 \\
193 & .65997 & .67343 \\
198 & .65090 & .66397 \\
206 & .64038 & .65300 \\
214 & .63041 & .64264 \\
219 & .62494 & .63698 \\
231 & .61399 & .62560 \\
257 & .59622 & .60712 \\
274 & .58752 & .59811 \\
340 & .56748 & .57738 \\
396 & .55815 & .56771 \\
410 & .55650 & .56600 \\
486 & .54968 & .55896 \\
589 & .54424 & .55334 \\
656 & .54189 & .55091 \\
686 & .54099 & .54998 \\
760 & .53917 & .54811 \\
\hline \hline
\end{tabular}

Disch $^{31}$ was one of the first to employ the mercury lamp in polarimetry. The green line of the mercury spectrum is exceptionally pure, and where a high intensity of monochromatic radiation is desired this line is easily separated by means of filters which are less wasteful than the spectroscope in isolating monochromatic radiation. In polarimetry, very high intensity is not usually required, so that Lowry ${ }^{32}$ has used a globule of mercury in a hydrogen discharge tube. Such a tube starts readily and by heating the mercury, its spectrum can be increased in brightness if necessary.

Sirks ${ }^{33}$ has determined the rotation of the plane of polarization for ultraviolet radiation of various wavelengths for hydrogen, oxygen, and carbon dioxide. His determinations extended as far as $238 \mathrm{~m} \mu$. 
Photography is one of the most helpful allies in the study of ultraviolet radiation. There are many emulsions available on glass plates, celluloid films, and paper, and the choice will be influenced by the work to be done in a particular case. In general, ordinary emulsions are satisfactory for the photography of radiation of wavelengths between 200 and $500 \mathrm{~m} \mu$. In the case of the photographic emulsion it is necessary to establish relations between the density of the photographic image, the time exposure, and the intensity of radiation. This is necessary for each wave-length for accurate work. Schwarzschild's law is expressed thus,

$$
\mathrm{It}^{\mathrm{p}}=\text { constant }
$$

where $I$ is the intensity of the radiation, $t$ is the time of exposure, and $\mathrm{p}$ is an exponent whose value lies usually between 0.7 and 1.0 for various emulsions. For example, if the intensity of radiation in one exposure is only onehalf the value for another exposure, the former exposure must be slightly greater than twice that of the other in order to produce the same photographic density.

After plates have been developed they are measured for transparency and the density is established by the following relation,

$$
\mathrm{D}=\log \mathrm{O}=\log \frac{1}{\mathrm{~T}}
$$

where $D$ is the density, $O$ is the opacity, and $T$ is the transmission-factor. The curve obtained by plotting density and the logarithm of the intensity of radiation has a straight portion which is considered to be the best region of exposures or densities. This straight-line relation was discovered by Hurter and Driffield in their pioneer researches. The range of this straight portion of the curve for any given case is a measure of the latitude of the emulsion under the conditions of development. 
Sheppard and Mees, ${ }^{34}$ Nutting, ${ }^{2}$ Sheppard ${ }^{35}$ and others have treated the photographic process so thoroughly as to obviate the necessity of doing so here.

In general, in the photography of the ultraviolet it is best to produce images of the same photographic density on the same plate and by equal exposures. One of these images is preferably produced by radiation of known intensity, although in many cases relative intensities are satisfactory. On producing equal densities with equal exposures it is obvious that relative (or absolute) intensities of radiation are obtained directly. Usually the inverse-square law is quite dependable if the distance from the source (a diffusing medium near the slit of the instrument), or from the photographic plate (when no spectroscope is used) is at least ten times the largest projected dimension of the source. In other words, if the source is a mercury tube two feet long, the distance should be at least 15 feet and preferably 20 feet if the inverse-square law is to be employed. Of course, when sufficient density is obtainable it is best to screen most of such a source, thereby obtaining an effective source of small dimension. Care must be taken to avoid attempting to use the inverse-square law when brightness of the source instead of illumination due to it is employed.

It is difficult to obtain non-selective screens for reducing the intensity. When this is necessary, however, a wire mesh or several of them can be employed in some cases with success. The sectored disk has been widely employed but doubt may arise as to the relation of the sector openings to the photographic action. It is well to test this in any case, and even better to eliminate this source of doubt by employing the same sector opening if possible for any comparison. Care must be taken to provide fog-strips when necessary in order to be able to subtract the density due to unavoidable fog, some of which is inherent in the emulsion. 
Photographic attachments can be purchased for spectroscopes. These include not only the camera but sectored disks with various openings. The Hilger sectorphotometer is quite satisfactory. Howe, ${ }^{36}$ among others, has descriked investigations using the sector-photometer in combination with the quartz spectrograph. Tyndall ${ }^{37}$ has described some minor improvements.

The neutral wedge is quite useful. If placed before the slit of a spectroscope so that its transparency varies along the length of the slit, the spectrogram will reveal very roughly the spectral characteristic. That is, the spectrogram will vary in height throughout its length depending upon the intensity of radiation and photographic sensibility.

A non-selective wedge can be made by flowing a gelatine solution of a neutral dye upon an inclined plate of quartz or glass. Nigrosine is sometimes nearly nonselective for visible and near ultraviolet radiation.

The measurement of photographic density can be accomplished by various photometric methods. Owing to the smallness of the areas, the optical pyrometer affords a convenient method. If the areas involved are large enough, an ordinary photometer can be used; that is, relative brightnesses are measured. The Martens polarization photometer is a very convenient device for this purpose.

Fabry and Buisson ${ }^{38}$ among others have described a microphotometer convenient for determining photographic densities. They compare the transparency of the image with that of various portions of a thin wedge of neutral glass.

Henri and Wurmser ${ }^{39}$ described spectrophotometric measurements by the method of equal densities. They varied the time of exposure until the density of the image produced by the direct beam of radiation was equal to that resulting from the radiation which has been absorbed 
to some extent. By using Schwarzschild's law a sufficient degree of accuracy is obtained for most purposes.

Nutting ${ }^{10}$ has described a method of photographic spectrophotometry in which radiation from each of two beams produces a series of interference bands. The bright bands of one series are superposed on the dark bands of the other series and when the intensities are equal the bands disappear.

The tungsten lamp is very useful for investigations in the near ultraviolet when a continuous spectrum is desired. By using a quartz bulb or window its usefulness extends into the middle ultraviolet. Some details pertaining to modern tungsten lamps and various plates are to be found elsewhere. ${ }^{41}$

Difregger ${ }^{42}$ has developed a method of decreasing the intensity of radiation in a continuous manner and at the same time moving the photographic plate so that it receives a correspondingly decreased intensity.

The author ${ }^{43}$ a number of years ago devised a method for approaching the ideal result obtainable with an uniform energy spectrum and a photographic emulsion of uniform spectral sensibility. By photographing a continuous-spectrum and developing the image to a proper density, this spectrogram may be placed in its correct position in the plate-holder so that spectra thereafter are photographed through it. This automatically compensates approximately for non-uniform spectral distribution of energy and non-uniform spectral sensitiveness of the emulsion. It is especially useful in obtaining the absorption spectra of substances. The "spectrophotographic filter" is made by placing the plate in the holder with the emulsion away from the prism or slit so that when it is replaced in the plate-holder the spectrogram is in contact with the emulsion of the plates upon which absorptionspectra are to be photographed. In the original paper various results with prism and grating spectrographs are 
shown. Of course such a "filter" is useful only for the region for which glass is transparent. For use in the middle ultraviolet it would be necessary to make it on a quartz photographic plate.

For work in the near and middle ultraviolet regions, ordinary emulsions are usually satisfactory; however, for ultraviolet radiation of shortest wave-lengths, gelatine is opaque. Schumann ${ }^{44}$ has described a method for making dry plates for the extreme region but it is not necessary at the present time for the investigator to make his emulsions unless he is concerned with the remote portion of the extreme ultraviolet region. Plates should be of fine grain and free from fog and defects. The spectral limits of sensitiveness of photographic plates and films are due to the opacity of the gelatine and not to the failure of the silver salt to respond. Schumann used a specially prepared emulsion of silver bromide very weak in gelatine. These plates were not sensitive to radiation longer than $300 \mathrm{~m} \mu$ in wave-length. Such emulsions are the only means at present for studying the ultraviolet region of shortest wave-lengths.

The speeds of commercial photographic plates and papers vary over a wide range. Plates of extremely high speed are more than thirty times faster than the slowest plates. The plate commonly used for lantern slides is of fine grain but more contrasty than the more common plate. Fast bromide paper is a thousand times faster than the slowest commercial paper.

Usually the slow emulsions are of fine grain which influences the resolving power. The latter is also greatly affected by the developer. Pyro and hydroquinone are among the best developers for obtaining high resolving power. Huse ${ }^{45}$ has published results obtained with present-day plates and developers. Using pyro-soda developer he found for several plates, the number of lines per millimeter which is just resolvable. The lines were 
opaque and separated by spaces of the same width. His results for typical plates are: albumen 125 , resolution 81 , process 67 , lantern 62, medium speed 35, high speed 27 . Using a lantern-slide plate he found the resolving power of developers to vary from 77 to 47 .

In Chapter IV references are made to atlases of absorption media. Many data pertaining to filters will be found elsewhere ${ }^{17}$ but there is not a great deal available for the ultraviolet. Various preceding chapters contain much of interest pertaining to filters which can be employed in photography. Recently Hodgman ${ }^{46}$ has presented various data pertaining to gelatine filters between glass plates cemented together with balsam. The flowing solution consisted of six per cent by weight of clarified gelatine, a definite quantity of one or more aqueous dye-solutions, and distilled water. The data which he presents includes the dye used, the strength of the aqueous dye-solution, the quantity of this solution used in the final mixture, the quantity flowed per unit area, the wave-length limits of action of light upon various types of photographic plates. The panchromatic plate used was acted upon by the radiation from a "Mazda C-2" lamp after passing through glass, between $350 \mathrm{~m} \mu$ and $720 \mathrm{~m} \mu$. A region of low sensitivity existed for this plate in the vicinity of $520 \mathrm{~m} \mu$. The ordinary plate used exhibited a range of action, under the conditions of the investigation, between $350 \mathrm{~m} \mu$ and $550 \mathrm{~m} \mu$. The action on the orthochromatic plates extended to $630 \mathrm{~m} \mu$. The data pertaining to 41 filters are presented and they include red, orange, yellow, green, blue, pink, violet and purple filters.

Of course, any photo-chemical reaction can be used for measuring the intensity of the radiation involved in producing the reaction. Many of these are discussed in other chapters but a few others may be of interest.

Ultraviolet radiation causes discoloration of filter-paper moistened with a 20 per cent solution of potassium ferrocyanide. 
According to Schall, ${ }^{47}$ paper prepared with p-phenylenediamine nitrate ( $\frac{2}{3}$ normal) is sensitive only to radiation shorter than $313 \mathrm{~m} \mu$ in wave-length. Inasmuch as the solar spectrum does not extend beyond $290 \mathrm{~m} \mu$, this paper may be used for studying the variation in the ultraviolet energy of the shortest wave-lengths present in solar radiation.

The intensity of violet and ultraviolet radiation can be measured by the rate of decomposition of oxalic acid in the presence of uranyl acetate. According to Freer and Gibbs ${ }^{48}$ this reaction has a very small temperature coefficient. The effect of sunlight in promoting the coloration of benzene derivatives such as aniline and cresol has been studied by Gibbs, but these reactions have large temperature coefficients which make them less suitable for measuring the effective radiation than those possessing small or negligible temperature coefficients. In their tests at Manila they found that the average amount of oxalic acid decomposed per hour was 12.45 per cent, the minimum being 1.15 per cent and the maximum being 17.8 per cent. The average obtained by others at Baguio, Philippine Islands, was 14.9 per cent and at Honolulu, 13.9 per cent.

According to Baudisch and Furst ${ }^{49}$ the ammonium salt of alpha-nitrosonaphthylhydroxylamine turns red under exposure to blue, violet, and other radiations which pass through glass. If a piece of spongy paper is treated with this salt, then steamed and exposed to the radiation from a quartz mercury lamp, it will turn a reddish hue whether covered with glass or wholly exposed. If the paper, treated with a solution containing potassium nitrate or potassium iodide and starch, is exposed to the quartz mercury arc it will turn blue where it is bare but not where it is covered with glass.

Bichromated gelatine is easily prepared and is quite useful in studying ultraviolet radiation. Details per- 
taining to this and many other preparations will be found in treatises on the subject. ${ }^{50}$

Photographs of objects illuminated only by ultraviolet radiation differ in general in brightness distribution from that seen by the eye. Various so-called white objects, such as flowers and paints, do not necessarily appear of equal brightness in the photograph. There are many applications for this difference such as in the distinguishing between so-called black inks, the detection of erasures in checks and documents. Wood ${ }^{51}$ made interesting photographs of the moon with ultraviolet filters before the camera. The craters of the moon, for example, exhibited new aspects. He described various screens.

Michand ${ }^{52}$ photographed twenty-four powdered alkaloids illuminated by ultraviolet radiation. $\mathrm{He}$ took one photograph of each under the usual conditions and one of each with a quartz lens silvered on both sides to exclude all radiation but a region between 300 and $330 \mathrm{~m} \mu$. The photographs taken under ordinary conditions showed the alkaloids as white with the exception of that of berberine, which appeared black. The photographs made solely with ultraviolet radiation differed from the other group. Berberine still showed black, 12 were nearly black, 3 were gray, and 8 remained white.

The phenomena of fluorescence and phosphorescence can be employed in the detection and measurement of ultraviolet radiation. In general, ultraviolet radiation excites photo-luminescence and it has been the author's experience that the near ultraviolet is usually most effective. At least the middle region does not appear to be as effective in exciting phosphorescence in the sulphides as in producing photographic action when the effects of the near region are used for comparison. However, photo-luminescence is excited in many substances throughout the entire ultraviolet region represented in the radiation of the quartz mercury arc. 
Fluorescence and phosphorescence have been widely used for the purpose of detecting ultraviolet radiation and to some extent for actually measuring the intensity of radiation. During the recent war signaling by ultraviolet radiation was accomplished by directing the invisible beam upon luminescent substances. This can be done by using a filter of dense cobalt glass which is transparent to near ultraviolet and opaque to visible radiation. Even more efficient filters can be obtained. One of the problems in such a case is to conserve the ultraviolet energy. It can be directed by a parabolic mirror and caught by another at a distance. In the first case the source of the radiation is at the focus of the mirror and in the second case the "luminescent" substance is at the focus. Various methods, sources, and filters were tried and as a consequence of combined experience such signaling was accomplished.

A somewhat similar application was tried out in the convoy system and elsewhere. For example, a quartz mercury arc enclosed in a very dense cobalt blue glass was hung on one vessel. Observers on other vessels equipped with telescopes with fluorescent eye-pieces kept their vessels in correct positions by noting the position of the fluorescent image.

It is known that infra-red radiation quenches phosphorescence. Ives and Luckiesh ${ }^{53}$ studied this phenomenon quite extensively. They also discovered that infra-red caused a momentary flashing-up of the phosphorescence of zinc sulphide several minutes after excitation. These phenomena can be utilized in signaling by projecting a beam of invisible infra-red upon glowing zinc sulphide.

Hauer and Kowalski ${ }^{54}$ devised a monochromatic ultraviolet illuminator and a spectrophotometer designed to measure the comparatively feeble luminosities of phosphorescent and fluorescent substances. They could study the effect of wave-length of the exciting radiation. They 
found, for example, that the fluorescence of lithium platinocyanide is a maximum when the wave-length of the exciting radiation is $390 \mathrm{~m} \mu$. They found that the momentary and the enduring phosphorescence could be easily separated and, for example, the enduring phosphorescence of phenanthrene is excited only by the radiations in the region of selective absorption of the substance.

The rate of decay of phosphorescence depends upon the temperature, as Ives and Luckiesh ${ }^{53}$ showed in their investigations. Phosphorescence may consist of several spectral bands and if the rates of decay of these bands differ there is necessarily a change of color during decay. The author has observed different colors of phosphorescences depending upon the wave-length of the exciting light. This was observed by focusing a large image of the ultraviolet spectrum of mercury upon phosphorescent and fluorescent substances. It appeared that the colordifference was generally due to the superposition of fluorescence (of slightly different color) upon the phosphorescence. The observations of color-differences between the various images of the mercury lines upon the luminescent substance were generally made during excitation. Interesting changes in color during decay of phosphorescence can be produced by mixing two luminescent substances emitting, for example, red and blue phosphorescence respectively. During excitation the combined color is purple but owing to different rates of decay the color may change during decay toward red or blue.

Winther ${ }^{55}$ has described a fluorometer, whose essential principle has been used by various investigators. By means of this device the energy of a given wave-length can be measured in terms of the radiation of a standard lamp whose spectral energy-distribution is known. A pencil of radiation from the standard lamp is permitted to enter a quartz vessel containing a fluorescent liquid. This fluorescent beam is compared in brightness with 
the second or " unknown" beam which is admitted parallel and close to the first. Details of varying the intensity of the standard and of making the photometric comparison are obvious. Of course, the two radiations must have the same wave-lengths in order that their intensities may be proportional to their fluorescence. For the fluorescent materials he used solutions of, (1) rhodamine-B, 0.004 gram per liter (useful for wavelengths shorter than $340 \mathrm{~m} \mu$ and for those between 460 and $600 \mathrm{~m} \mu$ ); (2) sodium fluorescein, 0.01 gram per liter and $2.5 \mathrm{cc}$. of $\mathrm{N}$-sodium hydroxide (useful between 254 and $520 \mathrm{~m} \mu$ ); (3) quinine sulphate, 0.1 gram per liter and $4 \mathrm{cc}$. $\mathrm{N}$-sulphuric acid (useful from $260 \mathrm{~m} \mu$ to the visible region).

The phosphoroscope is a device for observing the phosphorescence of a substance at any desired interval after excitation. It usually involves the rotation of the phosphorescent substance and an adjustment of the observation orifice so that it can be placed at any desired timeinterval after excitation. For so-called fluroescent substances the rotation is rapid because the period of decay of the luminescence is short. For phosphorescent substances the rotation is slower and sometimes may be very slow. For example, Ives and Luckiesh ${ }^{53}$ devised a phosphoroscope by using an 8-day clock and placing a disk containing the material to be studied on the spindle of the hour-hand. They made single photographic exposures requiring as long as 240 hours to obtain the spectrogram desired.

The phosphoroscope has been widely used by investigators of phosphorescent phenomena. Andrews ${ }^{56}$ has described a phosphoroscope which includes a source of ultraviolet radiation and small motor for revolving a disk upon which the luminescent material is placed. A revolving shutter eclipses the exciting radiation several thousand times per minute. By altering the speed of the 
motor the periods of exposure and of darkness may be changed.

By placing a fluorescent screen in the plate-holder of a quartz spectrograph a great deal of qualitative data pertaining to transparency of media in the ultraviolet region can be obtained. An iron arc or other powerful source is focused on the slit by means of a quartz lens and the spectrum is viewed on the fluorescent screen. Uranium glass is very satisfactory for this screen. If stray light is eliminated and the room is quite dark so that the eyes may be adapted to the faint brightnesses, much can be done without resorting to photography. For the study of opaque materials, a hole may be provided in the side of the camera near the acute angle made with the plateholder. Fluorescent liquids can be utilized or studied to advantage by projecting the exciting spectrum upon their surfaces. They may be viewed from above or from the side. There are a great many variations of interesting modes of attack.

Krïss ${ }^{57}$ among others has described a spectrophotometer for the ultraviolet region in which a fluorescent screen is used in the eye-piece. The principle employed in this instrument is extremely valuable in qualitative studies and it has some possibilities in quantitative work.

To separate radiations differing considerably in wavelength advantage may be taken of the chromatic aberration of a simple lens. In other words, radiation of shorter wave-length comes to a focus nearer to the lens than radiation of longer wave-length. This expedient has been used in infra-red work to excellent advantage. For separating ultraviolet from visible radiation a quartz lens may be used to bring the rays of a spark to a focus. This focus will not be at a point, but considering all wavelengths, it will be along a line. If a small hole in a sheet of metal be placed at a certain point along this line, the radiation passing through the hole will consist chiefly of 
radiation near the wave-length of that radiation which happens to be focused upon the hole. The radiation coming directly from the spark along the optical axis consists of all radiations so that beyond the hole at some distance a small shield must be placed to absorb this radiation which includes undesired radiations. The principle has often been applied in research in radiation. If a more detailed description is desired reference may be made to an article by Andrews. ${ }^{58}$

The ultraviolet may be separated from the visible radiation by forming a spectrum with a quartz spectrograph, screening off the visible, and recombining the ultraviolet spectrum by means of a quartz lens.

Chemically pure substances in general exhibit fluorescence and phosphorescence only faintly. Different kinds of glass exhibit characteristic fluorescence. Rods of sodium hydroxide exhibit a reddish fluorescence and a greenish color when rapidly moved away from the exciting source. There are many applications of phosphorescence not only in the detection of ultraviolet radiation but also in the detection of substances.

Almost any substance fluoresces to some degree at least and a great many have been studied. Space does not permit a discussion of these investigations. Nichols and Merritt have conducted such investigations for years and much of their work has been collected in a single publication. ${ }^{59}$ Among the substances which they investigated are rhodamin, fluorescein, eosin, chorophyll, uranium glass, fluorspar, esculin, resorufin, sidot blende, Balmain's paint (calcium sulphide), willemite, and various other aniline dyes and salts.

The colors of the luminescence of a few substances are as follows: calcite, red; barium sulphide, orange; fluorescein and eosin, yellow; cadmium compounds, yellow; uranium glass, greenish yellow; willemite, yellow-green; some salts of salicylic acid, blue; calcium sulphide and 
some other compounds of calcium, violet; calcium tungstate, light blue; zinc silicate, green. Other colors are emitted by other substances and they can be obtained by mixture. Such mixtures are interesting because of the different rates of decay of the luminescence of the components. Certain blue fluorspars exhibit luminescence after exposure to radiation. It is said that the phosphorescence of these media excited by heat emits ultraviolet radiation which is photo-chemically active.

An aqueous solution of quinine sulphate fluoresces a violet-blue color. It is excellent for demonstrating to a large audience the existence of ultraviolet radiation.

Baskerville ${ }^{60}$ has noted the application of ultraviolet radiation in testing minerals. Certain minerals are unaffected, some fluoresce and others phosphoresce. Kunzite was discovered with the aid of ultraviolet radiation. Spodumene specimens were found to be generally unaffected. He claims that the fluorescence of diamonds is an indication of genuineness. A crushed mineral may be separated into fluorescent and non-fluorescent portions and this has been resorted to for testing willemite concentrates and tailings. Willemite is fluorescent but the gangue is not. If the tailings contain no fluorescent particles the concentration process is known to be efficient.

The color of the fluorescence is generally diluted or altered by the body color of the substance. This can be easily seen in oils and dye solutions. A tablet of soda salicylate may appear white or slightly bluish in daylight owing to its blue fluorescence but the latter is quite overwhelmed by the luminosity of the reflected radiation. Under a high-tension spark, which emits relatively much less visible but a great deal of ultraviolet radiation, the blue fluorescence of the soda salicylate is more prominent. Ordinary glass and quartz are readily distinguished by interposing between the soda salicylate and the source. The former absorbs the radiations which, excite the blue fluorescence but quartz does not. 
Wolff ${ }^{61}$ found certain specimens of dehydrated potassium carbonate exhibited a reddish luminescence but the purified salt did not. He concluded that the luminescence was due to potassium sulphide, and that ultraviolet radiation is an aid in detecting this compound in commercial potassium carbonate.

Tiede ${ }^{62}$ found all pure preparations of magnesium sulphide fluoresced faintly under exposure to radiation from the sun or an arc lamp. Apparently magnesium sulphide is sensitive particularly to the longer wave-lengths for it did not appear to respond to ultraviolet, radium, or Röntgen rays. Cathode rays caused it to fluoresce blue or red.

Stark and Meyer ${ }^{63}$ have discovered that many substances exhibit fluorescence in the ultraviolet region. This makes it necessary to recast some of the theories which are based only upon visual observations.

Stokes was one of the earliest investigators of fluorescence and phosphorescence and from his work he enunciated the law that the emitted radiation is always of greater wave-lengths than those of the exciting radiation which is absorbed by the fluorescent substance.

Kauffmann ${ }^{64}$ suggested that the change in color of fluorescence with change in the solvent follows the same order as the change of color itself. The fluorescent band of a solid substance lies farthest toward the ultraviolet, then follow the solutions in indifferent solvents, then those in dissociating solvents. According to Baly's theory the fluorescence continues a phase ahead of the absorption.

Stark has advanced the opinion that all substances possessing selective absorption are fluorescent. This is not based upon complete experimental evidence but there are many data which seem to fit the theory.

Wasicky and Wimmer ${ }^{65}$ have used ultraviolet radiation for illuminating cocoa for the purpose of distinguishing by means of a microscope the shell and nib tissue. They used a carbon arc and the well-known filter consisting of 
" uviol" (Jena) glass cells one of which contained a concentrated solution of copper sulphate and the other a solution (1:12000) of nitrosodimethylaniline. The tissue of the shell in this case appeared brownish; the nib tissue appeared bluish-violet. Ultraviolet radiation may be used in this manner owing to fluorescent effects or in the case of photo-micrography because of the greater resolving power of the microscope for radiation of short wave-length. Of course, in the latter case only the radiation of greater wave-length than about $350 \mathrm{~m} \mu$ would be effective with a glass optical system.

The photo-electric cell has been used in the detection and measurement of ultraviolet radiation as has been noted in other chapters. In fact, it appears to be the most sensitive device for this purpose, provided a suitable galvanometer or electrometer is available. Many scientific applications have been made of photo-electric phenomena during recent years. Allen ${ }^{66}$ and Hughes ${ }^{67}$ have presented extensive discussions of the phenomena.

Herz, in 1887, discovered that ultraviolet radiation incident upon a spark-gap caused a decrease in the voltage necessary for the passage of a spark. It was soon found that the effect was due to the emission of electrons and the formation of ions. Hallwachs ${ }^{68}$ was the first to investigate the phenomena systematically. He found that a clean piece of zinc when illuminated by ultraviolet radiation, lost the electric charge which it possessed. It was also found that an insulated body acquired a positive charge when illuminated by ultraviolet radiation. This is due to the emission of negative electrons.

Many metals exhibit the photo-electric effect when illuminated by ultraviolet radiation. The electric current produced increases with the intensity of the radiation. Apparently under certain conditions the current is proportional to the intensity of radiation. This proportionality may not always exist under the conditions of the 
experiment so that it is well to determine the relation between current and intensity of radiation in any given case.

Elster and Geitel ${ }^{69}$ have been pioneers in this field of research. They have shown that electro-positive bodies such as potassium and sodium are photo-electrically active under visible radiation. Zinc and aluminum exhibit the effect under solar radiation. Rubidium is photo-electrically active even under the radiation of a carbon filament lamp. Various metals, liquids, and vapors exhibit the effect so that there are many substances to choose from in utilizing the photo-electric effect in the detection and measurement of ultraviolet radiation. Photo-electric cells can be purchased or they can be made by following the methods described in the references.

Kreusler ${ }^{70}$ was one of the earliest to use the photoelectric phenomenon for the purpose of measuring ultraviolet radiation. He employed a piece of clean platinum in a vessel containing hydrogen at about $200 \mathrm{~mm}$. pressure. The piece of platinum which was charged negatively, was near another metal which was the anode. The current flowing from the cathode to the anode when the former was illuminated by radiation was taken as a measure of the intensity of radiation. Of course, he ascertained the relation between current and intensity of radiation.

Elster and Geitel ${ }^{71}$ have described very sensitive cells consisting of colloidal potassium. The alkali metals are quite widely used for photo-electric cells. Hughes ${ }^{72}$ has described a sodium cell which appears quite suitable to the measurement of ultraviolet radiation. Among other results he found that the ionization of the air by ultraviolet radiation begins at about $135 \mathrm{~m} \mu$.

The relation of the wave-length of radiation to the photo-electric effect differs for various metals. Sodium is most sensitive to yellow light and potassium to blue 
light. Most metals exhibit the maximum effect under ultraviolet radiation. Among others Ladenburg ${ }^{73}$ has studied this phase of photo-electricity. Using a mercury arc as the source and a fluorespar prism he found that copper, platinum and zinc exhibited the maximum photoelectric effect in the region of $215 \mathrm{~m} \mu$. For equal intensities of radiation the photo-electric effect increased with decreasing wave-length throughout the ultraviolet regions.

That the middle ultraviolet is more active than the near ultraviolet radiation in producing the photo-electric effect with such metals as aluminum, magnesium, and zinc is shown by the fact that solar radiation is not as active as radiation from sparks and arcs. The active rays in solar radiation are almost completely absorbed by glass. However, even visible rays produce photo-electrons to some extent from aluminum.

The velocity of the electrons emitted by a metal plate in a vacuum is proportional to the frequency (or wavelength) of the incident radiation. This is Ladenburg's law and it apparently holds, at least approximately throughout the ultraviolet region.

Lenard ${ }^{74}$ discovered a volume ionization in the gas surrounding the metal plate. This is independent of the Hallwach's effect exhibited by the metal. Lenard showed that the ionization of the gas was associated with the absorption of the ultraviolet radiation by the gas.

One of the latest papers on the photo-electric photometry of ultraviolet radiation is by Elster and Geitel. ${ }^{75}$ They discuss improvements in the cadmium ultraviolet photometer.

Gibson ${ }^{76}$ has recently described a photo-electric method of photometry which may serve as an example of the procedure. This is a null method which has been used very successfully. He discusses the utility of the photo-electric photometer as compared with that of the Hilger 
sector-photometer for the ultraviolet region; and the spectrophotometer for the blue and violet regions. The potassium-hydride cell which is on the market exhibits a maximum activity for radiation of $460 \mathrm{~m} \mu$ in wave-length when used with an incandescent lamp and a glass prism.

Coblentz ${ }^{77}$ has presented a summary of the characteristics and methods of use of the photo-electric cell and also a valuable bibliography of the subject.

Among the more recent investigations of the color-sensitiveness of photo-electric cells is that of Seiler, ${ }^{84}$ but the sensibility curves were not obtained for the ultraviolet region. Thirty cells were studied including all the alkali metals and hydrides of $\mathrm{Na}, \mathrm{K}, \mathrm{Rb}$, and $\mathrm{Cs}$. It was found that as the atomic weight of the alkali metal increases, the maximum sensitiveness decreases, the resonance peak becomes broader, and the wave-length of maximum sensitiveness shifts toward the red. The author suggests that these changes may be associated with the increase in atomic volume. For glass cells containing argon at low pressure the wave-lengths of maximum sensitiveness were found to be as follows: $\mathrm{Li} 405 \mathrm{~m} \mu, \mathrm{Na} 419 \mathrm{~m} \mu, \mathrm{K}$ $440 \mathrm{~m} \mu$, Rb $473 \mathrm{~m} \mu$, Cs $539 \mathrm{~m} \mu, \mathrm{NaH} 427 \mathrm{~m} \mu, \mathrm{KH} 456 \mathrm{~m} \mu$, $\mathrm{RbH} 481 \mathrm{~m} \mu \mathrm{CsH} 540 \mathrm{~m} \mu$. It was found that the substitution of quartz for the glass shifts the maximum toward longer wave-lengths. No fatigue effect could be detected in these cells.

According to Halban and Geigel ${ }^{85}$ the photo-electric cell is applicable to the measurement of absorption of radiation from 300 to $630 \mathrm{~m} \mu$ with the gas-filled tungsten lamp and as far into the ultraviolet as $253 \mathrm{~m} \mu$ with the mercury arc.

Barnard ${ }^{88}$ has described a microscope designed to be used with ultraviolet radiation. Objects that exhibit little or no structure by ordinary transmitted light are seen to be highly organized when examined by ultraviolet radiation and the structure seen is in part dependent on the wave- 
length used. Objects examined by this method must be dealt with in the living state or at least under conditions such that no change takes place in their constitution, hence the ordinary methods of mounting can not be employed. The method is, in effect, its own staining process, differentiation of structure depending on the difference in absorption in the ultraviolet. The organisms or tissue are placed in any suitable fluid which is transparent to ultraviolet radiation and the photograph is taken. The slides used are of fused quartz with the smallest possible amount of gelatine upon them.

Kögel ${ }^{87}$ has successfully utilized fluorescence in the photography of palimpsests. Under the illumination by ultraviolet radiation $(334 \mathrm{~m} \mu)$ of a quartz mercury arc, the parchment fluoresces but the erased writing remains almost dark, though the old inks used sometimes contained sulphur compounds. Chemical alteration of the parchment or greasing generally does not weaken the contrasts. This fluorescent photography often brings out detail not disclosed by the other methods and has much improved the exploration of old manuscripts.

The index of refraction of air has been studied by many investigators but usually the work has been done with white light or with one monochromatic radiation. Recently Meggers and Peters ${ }^{88}$ made observations at spectrum intervals of about $4 \mathrm{~m} \mu$ from 220 to $900 \mathrm{~m} \mu$. Complete sets of observations were made on dry air at atmospheric pressure and at temperatures of $0^{\circ}, 15^{\circ}$, and $30^{\circ} \mathrm{C}$. They found that the data are quite closely represented by certain dispersion formulae of the Cauchy form. They used these observations in the construction of a table giving the corrections which must be applied to wave-lengths measured in air whose density is not normal. They also present a table of corrections for converting wave-lengths or frequencies measured in air to their values in a vacuum. 
The dispersion of hydrogen has recently been investigated by Kirn ${ }^{89}$ with the result that he has tabulated the refractive indices between 185.4 and $546.2 \mathrm{~m} \mu$.

Duclaux and Jeantet ${ }^{90}$ have recently described a method of treating ordinary plates so as to increase greatly the sensitiveness to the radiation of the shorter wave-lengths. They had need of plates sensitive beyond $190 \mathrm{~m} \mu$, and tried the procedure advocated by Schumann, but found it tedious and uncertain. Schumann plates are distinguished by the small proportion of gelatin, and it was thought that this condition could be secured by degelatinizing to a great extent ordinary plates. Trials of various methods, such as immersion in warm water, acid solutions, digestive enzymes, were without success, but a simple and satisfactory procedure was devised.

The plate is placed horizontally in a dish with dilute sulphuric acid (one volume of the strong acid to ten volumes of water), and kept for four hours at room temperature (about $77^{\circ} \mathrm{F}$.), the temperature being a little higher than this at the beginning and a little lower at the end. They are then removed to a dish in which they are washed by a very slow current of water, as the remaining gelatin is tender. Thirty minutes will be a sufficient washing. They are then dried, which requires but little time on account of the small amount of gelatin present. Plates thus treated retain a thin layer of emulsion poor in gelatin and uniformly spread on the glass. This deposit is extremely sensitive to ultraviolet radiation, but is also very fragile, and the authors recommend that before developing the surface should be coated with a thin film of collodion, the plate being immersed in the developing bath before collodion is quite dry. Although most commercial plates are adapted fairly well for this procedure, it is likely that trial with many forms will show some more suitable than others. For rays of much greater wave-length than above noted, these plates 
are ten times more sensitive than the best plates prepared according to Schumann's method, and at least 200 times as sensitive as the plate in its commercial form.

Another method for obtaining plates of high sensitiveness to radiation of short wave-lengths is by covering the emulsion with a layer of fluorescent substance. Such a substance absorbs, so to speak, the short waves and emits in turn waves of greater length, to which the gelatin is transparent, and thus permits an action on the silver compound, hence the impression is made as if the gelatin was not present. For this method, substances giving blue or violet fluorescence should be chosen, and they should be dissolved in a liquid that will not swell the gelatin, and is not absorbed by it, since the efficiency of the process depends on the fact that the fluorescent rays act before the light enters the gelatin film. Water is, therefore, not applicable. Duclaux and Jeantet obtained good results with a solution of esculin in glycerol, but found most satisfactory results with lubricating oil. Many of the commercial forms of these have a distinct fluorescence due to hydrocarbons. It is sufficient to smear a few drops of such an oil over the emulsion by means of a wad of cotton. After exposure this film should be removed by means of ether or alcohol. A very thin fluorescent layer may be obtained by immersing the plate for a few minutes in a solution of the fluorescent oil in light petroleum or alcohol and allowing the solvent to evaporate. These procedures are simple and effective. They enable the operator to secure photographs of rays ranging from the extreme red to the limit of the ultraviolet. One slight defect is noted, a very small enlargement of the rays by irradiation, but this does not go beyond the twentieth of a millimetre. The processes have been tried with many commercial plates, and the sensibility is found to be greater than with the sulphuric acid method. It is possible, indeed, to carry out an instantaneous spectrography. Detailed results 
with certain metallic spectra are given in the original paper.

In this chapter only glimpses of the chief facts of very extensive fields such as photography and photo-electricity have been presented. Some applications are touched upon in various chapters but for more complete treatises especially upon photography and photo-electricity the reader may consult the references given. It may appear that the photo-electric cell has not been adequately discussed; however, it appears the better plan to wait until it becomes better developed and the procedure more standardized for every-day applications.

\section{References}

I. Bul. Bur. Stds. 9, I912, 7 .

2. Outlines of Applied Optics, Igr2.

3. Ann. d. Phys. 37, 1899, 529.

4. Ann. d. Phys. 35, I910, 928.

5. Ann. d. Phys. 24, 1907, 25.

6. Phys. Zeit. 4, I903, 6I4 and 86I; 5, I904, 34.

7. Phil. Trans. 166, 1876, 325 .

8. Phys. Rev. 4, 1897, 297.

9. Bul. Bur. Stds. 4, 1908, 404.

ro. Proc. Roy. Soc. 42, 1887, $189 ; 44,1888,96 ; 47,1890,480$.

II. Soc. Franc. d. Phys. I886, 30 and 77 .

12. Soc. Franc. d. Phys. I908, I48.

I3. Ann. d. Phys. 29, I909, I003.

I4. Bul. Bur. Stds. 2, I906, 476.

15. Proc. Roy. Soc. 23, IgIo.

16. Arch. Sci. Phys. Nat. I8, I887, 347.

I7. Color and Its Applications, I92I, 200.

I8. Ann. d. Phys. I3, I904, 890.

r9. Phys. Zeit. 4, I903, 6r4 and 86r; 5, I904, 215.

20. Ann. d. Phys. 8, Igor, I.

21. Smithsonian Contrib. No. I4I3; Ber. Akad. Wien. I02, IIa, 625 .

22. Astrophys. Jour. 23, I906, I8I. 
23. Proc. Manchester Phil. Soc. 49, I904, I.

24. Proc. Roy. Soc. IgI9, 258.

25. Proc. Roy. Soc. Edinburgh, 32, I912, 40.

26. Chem. Abs. I9I7, 3I33.

27. Smithsonian Physical Tables, 1920.

28. Wied. Ann. 45, I892.

29. Ann. d. Phys. 6, I901; 8, 1902.

30. Inaug. Dis. Berlin, Igog.

3I. Ann. d. Phys. I2, I903, II 55.

32. Trans. Farady Soc. 7, 1912, 267.

33. Phys. Zeit. I4, I9I3, 336.

34. The Photographic Process, r907.

35. Photochemistry, IgI4.

36. Phys. Rev. 8, I9I6, 674.

37. Bur. Stds. Tech. Pap. I48.

38. Comp. Rend. 156, I913, 389.

39. Jour. d. Phys. 3, I9I3, 305.

40. Phys. Rev. I6, I903, I29.

4I. Trans. I. E. S. Io, I9I 5, I49; Elec. World, 64, I9I4, I29 and 954 .

42. Ann. d. Phys. 4I, I9I3, IOI2.

43. Astrophys. Jour. 43, I9I6, 302.

44. Ann. d. Phys. 5, I90I, 349.

45. J. Opt. Soc. July, rgr 7 .

46. Phys. Rev. I7, I921, 246.

47. Chem. Ztg. 34, 267 .

48. J. Phys. Chem. I6, I9I2, 709.

49. Ber. 45, I9I2, 3426 .

50. Cassell's Cycl. of Photography.

5I. Smithsonian Inst. IgII, 155.

53. Astrophys. Jour. 34, IgII, I73; 36, I9I2, 330.

52. Science, I9I2, 4I5.

54. Phys. Zeit. I5, I914, 322.

55. Z. Elecktrochem. I9, I9I3, 389.

56. Gen.. Elec. Rev. IgI7, 259.

57. Zeit. f. Inst. 23, I903, I97 and 229.

58. Gen. Elec. Rev. I9I7, 8I7.

59. Carnegie Inst. Pub. No. I52.

6o. Electrochem. Met. Ind. 1906, 435. 
6r. Chem. Zeit. 36, I9r2, I97.

62. Ber. 49, I745.

63. Phys. Zeit. 8, 1907, 250.

64. Ber. 4I, rgo8, 4396.

65. N. Nahr. Genussm. 30, 19r5, 25.

66. Photo-Electricity, rgr3.

67. Photo-Electricity, r9r4.

68. Wied. Ann. 33, r888, 3 or.

69. Ann. d. Phys. 38, 1889, 40 and 497.

70. Ann. d. Phys. 6, Igor, 4I2.

71. Phys. Zeit. I2, I9II, 758.

72. Phil. Mag. 25, I9r3, 679.

73. Phys. Zeit. 8, r907, 590.

74. Ann. d. Phys. I, I900, 486; 3, I900, 298.

75. Phys. Zeit. I9I 5, 405.

76. Bur. Stds. Sci. Pap. No. 349.

77. Bur. Stds. Sci. Pap. No. 3 I9.

78. Astrophys. Jour. 52, I920, 47.

79. Astrophys. Jour. 53, I92 I, I50.

8o. Proc. Roy. Soc. 99, I921, 78.

81. Collected Works, vol. I, p. 2 I3.

82. Phil. Trans. A, 2I7, I9I7, 24I.

83. Comp. Rend. I70, I920, 226.

84. Astrophys. Jour. 52, 1920, I29.

85. Z. Phys. Chem. 96, I920, 214.

86. Nature, I06, I920, 378.

87. Preuss. Akad. Wiss. Berlin, Ber. 37, I9r4, 974.

88. Bull. Bur. Stds. I4, 1918, 697.

89. Ann. d. Phys. 64, I92I, 566.

9o. Jour. d. Phys. ii, I921, I56. 


\section{CHAPTER XI}

\section{EFFECTS UPON LIVING MATTER}

That radiation affects living cells is evident by sunburn, snow-blindness, sterilization, and in many other ways. Man has no sensory organs for detecting radiation beyond the limits of the visible spectrum. He protects himself from the glare or the heat of the sun which saves him from the slight amounts of harmful ultraviolet radiation. Fortunately the shortwave limit of the spectrum of solar radiation is about the same as the short-wave limit of transparency of the cornea. As a matter of fact the eye evolved through adaptation to solar radiation and, therefore, it is not strange that these two limits practically coincide. Man has devised artificial sources of ultraviolet radiation of such wave-lengths as to be harmful. When these invisible rays accompany the light rays much damage may be done. But with the development of such sources, knowledge of the effects of radiation increased so that man is able to protect himself from the harmful rays and also to utilize them to his advantage.

It has long been known that intense radiation, especially of the shorter wave-lengths, caused painful irritation of the anterior tissue of the eye. "Snow-blindness" is a common result of intense solar radiation and it is now known that snow reflects the ultraviolet rays in solar radiation very efficiently. The result is a painful irritation which usually becomes apparent several hours after exposure. The eyes first appear to contain foreign matter, that is, to feel "sandy." This disorder has been termed "photophthalmia." Various associated effects arise from 


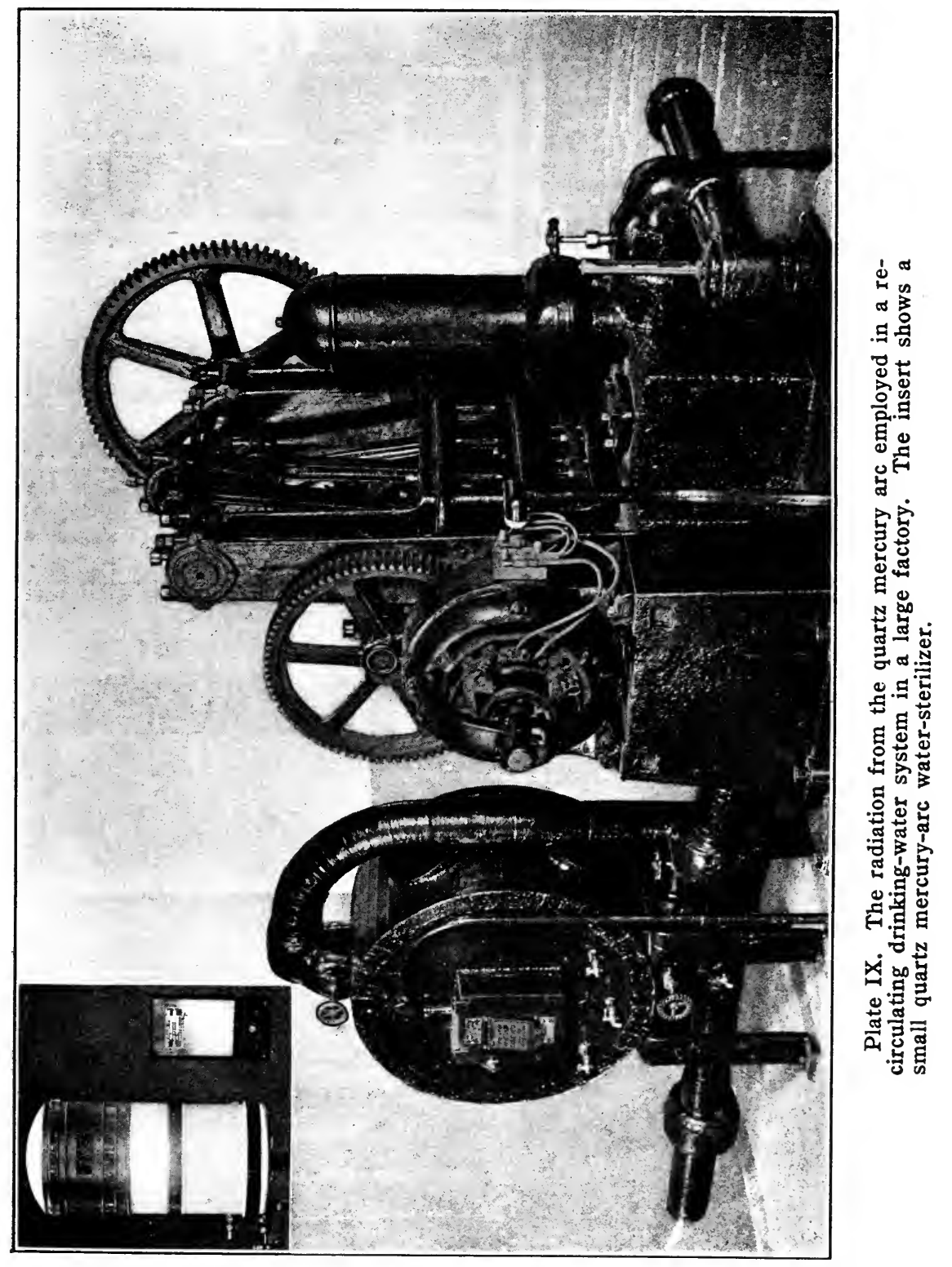



gazing at a partial eclipse of the sun and this disorder has been termed "eclipse blindness." Since the advent of artificial sources rich in ultraviolet radiation, the first one being the carbon arc, many cases have arisen of what was termed "ophthalmia electrica." It has long been known that the effective radiation has been that of the shorter wave-lengths in solar radiation and also those in the middle and extreme regions of the ultraviolet from artificial sources.

Verhoeff and Bell ${ }^{1}$ in their extensive investigations, which will be referred to occasionally, found that it is the radiation shorter than $305 \mathrm{~m} \mu$ in wave-length which is able to injure cells by chemical action. They found that at least $2 \times 10^{6}$ erg-seconds per sq. $\mathrm{cm}$. of such energy is necessary to produce a well marked photophthalmia. They found that for any source yielding rays capable of producing pathological effects on the cornea, the time of exposure required to produce the symptoms of photophthalmia is inversely proportional to the intensity of the radiation of the effective rays. Of course, allowance must be made for "physiological repair" when the intensity of radiation is so feeble as to require very long periods of exposure. They verified the inversesquare law over a large range of intensities of radiation, that is, that the time required for the development of characteristic symptoms varied according to the inverse square of the distance from the source of the harmful radiation. They also found that the energy effects are additive for at least the first 24 hours of intermittent exposure.

According to these investigators there is a practical limit to the abiotic action of ultraviolet radiation, for the action of radiation of longer wave-length than $305 \mathrm{~m} \mu$ is so slight as to be overcome under ordinary circumstances by the physiological activities of the cells.

Hallauer ${ }^{2}$ found that the lens of the adult human eye 
is opaque to radiation shorter than $376 \mathrm{~m} \mu$ in wave-length and often to that shorter than $400 \mathrm{~m} \mu$. He found a slight transparency between 315 and $330 \mathrm{~m} \mu$ in some lenses from the eyes of children. It may be safely stated that the retina of the average adult eye does not receive radiation of shorter wave-length than $350 \mathrm{~m} \mu$ and not much energy of shorter wave-length than $400 \mathrm{~m} \mu$. Parsons ${ }^{3}$ studied the spectral transmission of the parts of a rabbit's eye in normal saline solution. He found that the absorption by the lens began at $400 \mathrm{~m} \mu$ and became complete at $350 \mathrm{~m} \mu$. This result has been obtained by various other investigators.

There is a great deal of evidence that the transparency of the cornea extends to $295 \mathrm{~m} \mu$; that is, the cornea transmits radiation of greater wave-length than $295 \mathrm{~m} \mu$. Parsons found a layer, $3 / 16$ inches thick, of the vitreous humor of a rabbit's eye, to be transparent to $280 \mathrm{~m} \mu$, and the transparency to extend to $270 \mathrm{~m} \mu$. He also found that measurements upon eye-media several hours after death yielded results identical with fresh specimens.

Schanz and Stockhausen ${ }^{4}$ have published the transmission spectra of eye-media. They found that the cornea was transparent to $300 \mathrm{~m} \mu$ and later decided that it was transparent only as far as $320 \mathrm{~m} \mu$ for practical considerations because the transparency rapidly diminished from 320 to $300 \mathrm{~m} \mu$. Martin ${ }^{5}$ obtained results which agreed with those of Parsons, that is, that the cornea was transparent to $295 \mathrm{~m} \mu$.

In general, the aqueous and vitreous humors transmit radiation of shorter wave-length than that transmitted by the lens. Birsch-Hirschfeld ${ }^{6}$ found the limit of transparency of a thickness of $1 \mathrm{~cm}$. of vitreous humor to be at $300 \mathrm{~m} \mu$ and that it was the same for all animals. This result has been confirmed by others.

There appears to be a considerable variation in the transparency limit of lenses from the eyes of different 
animals as well as of lenses of the same species. As already seen, the latter statement applies to human lenses. Widmark ${ }^{7}$ found that the short-wave limit of visibility of radiation changed with age. Children between the ages of 11 and 20 years obtained a visual sensation from radiation of wave-length as short as $386 \mathrm{~m} \mu$. The limit shortened with increasing age so that it was at $402 \mathrm{~m} \mu$ for persons between the ages of 62 and 74 years. Of course, the limit is not necessarily established by the transparency of the lens. Apparently, fluorescence of the lens is caused by radiation between 350 and $400 \mathrm{~m} \mu$ in wave-length and the maximum effect is due to radiation of wave-length $385 \mathrm{~m} \mu$.

It is quite evident that the lens of the human eye absorbs the radiation between 295 and $350 \mathrm{~m} \mu$ in wave-length which is incident upon the cornea. An evidence of its absorption is the fluorescence which it exhibits. No radiation of shorter wave-length than $350 \mathrm{~m} \mu$ and perhaps $380 \mathrm{~m} \mu$, can reach the retina of an adult eye. In fact, as the eye ages, the cornea becomes yellowish and its absorption extends sometimes only as far as $420 \mathrm{~m} \mu$.

Chardonnet $^{8}$ employed a silvered quartz plate of such thickness of silver film as to be opaque except for the region between 301 and $343 \mathrm{~m} \mu$ in attacking the question of transparency of eye-media. Normal eyes could not see an electric arc through this glass but eyes from which lenses had been removed through operation for cataract, could detect movement of the arc.

It is certain that the radiations most effective in causing sunburn, irritation, and, in fact, the destruction of animal tissue, are chiefly confined to the middle ultraviolet region. Schunck $^{9}$ exposed the forearm to ultraviolet radiation and concluded that the greatest effect was in the region of 235 to $250 \mathrm{~m} \mu$ although the region was indefinite.

Henri and Moycho ${ }^{10}$ exposed the ear of a rabbit to the ultraviolet spectrum from 230 to $330 \mathrm{~m} \mu$. The most 
active radiation was that at $280 \mathrm{~m} \mu$ and the energy necessary to produce irritation was found to be $0.057 \times 10^{7}$ ergs per sq. $\mathrm{cm}$. No effects were detected for $330 \mathrm{~m} \mu$ and for the region of shorter wave-length than $250 \mathrm{~m} \mu$.

The work of Verhoeff and Bell ${ }^{1}$ has shown that abiotic action for living tissues is confined to wave-lengths shorter than $305 \mathrm{~m} \mu$. Their work was exhaustive and it included a discussion of the investigations by others. Their published article is accompanied by an extensive bibliography and digest of the pertinent literature by Walker. ${ }^{11}$

Burge ${ }^{12}$ found that the radiation from a quartz mercury arc sufficiently intense to coagulate egg albumen, egg globulin, vitellin, serum albumen, and serum globulin in one hour of exposure, did not coagulate the protein in the normal lens or of the humors in 100 hours of exposure. The radiation which coagulated egg-white was between 265 and $320 \mathrm{~m} \mu$, the most effective being near $265 \mathrm{~m} \mu$. The lens protein can be modified by solutions of calcium chloride, magnesium chloride, sodium silicate or dextrose too weak of themselves to affect the transparency of the lens, so that ultraviolet radiation can precipitate the modified protein and thus produce opacity of the lens. The effective region was between 265 and $302 \mathrm{~m} \mu$ for the source of radiation employed. He claims that senile cataractous human lenses show that calcium, magnesium, and in lenses from India, silicates are greatly increased in this type of cataract. The assumption is made that the accumulation of these substances modifies the lens protein in such a way that the ultraviolet radiation precipitates the protein thus producing cataract.

According to Burge ${ }^{13}$ ultraviolet radiation kills living cells and tissues by changing the protoplasm of the cells in such a way that certain salts can combine with the protoplasm to form an insoluble compound or coagulum. He found the effective radiation to be between 254 and $302 \mathrm{~m} \mu$ in wave-length. He produced cataract in the eyes 
of fish living in dilute solutions of those salts, found to be greatly increased in human cataractous lenses, by exposing the eyes to the radiation from a quartz mercury arc. Abnormal quantities of the salts of calcium and sodium silicate in the cells of the eyelids and of the cornea increase the effectiveness of ultraviolet radiation in producing anterior eye trouble. Abnormal quantities of these upon the skin also increase the effectiveness of the ultraviolet rays in solar radiation in producing sunburn.

Many germs appear to thrive better in the dark than when exposed to solar radiation. Perhaps ordinary visible radiation kills some kinds of germs but in general it is ultraviolet radiation which is effective. The modern artificial sources, such as the quartz mercury arc, the carbon and flame arc, the magnetite arc, and such processes as arc welding, yield ultraviolet radiation of powerful germicidal action.

Henri and his wife ${ }^{14}$ found that the absorption of eggalbumen for radiation of various wave-lengths corresponded closely to the time-value of bactericidal action for the same radiations. The absorption and abiotic action are taken to be indicative of each other. If this is true, the abiotic action is powerful near $200 \mathrm{~m} \mu$ and rapidly diminishes for radiation between wave-lengths 210 and $230 \mathrm{~m} \mu$. From 250 to $310 \mathrm{~m} \mu$ the effect is relatively small and decreases slowly. It apparently ends at $310 \mathrm{~m} \mu$. They found the abiotic action at $215 \mathrm{~m} \mu$ to be about 25 times greater than at $250 \mathrm{~m} \mu$ and several hundred times greater at $300 \mathrm{~m} \mu$.

In experiments which aim to determine the effect of ultraviolet radiation upon animal tissue, the so-called "heat effect" must be eliminated. This is especially true if the radiation is focused upon the tissue by means of lenses. Obviously, the radiation is destructive if it is of sufficient intensity to burn in the ordinary sense. A water-cell usually serves satisfactorily enough for eliminating a great deal of the infra-red. 
Browning and Russ ${ }^{15}$ have described experiments with radiation from 210 to $700 \mathrm{~m} \mu$ recorded by means of a quartz spectrograph. A glass plate coated with nutrient agar and an emulsion of staphylococcus pyłogenes aureus was exposed in the spectrograph for several minutes. It was then incubated and it was found that germicidal action had taken place between 238 and $294 \mathrm{~m} \mu$. The maximum action was between 254 and $280 \mathrm{~m} \mu$. An exposure of $3 \frac{1}{2}$ hours showed the limits of germicidal action to be $215 \mathrm{~m} \mu$ and $296 \mathrm{~m} \mu$. Radiations between 296 and $380 \mathrm{~m} \mu$ exhibited no effect on germs but they were found to penetrate the human skin for an appreciable depth. The radiation between 210 and $296 \mathrm{~m} \mu$ was absorbed by a thickness of $0.1 \mathrm{~mm}$. of human skin.

The more or less indefinite long-wave limit of germicidal action is in the vicinity of the short-wave limit of the solar radiation which reaches the earth. It is likely that a slight change in atmospheric conditions or a large variation in intensity of radiation might have a great influence upon the germicidal action of solar radiation.

Bovie ${ }^{16}$ studied the germicidal power between 250 and $300 \mathrm{~m} \mu$. He found that radiation of wave-lengths shorter than $292.5 \mathrm{~m} \mu$ killed bacteria and spores of various fungi in 10 minutes but radiation $2.5 \mathrm{~m} \mu$ longer in wave-length did not kill in two hours. In Chapter II it has been seen that the end of the solar spectrum varies in the vicinity of these wave-lengths.

Bovie found that ultraviolet radiation can penetrate blood-filled tissue to a depth of only a fraction of a millimeter, but if the skin is rendered anemic by eliminating the blood by pressure, ultraviolet radiation kills bacteria through $4.25 \mathrm{~mm}$. of tissue. He discussed at considerable length the interesting phase of fluorescence in relation to germs, living tissues, and various chemical reactions. 



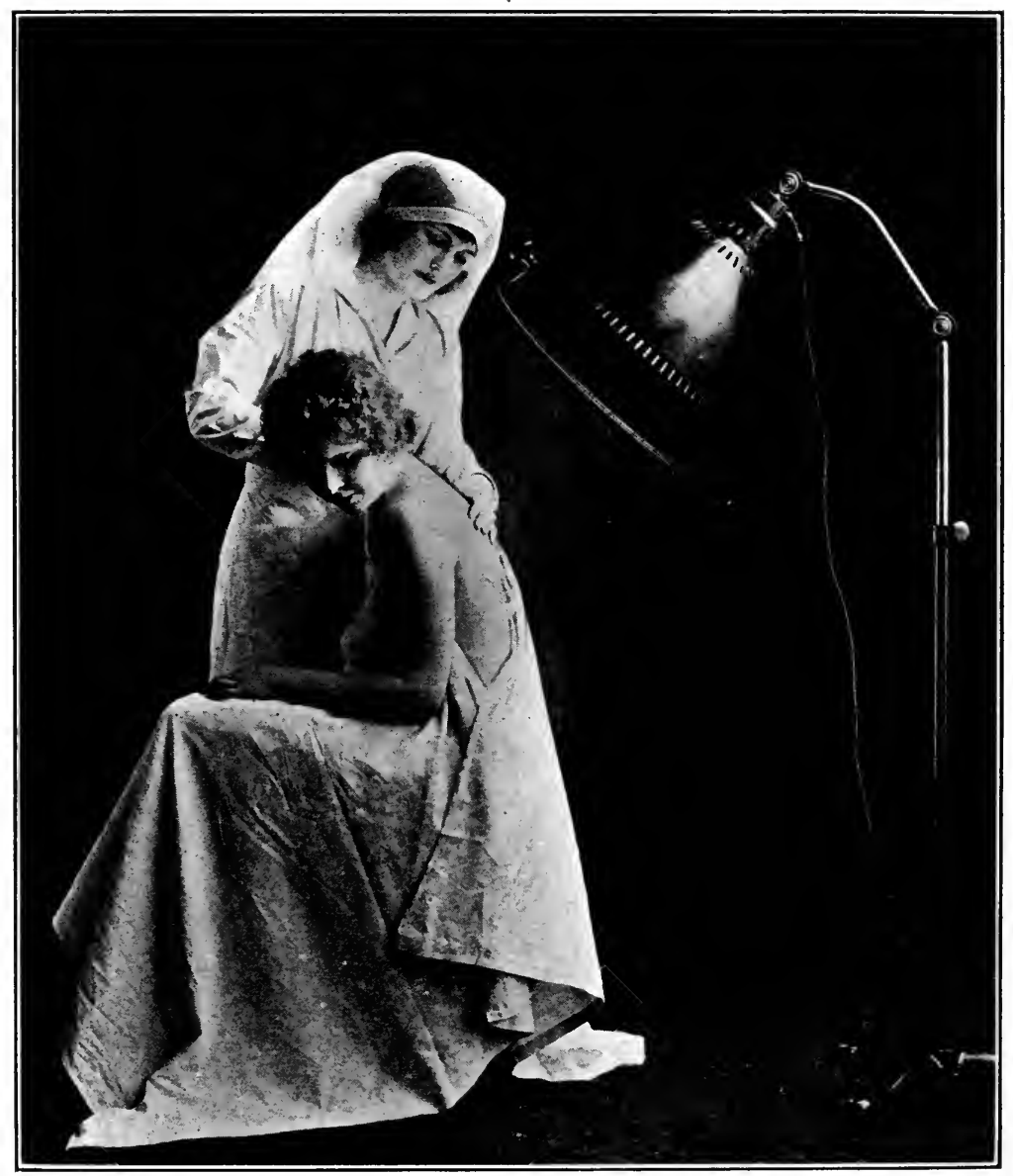

Plate X. Radiant energy is finding many applications in therapeutics. 
Burge ${ }^{17}$ studied the bactericidal action of the radiation from the quartz mercury arc upon seven different kinds of non-fluorescent bacteria and upon eight different types of fluorescent bacteria. He found that an exposure of 200 seconds killed all the non-fluorescent bacteria but at the end of that time none of the cultures of fluorescent bacteria were completely killed.

Cernovodeanu and Henri ${ }^{18}$ investigated the bactericidal action of the ultraviolet radiation emitted by mercury arcs. They employed emulsions containing from 10000 to 100000 bacteria per cubic centimeter and found that the action decreased more rapidly than the inverse square of the distance from the source. They found that air, oxygen, or hydrogen-peroxide was not essential to the destruction of bacteria by ultraviolet radiation. The most destructive radiation was found to be in the vicinity of $280 \mathrm{~m} \mu$. The resistance of different species of bacteria varied, bacillus coli being killed in 15 to 20 seconds and bacillus subtilis in 30 to 60 seconds. They found that protoplasm absorbs ultraviolet radiation shorter than $290 \mathrm{~m} \mu$ in wave-length.

The same investigators using as a standard the action of radiation which passed through glass (wave-lengths greater than $302 \mathrm{~m} \mu$ ) found the bactericidal power of radiation passing through a viscous screen (wave-lengths greater than $253 \mathrm{~m} \mu$ ) to be 300 times greater than that of the radiation passing through the glass but only 1.6 to 5 times greater in chemical action. The bactericidal power of radiation passing through a quartz screen was about 1000 times greater than the standard but the chemical action was only 4 to 6 times greater. A mercury arc was the source of radiation and the chemical reactions were the decomposition of hydrogen peroxide, the decomposition of potassium iodide in the presence of hydrochloric acid and of starch, the reaction between mercuric chloride and ammonium oxalate, the blackening 
of silver citrate paper, and the oxidation of leuco-derivatives of fluorescein.

Recklinghausen ${ }^{19}$ has discussed the sterilizing action of ultraviolet radiation from the quartz mercury arc. For the sterilization of water it should be free from suspended particles which cast shadows and thereby shield the bacteria. The water should be agitated. Colloidal material and coloring matter in small quantities does not seriously reduce the effectiveness. Clear ice does not interfere. He states that 100 kilowatt-hours of electric energy will sterilize one million gallons of water. There is an obvious advantage over the introduction of chemicals because of the unsatisfactory flavor caused by the latter.

$\mathrm{He}^{20}$ has discussed the economics of sterilization of water by ultraviolet radiation from the quartz mercury lamp. The quartz tube is made of the pistol type which is inside a quartz cylinder projecting into the water. He describes large lamps operating on a 500 -volt circuit at 3 amperes and claims that the production of ultraviolet radiation is 50 times greater than in the case of the 110-volt, 3.5-ampere lamp with a consumption of energy only 4 times as great. One lamp will sterilize about 1000 tons of water per 24 hours.

The same investigator ${ }^{21}$ has stated that water after leaving a mechanical filter can be sterilized at a total cost of 60 cents per million gallons. A comparison with ozone showed that ultraviolet radiation and ozone sterilized water at about the same cost for power but that the initial and operating cost of ozone equipment was higher than for the quartz mercury-arc apparatus.

A patent ${ }^{22}$ has been issued to von Recklinghausen which describes an apparatus for passing the liquid to be sterilized in thin films before a quartz mercury arc at various points. It involves the disposition of baffe plates. Mineral deposits are formed on the quartz pro- 
tecting tube which absorb the ultraviolet radiation. These are eliminated by circulating water around the tube. Opaque or colored liquids are sterilized by passing through a shallow chamber in thin film.

Barrels have been sterilized by inserting a quartz mercury arc through the bung-hole. ! I

The spectra of blood-coloring matters such as oxyhaemoglobin, haemoglobin, carbonyl-haemoglobin, methaemoglobin, acid haematin, alkaline haematin, haemochromogen, acid haematoporphyrin, and alkaline haematoporphyrin all exhibit absorption in the near ultraviolet. It has also been shown that red blood corpuscles are destroyed by radiation less than $310 \mathrm{~m} \mu$ in wave-length.

Deblet and Beauvy ${ }^{23}$ studied the effect of ultraviolet radiation in the hemolytic power and colloidal state of blood serum. After about an hour's exposure it was found that the hemolytic power of the blood serum was reduced about one-half. After 23 hours no changes were visible with the aid of the ultramicroscope.

Berthelot claims to have reproduced the digestive processes by the use of radiation from a quartz mercury arc and without the aid of ferments which are important in the natural process.

Henri and Moycho ${ }^{24}$ determined the action of ultraviolet radiation of various wave-lengths upon tissue and also the radiation responsible for sunstroke.

According to Grimm and Weldert, ${ }^{25}$ who employed a quartz mercury arc of 1200 candle power, clear water containing less than 100 bacteria per cubic centimeter was sterilized at a rate of 0.55 cubic meters per hour but in cases of water containing many more bacteria the rate of passage of water through the apparatus did not exceed 0.45 cubic meters per hour. They considered the cost of sterilization to be excessive compared with other existing processes.

Small sterilizers are available which employ the quartz 
mercury arc. Swimming pools are effectively purified by units of moderate size. Air bubbles by causing turbidity are the cause of incomplete sterilization. By exercising care the path of the water can be such as to minimize the production of bubbles.

Henri ${ }^{26}$ found that the bactericidal power of ultraviolet radiation is proportional to the coefficient of absorption of protoplasm, thus indicating that the action of ultraviolet radiation on micro-organisms obeys the common law of photochemical absorption. This also suggests that the destruction is brought about by direct action upon the cells instead of indirectly through the formation of hydrogen peroxide and other chemicals. The radiations of greatest bactericidal power penetrate only a few thousandths of a millimeter.

The penetration of solar radiation into the human flesh is reduced by acclimatization by the formation of a protective layer of pigment which is more or less opaque. This acclimatization may be either permanent or temporary. It has become permanent through ages of adaptation as is evidenced by the black or dark-colored races of the tropics. The tanning of white skin is a temporary effect which may become more or less permanent. The skin of the white race contains a slightly protective pigmentation which varies to some extent and this variation is responsible for the differences in sensitivity to solar radiation. For example, blondes who possess only very slight pigmentation are more easily sunburned and are more susceptible to sunstroke.

Courmot ${ }^{27}$ found that liquids containing suspended colloid particles absorb ultraviolet radiation strongly. $\mathrm{He}$ claims that the sterilization does not involve ozone or hydrogen peroxide. He investigated wine, beer, peptone solution and other liquids.

Other investigators have found that malt liquors cannot be sterilized effectively by ultraviolet radiation owing to their opacity for the effective rays. 
Burge ${ }^{28}$ has discussed the mode of action of ultraviolet radiation in effecting sterilization.

Various applications have been made of ultraviolet radiation in the sterilization of milk. One ${ }^{2,9}$ involves the flow of milk, beer, water, and other liquids from perforated pipes over inclined quartz plates and corrugated metal plates. These plates are suitably arranged in respect to the mercury arc. Another process ${ }^{30}$ involves freezing the milk into blocks or sheets and exposing them to the radiation. As the frozen milk thaws the thin film of liquid is sufficiently transparent to permit the radiation to penetrate. Another process ${ }^{31}$ combines the use of heat and ultraviolet radiation. It is claimed that by heating the milk to $60^{\circ} \mathrm{C}$ the bacteria are so enfeebled that they succumb to a very slight exposure to ultraviolet.

It has been claimed by Ayers and Johnson that ultraviolet radiation does not affect vegetable cells and that this treatment cannot be substituted for pasteurization because there would be no certainty regarding the destruction of pathogenic germs. According to them, ultraviolet radiation causes a disagreeable taste and odor in milk. Butter and other fats have been sterilized by ultraviolet radiation. In one method ${ }^{32}$ the fat is spread in a thin layer on an endless belt which passes under sources of ultraviolet radiation.

Bovie ${ }^{33}$ investigated the action of the radiation from a quartz mercury arc on living cells through its effects on the constituents of protoplasm. Ox-serum was coagulated in quartz tubes but not in glass ones. Fresh egg albumen was slightly coagulated in two hours at a distance of 10 $\mathrm{cm}$. from the arc. He also studied the influence of temperature.

Dorée and Dyer ${ }^{34}$ exposed clean bleached cotton cloth to a mercury vapor (glass tube) lamp for a week. They concluded that the ultraviolet radiation converted cellulose into oxycellulose and it lost its tensile strength. 
Chauchard and Mazoue ${ }^{35}$ found that the two enzymes, amylose and invertase, suffered the loss of their activity when exposed at a distance of $12 \mathrm{~cm}$. from a quartz mercury arc.

Agulhon ${ }^{36}$ has concluded that enzymes may be divided into three classes according to their sensitiveness to radiation. Sucrase, tyrosinase, and laccase are destroyed by visible radiation in the presence of oxygen but in a vacuum only ultraviolet radiation is destructive. Emulsion and catalase are destroyed by radiations of all wave-lengths in vacuo or in air. Oxygen hastens the destruction. He gives rennet as an example of the third type. Its activity is destroyed in a vacuum by ultraviolet radiation and is diminished by visible radiation.

Chauchard ${ }^{37}$ investigated the effect of wave-length of ultraviolet radiation on the destruction of amylase and lipase using sparks of zinc, cadmium, and magnesium. Radiations between 220 and $250 \mathrm{~m} \mu$ were more destructive than those of longer wave-length in the case of amylase.

$\mathrm{He}^{38}$ later found that the amylase of pancreatic juice was appreciably impaired only by radiation of about $280 \mathrm{~m} \mu$ in wave-length.

Gamgee ${ }^{39}$ has presented an account of the investigations of the absorption of violet and ultraviolet radiation by haemoglobin and its derivatives. Various researches on the absorption spectra have been made. Normal blood of rabbits, sheep, and pigs possesses the same absorption spectra. The maxima of the bands of methaemoglobin are slightly displaced in comparison with the oxyhaemaglobin bands.

According to Schumm ${ }^{40}$ the absorption spectrum of oxyhaemaglobin exhibits three bands, one of which is in the ultraviolet. He states that some variations appear in the spectra of blood of the same species and that the oxyhaemaglobin of different animals cannot be distinguished in this manner. Mashimo ${ }^{41}$ found the maximum of the 
ultraviolet band of oxyhaemaglobin to lie at $350 \mathrm{~m} \mu$ and was unable to observe any band at the extreme region of ultraviolet.

It has been found that diphtheria toxin is rendered atoxic by ultraviolet radiation. According to Lowenstein, the quartz mercury lamp is 30 times more effective than the iron arc. A 40-hour exposure to it completely destroyed 1000 fatal doses of the toxin. In his experiments radium had no destructive influence.

Ultraviolet radiation has been used very extensively in therapeutics, but the results which have been described are more or less confusing and indefinite owing to the absence of data pertaining to the spectral character. Woodruff ${ }^{42}$ has accumulated many abstracts pertaining to actino-therapy.

Ultraviolet radiation is said to relieve pain from superficial new growths and to lessen the odor of putrefaction. Primitive beings are known to expose a wound to the direct radiation from the sun with apparent hastening of healing. Solar radiation is said to cure persistent bedsore and many skin diseases. However, there are many claims which are contradictory. Certainly there are many cases where ultraviolet and visible radiations are harmful, and this has led to some applications of red light not for its effect but rather for its absence of effect. Sun-baths which were quite the thing some years ago now have many opposed to their use. Owing to the contradictory nature of many opinions, to the lack of physical data pertaining to the radiation employed and to the lack of control of experiments in many cases, the therapeutic aspects can not be discussed without many digressions and qualifications. To do this appears out of place here so it is recommended to those particularly interested that they consult the book of Woodruff ${ }^{42}$ and the one by Cleaves. ${ }^{43}$

Ultraviolet radiation has been detected at a depth of 1000 meters in the ocean and blue and violet rays at a 
depth of 500 meters. Apparently no radiation penetrates to depths of 1700 meters according to Hjort ${ }^{44}$ whose investigations were made in the north Atlantic. Radiation necessary for the growth of vegetation does not penetrate in sufficient quantity beyond the depth of 400 to 600 meters. There appears to be little doubt that powerful solar radiation sterilizes water, for more bacteria and vegetable plankton are found in winter than in summer in various waters. They are also more plentiful in foggy climates than in regions of more clear weather.

Insects suffer from ultraviolet in proportion to their lack of protection. The white ant cannot withstand exposure to solar radiation and therefore is obliged to construct subways in search of food. Many kinds of insects are easily killed by the radiation from the quartz mercury arc. Solar radiation is fatal to some kinds of mosquitoes, hence they avoid it and are most active at dusk and during the darkness of night. The grubs of wasps and bees are killed by solar radiation, hence they are protected in the cells which are light-proof.

Woodruff ${ }^{42}$ believes that it is strange that the human being does not have a nerve apparatus to receive impressions from ultraviolet radiations intense enough to be harmful or useful and still too feeble to make their presence known by conversion into heat. He suggests that our remote ancestors evolved in dark cloudy regions where ultraviolet radiation existed only in small quantities. Hence, no nerve-sense evolved as there was no need of it, but evolution later turned toward the development of protective pigment. Then it was too late to evolve by variation a new nerve sense.

It is reasonable to suppose that plant life as well as animal life has become particularly adapted to the radiation to which it has become accustomed throughout centuries of evolution. The primitive savage who lives unclothed is not subject to sunburn as is the civilized being 
who has lowered the resistance of his skin by the use of clothes. The cornea of the eye transmits practically all the short-wave energy of solar radiation. In fact, animal cells are not affected by solar radiation except under conditions which are uncommon. Plants also flourish in their customary environment whether in the desert, on the mountain top, or in the cool shadows. Beyond the outskirts of their ideal environment they show the scars of battle against hostile conditions. However, in general, it may be stated that solar radiation does not contain rays which kill plant life when the latter is in its customary environment.

Many investigations have been made upon the effect of radiation on plants but most of the results are indefinite owing to the absence of specific knowledge pertaining to the spectral character. Furthermore, much systematic work must be done before it can be stated with certainty that ultraviolet radiation of certain wave-lengths produces certain results. Perhaps some rays act only as catalysers; that is, they may have no direct influence but their presence is necessary. Of course, it is known that the development of chlorophyll is a photo-chemical reaction and its absorption spectrum is well known.

Shan $z^{45}$ has attempted to prove that all organic substances appear to be altered by the radiation which they absorb. He claims to have proved that organic substances are broken up by radiation into their elements and radicals. In the case of colorless substances the effective radiation is chiefly the ultraviolet and this is supposed to be true for those substances which are unaffected by visible radiation. According to him, the shorter the wavelength of radiation the greater the power of breaking down the structure of the molecules.

Radiation produces some more striking effects upon plants than upon animals. The effect produced upon plants by radiation is most obvious in the process of assim- 
ilation. The chlorophyll grain and the colorless struma, the chromoplast, are the principals. The former is a fluorescent dyestuff and the latter is albumen which Schanz considers to be sensitive to radiation of short wavelength. The cell sap penetrates the chlorophyll grain and carries to the latter the materials it requires in the process of assimilation. Among these materials there are supposed to be some which influence the photo-chemical reaction in the manner of catalysers.

Schanz considers that the chief function of the colors of flowers is to select the radiation required in any particular case and in accordance with this selection peculiar substances are carried over with the seeds to the new individual. The concept of colors as sensitizers implies that they are highly important with regard to the plant's own needs. He claims that assimilation is caused chiefly by radiation of the longer wave-lengths; that is, by those rays to which albumen is not sensitive in itself and to which it must first be sensitized, accordingly, by means of chlorophyll. The radiation of shorter wave-lengths appears to take less part in this process, notwithstanding the fact that they are otherwise chemically more effective.

This led Schanz to inquire why ultraviolet radiation plays such a small part in the process of assimilation. $\mathrm{He}$ planted cuttings of the same size in pots of the same soil. One plant was allowed to grow freely. The second was covered with a globe of Euphos glass which absorbs the ultraviolet radiation completely and partially absorbs blue and violet rays. The third plant was covered with a globe of clear glass which absorbs some of the ultraviolet rays of shortest wave-length in solar radiation. The globes were arranged so that they were ventilated. These experiments were repeated upon many plants for many years. The plant under Euphos glass grew much larger than the others and, although green, it reminded him of an etiolated plant. The plant under ordinary clear glass 
grew larger than that which grew freely but not as large as the one from which ultraviolet radiation was excluded. Schanz concluded that the form of plants is altered by radiation of short wave-lengths and most of all by ultraviolet radiation. $\mathrm{He}$ also concluded that, owing to the greater absorption of the radiation of the shorter wavelengths by the plant material, these rays are less effective. Schan $z$ claims that plants brought from high altitudes to low ones act as though, in the latter environment, they were protected by Euphos glass and that this is due to the relatively less amounts of ultraviolet energy at the lower altitudes than that to which the plants were accustomed at high altitudes. Of course, there are many other differences such as temperature and humidity but he feels that short-wave ultraviolet energy is an important factor. The differences in the extent of the solar spectrum are not great for various altitudes as seen in Chapter II, however, there are perhaps greater differences in relative total amounts.

Many other experiments indicate that there is much of interest to be learned regarding the rôle that ultraviolet radiation plays in plant life.

\section{References}

I. Proc. Amer. Acad. Arts and Sci. 5I, I9I6, 640.

2. Klin. Monatsbl. Augenh. I909, 721.

3. J. Amer. Med. Assn. Dec. Io, Igro.

4. Arch. f. Ophth. 69, I908, I.

5. Proc. Roy. Soc. 85 , IgI2, 319.

6. Arch. f. Ophth. 7I, I909, 573.

7. Mitteil. Augenkl. zu Stockholm, Jena, I898, 31.

8. Comp. Rend. I883, 509.

9. J. Röentgen Soc. Eng. I918.

ro. Comp. Rend. 158, r914, I509.

II. Proc. Amer. Acad. Arts and Sci. 51, I916, 760.

I2. Amer. J. Physiol. 34, I914, 2 I. 
I3. Amer. J. Physiol. 39, r916, 335.

I4. Comp. Rend. 135, r902, 3 I5.

15. Proc. Roy. Soc. I9r7, 33.

I6. Amer. J. Trop. Dis and Prev. Med. I915, 506.

r7. Arch of Ophth. 44, r9r5, 498.

I8. Comp. Rend. r50, r9ro, 52 and 549.

Ig. J. Frank. Inst. I9I4, 68I.

20. Elec. World 62, 8I.

21. Proc. A. I. E. E. 33, I9I4, I906.

22. U. S. Patent II 56947.

23. Comp. Rend. I 59, 278.

24. Comp. Rend. I58, I509.

25. Chem. Zentr. I, I9II, I454.

26. Comp. Rend. Soc. Biol. 73, 323.

27. Chem. Zeit. 35, I9II, 806.

28. J. Frank. Inst. I9I6, 264.

29. English patent I6Iro.

30. English patent 12333 .

3I. U. S. patent II4I056.

32. French patent 40092r.

33. Science r9r3, 24 and 374,

34. Chem. Abs. r9r 7, r753.

35. Comp. Rend. I52, I9II, I709.

36. Comp. Rend. I53, I9I I, 979.

37. Comp. Rend. I56, I9r3, I858.

38. Comp. Rend. I58, I914, I575.

39. Zeit. Bio. 34, 1897, 505 .

40. Zeit. Physiol. Chem. 83, r9r3.

4I. Chem. Abs. I9I8, 486.

42. Tropical Light, Igr6.

43. Light Energy, I904.

44. Geographical Jour. May Igrr.

45. Biol. Zentr. Berlin, rgI9; Sci. Amer. Mo. Jan. I920, I3; Pflüger's Arch. vol. I70. 


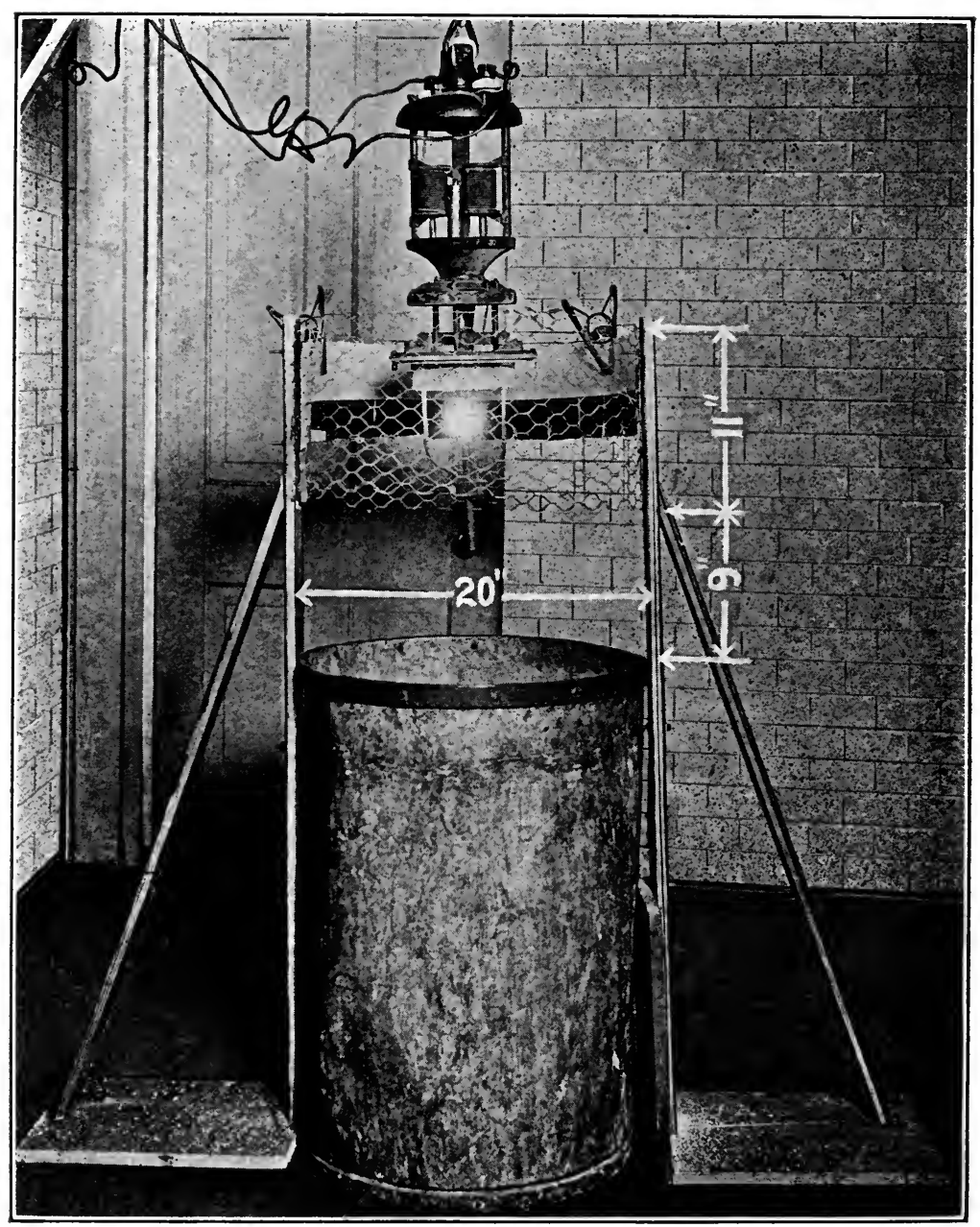

Plate XI. The white flame arc as used in dye-testing. 


\section{CHAPTER XII}

\section{VARIOUS PHOTOCHEMICAL EFFECTS}

A great amount of work has already been done in investigating the applications of ultraviolet radiation in chemical research and industry but much remains to be done before the subject can be summed up in generalizations. As Sheppard ${ }^{1}$ stated a few years ago, "We are only at the beginning of the conscious utilization of the powers of light, as distinct from the unconscious enjoyment of them.". In chemistry, radiation has many possibilities because it is an uncontaminating catalytic agent and it throws light on chemical constitution.

The ultraviolet radiations reaching the earth from the sun lie between about 290 and $400 \mathrm{~m} \mu$ as seen in Chapter II. In other words, it is almost totally confined to the near ultraviolet region.

No sweeping statements of the chemical effects can be made, for it is certain that there would be many exceptions; however, by way of introduction a few will be harzarded. The near ultraviolet radiations, 300 to $400 \mathrm{~m} \mu$, are not particularly effective in destroying micro-organisms but their great intensity in sunlight tends to make up this deficiency to some extent. They act somewhat similar, chemically, to the violet and blue rays, producing exothermic changes perhaps as a rule.

The middle ultraviolet radiations, 200 to $300 \mathrm{~m} \mu$, are readily produced by the arc, spark, and quartz mercury arc. They exert powerful germicidal action, coagulate albumen, and perform chemically in a manner similar to many enzymes and catalyzers in producing decomposition. They are readily absorbed by many substances and there- 
fore are responsible for many chemical reactions. Many endothermic reactions are prolonged at their expense and they also are responsible for various exothermic reactions of an irreversible character.

The extreme ultraviolet radiations, 100 to $200 \mathrm{~m} \mu$, possess similar bactericidal action. Chemically, they often act synthetically, producing reversible reactions of an endothermic nature. The chemical properties of radiations of shorter wave-length than $150 \mathrm{~m} \mu$ are little known. They are absorbed very readily by even thin layers of gas.

The chemical applications cannot be treated extensively in a single chapter but it is hoped that this account contains useful material which is necessary from the viewpoint of this book. The work of many investigators has been abstracted but there still remain many other works not alluded to here. Ellis and Wells ${ }^{2}$ have published an extensive series of abstracts to which the author is indebted for some references otherwise out of convenient reach.

In considering the results of exposure to ultraviolet radiation it is necessary to distinguish between purely chemical action, the production of nuclei, and the formation of carriers of electricity. For example, it is likely that the transformation of oxygen into ozone may be considered a purely chemical action quite independent of the formation of nuclei or ions. The production of nuclei is perhaps the result of chemical action. Apparently the production of ions is due to ultraviolet radiation which is selectively absorbed. The radiation of short wave-lengths is chiefly responsible for the production of ions.

Saltmarsh ${ }^{3}$ found that nuclei, produced in air by ultraviolet radiation, were not affected by an electric field after they had travelled through a few centimeters of air. The nuclei are equally effective in condensing water, toluene, and turpentine vapors. No nuclei were formed by ultraviolet radiation in the absence of oxygen and carbon 
dioxide. Oxygen containing ozone has nuclei for condensation which act the same as those provided by ultraviolet radiation. According to Saltmarsh, it seems probable that the nuclei formed by ultraviolet radiation do not cause condensation by chemical action. They probably act like dust particles as centers on which condensation is possible.

The nuclei formed by the ultraviolet radiation from the sun have figured prominently in theories concerning rainfall. Certainly they play a part as condensation nuclei but how important a part is a matter of conjecture. It is interesting to compute the number of negative electrons brought to earth in a certain amount of rainfall. The potential differences between a cloud and the earth arrived at in this manner are great enough to account for lightning discharges. Of course, there are various assumptions involved but the computations are interesting.

Berthelot and Gandechon ${ }^{4}$ have investigated a variety of photochemical effects of ultraviolet radiation. They found that cyanogen is oxidized to carbon dioxide and nitrogen; hydrogen is not appreciably oxidized by oxygen at ordinary temperatures; formic acid to some extent is formed from mixtures of acetylene and oxygen and also of ethylene and oxygen. Acetylene, cyanogen, ethylene, and oxygen decrease in volume due to polymerization. Acetylene is transformed into a yellowish solid; cyanogen into paracyanogen; ethylene yields a liquid polymer; and oxygen is partially converted into ozone. Air and mixtures of oxygen and nitrogen are not appreciably affected. Nitrous oxide alone or mixed with oxygen yields nitric acid, and sulphur dioxide alone or mixed with oxygen yields sulphur and sulphuric acid.

The same investigators ${ }^{5}$ found that solutions of ammonia in the presence of air or of oxygen are oxidized to nitrites but no nitrates are formed. Ammonium salts were oxidized to nitrites and urea is transformed to am- 
monia and then into the nitrite. Various other organic nitrogen compounds act similarly. They also found that ultraviolet radiation is capable of converting nitrates into nitrites and of liberating nitrogen by decomposing a solution of ammonium nitrite.

Under the action of ultraviolet radiation allylene is converted to a white solid and methane does not polymerize, but in the presence of oxygen it suffers the loss of hydrogen resulting in higher homologues of the paraffin series. Ketoses, in the solid state or in solution, are decomposed by ultraviolet radiation. Erythrulose, sorbose, laevulose, and perseulose decompose somewhat more slowly than dihydroxyacetone. Carbon monoxide is evolved in these cases, the reaction consisting of the elimination of the carbonyl group.

The same investigators ${ }^{6}$ found that carbon monoxide and oxygen, under the radiation from the mercury arc, yield some carbon dioxide and the latter with hydrogen yields water and formaldehyde. Carbon dioxide in the presence of phosphorus yields carbon monoxide under the influence of ultraviolet radiation from the quartz mercury arc. Water is produced by the action of ultraviolet radiation upon a mixture of oxygen and hydrogen. Formaldehyde is formed from hydrogen and carbon monoxide; it is decomposed in the presence of nitrogen by long exposure to the radiation; and it is also formed by direct action of the radiation upon carbon monoxide and gaseous ammonia.

Berthelot and Gandechon ${ }^{7}$ studied the influence of ultraviolet radiation of various wave-lengths in a number of chemical reactions. For example, equal volumes of carbon monoxide and ammonia unite to form formamide on a few hours' exposure to the radiation from a quartz mercury arc of wave-lengths shorter than $200 \mathrm{~m} \mu$. The action is slower for the middle ultraviolet but is not produced by the near ultraviolet, 300 to $400 \mathrm{~m} \mu$. Hydrogen 
chloride ${ }^{8}$ is decomposed only by radiation of shorter wave-length than $200 \mathrm{~m} \mu$. Hydrogen iodide is decomposed by blue and violet radiation. Hydrogen bromide is decomposed rapidly by radiation shorter than $200 \mathrm{~m} \mu$ in wave-length. The same investigators studied watervapor, hydrogen sulphide, telluride and selenide and carbon and nitrogen groups most of which exhibit decomposition on exposure to ultraviolet radiation.

Gerretson ${ }^{9}$ has considered the effect of radiant energy upon organic compounds and concludes that it depends upon wave-length. In general, ultraviolet radiation decomposes and radiation of longer wave-length polymerizes and condenses. Ultraviolet radiation decomposes carbon dioxide into the monoxide and water. It generally polymerizes hydrocarbons; for example, acetylene yields benzene and a resinous compound. It decomposes alcohols, aldehydes, and ketones. Esters yield carbon monoxide, carbon dioxide, hydrogen and a hydrocarbon. Ethers decompose similarly to alcohols. Acids evolve carbon dioxide, a hydrocarbon, and some carbon monoxide. Dibasic acids lose carbon dioxide leaving a monobasic acid. Bioses yield monoses; monoses evolve carbon monoxide, methane, and hydrogen. The complex absorption by aldehydes and ketones resolve into elementary absorptions. The solvent is influential in the photochemical reaction. Sugars can be produced from formaldehyde. Photo-chemical polymerization, isomerization, and condensation are common. Photochemical hydrolysis occurs; for example, most esters are saponified by water under exposure to radiation.

Tian ${ }^{10}$ found that water on exposure to ultraviolet radiation is decomposed into hydrogen and hydrogen peroxide and the latter is decomposed with the result that oxygen is liberated. Thus hydrogen and oxygen are evolved from water exposed to ultraviolet radiation. It is claimed that the effective radiation is in the vicinity of 
$185 \mathrm{~m} \mu$. The quartz mercury arc emits several lines in this neighborhood. The aluminum spark emits several lines of approximately this wave-length and its radiation decomposes water in the same manner. It has been found by others that solar radiation decomposes water into hydrogen and hydrogen peroxide but it contains no energy of shorter wave-length than about $290 \mathrm{~m} \mu$.

Schopper ${ }^{11}$ claims that solutions of coumarin such as a one per cent solution of dimethylamino-methylcoumarin absorbs ultraviolet radiation and may be used to protect the fabric of balloons from deterioration by solar radiation.

Flour has been treated with oxidizing agents such as peroxides and then exposed to ultraviolet radiation to decompose the peroxide.

Tian ${ }^{12}$ found that the reaction between oxygen and hydrogen peroxide is increased by ultraviolet radiation. He claims that radiation between 250 and $300 \mathrm{~m} \mu$ readily decomposes hydrogen peroxide but the decomposition of pure water is not accomplished excepting by radiation of extremely short wave-lengths. If the water contains oxygen, the latter combines with the freed hydrogen thus increasing the formation of hydrogen peroxide. The oxygen is also transformed to some extent into ozone which reacts with the hydrogen peroxide. He found the conditions favorable to the formation of hydrogen peroxide are, powerful ultraviolet radiation of extremely short wave-length, the exposure of the water in thin layers, and the elimination of the influences and conditions which tend toward the decomposition of hydrogen peroxide. This decomposition is diminished by using pure water and by eliminating the ultraviolet radiation of moderate wave-lengths. $\mathrm{He}$ recommends the use of low-voltage new quartz mercury arcs.

Jaubert ${ }^{13}$ patented a horizontal mercury arc surrounded 
by a jacket in which liquids containing air or oxygen were circulated for sterilization. The ultraviolet radiation produces ozone from the oxygen and the ozone sterilizes the liquid.

Thiele ${ }^{14}$ investigated the influences of ultraviolet radiation from a quartz mercury arc upon many chemical reactions. It was found that the combination of hydrogen and oxygen, with and without the presence of watervapor, was hastened. Hydrobromic acid was decomposed by air. Carbon monoxide and oxygen also combined. Hydrochloric acid and air interacted. Hydrogen peroxide was formed from oxygen and water to some extent. Potassium nitrate was decomposed into the nitrite and oxygen. Sulphuric anhydride was formed on passing air into water containing sulphur in suspension after the water and sulphur had been exposed to ultraviolet radiation for several hours. The decomposition of potassium percarbonate, ammonium persulphate, hydrogen peroxide, formic acid, ammonium oxalate, egg albumen, and peptone was accelerated.

Jacquier ${ }^{15}$ has patented a process of precipitating metals from solutions of their salts by the use of ultraviolet radiation in the presence of aluminum. He suggests the use of mercury arcs between aluminum plates in a receptacle containing the solution of the metallic salt.

Winther and Howe ${ }^{16}$ have studied the effect of ultraviolet radiation on the photo-chemical decomposition of iron oxalate, acetate, succinate, tartrate, and citrate.

Matthews and Elder have patented a process of producing compounds of sulphur dioxide and unsaturated hydrocarbons by the mixture of liquids exposed to ultraviolet radiation. The butylene product is a clear white solid which renders celluloid less inflammable and can be used in varnishes and other transparent films.

Stoklasa ${ }^{14}$ surveyed the literature on sugar synthesis and also reported his own work. He found that formic 
acid is first produced by ultraviolet radiation acting upon formaldehyde in the presence of caustic potash and air or oxygen. The formic acid is then decomposed into carbon dioxide and water.

Lenard and Wolff ${ }^{18}$ noted that metals are disintegrated when exposed to ultraviolet light and Svedberg ${ }^{17}$ by applying this knowledge has produced colloidal solutions of metals. He placed the clean metal in a dish containing a dispersion oxide medium and allowed the radiation from a quartz mercury arc to fall upon it. In the course of a few minutes' exposure he obtained colloidal solutions of lead, copper, tin, and silver, but was unsuccessful in the case of cadmium, platinum, and aluminum. By experimenting with silver and lead in water, ether, ethyl and isobutyl alcohol, acetone, ethyl and amyl acetate, he found that the dispersion medium was an important factor in the result obtained. The colloidal particles obtained in this manner are said to be very small. Svedberg ${ }^{20}$ found that the effect is decreased by oxidation of the metallic surfaces and that the active rays were those of shorter wave-length than $410 \mathrm{~m} \mu$. He obtained interesting data on colloidal gold.

Nordenson ${ }^{21}$ proceeded in a manner similar to Svedberg in investigating the production of colloidal metals. He immersed the metals in water, alcohol, and other liquids and exposed them to ultraviolet radiation, X-rays, and even to the radiations from radium. All these radiations were effective but ultraviolet was more powerful than the others. He obtained colloidal solutions from silver, copper, mercury, lead, tin, and zinc, but not from gold, iron, nickel, manganese, platinum, cobalt, chromium, and bismuth. On immersing silver in pyridene or benzene no colloid was obtained but in ethyl alcohol, acetone, water, and methyl alcohol, colloid metal was formed. He concluded that the hydrogen peroxide formed by exposure of certain solutions to the ultraviolet radiation attacks 
the metal, and the resulting oxide or hydrate is dissolved and reduced to metallic colloid by the action of the radiation.

The radiation from a quartz mercury arc colors phenol, in the presence of oxygen, very quickly to a red.

Acetylene and methane unite when heated in the presence of various metals. It is said that ultraviolet radiation produces the same result as heat in this case.

Flour is slowly bleached by ultraviolet radiation.

Chlorine gas, exposed to the silent electrical discharge in a manner similar to that used in the production of ozone, is transformed into a more active form.

Zinc ethyl is quickly decomposed by the radiation from the quartz mercury arc.

Carbonyl chloride is slowly decomposed by ultraviolet radiation of short wave-lengths.

Cyanogen polymerizes when exposed to solar radiation. On exposure to ultraviolet radiation in the presence of oxygen it gives para-cyanogen and nitrogen.

Acetone is not decomposed by solar radiation but is decomposed into carbon monoxide and ethane by the radiation from the quartz mercury arc.

Formamide slowly decomposes on exposure to ultraviolet radiation.

The blue, violet, and ultraviolet radiations are responsible for the transformation of yellow phosphorus which is soluble in carbon bisulphide into red phosphorus which is insoluble.

Weigert and $\mathrm{Böhm}{ }^{22}$ investigated the effect of ultraviolet radiation on the decomposition of ozone and the formation of water by exposing mixtures of hydrogen and ozonized oxygen to the radiation from a quartz mercury lamp.

According to Mack ${ }^{23}$ chlorate may be oxidized to perchlorate by means of oxygen exposed to ultraviolet radiation. 
By exposing chlorine and sulphur dioxide to the radiation from a quartz mercury arc, oxychloride is formed even in glass vessels.

The electrical conductivity of amorphous sulphur is increased by exposure to radiation, that of shorter wavelength than $280 \mathrm{~m} \mu$ being the more active.

Boeseken and Cohen ${ }^{24}$ have investigated the photochemical reduction of ketones by anhydrous alcohol under the influence of solar radiation and of quartz mercury-arc radiation. The particularly active radiation appears to be in the region of $410 \mathrm{~m} \mu$.

Behthelot and Gaudechon ${ }^{25}$ found that ultraviolet radiation photolyzes di-saccharides. Hydrolysis first takes place without the evolution of gas, then later the decomposition of the monoses, produced at first, results in evolution of gas. During the photolysis of sucrose to dextrose and levulose, and of maltose to two molecules of dextrose, the solutions remain neutral. The exposure of levulose, dextrose, maltose, and sucrose to the radiation from the quartz mercury lamp results in the evolution of carbon monoxide, methane, hydrogen, and carbon dioxide.

They ${ }^{26}$ also found that acetaldehyde was decomposed by solar radiation but acetic acid and ethyl alcohol were unaffected. However, the radiation from a quartz mercury arc photolyzed each of them. Acetaldehyde is decomposed to carbon monoxide and methane but is also polymerized to paraldehyde, the latter being decomposed into carbon monoxide, ethane, and some complex compounds. Ethyl alcohol is decomposed into acetaldehyde and hydrogen, but there is also a further decomposition of the former into carbon monoxide and ethane. Acetic acid decomposes into carbon monoxide, carbon dioxide, and other gases.

The same investigators found ammonia and also hydrogen phosphide were decomposed by the radiation from the quartz mercury arc. Hydrogen arsenide in a quartz 
tube suffered decomposition but was unaffected in a glass tube. This was also true of carbonyl chloride. Sulphur fluoride and methane respectively were unaffected even in quartz tubes. Zinc ethyl yielded zinc and ethane free from ethylene.

They ${ }^{27}$ claim that the photo-chemical effect of ultraviolet radiation is to lower the temperature of reaction. For example, decompositions and oxidations are caused by it below $100^{\circ} \mathrm{C}$. which would not be consummated ordinarily at much higher temperatures. The reactions produced are reversible and the radiation possesses great polymerizing power especially in some cases. In several respects the photo-chemical action is similar to the reactions produced in plants. Methyl compounds are easily synthesized but the production of ethyl compounds is less certain and more difficult.

Ultraviolet radiation greatly accelerates the chlorination of toluol. Some results indicate that visible radiation retards it.

Baskerville and Riederer ${ }^{28}$ found that ultraviolet radiation did not materially accelerate the reaction between natural gas and chlorine.

Mott and Bedford ${ }^{29}$ passed chlorine gas into benzol, isoamyl, chloride, and isopentane and investigated the effectiveness of the white flame arc and the quartz mercury arc in chlorination. By using quartz and glass containers they showed that the white flame arc radiated energy of more desirable wave-lengths in general than the quartz mercury arc for the chlorination reaction. On using a glass vessel the time necessary for the free chlorine to disappear was not materially longer than in the case of a quartz vessel when both were exposed to the radiation from the white flame arc. However, for the quartz mercury arc the time for chlorination in a glass vessel was much greater than that for a quartz vessel. They claim that the white flame arc is superior to the quartz 
mercury arc for this purpose. They summarize the sensitiveness of halogens and their compounds somewhat as follows: Flourine in its compounds is wonderfully stable to radiation. Silver fluoride is not sensitive like the other halogen salts of silver. Sulphur fluoride does not yield to ultraviolet (or visible) radiation although the sulphur oxides and hydride are sensitive to ultraviolet radiation. The great stability of calcium fluoride is associated with a remarkable transparency to ultraviolet radiation. Chlorine responds chiefly to blue, violet, and ultraviolet and its absorption spectrum extends further into the ultraviolet than that of bromine. The photo-sensitiveness of silver chloride is more marked in the ultraviolet than silver bromide. Bromine in the free form responds to radiation less in the ultraviolet than chlorine. On the other hand, hydrobromic acid is more easily decomposed by ultraviolet radiation than is hydrochloric acid. Iodine extends its spectrum still further towards the long wavelengths and hydriodic acid is decomposed by ordinary blue and violet light.

Bordier ${ }^{30}$ studied the effect of ultraviolet radiation on iodine and starch iodide. He states that the action is perhaps to remove the charges from the colloidal particles of these substances with the result that the iodine in the aqueous and alcoholic solution combines with the hydrogen ion to form hydriodic acid.

Pougnet ${ }^{31}$ investigated the influence of the radiation from a quartz mercury arc on a solution of mercuric chloride and on certain mercury salts. Mercuric chloride in water is gradually altered into mercurous chloride and mercury. Most of the salts examined were darkened whether in a dry or moist state.

Keyes ${ }^{32}$ has described an apparatus for the production of chlorine and bromine derivatives of hydrocarbons. It consists essentially of a quartz mercury arc with a straight tube which is surrounded by a quartz jacket which may 
also be exhausted. Another jacket surrounds this and the halogen mixed with the hydrocarbon is admitted to this outer jacket. The vacuum jacket protects the liquids in the outer jacket from the heat. The apparatus may be operated continuously.

Kailan ${ }^{83}$ found that strontium iodide in neutral solutions decomposes faster than barium iodide, and the latter more rapidly than potassium or magnesium iodide, but when exposed to ultraviolet radiation, barium iodide decomposes more rapidly than strontium iodide although both of them still decompose faster than the other two. In their experiments they found the effect of ultraviolet radiation and penetrating radium rays to be the same, but under the conditions of their experiments the decomposition produced by the former was several hundred times faster than by the radium rays.

Marmier ${ }^{34}$ decomposed solutions of sodium thiosulphate by ultraviolet radiation, sulphur and hydrosulphite being formed. The latter is also decomposed by continued exposure, the liquid containing chiefly sulphite. When the solution contained more than 5 grams per liter, no hydrosulphite was formed.

Sodium sulphite solutions are not oxidized by ultraviolet radiation in the absence of air but when air is present this radiation hastens the oxidization. Solutions of oxalic acid are decomposed slowly by ultraviolet radiation but the addition of uranium salts hastens decomposition. Potassium permanganate and potassium bichromate are quite unaffected by ultraviolet radiation.

Matthews, Bliss, and Elder ${ }^{35}$ obtained a patent for removing the halogen hydride from the compounds containing halogen by exposing the hydride vapor to ultraviolet radiation.

McLennan ${ }^{36}$ experimented with iodine crystals in an evacuated quartz tube which was inserted in a mercury vapor tube. He found that the fluorescence of the iodine 
vapor is excited by radiation between 180 and $210 \mathrm{~m} \mu$. Resonance spectra could not be obtained with iodine vapor with radiation shorter in wave-length than the green line, $546 \mathrm{~m} \mu$. The fluorescence of iodine was obtained at temperatures from that of the room up to $1000^{\circ} \mathrm{C}$. Mercury iodide and potassium iodide exhibited fluorescence spectra of their own at a temperature above $326^{\circ}$ C. when excited by the radiation from the mercury arc.

A German company developed a process for producing iodine derivatives of the paraffine series in the form of vapor by exposing to ultraviolet radiation mixtures of hydrocarbons and hydriodic acid.

Cohen ${ }^{38}$ found hydrochloric acid to be decomposed by the ultraviolet radiation from a quartz mercury arc. The result at a comparatively low temperature was as great as ordinarily obtained at $1500^{\circ} \mathrm{C}$.

Fischer and Braehmer ${ }^{39}$ devised a double-walled mercury arc, the quartz walls being separated from each other by about $1 \mathrm{~mm}$. Electrolytically produced oxygen was passed through the annulus and thus was exposed to intense ultraviolet radiation. The yield of ozone was increased very much by cooling the annulus with water.

Ozone is a common product of ultraviolet radiations of the shorter wave-lengths emitted by the quartz mercury arc and some other sources so that its presence often must be reckoned with.

According to Pribram and Franke ${ }^{40}$ the radiation from a quartz mercury arc produces no visible change upon a redistilled 30 per cent solution of formaldehyde, but if the liquid is distilled after exposure a white residue remains. The distillate and the residue are strongly reducing.

Kailan ${ }^{41}$ found dilute solutions of tartaric, succine, malonic, acetic, and oxalic acid were slightly decomposed by the radiation from a quartz mercury arc. No decomposition took place when the solutions were in glass vessels. The decomposition of a dibasic acid was hastened by introducing an alcoholic hydroxyl group. 


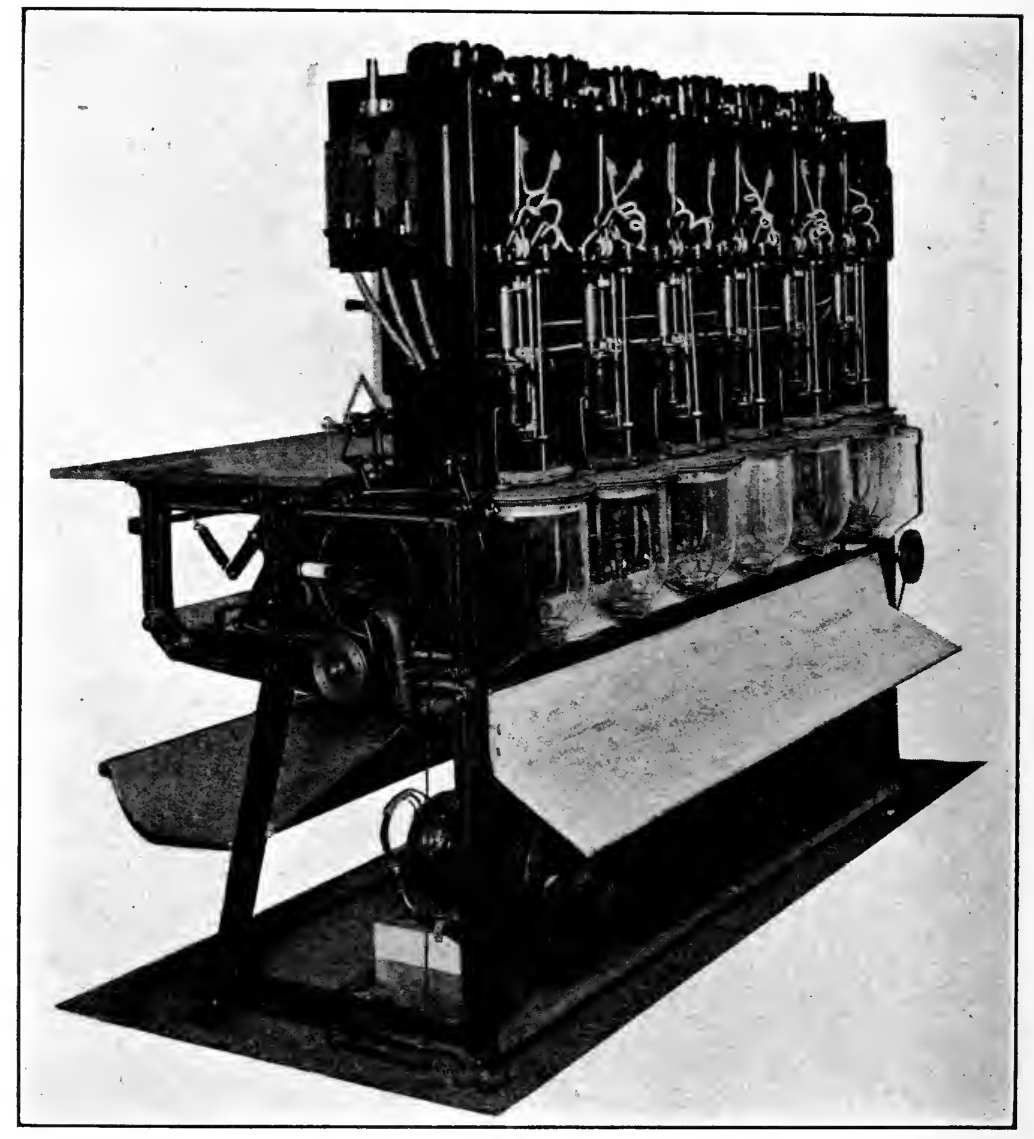

Plate XII. The carbon arc as used in blue-printing. 
Sulphuric acid ${ }^{42}$ is produced by exposing a mixture of sulphur dioxide and air (or oxygen) to ultraviolet radiation when the gases are at a temperature above $300^{\circ} \mathrm{C}$.

Cohen and Becker ${ }^{43}$ investigated the production of sulphur trioxide by exposing sulphur dioxide and oxygen to the radiation from a quartz mercury arc. No oxides of nitrogen were formed when air was used instead of oxygen.

Lesure ${ }^{44}$ found the radiation from a Cooper-Hewitt lamp to exert influences as follows: Solutions of silver nitrate, eserine salicylate, apomorphine hydrochloride, arbutin, and guaiacol were slightly discolored in about 30 minutes. Solutions of cocaine hydrochloride, mercury benzoate and bichloride, sodium cacodylate, calcium glycerophosphate, quinine bichloride, pilocarpine hydrochloride, and artificial serums were unaffected by exposures of thirty minutes. Olive oil was bleached. Cultures of bacillus coli were added to solutions of aucubin and of gentiopicrin. These solutions were sterilized in 30 seconds to 30 minutes.

Bierry, Henri, and Ranc ${ }^{45}$ found that a 5 per cent solution of sucrose is appreciably hydrolyzed on exposure to the radiation from a quartz mercury arc for 20 hours. After 40 hours' exposure the solution contained formaldehyde. In the absence of calcium carbonate a gas is liberated which consists largely of carbon monoxide.

Holbronner and Bernstein ${ }^{46}$ found that ultraviolet radiation effected a permanent vulcanization upon rubber solutions containing sulphur. They made various experiments on layers of rubber solutions carried underneath a quartz mercury arc provided with a cooling jacket. It is stated that the vulcanized rubber forms a stable gel and is not precipitated after several months or by prolonged heating at $80^{\circ} \mathrm{C}$. Bernstein ${ }^{47}$ obtained a patent for vulcanizing India rubber solutions containing sulphur by exposing them to the radiation of a quartz mercury 
lamp. A solution of rubber in benzene containing 6 per cent of rubber and 0.6 per cent of sulphur is vulcanized in less than one minute when in a thin layer about 0.5 $\mathrm{mm}$. thick. A xylene solution of rubber containing 6 per cent of sulphur was evaporated on a quartz plate and then exposed to a quartz mercury arc at a distance of $15 \mathrm{~cm}$. After 40 minutes' exposure on both sides the film exhibited the properties of vulcanized rubber and was found to contain 2.56 per cent of combined sulphur. ${ }^{48}$ The percentage of combined sulphur increases with the duration of exposure to the ultraviolet radiation. Apparently excessive exposure tends to deteriorate vulcanized rubber. ${ }^{49}$

It has been claimed that wine, after passing the fermentation stage, on being exposed to ultraviolet radiation in thin films, changes in taste and color and attains the characteristics of old wine. It is said that the duration of treatment is not long and that this application made some advances in France before the war. Red wines are bleached to some extent by ultraviolet radiation. In fact, many of the fruit colors are rapidly faded by ultraviolet radiation.

Henri and Ranc ${ }^{50}$ found that a 10 per cent aqueous solution of glycerine exposed for several hours to the radiation from a quartz mercury arc resulted in the decomposition of the glycerol molecule and the production of formaldehyde and acids and also other aldehydes. Others have obtained the same results. Apparently the presence of hydrogen peroxide increases the decomposition.

The same investigators with Bierry ${ }^{51}$ experimented with glycerol and ultraviolet radiation from quartz mercury arcs. They used various concentrations of glycerol from 1 to 100 per cent and varied the temperature and admitted and excluded air.

The action of ultraviolet radiation on egg and serum proteins has been studied by several investigators. (See 
Chapter XI). In general, it is the radiation shorter than $300 \mathrm{~m} \mu$ in wave-length which is effective in coagulating them. Schanz $z^{52}$ concluded that the change produced by ultraviolet radiation could be regarded as a gelatinization of the protein. In acid solutions the precipitation produced by ammonium sulphate and sodium chloride was increased but in alkaline solutions it was decreased. Henri ${ }^{53}$ determined the absorption of egg albumen and found it to be negligible at $300 \mathrm{~m} \mu$ but rapidly increased with decreasing wave-length.

The reaction of chlorine and hydrogen is purely photochemical. Bunsen and Roscoe ascribed the maximum activity to radiation between 395 and $413 \mathrm{~m} \mu$. They used a gas bulb in a thermostat with glass walls and obtained their radiant energy from a mercury arc. They studied the temperature coefficient of the reaction and found it to be small for ultraviolet radiation, greater for violet and blue, and greatest for green light. It was intermediate for total (white) light. The temperature coefficient also has been investigated by Padoa and Butironi. ${ }^{54}$ Favre and Silbermann ${ }^{55}$ have verified the variation of catalytic action with wave-length.

Ekely and Banta ${ }^{56}$ found that lead phthalate on exposure to the radiation from a quartz mercury arc decomposed and a yellowish brown substance was formed. Mercuric phthalate exposed in the same manner was not decomposed.

According to de $\mathrm{Fazi}^{57}$ ultraviolet radiation favors alcoholic fermentation and beer yeast exposed to it increases in activity. A 14-hour exposure to the radiation from a quartz mercury arc about $20 \mathrm{~cm}$. distant did not destroy the activity of the yeast.

Davis ${ }^{58}$ has patented apparatus which exposes air to violet and ultraviolet radiations and partially ozonizes it. Iron and carbon plates are connected to an electric circuit, preferably alternating, and air is drawn between these 
plates. The carbon is supported on a glass plate and a thin silica plate is supported on an iron plate.

The temperature effect produced by the quartz mercury arc in chemical applications is sometimes confusing. Weigert ${ }^{59}$ has attempted to avoid this by water-cooling in such a manner that the reaction proceeds outside the lamp itself, but the reaction receives radiation which has passed through non-absorbing media.

Cohen and Becker ${ }^{60}$ studied the decomposition of carbonyl chloride into carbon monoxide and chlorine under the influence of the radiation from the quartz mercury lamp. They found that the effective radiation was of shorter wave-length than $265 \mathrm{~m} \mu$.

Cassel ${ }^{61}$ studied the influence of radiation from an arc lamp upon mixtures of alcohol with chloracetic and bromacetic acid respectively. He found the reaction was not sensitive to radiation of longer wave-lengths than $250 \mathrm{~m} \mu$. The decomposition under the influence of the short-wave ultraviolet resulted in the formation of methyl alcohol, acetic aldehyde, and the halogen acid. The chlorine compound is less easily decomposed by alcohol than the bromine compound.

Various suggestions have been made regarding the treatment of seeds with ultraviolet radiation but conclusive data pertaining to economic advantages is lacking. Pougnet ${ }^{62}$ found that green vanilla pods under exposure to ultraviolet radiation gave forth the odor of vanillan. $\mathrm{He}^{63}$ also exposed other plants to the radiation from a quartz mercury arc. Those containing coumarin emitted the odor of coumarin, and other plants yielded characteristic odors.

Plants grown under glass appear to be more sensitive to ultraviolet radiation than those grown outdoors. An alcoholic solution of chlorophyll is not readily decomposed by ultraviolet radiation, but this radiation appears to develop the green coloring matter in some leaves more rapidly than solar radiation. 
Euler ${ }^{64}$ found that aqueous solutions of haloacetic acids exposed to ultraviolet radiation from the mercury arc resulted in decomposition at $18^{\circ} \mathrm{C}$. equal to that at $100^{\circ} \mathrm{C}$. without exposure to ultraviolet.

Ultraviolet radiation of short wave-lengths causes the evolution of oxygen from potassium nitrate.

It has been reported that ultraviolet radiation causes polymerization of vinyl esters and the solids yielded are substitutes for celluloid. These solids are odorless and non-inflammable. The polymerization of vinyl acetate and of vinyl chloracetate is aided by organic peroxides.

Pougnet ${ }^{65}$ investigated the action of the radiation from a mercury arc on a 5 per cent solution of mercuric chloride. At a distance of $15 \mathrm{~cm}$. from a 110-volt, 4-ampere lamp the solution at once became clouded by the calomel which was formed. Most of the mercury salts were affected by ultraviolet radiation.

Ross ${ }^{66}$ has studied the effect of the radiation from the aluminum spark upon solutions of potassium iodide and upon the reduction of chlorates and bromates.

A number of patents have been obtained which cover certain chlorination processes. One ${ }^{67}$ describes the use of a mercury vapor lamp or large tungsten lamp for chlorinating liquid hydrocarbons such as gasoline, petroleum oils, toluol, and benzol. Another ${ }^{68}$ pertains to the production of unsaturated hydrocarbons from petroleum oils. Others ${ }^{69}$ involve the chlorination of toluol and the production ${ }^{70}$ of benzol chloride, benzyl chloride, and benzotrichloride. Another ${ }^{71}$ pertains to the production of tetrachlorotoluene by passing dry chlorine into toluene in the presence of iron. A patent ${ }^{72}$ involves the bromination of hydrocarbons by the use of a mercury arc.

Bedford ${ }^{73}$ exposed a mixture of chlorine and natural gas, in a vessel containing ice, to the radiation from a flame arc. Besides water from the melted ice he obtained a heavy liquid consisting of methylene chloride, 
chloroform, carbon tetrachloride, and chloroethanes. These were also dissolved in the water to some extent. Tolloczko ${ }^{74}$ describes the chlorination of natural gas with aid of the mercury arc.

Phosgene has been produced by uniting carbon dioxide and chlorine under the influence of ultraviolet radiation.

Cohen and Sieper ${ }^{75}$ found that the action of ultraviolet radiation of shorter wave-length than $254 \mathrm{~m} \mu$ on carbon dioxide results in decomposition which is greatly decreased by the presence of water-vapor. They found that no formic acid or formaldehyde is produced but a mixture of equal volumes of hydogen and carbon dioxide results in the formation of formaldehyde. They found that the presence of carbon monoxide or dioxide does not increase the amount of ozone formed on exposing oxygen to ultraviolet radiation.

The ultraviolet radiation in the middle spectral region is used on a large scale for bleaching olive oil. Linseed oil, other oils, and resins are bleached by ultraviolet radiation.

Rohm ${ }^{78}$ has prepared a substitute for drying oil in paints which consists of a solution of polymerized acrylic acid ester in acetone or other solvents. When this solution is exposed to ultraviolet radiation it is transformed into a colorless, transparent, elastic substance soluble in the usual oil-solvents.

Klatte and Rollett ${ }^{77}$ have patented a process for making celluloid substitutes by polymerizing vinyl esters under the influence of the mercury arc and other sources.

Mott ${ }^{78}$ made an extensive investigation of the use of the flame arc in dye-testing and concluded that the highamperage arc is more powerful than sunlight. $\mathrm{He}$ obtained essentially similar results in fading dyes as he obtained with June sunlight and at a much greater speed. The best June sunlight for 50 hours produced an effect equal to that produced by a 28-ampere white flame arc in 
10 to 20 hours at a distance of 10 inches. The blue flame arc produced results with some dyes unlike that of daylight. This arc is especially rich in ultraviolet radiation. Some dyed clothes faded in an hour under exposure to the radiation from the white flame arc. Lithopone showed maximum darkening at low temperatures. Mott presented a brief summary of the literature.

The author found that lithopone is darkened by radiation from the quartz mercury arc chiefly between 300 and $350 \mathrm{~m} \mu$ in wave-length. By focusing the image of a quartz mercury arc upon a lithopone surface darkening was produced in a few seconds. Both the commercial magnetite arc and an experimental iron arc produced blackening in a few minutes. Hydrogen peroxide blackened the lithopone at once. O'Brien ${ }^{79}$ made an extensive study of lithopone using a flame arc.

Scheurer ${ }^{80}$ tested benzo colors by exposing them to radiation from the sun and to the quartz mercury arc. Under the former they were only slightly faded but under the quartz mercury arc they were quite faded in 24 hours. Indigo was less changed by the mercury radiation than by solar radiation.

There are dye-testing equipments available commercially which employ various arcs. The testing of permanency of colors is unsatisfactory when solar radiation is used owing to the variation of conditions.

Chevreul showed in 1837 that many dyes are not faded in a vacuum but tumeric and prussian blue were exceptions. Joffre ${ }^{81}$ found many dyes to be unaffected in nitrogen but picric acid was an exception. The action of air can be eliminated by the use of paraffin. According to Dufton ${ }^{82}$ the radiations complementary to the color of the dye are most effective. This is merely a statement of the law of photo-chemical absorption but it is necessary to know what takes place in the ultraviolet region as well as in the visible. To state that a dyed color is not appre- 
ciably affected by light of the same color must not mislead one into forgetting that invisible radiation may be present.

According to Brownlie, ${ }^{83}$ ammonia, alcohol, or pyridine vapors enormously increase the action of radiation on dyes, and naphtha and chloroform slightly retard it.

Toch ${ }^{84}$ has discussed the influence of solar radiation on paints and varnishes. He found glass to be protective. Varnish performs the useful function of excluding oxygen. He states that linseed oil bleaches due to the action of radiation on green chlorophyll.

In dye-testing outdoors it is well to note that the atmosphere in cities is usually more acid than in the country. In fact, it is said that the atmosphere in the country is alkaline. According to some investigators the most favorable condition for bleaching by solar radiation is one which is hot, moist, and alkaline.

According to Gebhard ${ }^{85}$ oxidation in the light may be quite different from that in darkness even when the same oxidizing agent is used.

There appears to be no doubt that the fastness of dyes is decreased by moisture and that there is little or no action in a vacuum in a great many cases. Apparently the oxidation theory of fading has been confirmed by experiments and is adhered to by many, but the reduction theory is favored by some, at least in particular cases. Gebhard ${ }^{86}$ has confirmed the oxidation theory and also states that permanency of dyeing affects permanency of the fiber. Oxidation and the formation of peroxide hydrates are involved in the bleaching of many if not all dyes.

Inks may be tested quickly by drawing lines on paper and exposing these to ultraviolet radiation.

Ellis and Wells ${ }^{87}$ have described a variety of experiments with oils, resins, and varnishes exposed to the radiation from a quartz mercury arc. Various effects of 
bleaching and gelatinization were noted. Among the substances tested were cotton-seed, crude whale, linseed, and castor oils.

Gray ${ }^{88}$ has patented a process for producing fatty acids and esters from hydrocarbons with the aid of a mercury arc.

Graul and Hanschke ${ }^{80}$ have been granted a patent for a process for producing halogenated paraffin hydrocarbons by mixing chlorine with the hydrocarbon in the dark and then exposing to radiation from the mercury arc or other source. They describe the method of making chlorhexane and heptane.

Darée and Dyer ${ }^{80}$ exposed clean bleached cotton cloth to the radiation from a mercury (glass tube) arc for a week. They concluded that the ultraviolet radiation converted cellulose into oxycellulose and it lost its tensile strength.

Ellis and Wells ${ }^{91}$ investigated the effect of ultraviolet radiation on the production of benzyl chloride, benzal chloride, and benzo trichloride by chlorinating toluol. They used the quartz mercury arc and passed an excess of toluol vapors mixed with chlorine through a quartz tube exposed to ultraviolet radiation.

Boll ${ }^{92}$ has described an investigation of the decomposition of the chloroplatinic acids. He found that they were influenced by radiation from the extreme yellow region to the extreme ultraviolet.93

Luther and Forbes ${ }^{94}$ investigating the oxidation of quinine by chromic acid under the influence of radiation found that the relative effects of the radiation from a mercury arc for $362 \mathrm{~m} \mu$ and $406 \mathrm{~m} \mu$ were 75 and 100 respectively.

When an aqueous solution of ferrous and mercuric chlorides is exposed to ultraviolet radiation, ferric chloride and calomel are formed. Inasmuch as the reverse action takes place completely, Winther ${ }^{95}$ proposed an 
electric battery based upon these reactions. The action is slow at ordinary temperatures but proceeds rapidly when the battery is short-circuited. He obtained as much as 0.1 volt and 1 milliampere.

Kailan ${ }^{96}$ has reported experiments upon water solutions of urea, benzoic, and formic acids.

There appear to be many counteracting phenomena of different radiations such as ultraviolet, visible and infrared. According to le Bon ${ }^{97}$ infra-red radiation destroys chlorophyll and alters the color of tomatoes and artichokes. Pech ${ }^{98}$ claims that the bleaching action of ultraviolet radiation on raw cotton is retarded slightly by visible radiation and greatly by infra-red. Ultraviolet radiation which produced erythema on an animal skin placed in a dark chamber in five minutes was found to produce the same effect in seven minutes when visible radiation was present and in ten minutes when infra-red was present. Many such counteracting influences may be suspected since Becquerel in 1872 found that certain samples of zinc sulphide phosphoresced under ultraviolet radiation but did not phosphoresce when infra-red was present. In this case visible radiation of shorter wavelength than yellow rays increases the phosphorescence.

If a beam of infra-red radiation is projected upon a surface of zinc sulphide under excitation of near ultraviolet radiation a black spot appears amid the brilliantly phosphorescent surroundings. This black spot is at the place where the infra-red is incident, showing that the latter prevents the production of phosphorescence by the radiation of shorter wave-lengths.

Curie ${ }^{99}$ found that with a fluorescent substance no black spot or variation of intensity of the fluorescence could be observed at the place where the infra-red rays were concentrated.

T. Swensson ${ }^{100}$ has described researches pertaining to the potential changes by ultraviolet radiation on oxidizing 
agents. When mixtures of potassium dichromate and sulphuric acid are illuminated by a quartz mercury arc at $18^{\circ}$, potential changes appear. The electrodes, bright or platinized platinum, need not themselves be illuminated. In the mixture of dichromate and sulphuric acid the potential rises, in the separate solutions of the components it falls, and it falls also when chromic acid is illuminated. Apparently the liberation of this chromic acid is not essential for the rapid first effect.

\section{References}

I. Photo-chemistry, rgr4.

2. Chem. Engr., Vols. 25-27.

3. Proc. Phys. Soc., London, 27, I915, 357.

4. Comp. Rend., I50, I910, II69, I327, I5I7.

5. Comp. Rend., I52, I9II, 522.

6. Comp. Rend., I50, Igro, I69o.

7. Comp. Rend., I55, I9I2, 207.

8. Comp. Rend., I56, I913, 889, I243.

9. Chem. Weekblad., I3, I9I6, 220.

ro. Comp. Rend., I52, IgIr, IoI2 and 1483.

II. J. S. C. D., I9I6, 356 .

I2. J. Chem. Soc., I08, I9I5, 828.

I3. French patent, 4I5-574.

14. Zeit. Aug. Chem., 22, I909, 2472.

I5. English patent, I7790.

r6. Zeit. Wiss. Phot., I4, I9r4, rg6.

I7. Zentr. Biochem. Biophys., I8, 370.

r8. Ann. Phys. Chim., 37, 1889, 443.

I9. Ber. 42, I909, 4375 .

20. Z. Chem. Ind. Kol., 6, I910, I29 and 238.

2I. Kolloid. Chem. Beihefte, 7, rgr5, Iro.

22. Z. Phys. Chem., 90, I89.

23. J. Phys. Chem., I9I 7, 238.

24. Wetenschappen, 23, I914, 765 .

25. Comp. Rend., 155, I9I2, I0I6.

26. Comp. Rend., r56, r9r3, 68 and 1243. 
27. Comp. Rend., I5I, I9ro, 395.

28. J. Ind. Eng. Chem., Igr3, 5.

29. J. Ind. Eng. Chem., 8, I916, ro29.

30. Comp. Rend., I63, I916, 205.

31. Comp. Rend., I6I, I9I 5, 348.

32. U. S. patent, 1237652 .

33. Chem. Abs., IgI4, I4.

34. Comp. Rend., I54, I9I2, 32.

35. English patent, I6828.

36. Proc. Roy. Soc., London, 9I, I9I4, 23.

37. German patent, 266rig.

38. Ber., 42, 1909, 3183.

39. Ber., 38, I905, 2633.

40. Ber., 44, I9II, I035.

4I. Mon. Chem., 34, I9I3, I209.

42. German patent, 2I7772.

43. Z. Phys. Chem., 70, I9I0, 88.

44. Chem. Abs., I9II, 963.

45. Comp. Rend., I52, I9II, I629.

46. Rubber Ind., 1914, 156.

47. English patent, I7I95.

48. J. Frank. Inst., 1913, 345 .

49. U. S. patent, I240II6.

50. Comp. Rend., I54, I9I2, I26I.

51. Comp. Rend., I52, I9II, 535.

52. Arch. Ges. Physiol., I64, I9I6, 445.

53. Comp. Rend., I35, I902, 3 I 5.

54. Chem. Abs., I9I7, I356.

55. Ann. Phys. Chim., 37, 297.

56. J. Amer. Chem. Soc., I9I 7,762 .

57. Chem. Abs., I916, 950.

58. U. S. patent, I209132.

59. Z. Phys. Chem., 80, I9r2, 67.

6o. Ber., 43, I9ro, Iзо.

6r. Z. Phys. Chem., 92, I9r6, II3.

62. Comp. Rend., I52, I9II, II84.

63. Comp. Rend., I5I, I9I0, 355.

64. Ber., 49, I916, I366.

65. Comp. Rend., I6r, I9I5, 348. 
66. J. Amer. Chem. Soc., I906, 786.

67. U. S. patent, Irgrgi6.

68. U. S. patent, I22082I.

69. U. S. Patent II46I42.

70. U. S. patent, 1202040.

7I. English patent, I63I7.

72. U. S. patent, II98356.

73. J. Ind. Eng. Chem., I916, Iogo.

74. Chem. Abs., I914, I282.

75. J. Phys. Chem., r9r6, 347.

76. German patent, 295340.

77. U. S. patent, I24I 738.

78. Trans. Amer. Electrochem. Soc., 28, I9I5, 37 I.

79. J. Phys. Chem. I9, I9I5, II3.

80. Bul. Soc. Ind. Muhl., 80, I9I1, 324.

8I. Bul. Soc. Chim., Paris, I, I889.

82. J. Soc. Dyers, $1885,245$.

83. J. Soc. Dyers, I902, 295.

84. J. Soc. Chem. Ind., 37, I908, 3 II.

85. J. Agew. Chem., 26, I913, 79.

86. Färber $Z$ tg., 2I, I9II, 253.

87. Chem. Engr., 26, I9I8, II4.

88. U. S. patent, II58205.

89. U. S. patent. 1032822.

90. Chem. Abs., I9I 7, I753.

9I. Chem. Engr., 26, I918, I82.

92. Ann. D. Phys., 2, I914, 56.

93. Comp. Rend., I56, I913, I38.

94. J. Chem. Soc., I909, Abs. 96, 632.

95. Z. Electrochem., I8, I912, I38.

96. Mon. Chem., 4I, I920, 305.

97. Comp. Rend. June I4, I920, I450.

98. Comp. Rend. May 25, 1920, I246.

99. Comp. Rend., I72, I921, 274.

100. Ark. Kem. Min. Geol. Stockholm, 7, I9I7, I: Sci. Abs. No. III3 (I920) and No. I500 (Ig2I). 



\section{INDEX}

Abiotic action, 205

Absorption bands, 44 and frequency, 42

Acetaldehyde, 232

Acetate, 229

Acetic acid, 52, 236

Acetoacetates, 60

Acetone, 5I, 52, 60, 62, 68, 23 I

Aceturic acid, 65

Acetylene, 225, 227, 23I flame, III

Acids, 62, 66, 227

Acrylic acid ester, 242

Actino-therapy, 217

Adularia, 74

Aesculine, 123

Agar, 210

Air, 30, 39

Albumen, 67

Alcohol, 55, 56, 66, 67, 69, 227,

244

ethyl, 51, 232

Aldehydes, 61, 66, 227

Alkaloids, 63, 186

Alloys, 95 silver and cadmium, 147

Allylene, 226

Alum, 74

Aluminum, I02 spark, I38, I4I, 145

Amino-acids, 64

Ammonia, 44, 50, 52, 232, 244

Ammonium molybdate, I37

oxalate, 229

persulphate, 229

salt, 185, 225

sulphite, 66

Aniline, 65

Anilonoacetic acid, 65

Anthracene, 6I, 12I
Antimony, I02

spark, 143

Apoatropine, 63

Apomorphine hydrochloride, 237

Apophyllite, 74

Arbutin, 237

Arc, II0, III, II6, I34, I45,

crater, 154

flame, 124, 126, 127

tungsten-mercury, 130

white flame, I25

Argon, 38, 135

Aristo arc, III

Arragonite, 74

Atmosphere, 33

transmission of, 20

Atropine, 63

Bacillus coli, 237 communis, 67

Bactericidal action, 209, 224

Ballon fabric, 228

Barite, 74

Barium

iodide, 325

spark, 140

Beer, 215

Beer's law, 47, 68

Beer yeast, 239

Benzal chloride, 245

Benzene, 43, 63, 66

derivatives of, 42

ethyl, 43, 66

halogen, 64

vapor, 4I

Benzo colors, 243

Benzoic acid, 64, 246

Benzol, 5I, 233, 24I

chloride, 24I

Benzotrichloride, 24I, 245 
Benzyl, 63

chloride, 24I, 245

Beryl, 76

Bioses, 227

Bismuth, 99, 102

Bleaching, 2I5, 244 oils, 242

Blindness eclipse, 205 snow, 204

Blood, 2I3, 2 I6 serum, $2 I_{3}$

Bolometer, I66

Borax, 74

Boric oxide, 83

Brandes-Schünemann's alloy, 95

Brashear alloy, 96

Bromacetic acid, 240

Bromination, I26, 24I

Bromine, 4I, 43, 55, 234

Butylene, 229

Cadmium, I02 arc, I40, I46, I 47 spark, I4I vapor, 43

Cairngorm, 76

Calcite, 74

Calcium nitrate, $5^{\mathrm{I}}$ spark, I 40

Calcspar, 75

Canada balsam, $5^{2}$

Carbon, I02, I 53 arc, III, II6, I 24 bisulphide, 43 dioxide, 3I, 39, 226, 242 monoxide, 38, 226, 229 tetrachloride, 242

Carbons, impregnated, 125

Carbonyl chloride, 23I, 233, 240

Carborundum, I02

Catalyzer, 223

Cataract, 208

Catechol, 62

Celestite, 74

Cells, 2 I 5
Celluloid, 77 substitute, 242

Cellulose, 245

Cerium nitrate, ${ }^{5} 5$

Chemical applications, 224

Chloracetic acid, 240

Chlorate, 23I

Chloride, 233

Chlorination, 233, 239, 24I

Chlorine, 4I, 232, 234 gas, $23 I$

Chlorites, 67

Chloroform, 242

Chlorophyll, 8, 9, 220

Chloroplatinic acids, 245

Chlorous acid, 67

Chromatic aberration, I90

Chromic acid, 245

Chromium, ro3

Chrysoberyl, 74

Cinnamic acid, 68

Citrate, 229

Cobalt, 97, I03 blue glass, 77 glass, 53 spark, 142

Cocaine, 63 hydrochloride, 237

Cocoa, I93

Colemanite, 74

Collodion, 52

Colloidal metals, 50, 230

Copper, 88, 95, 97, I03 spark, I40, I42 sulphate, 54

Cordierite, 76

Cornea, 78, 206

Cotton, 245, 246

Coumarin, 228, 240

Crookes glass, 88, II9

Cultures, 237

Cyanine, Ioo

Cyanogen, 225, $23 \mathrm{I}$ bands, I60

Daylight intensity of, I7 photochemical action of, 33 
Detection of ultraviolet, $\mathrm{I}_{5}$

Diamond, 74

Didymium, 87

Digestion, 213

Di-saccharides, 232

Discharge tube, I 34

Dyes, 52, 57, 67, 123, 243 , yellow, 53

-testing, 242

Eclipse blindness, 205

Egg albumen, 208, 229

Egg globulin, 208

Electric waves, 5

Electromagnetic theory, Io

Emerald, 76

Enzymes, 216, 223

Eosins, 57, 67

Erythemia, 240

Eserine salicylate, 237

Esculine, 54

Esters, 59, 66, 227, 245

Ethane, 233

Ether, 52

Ethyl acetate, 62

Ethylene, 52, 225, 233

Euphos glass, 8I

Exploding wires, I60

Eye, 78, 205

lens, 78

media, 206

Fatty acids, 59, 245

Fermentation, 239

Ferrous chloride, 245

Filters, 87, I84, I86, for mercury lines, 123

Flame arcs, III, I24, 242

Flames, 134

Flesh, 214

Flour, 228

Flowers, colors of, 220

Fluorenone, 6r

Fluorescein, 58, 67

Fluorescence, 186

color of, 192

effect of solvent, 193

of various substances, I9I
Fluorescent

eyepiece, 190

solutions, 54

Fluorine, 234

Fluorite, 75

Fluorometer, 188

Fluorspar, 76

Formaldehyde, 226, 236

Formamide, 3 I

Formic acid, 229, 246

Fraunhofer lines, 23

Fresnel's formula, 8I

Gamma rays, 5

Gases

compound, 159

transparency of, 35

Gas-mantle, 109

Gasoline, 24I

Geissler tube, ${ }_{3} 6$

Gelatine, I I, 77, I83

bichromated, 185

Gelatinization, 245

Gems, 75

Germicidal action, 209

Germs, 209

Glass

blue uvial, 87

borosilicate, 82

chromium, 88

cobalt, 88

cobalt blue, 87

colored, 87

coloring media, 89

copper, 88

decolorizing, 86

effect of cathode rays, 86

effect of temperature, 85

effect of ultraviolet, 86

effect of X-Rays, 86

gold pink, 87

iron, 88

lead, 82,88

lead oxide in, 83

manganese in, 85

nickel, 88

potassium oxide in, 83

reflection from, 8I 
reflection of, 99

soda, 82

sodium oxide in, 83

smoke, 89

transparent to ultraviolet, 83

uranium, 88,89

uviol, 83

Glasses, 79, II9

colored, 84

crown, 79

eye-protective, 89

flint, 79

transparency of, 84

Glycerine, 5I, 75, 238

Glycerol, 67, 238

Glycine, 65

Gold, 95, 99, I03

film, II 9

spark, I40, I42

Grating, I53, I74

Grating spectroscope, I 72

Grotthus' Law, 62

Guaiacol, 237

Gypsum, 74

Haematite, I37

Haloacetic acids, 24I

Halogen, 67, 234

hydride, 235

Helium, 38, I36, I 58

Hydriodic acid, 236

Hydrobromic acid, 229

Hydrocarbons, 42, 55, 227, 229, $234,236,245$

Hydrochloric acid, 229, 236

Hydrogen, 37, I35, 227

arsenide, 233

chloride, 227

dispersion, 198

iodide, 227

peroxide, 66, 227, 228, 229

phosphide, 232

sulphide, 227

Hydrosulphite, 235

Illuminants, common, I07

Infra-red, 5

Inks, 244
Insects, 218

Iodide, starch, 234

Iodides, 235

Iodine, 99, 234, 235 derivatives, 236

Ionization, volume, 40, I96

Ions, 224

Iron, 95, II $, I_{37}, I_{53}$

arc, I6I

arc in hydrogen, 147

arc simple, I 46

oxalate, 229

spark, I4I

Isoamyl, 233

Isopentane, 233

Ketones, 6r, 66, 68, 227, 232

Ketoses, 226

Knowledge, early, 8

Kunzite, 74, I92

Kyanite, 76

Lead, I03 oxide, 83

phthalate, 239

Light, velocity of, 3

Limelight, rog

Linseed oil, 244

Liquids, transparency of, 46

Lithopone, 133, 243

Living matter, 204

Luminescence, colors of, IgI

Magenta, 57

Magnalium, 95, I03

Magnesium, I03

burning, I Io

iodide, 235

spark, I 43

sulphide, 193

Magnetite arc, III, II5, II9

Malonic acid, 236

Manganese, 88

Measurement of ultraviolet, 165

Mercuric chloride, 234, 24I, 245

Mercury, 99

arc, 53, III, II6, II9, I28, I $30, I_{48}$ 
energy in, I5I

jacket, 229

benzoate, 237

bichloride, 237

lines, I2I, I43, I52

filters for, 123

vapor, 43,136

Metals, 94

disintegration of, 230

Methane, 23I

Methylene chloride, 24I

Mica, 77, II9

Microphotometer, I8I

Micro-radiometer, I70

Milk, 2 I 5

Minerals, 75

Molybdenum, I04, I37

Monamines, 6r

Monoses, 227

Moon, I7

Napthalene, 66

Natural gas, 233

Noedymium, 54, 87, I22

Neon, ${ }^{5} 8$

Nernst glower, rog

Nernst lamp, II 6

Newton's experiment, I

Nickel, 88, 95, 99, I04, I39, I 53 spark, I42

Nitrates, 67

Nitric acid, 67

Nitric oxide, 40

Nitrites, 225

Nitro compounds, 65

Nitrogen, I36

Nitrosodimethylaniline, 52, 67

Nitrous oxide, 30, 39, 225

Nuclei, 224

Oils, 67, 244

bleaching, 242

ethereal, 66

Olive oil, 237, 242

Ophthalmia, 205

Organic compounds, 227

Oxalic acid, 66, I85, 235, 236
Oxidation, 244

Oxidizing agents, 246

Oxycellulose, 245

Oxygen, 29, 30, 36, 135, 224, 228

Ozone, 29, 37, 39, 15I, 224, 23I, 236,239

Paints, 244

Palladium, I04 spark, 143

Paraphenylenediamine, I27

Pathological effects, II 7

Pentane lamp, III

Peptides, 64

Peptone, 67, 229

Perchlorate, 23I

Petroleum, 24I

Phenol, 64, 65, 23I

Phosgene, 242

Phosphorescence, 186 decay of, 188

Phosphorus, 152, 226, 23I

Photo-electric cell, IOI, I7I, I94 spectral sensibility, 196

Photo-electric effect, I94

Photo-electric method, 47

Photo-chemistry, 223

Photographic

density, I8I

efficiencies, Iro

emulsions, 183, 199

laws, 179

process, 180

value of radiants, 130

Photography by ultraviolet, $\mathrm{I} 86$

Photo-phthalmia, 205

Pitchblende, 137

Plant life, 218

Plants, 219, 240

Platinum, 95, 99 spark, 143

Polarimetry, 178

Polymerization, 225

Potassium, 99

bichromate, 123

carbonate, 193

iodide, 235, 24I

metabisulphite, 66 


\section{nitrate, $24 \mathrm{I}$}

oxide, 83

percarbonate, 229

permanganate, 123

sodium sulphite, 66

P-phenylenediamine nitrate, 185

Precipitating metals, 229

Proteins, 238

Purines, 63

Purplish tint in glass, 86

Putrefaction, 2 I 7

Pyridine, 65, 244

Quartz, I0, 35, 72

expansion of, I 50

fused, 73

spectrograph, I75

Quinine, 245 bichloride, 237

sulphate, I23, I92

Quinol, 62

Radiation, 2

visible, 5

Radioactive substances, 67

Radiometer, I67

Radiomicrometer, 169

Reflection of ultraviolet, 93

Refractive index, 177

Resins, 244

Resonance spectra, 236

Resorcinol, 62

Retene, 52

Rock-salt, 75

Röntgen rays, 5, Io

Ross alloy, 95

Rubber, 237

Ruby, 76

Salicylaldehyde, 65

Saline solutions, 67

Saltpetre, 76

Salts, solutions of, 47

Sanidin, 74

Santonin, 63

Scandium, I 57

Schröder's alloy, 95

Screens, non-selective, 180
Search-lights, 147

Sector-photometer, I8I

Selenide, 227

Selenium, 99, I04

Serum

cell, I 70

albumen, 208

globulin, 208

Signalling by ultraviolet, 187

Silicon, I04

Silver, 95, 97, I 53

bromide, IIO, 234

chloride, 74, 234

compounds, 9

film, 77, I23

fluoride, 234

nitrate, 237

spark, I40, I 42

Silvered mirror, 68

Skin

diseases, 217

effect on, 2 ro

Skylight, I08

spectrum, I9

Sky, overcast, 108

Snow, 93

blindness, 204

Sodium, 99

cacodylate, 237

metabisuphite, 66

oxide, 83

sulphite, 66, 235

tungstate, 137

vapor arc, I6I

Solar radiation, I5, I30

Solids, transparency of, 72

Sources, experimental, I33

Spark, I34, I36, I38, I 53

apparatus, 136

gap, effect of ultraviolet on,

I94

oscillating, I 50

spectra, I 55

spectral lines, I44

Spectrograph, I75

Spectrophotographic filter, 182

Spectroscope, I 76

Spectrum, 2 


\section{entire, 5 \\ regions of, 5}

Speculum, I04

Spodumene, I 92

Spores, 2 Io

Spinel, 76

Steel, 97, I00, I05

Stellite, I05

Sterilization, 2I2

Stilbene, 68

Stokes law, I93

Strontium

$$
\text { iodide, } 235
$$

spark, I 40

Styrene, 68

Succinate, 229

Succine acid, 236

Sucrose, 237

Sugar, 74, 227, 229

Sulphur, 232, 235

Sulphur dioxide, 67, 229, 232

fluoride, 234

trioxide, 237

Sulphuric acid, 66, 237

Sulphurous acid, 67

Sunlight, 108 duration of, 18 spectrum, I9, 23, 24

Sunstroke, 2 I 3

Sylvite, 76

Tantalum, I05

Tartaric acid, 236

Tartrate, 229

Tartrazine, 67

Telluride, 227

Tellurium, I05

Temperature, high, I6I

Thermometer, 169

Thermopile, 167

Tin, 105 spark, I40, I42

Titanium, II 5

Titanous chloride, I37

Toluene, halogen, 64

Toluol, 233, 24I, 245

Topaz, 74
Tourmaline, 76

Toxin, 217

Transparency of

of glasses, 79

of solids, 72

Tungsten, I05, I 37 arc, 147

filament, I29 temperature of, I3I

lamp, III, II4, I30, I82

-mercury arc, I30

Turpentine, 52

Ultraviolet

radiation from various
sources, I 6
reflection of, 93
regions of, 5

Uranium glass, 88

Uranyl acetate, 185

Urea acid, 246

Vanillan, 240

Vapors of metals, 43

Varnishes, 244

Velocity of radiation, 3

Vinyl ester, 24I, 242

Vitellin, 208

Water, 3I, 47, II9, 2 I 5

absorption by, 49

color of, 50

-cooling, 240

transparency of, 217

vapor, $30,39,227$

Wavelength influence of, 226 symbols of, 3

Wedge, I8I

White pigments, 94

Wine, 238

Wires, exploded, I60

Wolframite, I37

Wood's alloy, 98

Writing, 198

X-rays, 5, I I, I 53 
Xylene, 52

Yellow dyes, 67, 68

Zinc, 99, 105, I53

arc, 140,146 ethyl, 23I, 233

spark, I40, I4I

vapor, 43

Zircon, 76

Zirconium nitrate, ${ }_{5} 8$ 
OTHER BOOKS

BY

M. LUCKIESH 


\section{COLOR AND ITS APPLICATIONS}

\section{Second Edition, Revised and Enlarged.}

$6 \times 9,150$ illustrations, 4 color plates, 431 pages.$\$ 4.50$

The object of this treatise is not only to discuss the many applications of color, but to establish a sound scientific basis for these applications. The book is authoritative, well illustrated, and contains many references and a wealth of new material. It was written by an investigator in the general field of color and is therefore not narrowly limited in scope. It fills a distinct gap that has existed on the book shelves.

\section{LIGHT AND SHADE AND THEIR APPLICA- TIONS}

$6 \times 9,135$ illustrations, 277 pages. . . . . . \$3.00

The book is a condensed record of several years' research by the author in the science of light and shade. It is the first published work which deals with the science of light and shade in a complete and analytical manner. The author has the faculty of bringing forth scientific facts in such a manner as to be helpful to those interested in the various arts. The book is of extremely wide interest because it deals with the appearances of objects and hence with vision and with lighting. It is well illustrated and represents the first elaborate attempt to formulate the science of light and shade and to correlate it with various arts.

\section{VISUAL ILLUSIONS, THEIR CAUSES, CHARACTERISTICS AND APPLICATIONS}

$6 \times 9,100$ illustrations, 258 pages. . . . . . .\$3.00

There are numberless visual illusions, all of them interesting but many can be put to useful service in daily life. In this book will be found a condensed treatment of the practical aspects of visual illusions. The complexity of the subject is not overlooked but simplicity is attained by confining the treatment mainly to static illusions, by suppressing mere details and by subordinating theory. The book emphasizes experimental facts and introduces theoretical considerations occasionally but chiefly for illustrating explanations which otherwise would be too complex. 


\section{LIGHTING THE HOME}

$5 \times 7 \frac{1}{2}$, illustrated, 289 pages . . . . . . . $\$ 2.00$

This is a pioneer book. It ranks with books on interior decoration and furniture as a help toward transforming a house into a home. It is practical in that it offers advice on all sorts of lighting problems and it is fascinating reading as well.

\section{ARTIFICIAL LIGHT, ITS INFLUENCE ON CIVILIZATION}

$6 \times 9$, illustrated, 366 pages. . . . . . . . . $\$ 3.00$

This story of the achievements of artificial light is written especially for the man in the street who is not interested in technical scientific terms and formulae, but who looks with admiration upon the huge signs which flash and sparkle above the crowds on the Great White Way, who marvels at the colors and brilliance of a spectacular theatrical production and desires to know how it is accomplished, and who takes a natural delight in hearing about scientific discoveries when they are explained in the simple, vivid language he understands best.

\section{THE LIGHTING ART, ITS PRACTICE AND POSSIBILITIES}

$6 \times 9$, illustrated, 229 pages.

This book discusses lighting as engineering plus art, and treats the subject as a branch of interior and exterior decoration. The technical aspect of the subject is not neglected, but the main emphasis is upon the "why" and not merely the "how" of lighting.

\section{THE LANGUAGE OF COLOR}

$6 \times 9$, illustrated, 282 pages. . . . . . . . $\$ 2.00$

A practical volume on color, the various fields in which it is used and its importance in portraying the ideas that make for progress. A book of special interest to all those who deal in color schemes and values.

\section{THE BOOK OF THE SKY}

$6 \times 9$, illustrated, 236 pages. . . . . . . . .\$3.50

"The beauties, wonders, awesome spectacles, inspiring panoramas, and extensive ranges of vision which await the aerial traveler, make of cloudland a veritable fairyland if he will open his consciousness to them. Aircraft have brought this new world of experiences within easy reach of mankind and it is one of the aims of this volume to awaken those who fly, or would fly, to the variety of interest which air travel affords." 


\section{The \\ Literature of Engineering and the Industries}

9. On our shelves is the most complete stock of engineering, scientific, technical and industrial books in the United States. A large number of these we publish and for an ever increasing number we are the sole agents.

I All inquiries are cheerfully and carefully answered and complete catalogs as well as special lists are sent free on request.

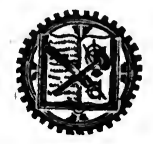

D. Van Nostrand Company PUBLISHERS AND BOOKSELLERS 8 WARREN STREET NEW YORK 


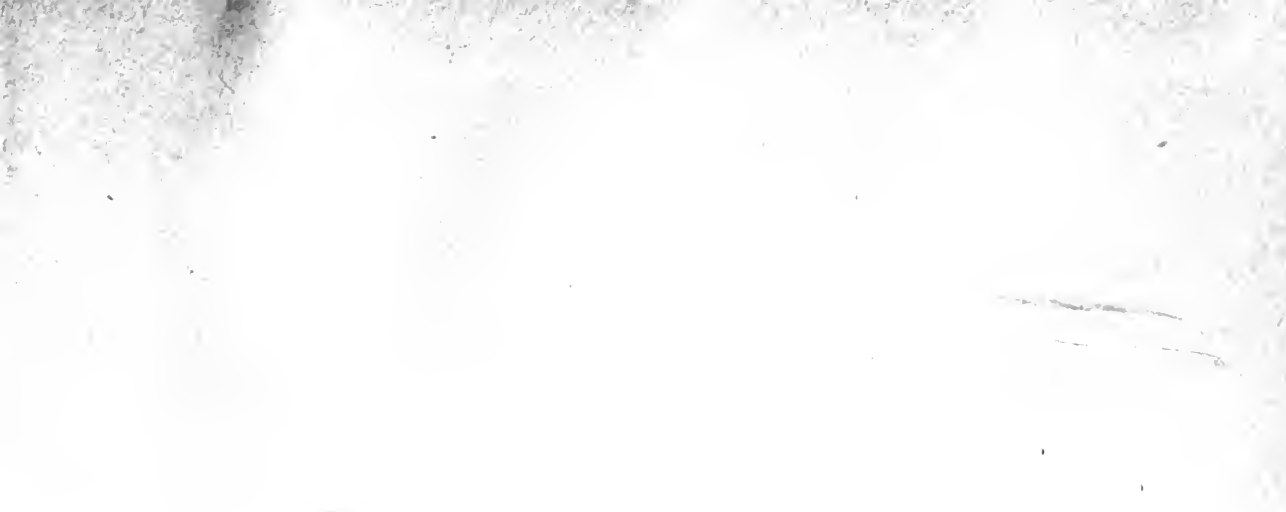


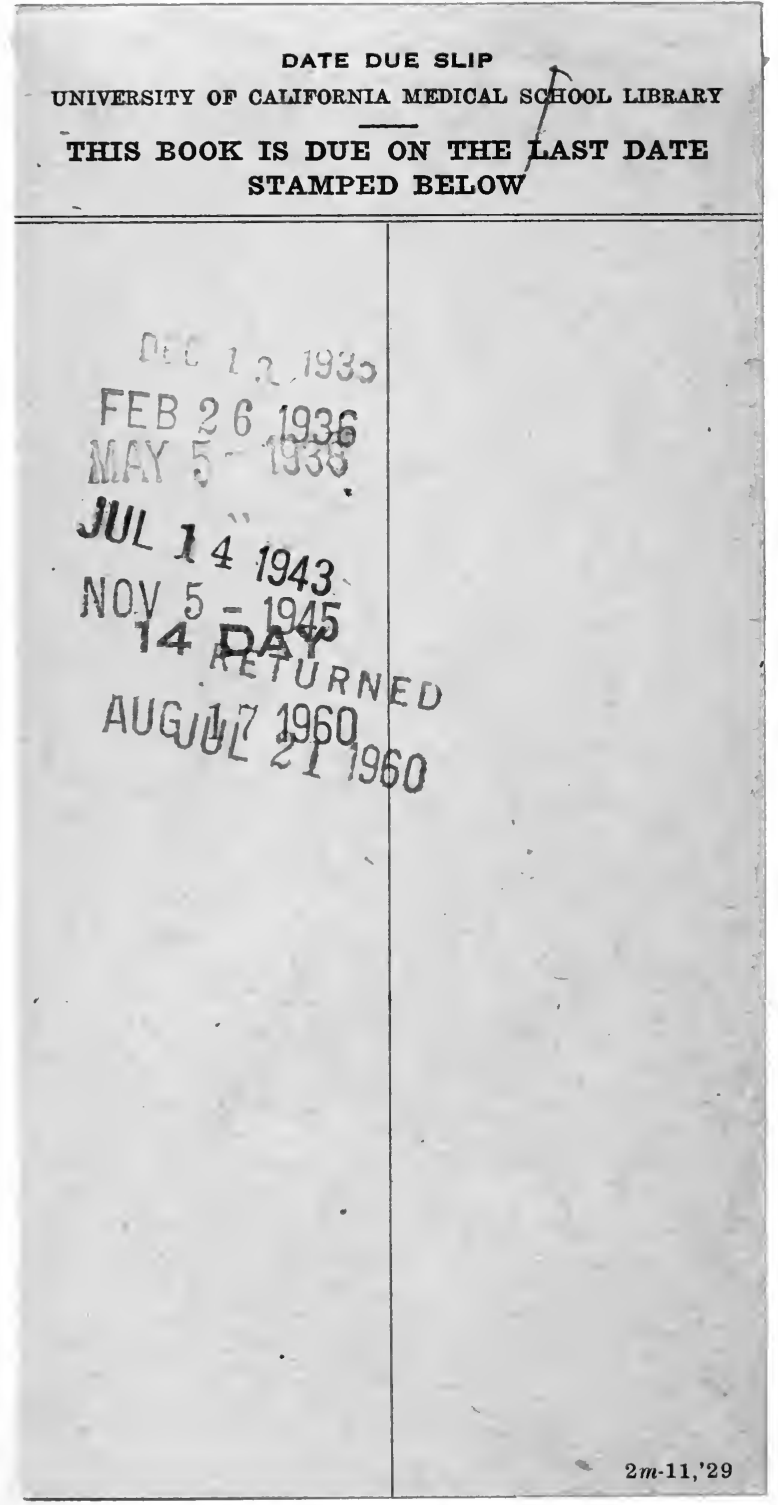




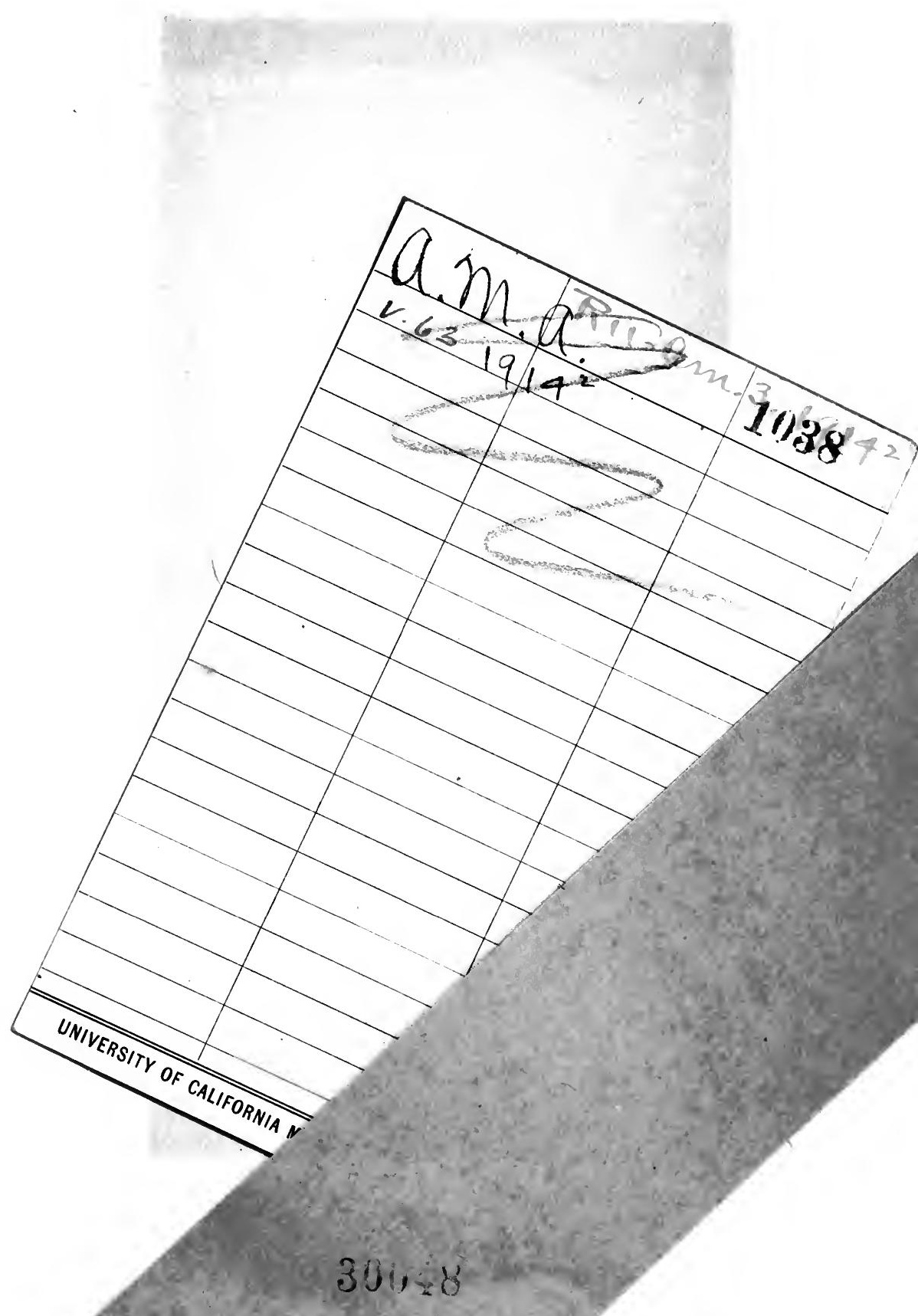


